\title{
ESTUDO DA INTERAÇÃO DE LÍQUIDOS IÔNICOS COM PROTEÍNAS MODELO
}

\section{Juliana Raw}

Banca Examinadora:

Prof. Dr. Leandro R. S. Babosa (IFUSP)

Prof. a Dr.a Patrícia Soares Santiago (UNESP)

Prof.a Dr. a Martha Simões Ribeiro (IPEN) 
FICHA CATALOGRÁFICA

Preparada pelo Serviço de Biblioteca e Informação do Instituto de Física da Universidade de São Paulo

Raw, Juliana

Estudo da interação de líquidos iônicos com proteínas modelo. São Paulo. São Paulo, 2016.

Dissertação (Mestrado) - Universidade de São Paulo. Instituto de Física. Depto. de Física Geral

Orientador: Prof. Dr. Leandro Ramos de Souza Barbosa

Área de Concentração: Física Experimental - Biofísica

Unitermos: 1. Líquido iônico; 2. Proteínas; 3. Fluorescência; 4. Espectroscopia.

USP/IF/SBI-093/2016 


\title{
STUDY ON THE INTERACTION OF IONIC LIQUIDS WITH MODEL PROTEINS.
}

\author{
Juliana Raw
}

Advisor: Prof. Dr. Leandro R. S. Barbosa

Examining Commitee:

Prof. Dr. Leandro R. S. Babosa (IFUSP)

Prof.a Dr.a Patrícia Soares Santiago (UNESP)

Prof.a Dr. a Martha Simões Ribeiro (IPEN) 



\section{Agradecimentos}

Gostaria de agradecer ao Prof. Dr. Leandro R. S. Barbosa pela oportunidade, pela orientação, auxílio e aprendizagem ao longo deste trabalho.

À Prof. $^{\text {a }}$ Dr. $^{\text {a }}$ Maria Teresa Lamy pelos esclarecimentos e discussões, principalmente com relação as técnicas de absorção óptica e fluorescência.

Ao Dr. Evandro e ao Marcelo pela ajuda e disposição nos laboratórios.

À Prof. Dr. ${ }^{a}$ Denise Petri pela oportunidade de realizar as medidas de tensão superficial, através do projeto FAPESP \#2010/51219-4.

À Dr. ${ }^{a}$ Letícia Zamphorlin, Centro Brasileiro de Biotecnologia do Etanol, CTBE, Campinas, SP, pelo auxílio na realização das medidas de dicroísmo circular.

Às colegas de departamento: Daniela, Luma, Lorraine, Natália e Sara por toda a ajuda, conversas e sugestões.

À minha família: Maurício, Elizabeth, Marina e Caio por todo o amor, apoio, compreensão e paciência por esses anos.

Ao laboratório de Biofísica, ao Centro Brasileiro de Tecnologia de Bioetanol, ao Laboratório Nacional de Luz Sincrotón pela realização dos experimentos contidos neste trabalho.

Às agencias de fomento CNPq e FAPESP (\#2015/15822-1) pelo auxílio financeiro essencial à realização deste trabalho. 



\section{Resumo}

Líquidos iônicos (LIs) são sais que se encontram no estado líquido em temperaturas menores que $100^{\circ} \mathrm{C}$ e que vêm ganhando protagonismo na área chamada química verde, prometendo: substituir solventes nocivos ao meio ambiente, aprimorar componentes eletrônicos, favorecer biocatálises dentre outros. Sua alta estabilidade e baixa toxicidade são frequentemente afirmadas, porém, devem ainda ser melhor investigadas. Com o objetivo de implementar o entendimento da interação dos líquidos iônicos com sistemas de relevância biológica, realizamos um estudo sistemático acerca da interação de 3 diferentes líquidos iônicos anfifílicos de mesma cabeça polar e diferentes caudas carbônicas $\left(\left[\mathrm{C}_{10 \mathrm{mim}}\right][\mathrm{Cl}],\left[\mathrm{C}_{12 \mathrm{mim}}\right][\mathrm{Cl}]\right.$ e $\left.\left[\mathrm{C}_{14 \mathrm{mim}}\right][\mathrm{Cl}]\right)$ com 3 diferentes proteínas modelo, através das técnicas de absorção óptica, fluorescência, dicroísmo circular (CD) e espalhamento de raios-X a baixos ângulos (SAXS). Para Tanto, utilizamos as proteínas BSA e HSA (Albuminas de Soro Bovino e Humano, respectivamente) além da lisozima. Observamos a supressão da fluorescência das proteínas em todos os casos analisados, onde a diminuição da intensidade correspondeu a, para as proteínas BSA, HSA e lisozima, respectivamente, $(55 \pm 3) \%,(16.1 \pm 0.8) \%$ e $(4.1 \pm 0.2) \%$, em presença de $0.6 \mathrm{mM}$ de $\left[\mathrm{C}_{14 \mathrm{mim}}\right][\mathrm{Cl}],(38 \pm 2) \%,(13.2 \pm 0.7) \%$ e $(0.6 \pm 0.1) \%$ em presença de $0.6 \mathrm{mM}$ de $\left[\mathrm{C}_{12 \mathrm{mim}}\right][\mathrm{Cl}]$ e $(11.0 \pm 0.5) \%,(9.2 \pm 0.5) \%$ e $(0.0 \pm 0.1) \%$ em presença de $0.6 \mathrm{mM}$ de $\left[\mathrm{C}_{10 \mathrm{mim}}\right][\mathrm{Cl}]$. Os espectros de absorbância e fluorescência de todos os sistemas nos indicam uma interação de contato entre as proteínas e os líquidos iônicos. Constatamos também o deslocamento do pico de fluorescência, das proteínas BSA e HSA, para menores comprimentos de onda (blueshift), na medida em que a concentração de LI era aumentada. O máximo deslocamento $(\Delta \lambda)$ alcançado correspondeu a $(21 \pm 1) n m$ para ambas albuminas, enquanto que a 
lisozima não apresentou deslocamento significativo. O blue-shift pode ser explicado pela aproximação das cadeias carbônicas e formações de pontes de hidrogênio nas proximidades dos triptofanos. De acordo com a técnica de SAXS, evidenciamos o aumento do raio de giro das proteínas, na medida em que adicionamos LIs. O raio de

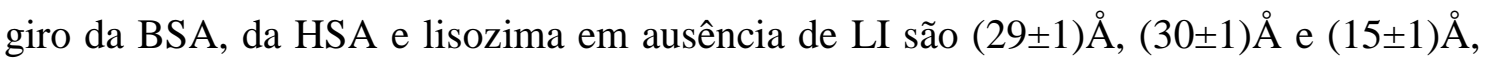
respectivamente, e passam para $(46 \pm 1) \AA,(44 \pm 1) \AA$ e $(20 \pm 1) \AA$ respectivamente, em presença de $0.6 \mathrm{mM}$ de $\left[\mathrm{C}_{14 \mathrm{mim}}\right][\mathrm{Cl}]$. As curvas de SAXS também apresentaram o indício da formação de estruturas micelares a partir de uma dada concentração. Além da alteração em sua estrutura terciária, os dados de CD indicam uma leve perda de estrutura secundária de ambas as albuminas (BSA e HSA), passando de 80 para $65 \%$ de $\alpha$-hélice em ausência e presença de $0.6 \mathrm{mM}$ de $\left[\mathrm{C}_{14 \mathrm{mim}}\right][\mathrm{Cl}]$, respectivamente. Sugerimos que as interações das proteínas com os líquidos iônicos, embora inicialmente movidas por forças eletroestática, possuem como principal fator o efeito hidrofóbico, portanto quanto maior a cadeia carbônica do LI maior é sua interação com a proteína. Tal interação causa o desenovelamento das proteínas e formação de um complexo e estruturas micelares a altas concentrações de LI. Acreditamos que este trabalho traz novas informações acerca da interação dos LIs com proteínas modelo, indicando sua capacidade de alterar a conformação das mesmas.

Palavras-Chave: Líquidos iônicos; Proteínas Modelo; Espectroscopias; SAXS; CD; Fluorescência; Absorção ótica; interação proteína surfactante. 


\section{Abstract}

Ionic liquids (ILs) are salts that are liquid at temperatures smaller than $100{ }^{\circ} \mathrm{C}$ and are gaining prominence in the so-called green chemistry, promising: replace harmful solvents to the environment, improve electronic components, and favor biocatalysis, among others. Its high stability and low toxicity are often asserted; nevertheless, they are ascribed to ILs due to its small volatility. With the aim of improving the understanding of the interaction of ILs with biological relevant systems, we conducted a systematic study of the interaction of three different ionic liquids of the same polar head and different paraffinic tails $\left(\left[\mathrm{C}_{10} \mathrm{mim}\right][\mathrm{Cl}],\left[\mathrm{C}_{12} \mathrm{mim}\right][\mathrm{Cl}]\right.$ and $\left.\left[\mathrm{C}_{14} \mathrm{mim}\right][\mathrm{Cl}]\right)$ with three different model proteins, through the techniques of optical absorption, fluorescence, circular dicrhoism (CD) and small angle X-ray scattering (SAXS). To do so, we use BSA and HSA proteins (Bovine Serum Albumin and the Human Serum Albumin, respectively) and lysozyme. We observed fluorescence quenching, of all studied proteins, where the decrease in the fluorescence was (for BSA, HAS and lysozyme, respectively): $(55 \pm 3) \%,(16.1 \pm 0.8) \%$ to $(4.1 \pm 0.2) \%$ in the presence of $0.6 \mathrm{~mm}\left[\mathrm{C}_{14} \mathrm{mim}\right][\mathrm{Cl}],(38 \pm 2) \%,(13.2 \pm 0.7) \%$ to $(0.6 \pm 0.1) \%$ in the presence of $0.6 \mathrm{~mm}\left[\mathrm{C}_{12} \mathrm{mim}\right][\mathrm{Cl}]$ and $(11.0 \pm 0.5) \%(9.2 \pm 0.5) \%$ and $(0.0 \pm 0.1) \%$ in the presence of $0.6 \mathrm{~mm}\left[\mathrm{C}_{10} \mathrm{mim}\right][\mathrm{Cl}]$. UV-vis absorbance spectra and fluorescence indicate all systems in a contact interaction between proteins and ionic liquids. We also note the shift of the fluorescent peak of BSA and HSA proteins for shorter wavelengths (blue-shift), as the IL content was increased. The maximum shift $(\Delta \lambda)$ achieved corresponded to $(21 \pm 1) \mathrm{nm}$ for both albumins, whereas no significant displacement was observed for lysozyme. The blue-shift can be explained by the approach of carbon chains and formation of hydrogen bonds in the vicinity of tryptophan. SAXS data indicate an increasing in the proteins radius of gyration value as ILs was added in the 
solution. The turning radius of BSA, HSA and lysozyme in the absence of IL are $(29 \pm$ 1) $\AA$, $(30 \pm 1) \AA$ and $(15 \pm 1) \AA$, respectively, and go to $(46 \pm 1) \AA,(44 \pm 1) \AA$ and $(20$ $\pm 1) \AA$, respectively, in the presence of $0.6 \mathrm{~mm}\left[\mathrm{C}_{14} \mathrm{mim}\right][\mathrm{Cl}]$. The SAXS curves also show evidence of the formation of micellar structures from a given concentration. Besides the change in its tertiary structure, the $\mathrm{CD}$ data indicates a slight loss of secondary structure of both albumins (BSA and HSA), from 80 to $65 \%$ of $\alpha$-helix in the absence and presence of $0.6 \mathrm{~mm}\left[\mathrm{C}_{14} \mathrm{mim}\right][\mathrm{Cl}]$, respectively. We suggest that the interactions of the protein with the ionic liquid, although initially driven by electrostatic forces, have a major factor hydrophobic effect and thus the higher the carbon chain of greater IL is its interaction with the protein. This interaction causes unfolding of the protein and formation of a micellar structures at high concentrations of IL. We believe this work provides new information about the interaction of ILs with model proteins, indicating its ability to alter the conformation of the same.

Keywords: Ionic liquids; Model Proteins; Spectroscopy; SAXS; CD; Fluorescence; optical absorption; surfactant-protein interaction 


\section{Sumário}

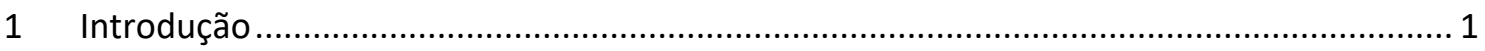

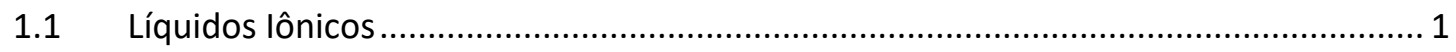

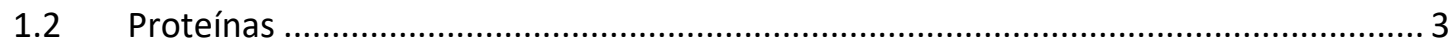

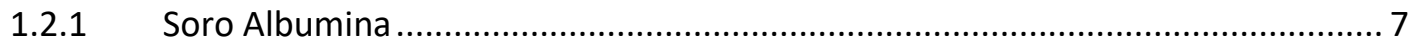

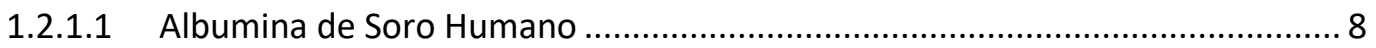

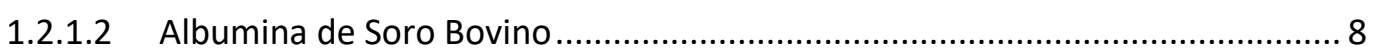

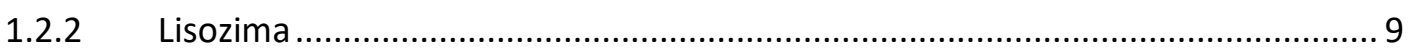

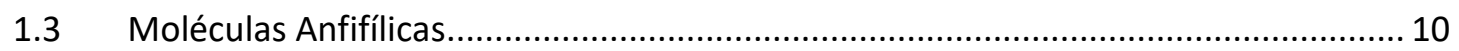

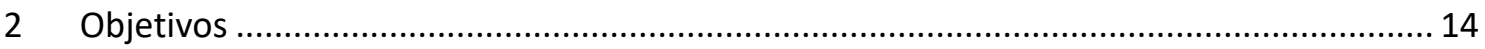

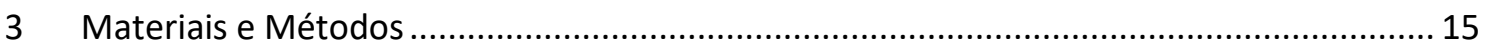

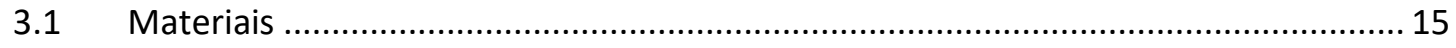

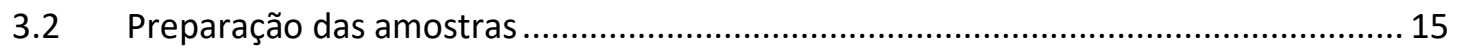

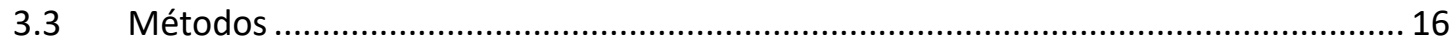

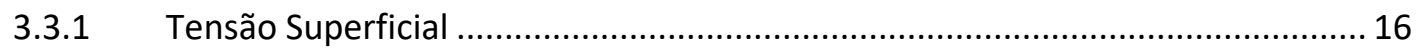

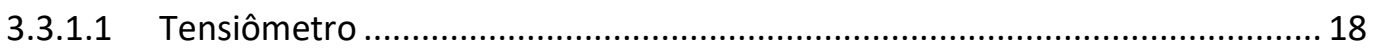

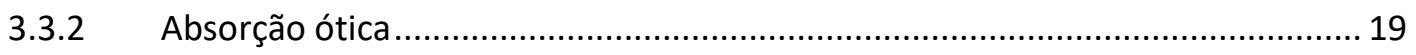

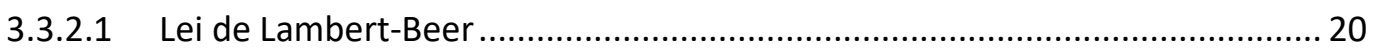

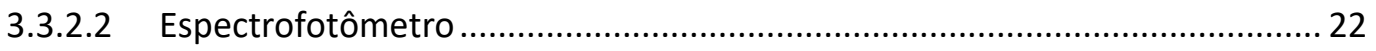

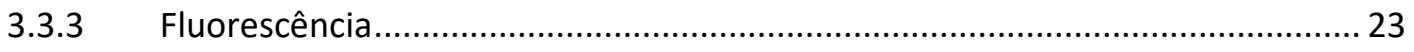

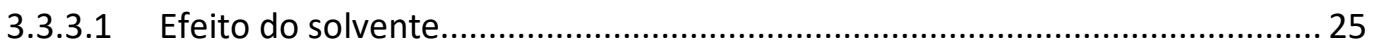

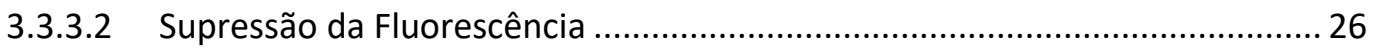

3.3.3.3 Fluorescência das proteínas....................................................................... 27

3.3.3.4 Correção de Filtro Interno .......................................................................... 29

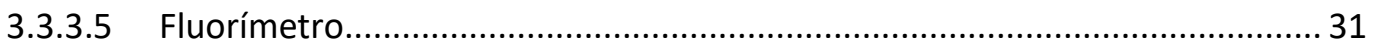

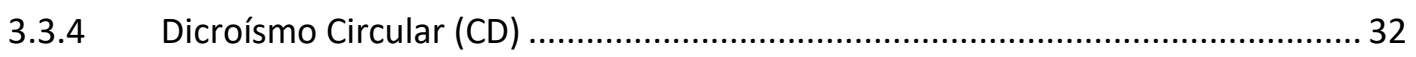

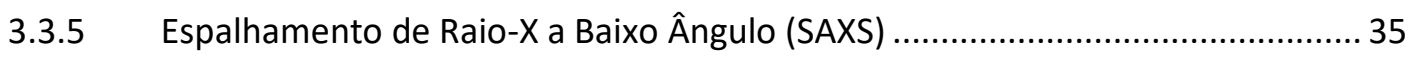

3.3.6 Representação de Kratky e Lei de Guinier ....................................................... 38

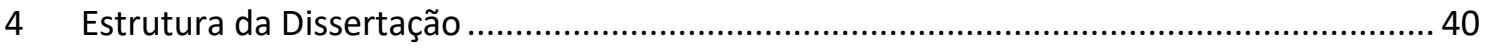

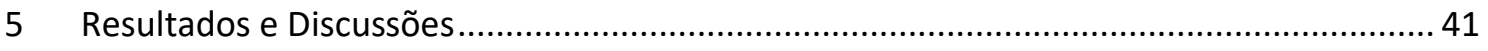

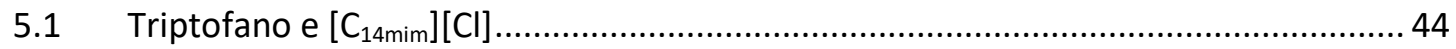

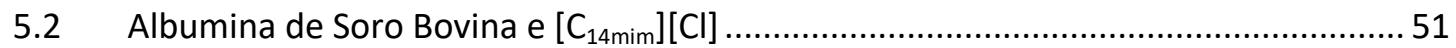

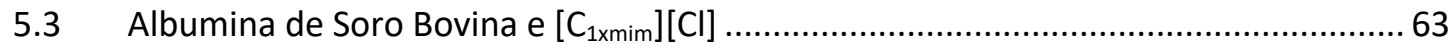




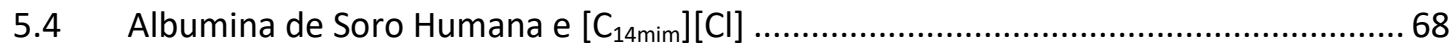

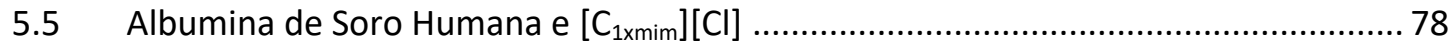

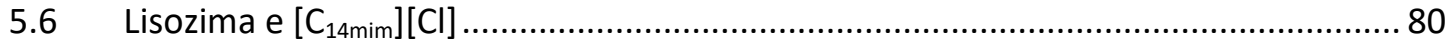

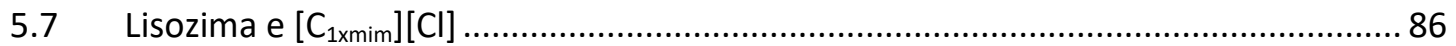

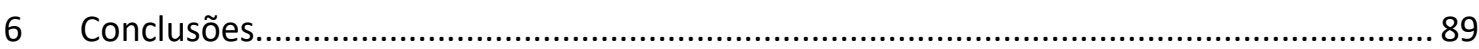

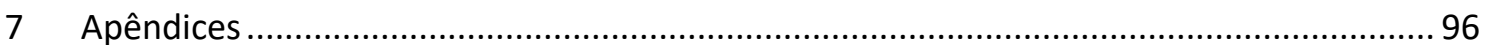




\section{Lista de Figuras}

Figura 1.1: (A) 1-Butyl-4-methylpyridinium chloride (B) Tetrabutylphosphonium methanesulfonate (C) 1-Allyl-3-methylimidazolium bis(trifluoromethylsulfonyl)imide (D) Tetrabutylammonium heptadecafluorooctanesulfonate [Sigma Aldrich] ................................... 2 Figura 1.2: Estrutura geral dos aminoácidos comuns a pH 7. Modificado de [http://saladebioquimica2014.blogspot.com.br/] ........................................................ 4 Figura 1.3: Aminoácidos comuns, com suas respectivas cargas e abreviaturas. [https://commons.wikimedia.org/wiki/File:Amino_Acids.svg] ............................................... 5 Figura 1.4: Níveis de organização de proteínas. [Modificado de Pearsonal Educacion, Inc., publising as Benjamin Cummings http://biology.reachingfordreams.com/biomolecules/proteins.html] ..................................... 7

Figura 1.5: Estrutura da BSA (vermelha) e HSA (verde) e posição dos triptofanos. ...................... 9 Figura 1.6: Estrutura da Lisozima e triptofanos marcados em azul. [Protein Data Bank; Código: 1DPX] 10

Figura 1.7: Algumas diferentes estruturas dos agregados de tensoativos para algumas formas e meios. [Modificado de IsraelavichVilli, 1985]

Figura 1.8:Representação da variação de diversas propriedades físico-química ao atingir a CMC do surfactante SDS. [Modificado de ELWORHY et al., 1968] ..... 13 Figura 3.1: Molécula de água. Modificado de [https://pt.wikibooks.org/wiki/Bioqu\%C3\%ADmica/A_\%C3\%A1gua,_solvente_da_Vida]........ 17 Figura 3.2: Método da Placa Wilhelmy. [Modificado de https://en.wikipedia.org/wiki/Wilhelmy_plate] .. 18 Figura 3.3: Espectro da radiação eletromagnética e suas classificações conforme o comprimento de onda. [http://www.aprenderciencias.com/] ............................................ 19 Figura 3.4: Espectrofotômetro Varian Cary 50 Bio. [Modificado de http://www.agilant.com] . 23 Figura 3.5: Diagrama de Jablonsk com os níveis de energia. Na fluorescência as setas com linha cheia representam transições radiativas e as pontilhadas não radiativas, as conversões internas. A transição entre S1 e T1 é um processo não radiativo conhecido como cruzamento entre sistemas. [Modificado de http://photobiology.info/Visser-Rolinski.html] 24 Figura 3.6: Efeito do solvente, representado pelos círculos menores e seu momento de dipolo. Dada uma molécula com momento de dipolo diferente de zero $\mu \boldsymbol{G}$ no estado fundamental e $\mu \boldsymbol{E}$ no estado excitado onde $\mu \boldsymbol{E}>\mu \boldsymbol{G}$. A energia do fóton absorvido vale $\boldsymbol{h} v \boldsymbol{A}$ e do fóton emitido vale $\boldsymbol{h} v \boldsymbol{F}$. Modificado de [17]

Figura 3.7: Esquema ilustrativo do efeito da supressão dinâmica e estática. O Circulo amarelo representa o fluoróforo em seu estado fundamental, o círculo verde representa o fluoróforo em seu estado excitado e o círculo laranja representa o supressor.

Figura 3.8: Espectros de absorbância (A) e fluorescência (F) dos aminoácidos arômáticos em solução aquasa de pH 7. Modificado de [17].

Figura 3.9: Esquema ilustrativo de uma cubeta onde há o feixe incidente no ponto i, ocorre a excitação e emissão no ponto ii e a detecção da intensidade de fluorescência no ponto iii. .... 30 Figura 3.10: Fluorímetro Varian Cary Eclipse. Modificado de [http://www.agilant.com] .......... 32 Figura 3.11: Origem do $C D(A)$ Componente a direita $(R)$ e a esquerda $(L)$ de uma radiação circularmente polarizada: (I) as duas componentes possuem a mesma amplitude; (II) as duas 
componentes possuem amplitudes diferentes que resultam em uma polarização elíptica. (B) relação dentre a absorbância e espectro de $C D$. Na banda 1 ocorre maior absorção $L$ que $R$, em 2 maior absorção em $R$ que $L$, em 3 a absorção em $R$ e $L$ são iguais. [26] .

Figura 3.12: Espectro de CD. (Adaptado de: http://www.proteinchemist.com/cd/cdspec.html)

Figura 3.13: Ilustração e fórmula da Lei de Bragg. (Retirado de HTTP: hyperphysics.phyastr.gsu.edu).

Figura 3.14: (A) Representação de um experimento de difração de raios-X. (B) Exemplo dos dados coletados para BSA. [29].

Figura 5.1: Espectro de Absorbância de variadas concentrações de $\left[\mathrm{C}_{14 \operatorname{mim}}\right][\mathrm{Cl}]$ descritas na legenda. A absorbância do tampão e da cubeta foram subtraídos das curvas.

Figura 5.2: Absorbância nos comprimentos de onda $280 \mathrm{~nm}, 295 \mathrm{~nm}$ e $350 \mathrm{~nm}$ de $\left[\mathrm{C}_{14 \mathrm{mim}}\right][\mathrm{Cl}] \mathrm{em}$ função da concentração.

Figura 5.3: Medias de tensão superficial de [C14mim][Cl] (A) em água (B) em tampão (AC, FO, BO pH 7.25).

Figura 5.4: Espectro de absorbância do Trp a $60 \mu \mathrm{M}$ em presença de variadas concentrações de $\left[\mathrm{C}_{14 \mathrm{mim}}\right][\mathrm{Cl}]$ descritas na legenda junto a razão molar. A absorbância do tampão e da cubeta foram subtraídas das curvas.

Figura 5.5: Absorbância em $280 \mathrm{~nm}$ do $\operatorname{Trp}$ a $60 \mu \mathrm{M}$ (A) e turbidez (B) em função da concentração de $\left[\mathrm{C}_{14 \mathrm{mim}}\right][\mathrm{Cl}]$ (escala superior) e razão molar (escala inferior), ambas logarítmicas. A faixa vermelha preenchida e listrada correspondem ao triptofano em ausência de LI e incerteza, respectivamente.

Figura 5.6: Absorbância normalizada pelo pico para o sistema triptofano a $60 \mu \mathrm{M}$ e $\left[\mathrm{C}_{14 \text { mim }}\right][\mathrm{Cl}]$.

Figura 5.7: Espectro de fluorescência do Trp a $60 \mu \mathrm{M}$ em presença de variadas concentrações de $\left[\mathrm{C}_{14 \mathrm{mim}}\right][\mathrm{Cl}]$ descritas na legenda junto a razão molar. Espectros com correção de filtro interno.

Figura 5.8: Intensidade do pico de fluorescência $(357 \mathrm{~nm})$ do Trp a $60 \mu \mathrm{M}$ em função da concentração de $\left[\mathrm{C}_{14 \mathrm{mim}}\right][\mathrm{Cl}]$ (escala superior) e razão molar (escala inferior), ambas logarítmicas. A faixa vermelha preenchida e listrada correspondem ao triptofano em ausência

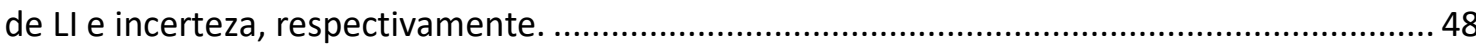

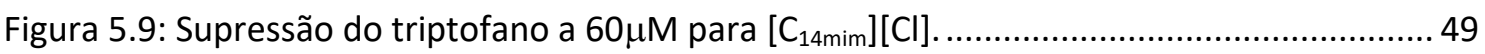

Figura 5.10: Intensidades de fluorescência normalizadas pelo pico do sistema $\operatorname{Trp}+\left[\mathrm{C}_{14 \mathrm{mim}}\right][\mathrm{Cl}]$. .50

Figura 5.11: Espectro de absorbância da BSA a $30 \mu \mathrm{M}$ em presença de variadas concentrações de $\left[C_{14 m i m}\right][C l]$ descritas na legenda junto a razão molar. A absorbância do tampão e da cubeta

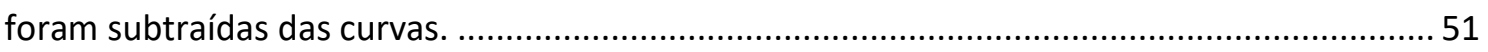
Figura 5.12: Absorbância em 295nm (A) e turbidez (B) da BSA a $30 \mu \mathrm{M}$ em função da concentração de $\left[\mathrm{C}_{14 \mathrm{mim}}\right][\mathrm{Cl}]$ (escala superior) e razão molar (escala inferior), ambas logarítmicas. A faixa vermelha preenchida e listrada correspondem a BSA em ausência de LI e incerteza, respectivamente.

Figura 5.13: Espectro de fluorescência da BSA a $30 \mu \mathrm{M}$ em presença de variadas concentrações de $\left[C_{14 \text { mim }}\right][\mathrm{Cl}]$ descritas na legenda junto a razão molar. Espectros com correção de filtro interno. 
Figura 5.14: Integral da intensidade de fluorescência (de $300 \mathrm{~nm}$ a $500 \mathrm{~nm}$ ) da BSA a $30 \mu \mathrm{M}$ em função da concentração de $\left[\mathrm{C}_{14 \mathrm{mim}}\right][\mathrm{Cl}]$ (escala superior) e razão molar (escala inferior), ambas logarítmicas. A faixa vermelha preenchida e listrada correspondem a BSA em ausência de LI e incerteza, respectivamente. .54

Figura 5.15: Espectro de fluorescência normalizado pelo pico do sistema $B S A+\left[C_{14 m i m}\right][C l]$. A seta indica o deslocamento com o aumento da concentração de $\left[\mathrm{C}_{14 \mathrm{mim}}\right][\mathrm{Cl}]$. 56 Figura 5.16: Comprimento de onda correspondente ao máximo de fluorescência da BSA a $30 \mu \mathrm{M}$ em função da concentração de $\left[\mathrm{C}_{14 \mathrm{mim}}\right][\mathrm{Cl}]$ (escala superior) e razão molar (escala inferior), ambas logarítmicas. A faixa vermelha preenchida e listrada correspondem a BSA em ausência de LI e incerteza, respectivamente. A linha vermelha é o ajuste utilizando a função de Boltzmann.

Figura 5.17: Curvas de SAXS obtidas para o sistema BSA a $60 \mu \mathrm{M}$ e variadas concentrações de $\left[\mathrm{C}_{14 \mathrm{mim}}\right][\mathrm{Cl}]$ descritas na legenda junto a razão molar. As curvas estão deslocadas na vertical para melhor visualização. 59

Figura 5.18: Raio de giro da BSA a $60 \mu \mathrm{M}$ em função da concentração de $\left[\mathrm{C}_{14 \mathrm{mim}}\right][\mathrm{Cl}$ ] (escala superior) e razão molar (escala inferior), ambas logarítmicas.

Figura 5.19: Curvas de Kratky obtidas para o sistema BSA a $60 \mu \mathrm{M}$ e variadas concentrações de $\left[\mathrm{C}_{14 \mathrm{mim}}\right][\mathrm{Cl}]$ descritas na legenda junto a razão molar.

Figura 5.20: Espectro de CD para BSA $(5 \mu \mathrm{M})$ em ausência e em presença de variadas concentrações de [ $\left.\mathrm{C}_{14 \mathrm{mim}}\right][\mathrm{Cl}]$ descritas na legenda junto a razão molar. A seta vermelha indica a direção do deslocamento das curvas com o aumento da concentração de LI.

Figura 5.21: Variação dos parâmetros estudados separados por estágios de interação.

Figura 5.22: Espectro de absorbância da HSA a $60 \mu \mathrm{M}$ em presença de variadas concentrações de $\left[C_{14 m i m}\right][C l]$ descritas na legenda junto a razão molar. $A$ absorbância do tampão e da cubeta foram subtraídas das curvas. 68

Figura 5.23: Absorbância em 295nm (A) e turbidez (B) da HSA a $60 \mu \mathrm{M}$ em função da concentração de $\left[\mathrm{C}_{14 \mathrm{mim}}\right][\mathrm{Cl}]$ (escala superior) e razão molar (escala inferior), ambas logarítmicas. A faixa vermelha preenchida e listrada correspondem a HSA em ausência de LI e incerteza, respectivamente.

Figura 5.24: Espectro de fluorescência da HSA a $60 \mu \mathrm{M}$ em presença de variadas concentrações de $\left[\mathrm{C}_{14 \mathrm{mim}}\right][\mathrm{Cl}]$ descritas na legenda junto a razão molar. Espectros com correção de filtro interno.

Figura 5.25: Integral da intensidade de fluorescência (de 300nm a 500nm) da HSA a $60 \mu \mathrm{M}$ em função da concentração de [ $\left.\mathrm{C}_{14 \mathrm{mim}}\right][\mathrm{Cl}]$ (escala superior) e razão molar (escala inferior), ambas logarítmicas. A faixa vermelha preenchida e listrada correspondem a HSA em ausência de LI e incerteza, respectivamente. 71

Figura 5.26: Intensidades de fluorescência normalizadas pelo pico do sistema HSA + $\left[\mathrm{C}_{14 \operatorname{mim}}\right][\mathrm{Cl}]$. 72

Figura 5.27: Comprimento de onda correspondente ao máximo de fluorescência da HSA a $60 \mu \mathrm{M}$ em função da concentração de $\left[\mathrm{C}_{14 \mathrm{mim}}\right][\mathrm{Cl}]$ (escala superior) e razão molar (escala inferior), ambas logarítmicas. A faixa vermelha preenchida e listrada correspondem a HSA em ausência de $\mathrm{LI}$ e incerteza, respectivamente. .73 Figura 5.28: Curvas de SAXS obtidas para o sistema HSA a $60 \mu \mathrm{M}$ e variadas concentrações de [ $\left.\mathrm{C}_{14 \mathrm{mim}}\right][\mathrm{Cl}]$ descritas na legenda junto a razão molar. As curvas estão deslocadas na vertical para melhor visualização. 
Figura 5.29: Raio de giro da $\mathrm{HSA}$ a $60 \mu \mathrm{M}$ em função da concentração de $\left[\mathrm{C}_{14 \operatorname{mim}}\right][\mathrm{Cl}]$ (escala superior) e razão molar (escala inferior), ambas logarítmicas.

Figura 5.30: Curvas de Kratky obtidas para o sistema HSA a $60 \mu \mathrm{M}$ e variadas concentrações de $\left[\mathrm{C}_{14 \mathrm{mim}}\right][\mathrm{Cl}]$ descritas na legenda junto a razão molar. 76

Figura 5.31: Espectro de CD para HSA $(5 \mu \mathrm{M})$ em ausência e em presença de variadas concentrações de $\left[\mathrm{C}_{14 \mathrm{mim}}\right][\mathrm{Cl}]$ descritas na legenda junto a razão molar. A seta vermelha indica a direção do deslocamento das curvas com o aumento da concentração de LI.

Figura 5.32: Espectro de absorbância da lisozima a $60 \mu \mathrm{M}$ em presença de variadas concentrações de $\left[\mathrm{C}_{14 \mathrm{mim}}\right][\mathrm{Cl}]$ descritas na legenda junto a razão molar. A absorbância do tampão e da cubeta foram subtraídas das curvas.

Figura 5.33: Absorbância em 295nm (A) e turbidez (B) da lisozima a $60 \mu \mathrm{M}$ em função da concentração de $\left[\mathrm{C}_{14 \mathrm{mim}}\right][\mathrm{Cl}]$ (escala superior) e razão molar (escala inferior), ambas logarítmicas. A faixa vermelha preenchida e listrada correspondem a HSA em ausência de LI e incerteza, respectivamente.

Figura 5.34: Espectro de fluorescência da lisozima a $60 \mu \mathrm{M}$ em presença de variadas concentrações de $\left[\mathrm{C}_{14 \mathrm{mim}}\right][\mathrm{Cl}]$ descritas na legenda junto a razão molar. Espectros com correção de filtro interno.

Figura 5.35: Espectro de fluorescência normalizado pelo pico do sistema lisozima $+\left[\mathrm{C}_{14 \operatorname{mim}}\right][\mathrm{Cl}]$.

Figura 5.36: Integral da intensidade de fluorescência (de $300 \mathrm{~nm}$ a $500 \mathrm{~nm}$ ) da lisozima a $60 \mu \mathrm{M}$ em função da concentração de $\left[\mathrm{C}_{14 \mathrm{mim}}\right][\mathrm{Cl}]$ (escala superior) e razão molar (escala inferior), ambas logarítmicas. A faixa vermelha preenchida e listrada correspondem ao triptofano em ausência de $\mathrm{LI}$ e incerteza, respectivamente. A linha vermelha é o ajuste utilizando a função de Boltzmann.

Figura 5.37: Curvas de SAXS obtidas para o sistema lisozima a $60 \mu \mathrm{M}$ e variadas concentrações de $\left[C_{14 m i m}\right][C l]$ descritas na legenda junto a razão molar. As curvas estão deslocadas na vertical para melhor visualização 84

Figura 5.38: Raio de giro da lisozima a $60 \mu \mathrm{M}$ em função da concentração de [ $\left.\mathrm{C}_{14 \mathrm{mim}}\right][\mathrm{Cl}]$ (escala superior) e razão molar (escala inferior), ambas logarítmicas

Figura 5.39: Curvas de Kratky obtidas para o sistema lisozima a $60 \mu \mathrm{M}$ e variadas concentrações de $\left[\mathrm{C}_{14 \mathrm{mim}}\right][\mathrm{Cl}]$ descritas na legenda junto a razão molar. 


\section{Lista de Tabelas}

Tabela 1.1: Nomenclatura, fórmula e estrutura dos líquidos iônicos utilizados. ........................... 3

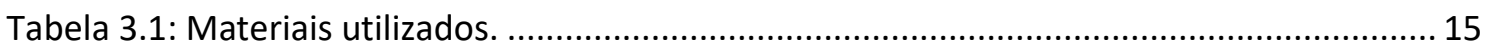

Tabela 3.2: Coeficientes de Extinção Molar e massa molar dos fluoróforos utilizados no

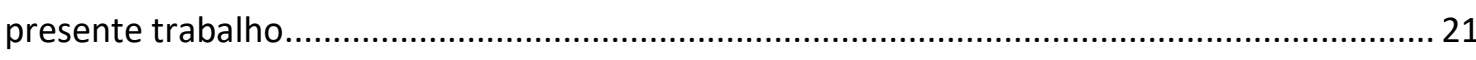

Tabela 5.1: : Supressão relativa e razão molar do ponto de inflexão do deslocamento do pico

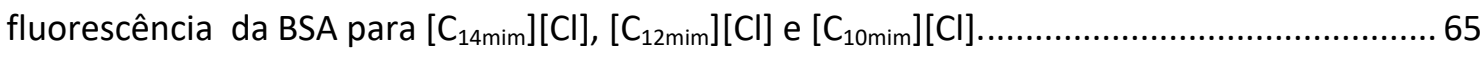

Tabela 5.2: Supressão relativa e deslocamento do pico de fluorescência da HSA para

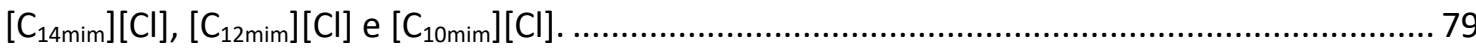

Tabela 5.3: Supressão relativa e deslocamento do pico de fluorescência da HSA para

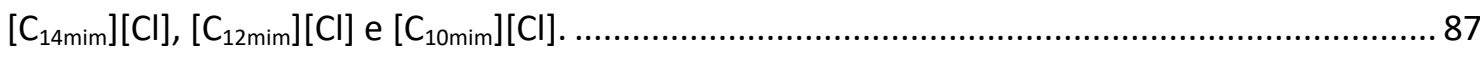





\section{Introdução}

\subsection{Líquidos Iônicos}

A área de pesquisa chamada química verde (green chemistry) ou química sustentável se caracteriza por ser voltada à criação ou desenvolvimento de novos materiais (ou processos) que gerem produtos menos nocivos ao meio ambiente e à saúde humana. Neste contexto, dentre as mais diversas classes de moléculas existentes, os líquidos iônicos (LIs) vêm ganhando destaque [1]. Suas propriedades físico-químicas são moldáveis, consequentemente, aplicáveis em diversas áreas do conhecimento. São promissores principalmente como solventes verdes e para aumentar a eficiência de supercapacitores, eletrodos e processos de biocatálises. [2] [3] [4] [5]

Os LIs são compostos iônicos constituídos por um ânion ou cátion orgânico e um contra-íon que também pode ser orgânico ou inorgânico. Os líquidos iônicos podem variar em sua estrutura, natureza e tamanho, associados a uma ou mais cadeias alquílicas substituintes (grupos $\mathrm{CH}_{2}$ e $\mathrm{CH}_{3}$ ), que ainda podem ser funcionalizadas, aumentando suas aplicações. [6]

Do ponto de vista físico-químico, os LIs são sais que possuem uma temperatura de fusão abaixo dos $100{ }^{\circ} \mathrm{C}$, ou seja, se apresentam no estado líquido numa vasta gama de temperaturas, incluindo valores próximos a temperatura ambiente [7]. É importante mencionar que sais convencionais (como $\mathrm{NaCl}$, por exemplo) possuem altos valores de ponto de fusão, geralmente maiores que $800{ }^{\circ} \mathrm{C}$. [8] Esta á a principal diferença entre os LIs em comparação aos sais convencionais.

Os LIs podem possuir uma elevada estabilidade química, térmica e eletroquímica, alta capacidade de solvatação, densidade e viscosidade variáveis, além da baixa pressão 
de vapor, de acordo com a necessidade e a utilização de interesse [3] [4]. Podem ser quimicamente alterados pela variação do cátion, ânion e dos grupos químicos funcionalizados. Tais alterações podem mudar suas propriedades físico-químicas, como: densidade, viscosidade e solubilidade em água [6] [7]. Segue alguns exemplos para visualização da diversidade dos LIs:

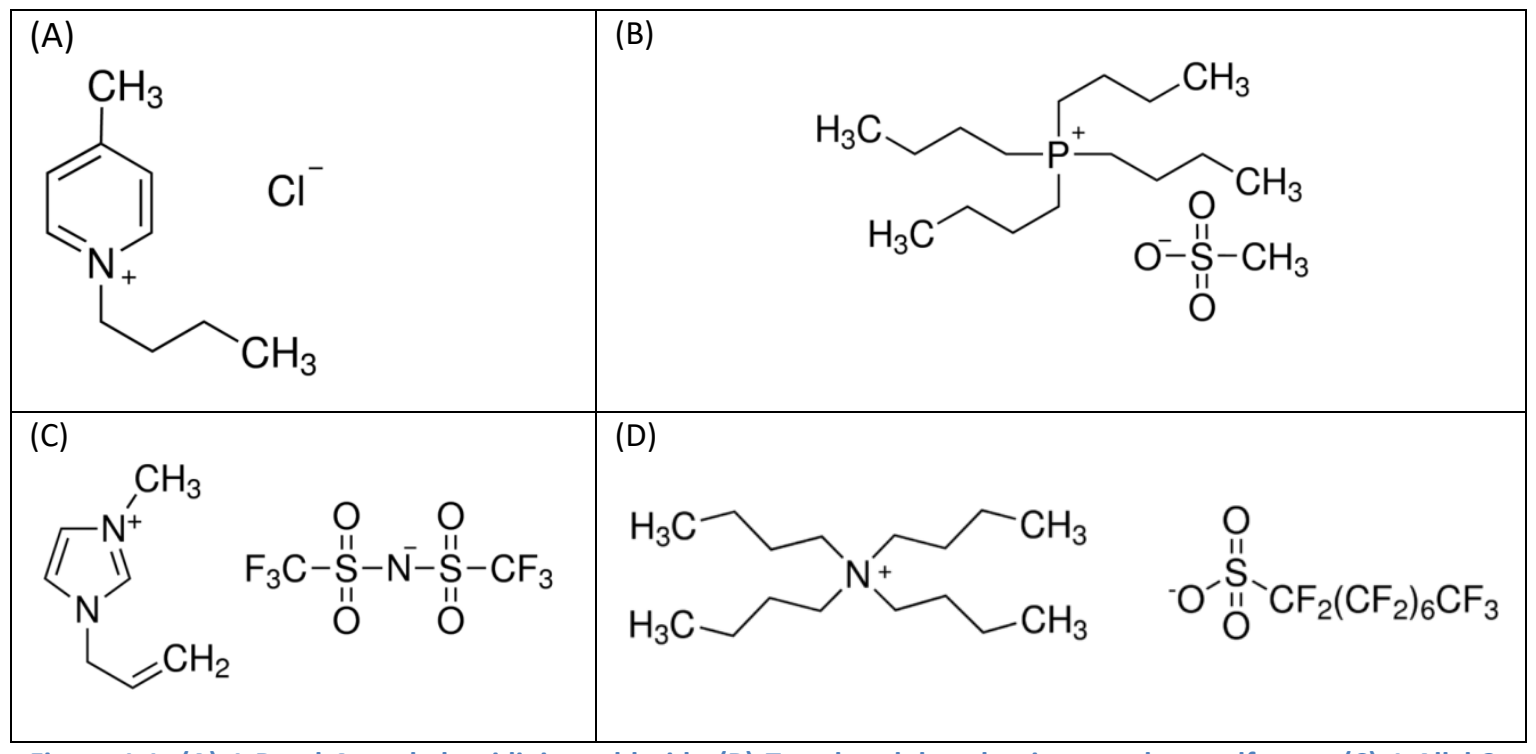

Figura 1.1: (A) 1-Butyl-4-methylpyridinium chloride (B) Tetrabutylphosphonium methanesulfonate (C) 1-Allyl-3methylimidazolium bis(trifluoromethylsulfonyl)imide (D) Tetrabutylammonium heptadecafluorooctanesulfonate [Sigma Aldrich]

A classificação dos LIs como moléculas de baixo impacto ambiental se dá, majoritariamente, pela sua baixa volatilidade, em comparação com solventes orgânicos. No entanto, este fato não deve assegurar a um composto sua classificação como material de baixo impacto biológico, ou seja, acreditamos que uma melhor compreensão da interação de diferentes LIs na estrutura de sistemas de interesse biológico deva ser considerada para sua classificação como solvente verde.

Embora seja crescente o interesse nas propriedades dos LIs, não existem muitos trabalhos na literatura que foquem no estudo de suas interações com o sistema de relevância biológica como proteínas, sistemas biomiméticos de membrana, DNA, RNA, 
e assim por diante. Por este motivo nosso grupo de pesquisa vem estudando a influência dos LIs neste tipo de biossistemas.

Os LIs que serão estudados no presente trabalho possuem em comum o anel imidazol como componente carregado (catiônico) ligado a uma cadeia carbônica (cadeia alquila). É importante mencionar que tais líquidos iônicos são utilizados como moldes ou templates para preparação de materiais, têm a capacidade de aumentar a atividade, estabilidade e solubilidade de enzimas. [9] [10]

A principal diferença entre os líquidos iônicos utilizados no presente trabalho é o tamanho da cadeia carbônica, um possui 14 carbonos, outro 12 e outro 10. As estruturas, os nomes e as abreviações podem ser apreciados na Tabela 1.1.

Tabela 1.1: Nomenclatura, fórmula e estrutura dos líquidos iônicos utilizados.

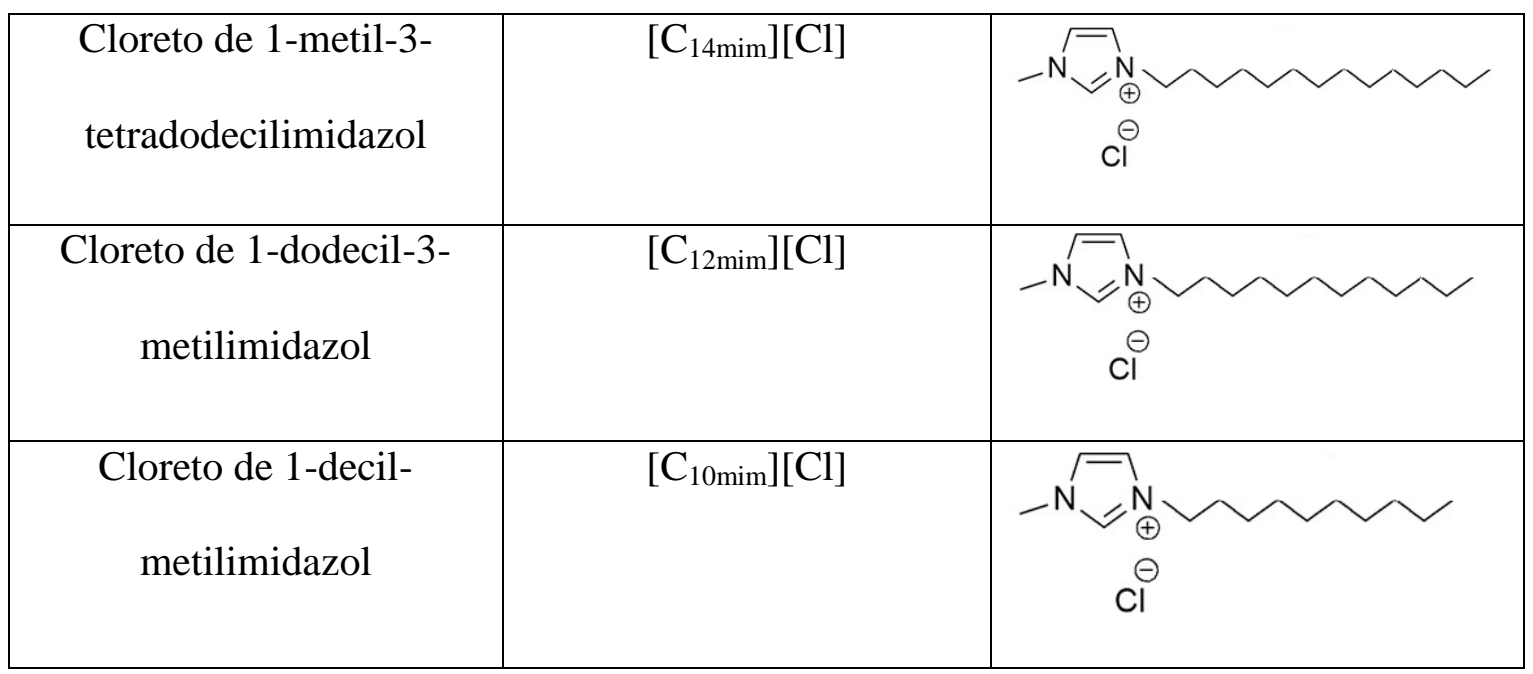

\subsection{Proteínas}

As proteínas desempenham funções essenciais nos organismos vivos, estão no centro da ação de inúmeros processos biológicos. Algumas dessas funções são: catálise de reações químicas (enzimas), transporte de pequenas moléculas ao longo do organismo (hemoglobina, mioglobina e albuminas), transporte de íons através da 
membrana plasmática da célula e de organelas (Na,K-ATPase), proteção contra agentes externos (imunoglobulina e lisozima) e funções estruturais (colágeno e elastina), dentre muitas outras. [11] [12]

De um modo geral, as proteínas são macromoléculas formadas por uma cadeia de aminoácidos, também chama de cadeia polipeptídica. Aminoácidos, por sua vez, possuem uma estrutura muito característica, que pode ser apreciada na Figura 1.2, um carbono central $\left(C_{\alpha}\right)$ ligado a um ácido carboxílico $(\mathrm{COOH})$, um grupo amina primária $\left(\mathrm{NH}_{2}\right)$, um átomo de hidrogênio e uma cadeia lateral $(\mathrm{R})$ que diferenciam a natureza e estrutura dos aminoácidos.

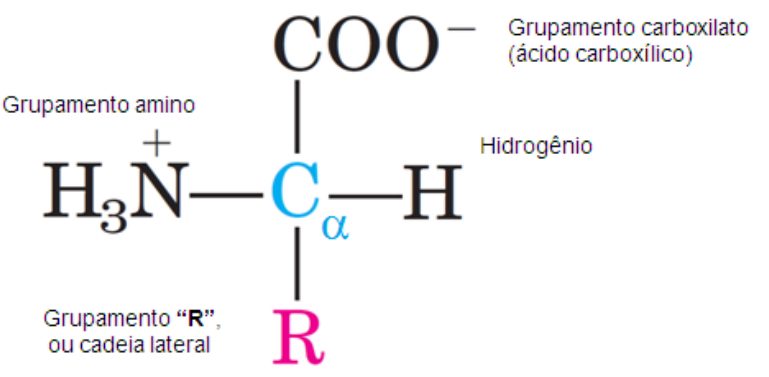

Figura 1.2: Estrutura geral dos aminoácidos comuns a pH 7 . Modificado de [http://saladebioquimica2014.blogspot.com.br/]

Existem 21 aminoácidos naturais, que constituem todas as proteínas, 20 desses apresentam a estrutura geral representada na Figura 1.2. Apenas o aminoácido prolina (P) possui uma estrutura diferenciada (ver figura 1.3). Os aminoácidos podem ser divididos das mais diferentes maneiras, como por exemplo, entre essenciais (podem ser produzidos pela célula) e não essenciais (não podem ser produzidos pela célula e precisam ser obtidos através da alimentação), ou ainda entre apolares e polares. 
Para representar uma sequência de aminoácidos utiliza-se a abreviatura de uma ou três letras. A estrutura, as cargas e as abreviaturas dos 21 aminoácidos naturais podem ser visualizadas na Figura 1.3.

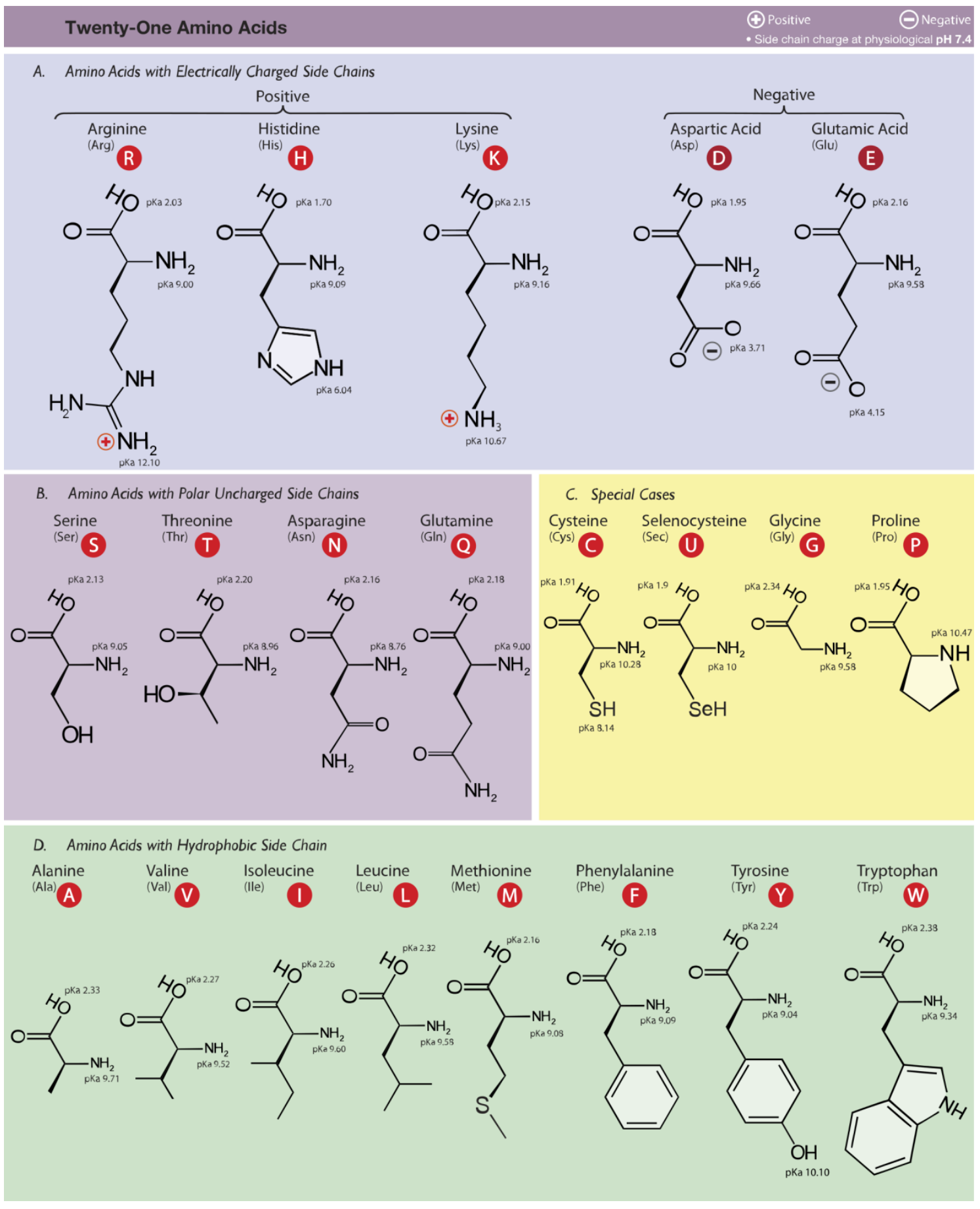

Figura 1.3: Aminoácidos comuns, com suas respectivas cargas e abreviaturas. [https://commons.wikimedia.org/wiki/File:Amino_Acids.svg] 
É importante ressaltar a importância dos aminoácidos aromáticos triptofano (W), tirosina (Y) e fenilalanina (F) em estudos biofísicos, mais especificamente em técnicas espectroscópicas. Tais aminoácidos possuem a propriedade de absorver e emitir fótons, tornando-os susceptíveis a alterações no meio em que se encontram e, consequentemente, interessantes ferramentas para o estudo de proteínas em solução. Este ponto será detalhado na seção 3.3.3.3.

A ligação entre os aminoácidos é, quimicamente, uma reação de desidratação. O grupo $\alpha$-carboxílico de um aminoácido forma uma ligação peptídica com o grupo $\alpha$ amino de outro aminoácido por eliminação de uma molécula de água, a repetição desse processo forma um polipeptídio, como uma proteína.

A sequência de aminoácidos forma a estrutura primária de uma proteína, fornece informações sobre função, biossíntese, estrutura e possibilita correlações a fim de prever similaridades entre proteínas. [11] [12]

A ligação peptídica é tipicamente rígida, não ocorrendo rotação entre o carbono e nitrogênio, porém entre o carbono $\alpha$ e os grupos amina e carboxila há a possibilidade de rotação. Tais rotações podem ocorrer de forma regular ou não, a forma como se dá tal organização é chamada de estrutura secundária. Ligações de hidrogênio ajudam a estabilizar e definir o tipo de estrutura secundária formada, as mais comuns entre proteínas são as chamadas $\alpha$-hélice e folha- $\beta$ e regiões desordenadas. [11] [12]

A estrutura terciária fornece a localização dos átomos e a forma tridimensional da proteína. A estrutura quaternária, nem sempre presente, refere-se a proteínas multicadeias, com arranjo de subunidades polipeptídicas através de ligações não covalentes. A função de uma proteína depende de todos os seus níveis estruturais. [11] [12]. Todos os níveis estruturais estão resumidos e ilustrados na Figura 1.4. 


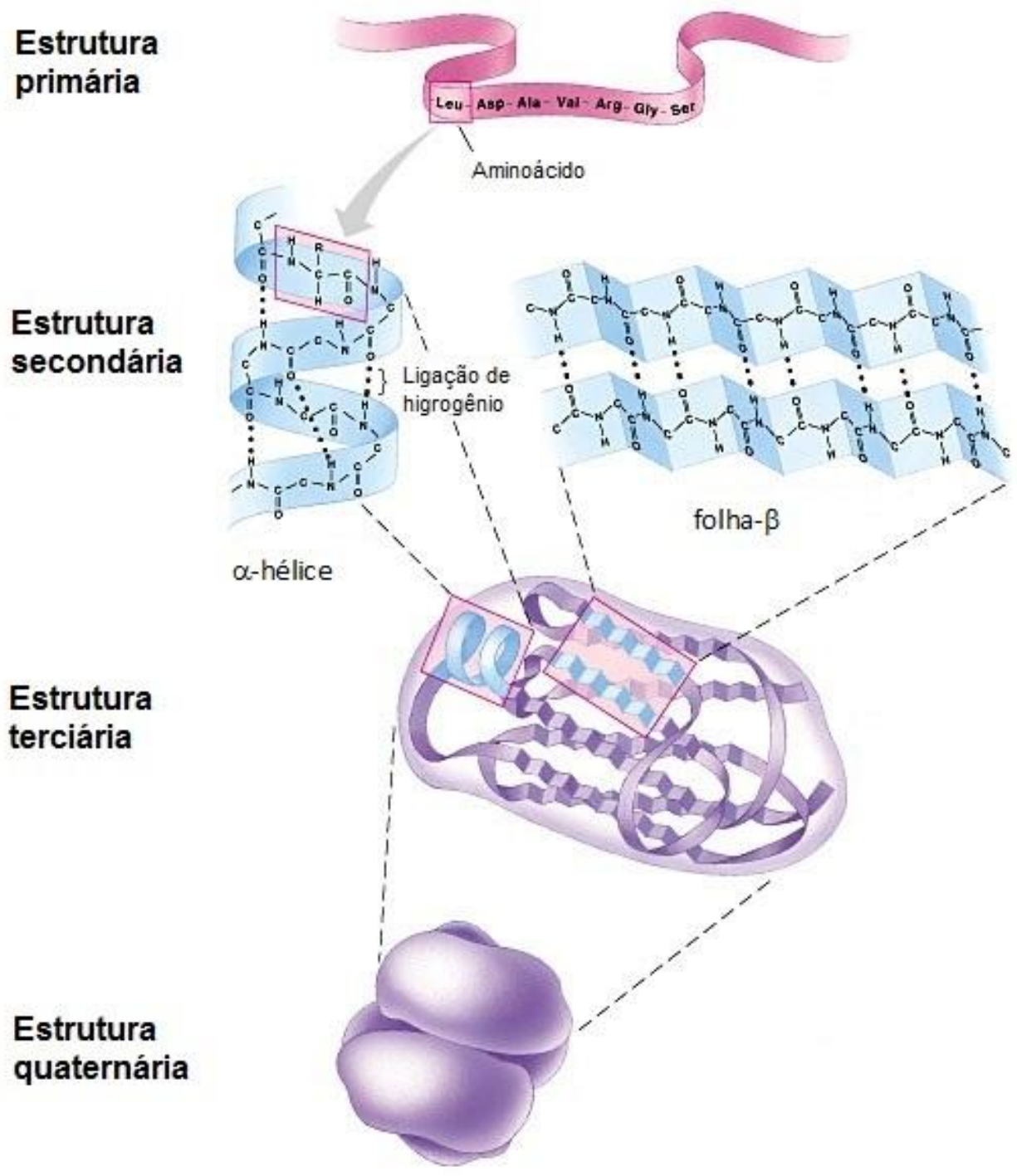

Figura 1.4: Níveis de organização de proteínas. [Modificado de Pearsonal Educacion, Inc., publising as Benjamin Cummings - http://biology.reachingfordreams.com/biomolecules/proteins.html]

\subsubsection{Soro Albumina}

Soro Albumina é o tipo de proteína solúvel mais abundante no corpo de todos os vertebrados, presentes no plasma sanguíneo. É responsável por $80 \%$ da pressão osmótica do plasma e transporta ácidos graxos, hormônios e pequenas moléculas pelo organismo [13]. É extensivamente estudada na medicina para transporte de fármacos, consequentemente, suas características são bem conhecidas, tornando-a um excelente objeto de estudos biofísicos. 


\subsubsection{Albumina de Soro Humano}

A Albumina de Soro Humano ou HSA (do inglês Human Serum Albumin) é a soro albumina presente nos seres humanos, pelas características citadas, comuns às soro albuminas, são amplamente estudadas. [13]

A HSA possui 585 aminoácidos, sendo um único triptofano na posição 214, massa molar igual a $66438 \mathrm{~g} / \mathrm{mol}$. Sua estrutura secundária é composta por aproximadamente $67 \%$ de $\alpha$-hélice, $10 \%$ de folha- $\beta$. Apresenta 3 domínios, que formam uma estrutura semelhante a uma coração [13], (ver Figura 1.5 em verde).

O ponto isoelétrico da HSA, ou seja, o valor de $\mathrm{pH}$ no qual a molécula se encontra com a mesma quantidade de cargas positivas e negativas, ou pI é igual a 4,7. Portanto, a proteína está negativamente carregada em $\mathrm{pH} 7,0$ e sofre mudanças conformacionais, ou transições, em pH acima de 8 e abaixo de 4, chegando a forma estendida em $\mathrm{pH}$ 2,7. [13]

É interessante mencionar que a HSA é encontrada in vivo em concentrações que podem variar de 35 a $42 \mathrm{mg} / \mathrm{ml}$ dependendo da idade do ser humano. [13]

\subsubsection{Albumina de Soro Bovino}

A Albumina de Soro Bovino (Bovine Serum Albumine, BSA) e HSA são ortólogas, ou seja, possuem a mesma função mas são encontradas em organismos diferentes. As estruturas primárias, secundárias e terciárias são semelhantes às encontradas na HSA (em torno de 76\%). A BSA possui massa molar igual a 66,411 $\mathrm{g} / \mathrm{mol}, \mathrm{pI}=4,7$, quantidade de estrutura secundária do tipo $\alpha$-hélice em torno de $68 \%$ e $17 \%$ de folha- $\beta$ [13]. A diferença mais importante entre BSA e a HSA para o presente 
trabalho é a quantidade de resíduos de triptofanos, a BSA possui dois, um na posição 134 e outro 213, a HSA possui somente um na posição 214. A Figura 1.5 traz a estrutura cristalográfica da BSA (vermelha) e da HSA (verde), com destaque para as posições dos resíduos de triptofano.

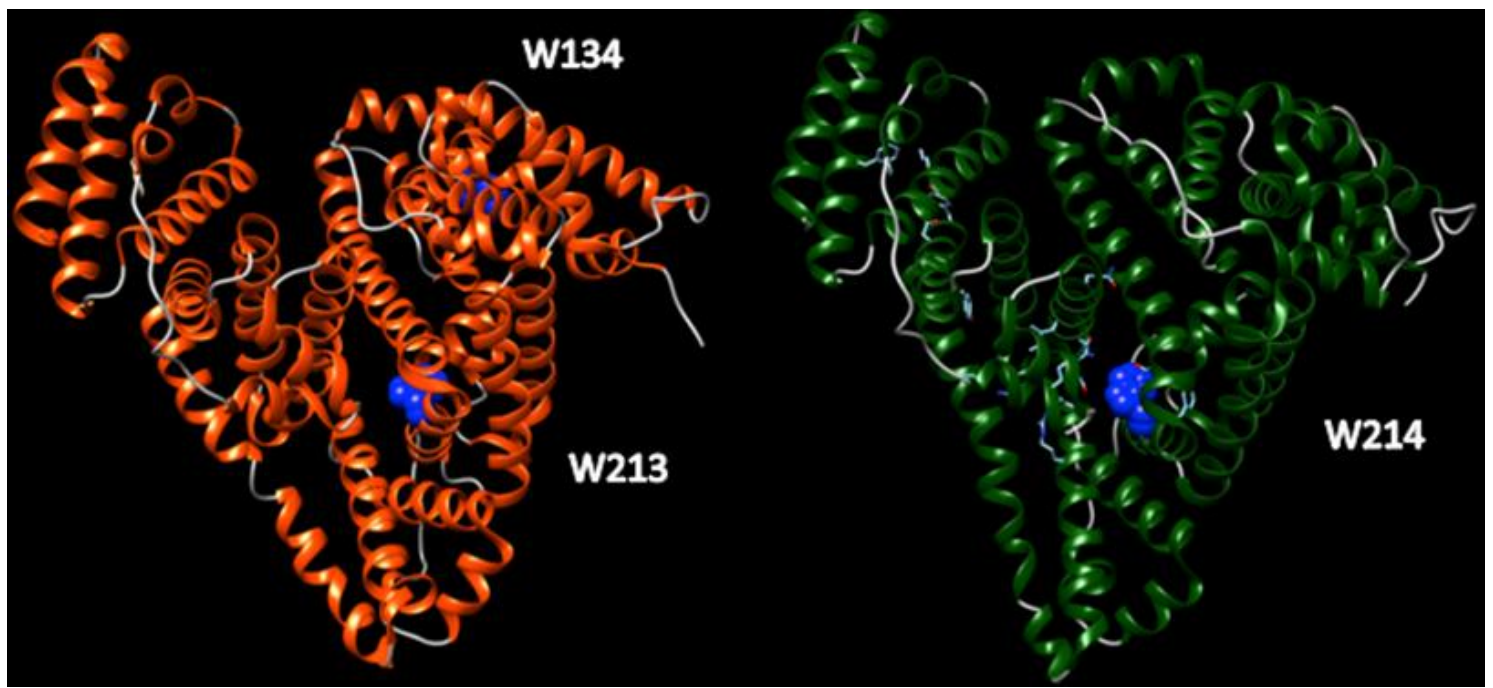

Figura 1.5: Estrutura da BSA (vermelha) e HSA (verde) e posição dos triptofanos.

Devido a essa semelhança a BSA é muito utilizada em estudos biomiméticos, pois possui grande estabilidade e custo menor que a HSA.

\subsubsection{Lisozima}

A Lisozima é uma enzima que catalisa a hidrólise de ligações glicosídicas, presentes nas paredes bacterianas em especial nas Gram-positivas [12]. Ela funciona, portanto, como um mecanismo de defesa de quem a produz. Pode ser encontrada no muco, na lágrima dos seres humanos e em ovos. Essa enzima também é produzida por bactérias, onde sua principal função é digerir carboidratos de alta massa molar. [12] 
A lisozima de clara de ovo é a mais estudada e bem conhecida dentre as lisozimas. A proteína é relativamente pequena, possui 129 aminoácidos, massa molar igual a $14600 \mathrm{~g} / \mathrm{mol}$, dimensões em torno de 30 X 30 X $45 \AA$ e seis triptofanos. Na estrutura secundária $30 \%$ de $\alpha$-hélice e $13 \%$ de folha- $\beta$.

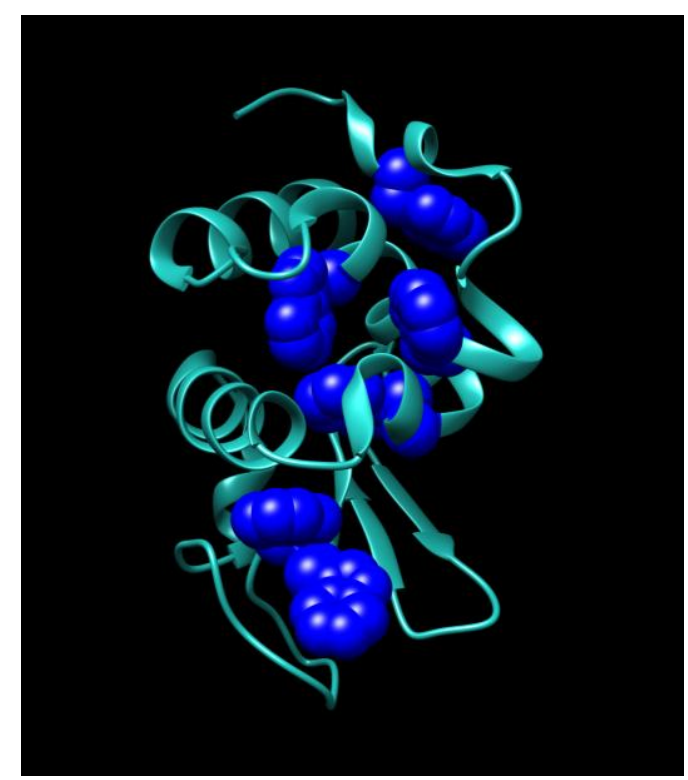

Figura 1.6: Estrutura da Lisozima e triptofanos marcados em azul. [Protein Data Bank; Código: 1DPX]

\subsection{Moléculas Anfifílicas}

Moléculas anfifílicas possuem uma parte polar (hidrofílica, solúvel em água) ligada covalentemente à outra apolar (hidrofóbica, insolúvel em água), frequentemente denominadas como cabeça polar e cauda apolar, respectivamente. Tais características possibilitam às moléculas anfifílicas a capacidade de alterar a tensão superficial a água, conferindo-lhes também o nome de tensoativos ou surfactantes.

Os tensoativos que apresentam cabeça polar com carga positiva são chamados catiônicos, enquanto que os com carga negativa são chamados aniônicos, no caso de não possuírem nenhum grupo carregado são chamados não iônicos. Os tensoativos que possuam grupos aniônicos e catiônicos na região polar são chamados anfóteros ou 
zwiteriônicos, portam dois grupos carregados de cargas opostas, tendo carga total nula, mas momento de dipolo elétrico não-nulo.

Os anfifílicos organizam-se, sob a ação da água, de forma a maximizar o contato da cabeça polar com a solução aquosa (aumentando assim o número de ligações da cabeça com a solução aquosa) e o isolomento da cadeia de hidrocarbonetos, minimizando o contato dessas regiões com a água.

Em baixas concentrações a disposição mais estável termodinamicamente é na superfície e com as caudas apolares voltadas para o ar, com o aumento do número de moléculas anfifílicas o espaço disponível na superfície é saturado e os choques entre estas são incentivados, possibilitando a formação de agregados na fase aquosa.

Os possíveis agregados formados pelos tensoativos são variados e dependem tanto da forma de seus constituintes quanto da polaridade do solvente, por exemplo, a micela é formada por moléculas com forma semelhante a um cone e em solução polar, este e outros exemplos na Figura 1.7. 
Meio

Forma

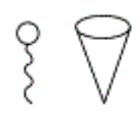

Cone Invertido

Polar

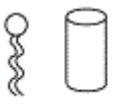

Cilindro

Polar
Estrutura
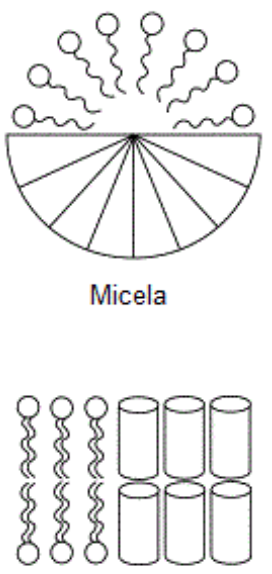

Bicamada

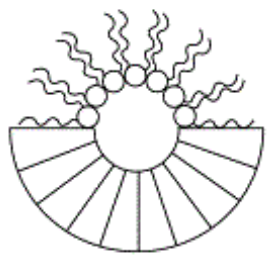

Micela Reversa

Figura 1.7: Algumas diferentes estruturas dos agregados de tensoativos para algumas formas e meios. [Modificado de IsraelavichVilli, 1985]

A concentração de anfifílico que inicia a formação de agregados micelares é chamada de concentração micelar crítica ou CMC. A CMC marca uma mudança conformacional brusca do sistema e pode ser detectada através de várias técnicas pela variação de qualquer propriedade físico-química. A Figura 1.8 mostra algumas alterações esperadas durante a formação de micelas. A escolha da utilização da técnica mais adequada vai depender do sistema em estudo. 


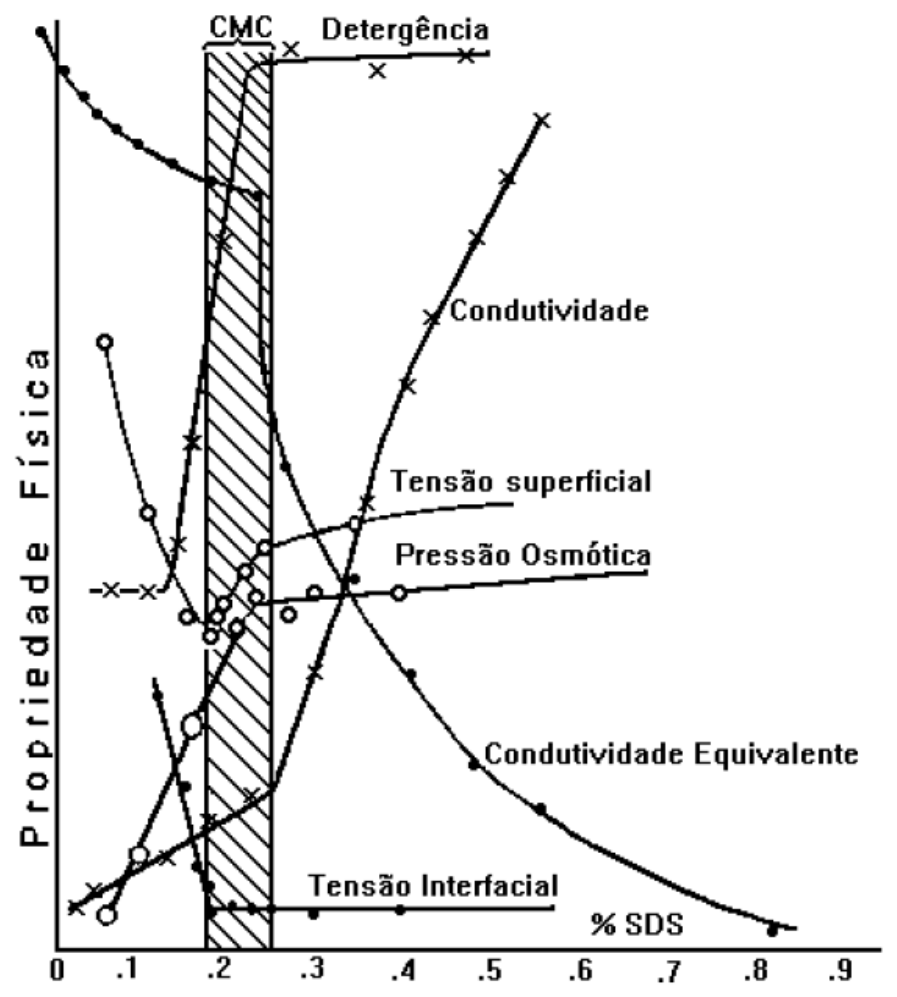

Figura 1.8:Representação da variação de diversas propriedades físico-química ao atingir a CMC do surfactante SDS. [Modificado de ELWORHY et al., 1968] 


\section{Objetivos}

Objetivo Geral

Determinar a influência estrutural de diferentes líquidos iônicos funcionalizados com cadeias de hidrocarbonetos em proteínas modelo.

Objetivos Específicos

- Determinar o comportamento dos LIs na estrutura terciária das proteínas BSA, HSA e Lisozima através das técnicas: absorção óptica, fluorescência e SAXS

- Estudar a influencia dos LIs na estrutura secundária das proteínas através da técnica de dicroísmo circular; 


\section{Materiais e Métodos}

\subsection{Materiais}

Todas as proteínas utilizadas neste trabalho foram adquiridas da empresa SigmaAldrich: BSA (do inglês Bovine Serum Albumine), HSA (do inglês Human Serum Albumine) e a Lisozima (do inglês Lysozyme). Todos os líquidos iônicos são da fabricante io-li-tec: 1-methyl-3-tetradecylimidazolium chloride ou $\left[\mathrm{C}_{14 \mathrm{mim}}\right][\mathrm{Cl}], 1$ dodecyk-3-metrhylimidazolium chloride ou $\left[\mathrm{C}_{12 \mathrm{mim}}\right][\mathrm{Cl}]$ e 1-decyl-methylimidazolium chloride ou $\left[\mathrm{C}_{10 \operatorname{mim}}\right][\mathrm{Cl}]$. Os materiais listados possuem código de referência do produto e de lote conforme a tabela abaixo:

Tabela 3.1: Materiais utilizados.

\begin{tabular}{|l|l|l|l|}
\hline & Fabricante & Referência do Produto & Lote \\
\hline Albumina de Soro Humana & Sigma & L6876-10g & 061M1329V \\
\hline Albumina de Soro Bovina & Sigma & A9511-1g & $122 \mathrm{H} 9309$ \\
\hline Lisozima de ovo branco & Sigma & A2153-10g & SLBN1377V \\
\hline$\left[\mathrm{C}_{14 \mathrm{mim}}\right][\mathrm{Cl}]$ & io-li-tec & IL-0141 & J00220.6 \\
\hline$\left[\mathrm{C}_{12 \mathrm{mim}}\right][\mathrm{Cl}]$ & io-li-tec & IL-0120 & K00141.1 \\
\hline$\left[\mathrm{C}_{10 \mathrm{mim}}\right][\mathrm{Cl}]$ & io-li-tec & IL-0065 & - \\
\hline
\end{tabular}

\subsection{Preparação das amostras}

Todas as amostras preparadas para o desenvolvimento deste trabalho foram feitas em tampão acetato-fosfato-borato de sódio, 20 mM, em pH 7.3.

Neste trabalho, para todas as proteínas estudadas utilizamos concentrações que variam de $1-20 \mathrm{mg} / \mathrm{ml}$. Em todos os casos, preparamos uma concentração estoque de 
até $30 \mathrm{mg} / \mathrm{ml}$ e depois diluímos para a concentração desejada. Todas as concentrações das soluções estoque foram determinadas espectroscopicamente, utilizando os coeficientes de extinção molar de cada proteína presente na Tabela 3.2, mais adiante.

Preparamos as soluções estoque dos líquidos iônicos pesando em uma balança de alta precisão (incerteza instrumental de $0.0001 \mathrm{~g}$ ) a massa desejada para uma solução estoque de 100mM e depois diluímos para a concentração final desejada.

\subsection{Métodos}

\subsubsection{Tensão Superficial}

A molécula de água se forma quando dois átomos de hidrogênio compartilham seus elétrons com um par de elétrons de um átomo de oxigênio. Os elétrons compartilhados sofrem uma atração mais forte pelo núcleo do oxigênio do que pelo o hidrogênio, causando uma diferença de carga, positiva $\left(\delta_{+}\right)$em cada hidrogênio e negativa $\left(\delta_{-}\right)$no oxigênio. Tal configuração de cargas confere à molécula de água a geometria presente na Figura 3.1 com um ângulo de $104.45^{\circ}$ entre os átomos de hidrogênio, tornando a molécula assimétrica e produzindo um dipolo elétrico. 


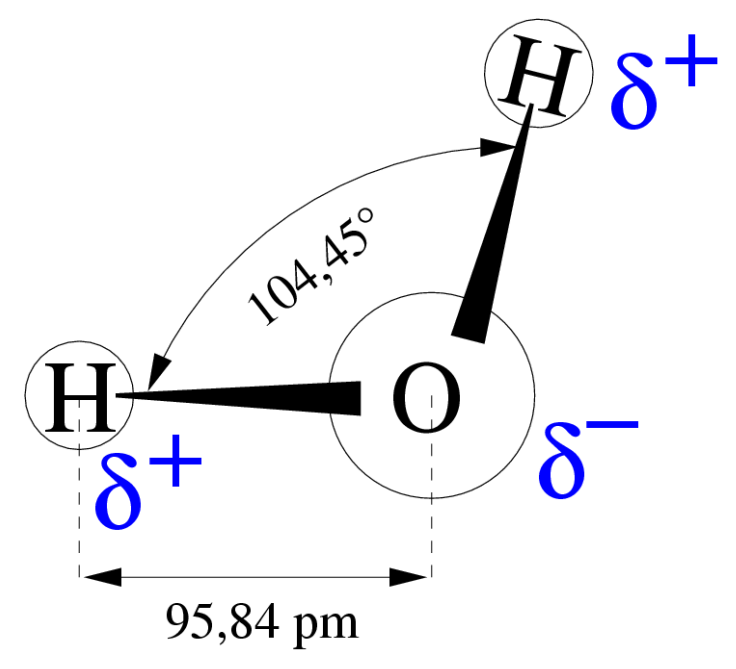

Figura 3.1: Molécula de água. Modificado de

[https://pt.wikibooks.org/wiki/Bioqu\%C3\%ADmica/A_\%C3\%A1gua,_solvente_da_Vida]

As moléculas de água têm alta capacidade de interação com as moléculas vizinhas em decorrência dos dipolos elétricos, formando as chamadas ligações de hidrogênio. Cinco moléculas se organizam dinamicamente na forma de um tetraedro onde a resultante da soma vetorial das forças é nula, exceto as moléculas da superfície que possuem resultantes voltadas para o líquido. A tensão superficial é a força que deve ser vencida para o aumento de uma superfície líquida, quanto maior a atração intermolecular dos compostos maior é a tensão superficial. [14]

Existem diversos métodos utilizados para medição da tensão superficial através de várias grandezas físicas como força, pressão e deformação da superfície, o método utilizado no presente trabalho é o da placa de Wilhelmy. 


\subsubsection{Tensiômetro}

O tensiômetro de força utilizado neste trabalho é da marca Kruss modelo K100 pertencente ao Instituto de Química da USP sob responsabilidade da Prof. Dra. Denise Petri, projeto FAPESP \#2010/51219-4.

A placa de Wilhelmy é posicionada próxima e perpendicular a superfície do líquido, o equipamento imerge a placa e inicia a medição da força necessária para desloca-la no sentido vertical para cima, como ilustrado na Figura 3.2.

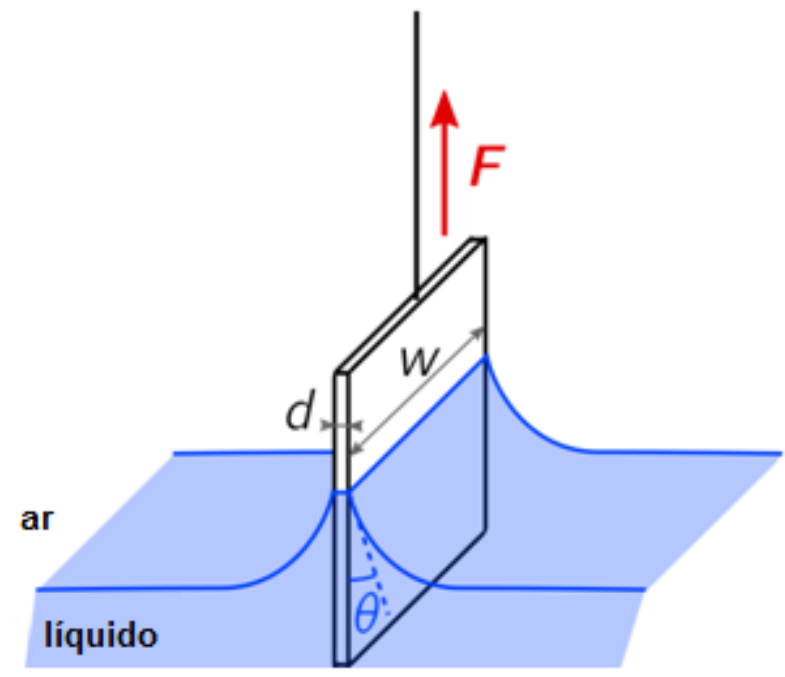

Figura 3.2: Método da Placa Wilhelmy. [Modificado de https://en.wikipedia.org/wiki/Wilhelmy_plate]

A tensão superficial é proporcional à força exercida, ao perímetro da placa que está em contato com o líquido, na interface ar-líquido e ao ângulo de contato entre estes conforme a fórmula a seguir:

$$
\gamma=\frac{F}{2(w+d) \cdot \cos \theta}
$$


Onde $2(w+d)$ é o perímetro da placa em contato com o líquido, $\mathrm{F}$ a força medida e $\theta$ o ângulo de contato entre a placa e o líquido, normalmente aproximado para zero. [15]

\subsubsection{Absorção ótica}

Inicialmente observado por Isaac Newton em 1704, um prisma pode separar a luz branca em diferentes comprimentos de onda, o chamado espectro. O espectro eletromagnético ocorre quando a onda eletromagnética é discriminada em função do comprimento de onda $(\lambda)$ ou frequência $(v)$. A Figura 3.3 esquematiza o espectro eletromagnético com destaque à região do visível $(\lambda$ de $400 \mathrm{~nm}$ a $750 \mathrm{~nm}$ aproximadamente).

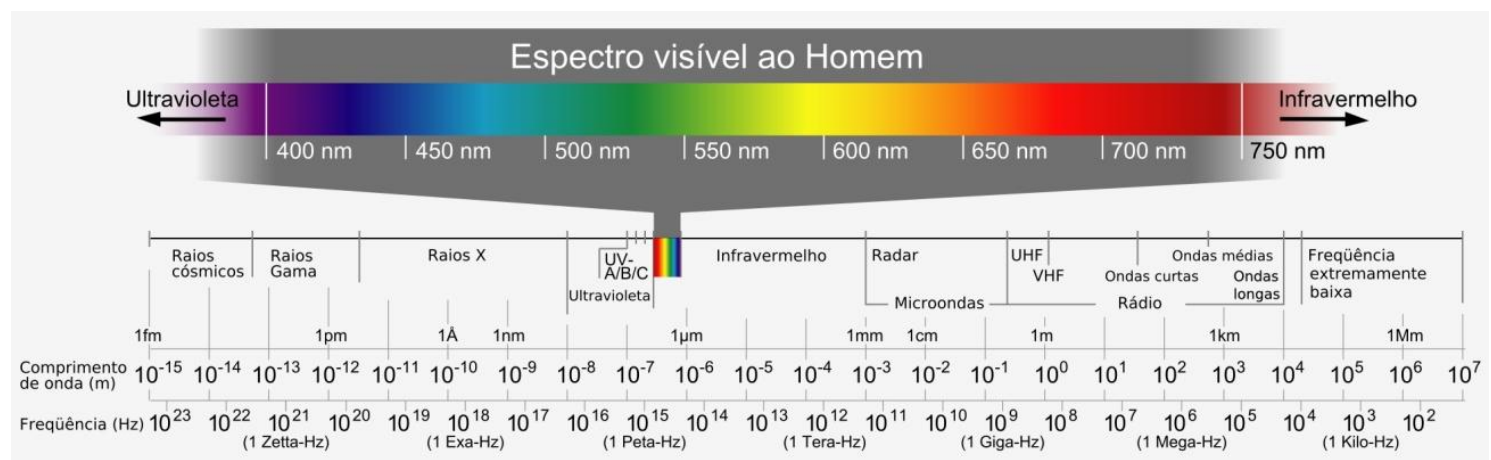

Figura 3.3: Espectro da radiação eletromagnética e suas classificações conforme o comprimento de onda. [http://www.aprenderciencias.com/]

Desde o século XVII muito se discute sobre a natureza da luz. A radiação eletromagnética tem algumas características atribuídas a sistemas corpusculares, como por exemplo, carregar momento linear e ser capaz de transmiti-lo. A radiação eletromagnética também possui propriedades exclusivas de onda, como sofrer difração e interferência. Dentro deste contexto foi determinado o conceito de dualidade onda- 
partícula, ou seja, a radiação eletromagnética ora se comporta como onda ora como partícula. A propagação das ondas eletromagnéticas se dá através de sua unidade padrão, o fóton, que carrega consigo uma determinada quantidade de energia (um quantum de energia).

Um fóton possui energia $E$ proporcional a sua frequência v, ou ao inverso de seu comprimento de onda $\lambda$ :

$$
E=h v=\frac{h c}{\lambda}
$$

Onde $c$ é a velocidade da onda eletromagnética no vácuo e $h$ a constante de Planck .

A onda eletromagnética, ao interagir com a matéria, pode ser absorvida em determinadas faixas do espectro. O comprimento de onda que será absorvido depende de particularidades moleculares e dinâmicas do sistema.

Átomos e moléculas possuem estados eletrônicos discretos, sendo possíveis as transições entre estes quando for cedido ao sistema exatamente as diferenças de energia entre eles. A transição entre um nível menos energético para um nível mais energético é chamada de excitação. Efetivamente há contribuições de estados rotacionais e vibracionais da molécula possibilitando transições em mais comprimentos de onda obtendo-se uma curva de absorbância, onde a intensidade está relacionada com a probabilidade de excitação, detalhamento na seção 3.3.3.

\subsubsection{Lei de Lambert-Beer}

A absorção óptica pode ser utilizada para analisar características interessantes de um sistema, pois carrega informações sobre a concentração, natureza molecular e a 
dinâmica das moléculas absorvedoras. As grandezas intensidade de luz absorvida e a absorbância são as mais corriqueiramente utilizadas com tal intuito.

A absorbância é definida como o logaritmo na base dez da razão entre a intensidade incidente e a transmitida. A absorção óptica depende da quantidade de moléculas absorvedoras no caminho óptico da radiação (ou seja, da concentração) e das características físico-químicas do componente absorvedor (quantificadas pelo coeficiente de extinção molar, $\varepsilon$, para um determinado comprimento de onda). A expressão para a absorbância é estabelecida pela lei de Lambert-Beer [16] [17]:

$$
\log \left(\frac{I_{0}}{I_{t}}\right)=A(\lambda)=C \cdot l \cdot \varepsilon(\lambda)
$$

Onde $A$ é absorbância, $I_{O}$ intensidade de luz incidente, $I_{t}$ a transmitida, $C$ a concentração do absorvedor, $I$ o caminho óptico e $\varepsilon(\lambda)$ o coeficiente de extinção molar.

Utilizaremos tal equação para calcular precisamente a concentração da substância absorvedora partindo do pico de absorbância medida pelo espectrofotômetro. Os coeficientes de extinção molar para cada fluoróforo seguem na Tabela 3.2.

Tabela 3.2: Coeficientes de Extinção Molar e massa molar dos fluoróforos utilizados no presente trabalho

\begin{tabular}{|c|c|c|c|}
\hline Substância & $\lambda(\mathrm{cm})$ & $\boldsymbol{\varepsilon}\left(M^{-1} \cdot \mathrm{cm}^{-1}\right)$ & $\mathrm{M}(\mathrm{g} / \mathrm{mol})$ \\
\hline Triptofano & 280 & 5690 & 204 \\
\hline Albumina de Soro Bovino & 280 & 43824 & 66463 \\
\hline Albumina de Soro Humano & 280 & 36500 & 66437 \\
\hline Lisozima & 280 & 38940 & 14300 \\
\hline
\end{tabular}

A técnica de absorção óptica foi utilizada também para investigar eventuais alterações estruturais ou de distribuição eletrônica na região dos resíduos aromáticos das 
proteínas, devido à presença de LIs. Vale ressaltar que o espectro de absorbância é extremamente sensível a distribuição eletrônica da molécula em estudo, tanto no estado fundamental como no estado excitado.

\subsubsection{Espectrofotômetro}

O equipamento utilizado para medição de absorbância no presente trabalho é o espectrofotômetro da marca Varian modelo Cary 50 bio (Figura 3.4), está presente no laboratório de Biofísica da USP, sob responsabilidade da Prof ${ }^{a}$. Dr ${ }^{\mathrm{a}}$. Maria Teresa Lamy.

O equipamento possui uma lâmpada de xenônio como fonte da radiação UVVis (A), um monocromador tipo Czerny-Turner composto por uma rede de difração (B), um sistema de espelhos e uma fenda de saída, um porta amostra (C) e um detector de diodo de silício (D), como pode ser obervado na Figura 3.4. 


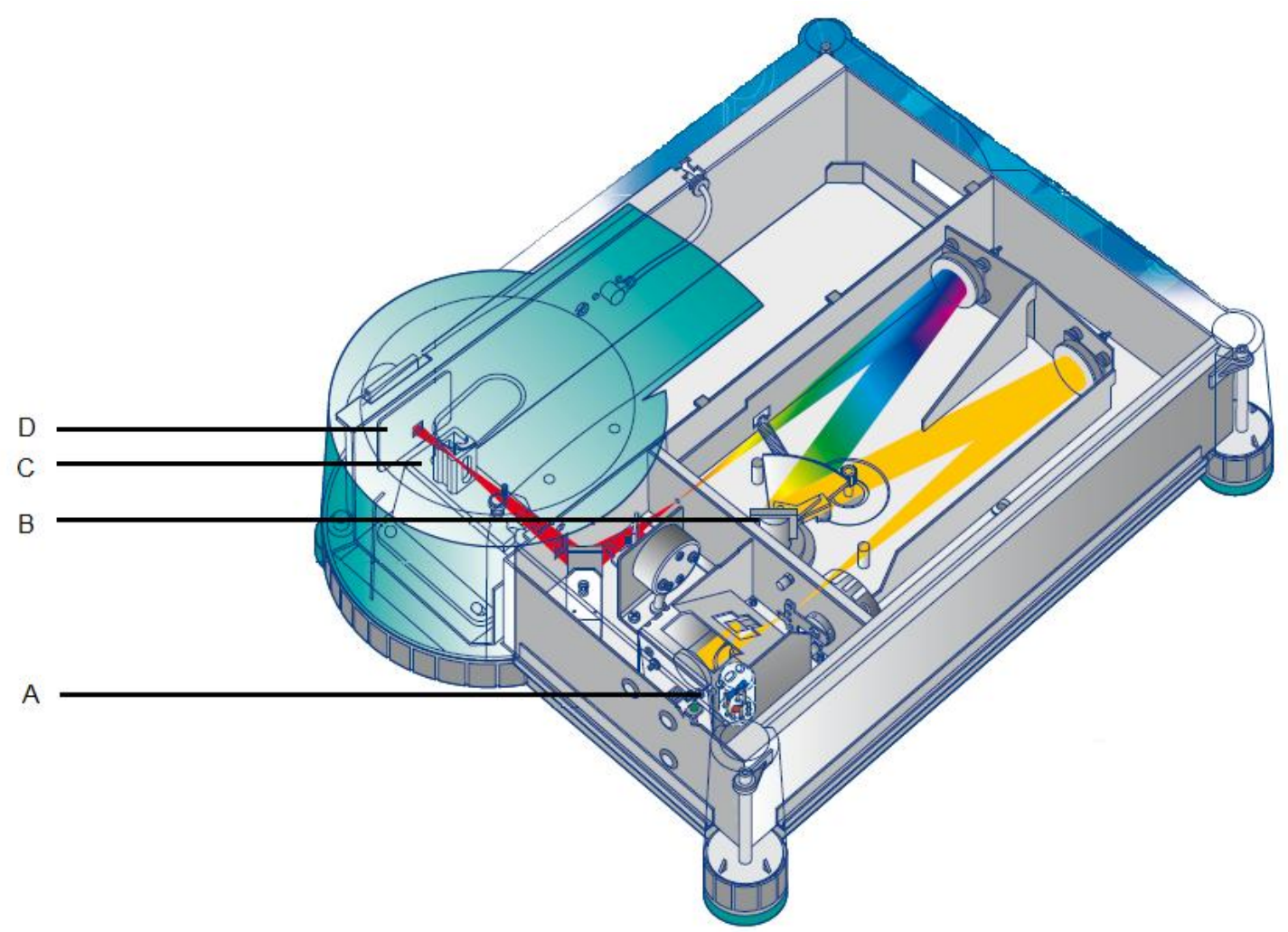

Figura 3.4: Espectrofotômetro Varian Cary 50 Bio. [Modificado de http://www.agilant.com]

Todas as medidas deste trabalho foram feitas em cubetas de quartzo, pois possuem baixa absorção na região de interesse $(200 \mathrm{~nm}-800 \mathrm{~nm})$, com dimensões $10 \mathrm{~mm} \times 10 \mathrm{~mm}$, portanto o caminho ótico é $l=10 \mathrm{~mm}$.

\subsubsection{Fluorescência}

Quando a absorção de uma onda eletromagnética promove transições eletrônicas levando os elétrons a um estado de maior energia, ou estado excitado, o retorno do elétron ao estado fundamental pode ser de forma radiativa, ou seja, com a emissão de um fóton - tal fenômeno é a luminescência. 
A excitação pode levar o elétron a vários estados possíveis, respeitados pelo princípio de exclusão de Pauli, porém o decaimento ao estado fundamental provém do primeiro estado excitado, ou seja, o de menor energia, assim transições internas podem ocorrer por relaxamento. Se o estado excitado é singleto $\left(S_{1}\right)$ o decaimento e emissão do fóton ocorrem em alta taxa, da ordem de $10^{9} \mathrm{~s}^{-1}$, constituindo a fluorescência. Se o estado excitado é um tripleto $\left(\mathrm{T}_{1}\right)$ o decaimento e emissão do fóton é em uma taxa menor, da ordem de $10^{3} \mathrm{~s}^{-1}$, constituindo a fosforescência. [17]

O tempo de vida do estado excitado é o tempo em que o elétron permanece neste, da ordem de $10^{-9} \mathrm{~s}$ e $10^{-3} \mathrm{~s}$ para a fluorescência e fosforescência respectivamente. Para um maior entendimento observe a figura a seguir que contém todas as etapas expostas anteriormente:

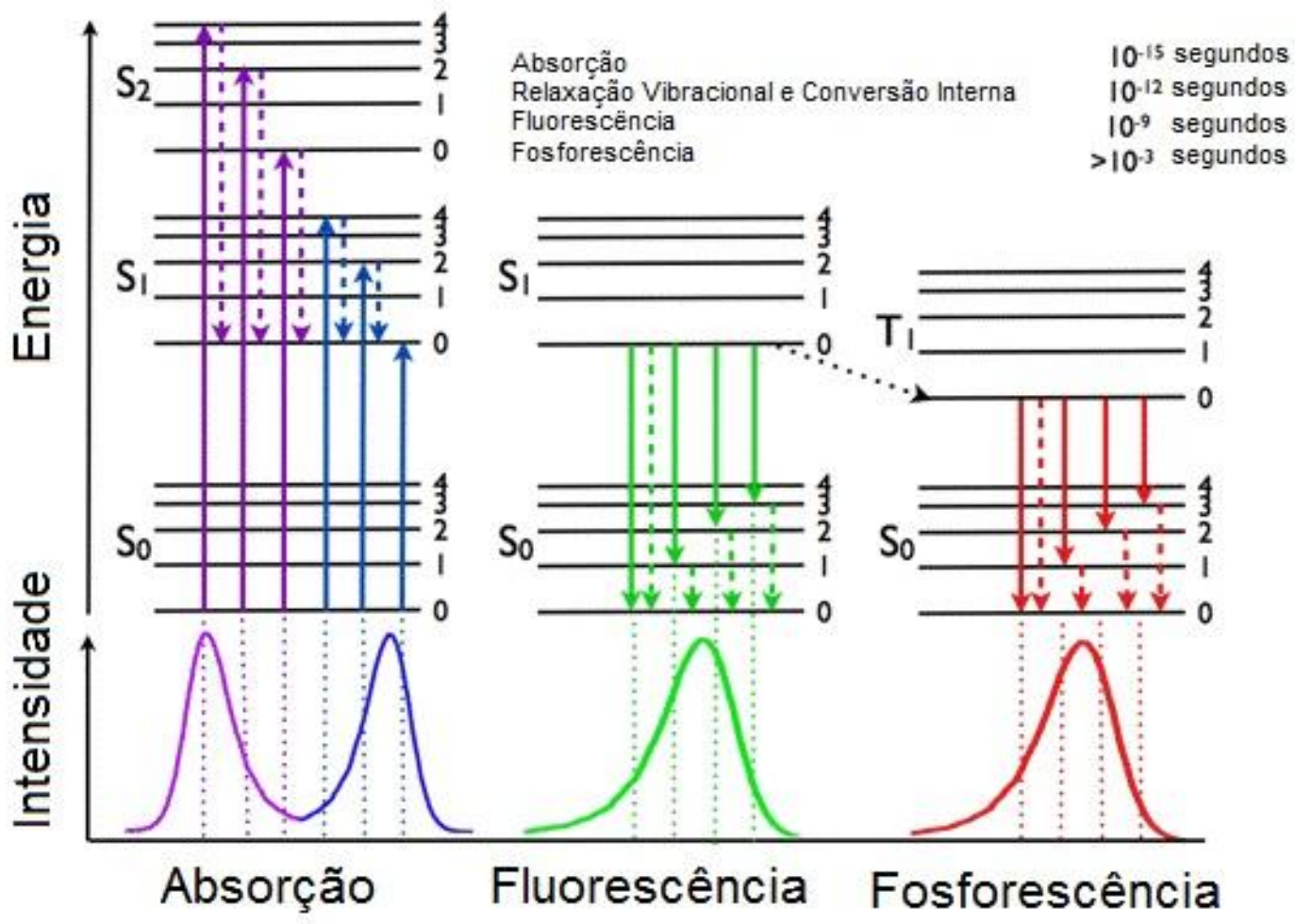

Figura 3.5: Diagrama de Jablonsk com os níveis de energia. Na fluorescência as setas com linha cheia representam transições radiativas e as pontilhadas não radiativas, as conversões internas. A transição entre S1 e T1 é um processo não radiativo conhecido como cruzamento entre sistemas. [Modificado de http://photobiology.info/Visser-Rolinski.html] 
Note que ao absorver um fóton o processo de decaimento será sempre com uma energia menor, pois há perda de energia pelas conversões internas. A menor energia significa um maior comprimento de onda, tal deslocamento do comprimento de onda entre a absorção e a fluorescência é conhecido como o Deslocamento de Stokes. [18]

\subsubsection{Efeito do solvente}

Há sistemas em que o tempo de vida do estado excitado comporta reorganizações das moléculas do solvente com os fluoróforos antes de seu decaimento para o estado fundamental. A reorganização provém do realinhamento do momento do dipolo das moléculas do solvente com o fluoróforo, isto é, uma interação com o estado excitado antes que acorra a emissão do fóton. Como a relaxação é não radiativa, o fóton emitido terá menor energia ou maior comprimento de onda quando comparado com o sistema que não sofreu relaxação. Conforme o esquema abaixo, Figura 3.6, também conhecido como modelo de Lippert:

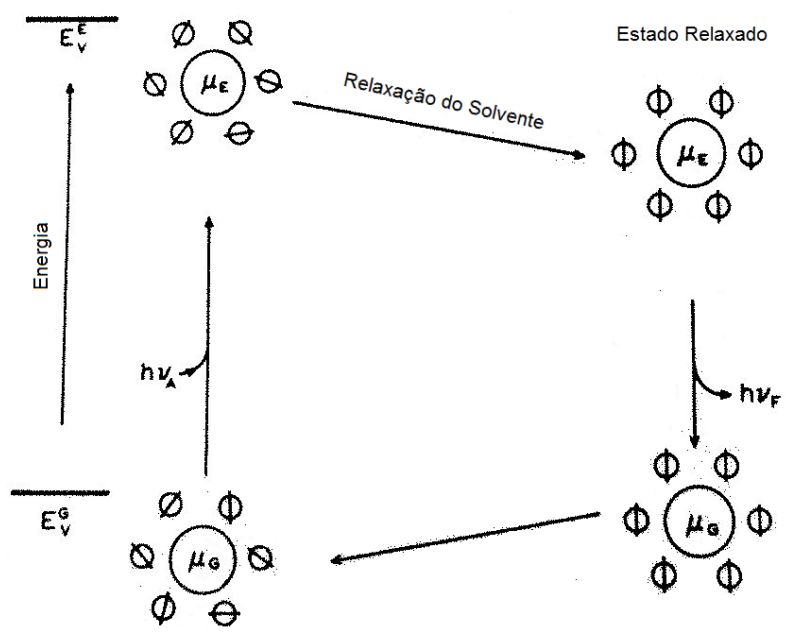

Figura 3.6: Efeito do solvente, representado pelos círculos menores e seu momento de dipolo. Dada uma molécula com momento de dipolo diferente de zero $\mu_{G}$ no estado fundamental e $\mu_{E}$ no estado excitado onde $\mu_{E}>\mu_{G}$. A energia do fóton absorvido vale $h v_{A}$ e do fóton emitido vale $h v_{F}$. Modificado de [17] 
Assim, podemos observar que mudanças no solvente podem promover deslocamentos no espectro de fluorescência, em especial na posição do máximo de emissão de fluorescência (fóton emitido com energia $h v_{f}$ na Figura 3.6). Quanto maior a relaxação da sonda com o meio, menor a energia do fóton emitido e vice-versa. Em outras palavras se o meio tornou-se mais polar maior será a energia custeada no rearranjo, menor será a energia remanescente que poderá ser emitida pelo fóton, portanto maior será o seu comprimento de onda, a este efeito chamamos de red-shift. Quando o meio torna-se mais apolar menor será a energia necessária para o rearranjo das moléculas, consequentemente a energia emitida pelo fóton poderá ser maior, ou com menor comprimento de onda, efeito chamado de blue-shift. [19] [20]

\subsubsection{Supressão da Fluorescência}

A diminuição da intensidade de fluorescência é chamada de supressão da fluorescência (ou ainda do inglês, quenching) e pode ocorrer por uma variedade de processos. Entre estes estão reações no estado excitado, rearranjo molecular, transferência de energia e formação de complexos. Enfatizaremos dois tipos de supressão: a dinâmica e a estática.

A supressão da fluorescência traz informações sobre a interação do fluoróforo e seu supressor (quencher). Tanto a supressão dinâmica quanto a estática requerem contato molecular entre o fluoróforo e o supressor, portanto também é possível extrair informações sobre a acessibilidade de um em relação ao outro. Por exemplo, um fluoróforo que está no interior de uma micela e isolado do supressor apresentará menor supressão em comparação ao mesmo fluoróforo em solução aquosa. 
A supressão estática ocorre quando há a formação de um complexo não fluorescente entre o supressor e o fluoróforo. A supressão dinâmica ocorre quando o supressor interage com o fluoróforo durante o tempo de vida do estado excitado, este retorna para o estado fundamental através de processos não radiativos e deixa de emitir um fóton, a comparação entre ambos pode ser apreciada na Figura 3.7. [17]

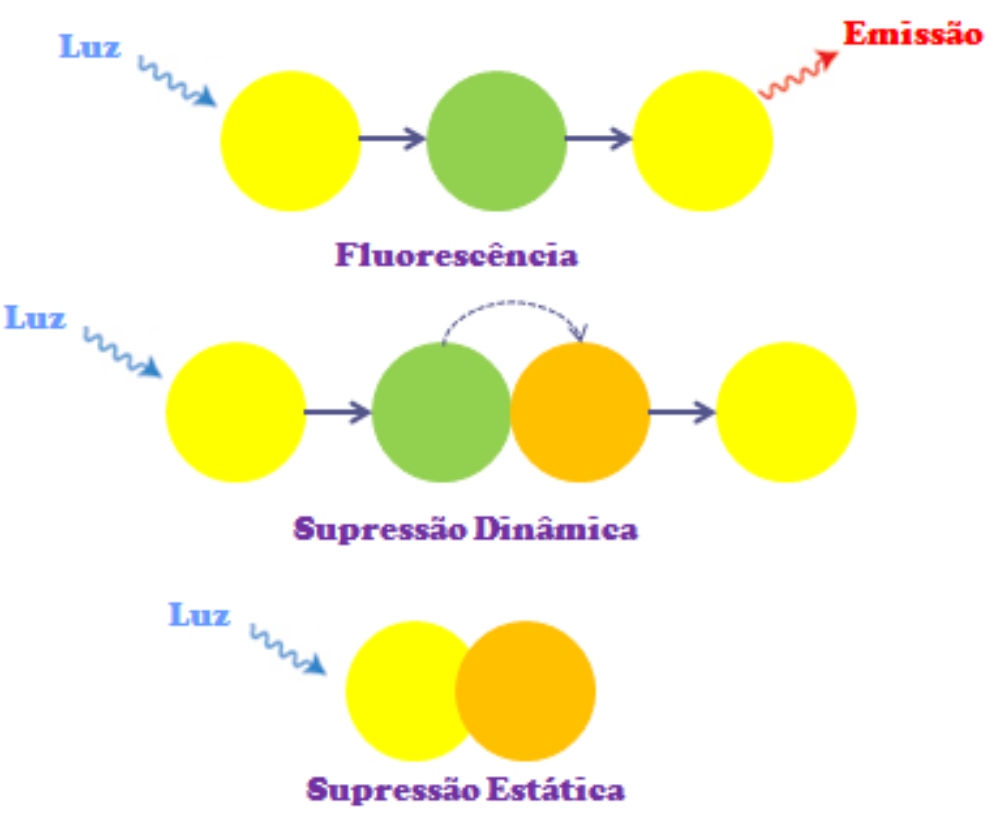

Figura 3.7: Esquema ilustrativo do efeito da supressão dinâmica e estática. 0 Circulo amarelo representa o fluoróforo em seu estado fundamental, o círculo verde representa o fluoróforo em seu estado excitado e o círculo laranja representa o supressor.

\subsubsection{Fluorescência das proteínas}

Como mencionado anteriormente, as proteínas podem possuir até três diferentes resíduos aromáticos que contribuem para a fluorescência: fenilalanina, tirosina e triptofano. Estes possuem espectros distintos como podem ser vistos na Figura 3.8: 


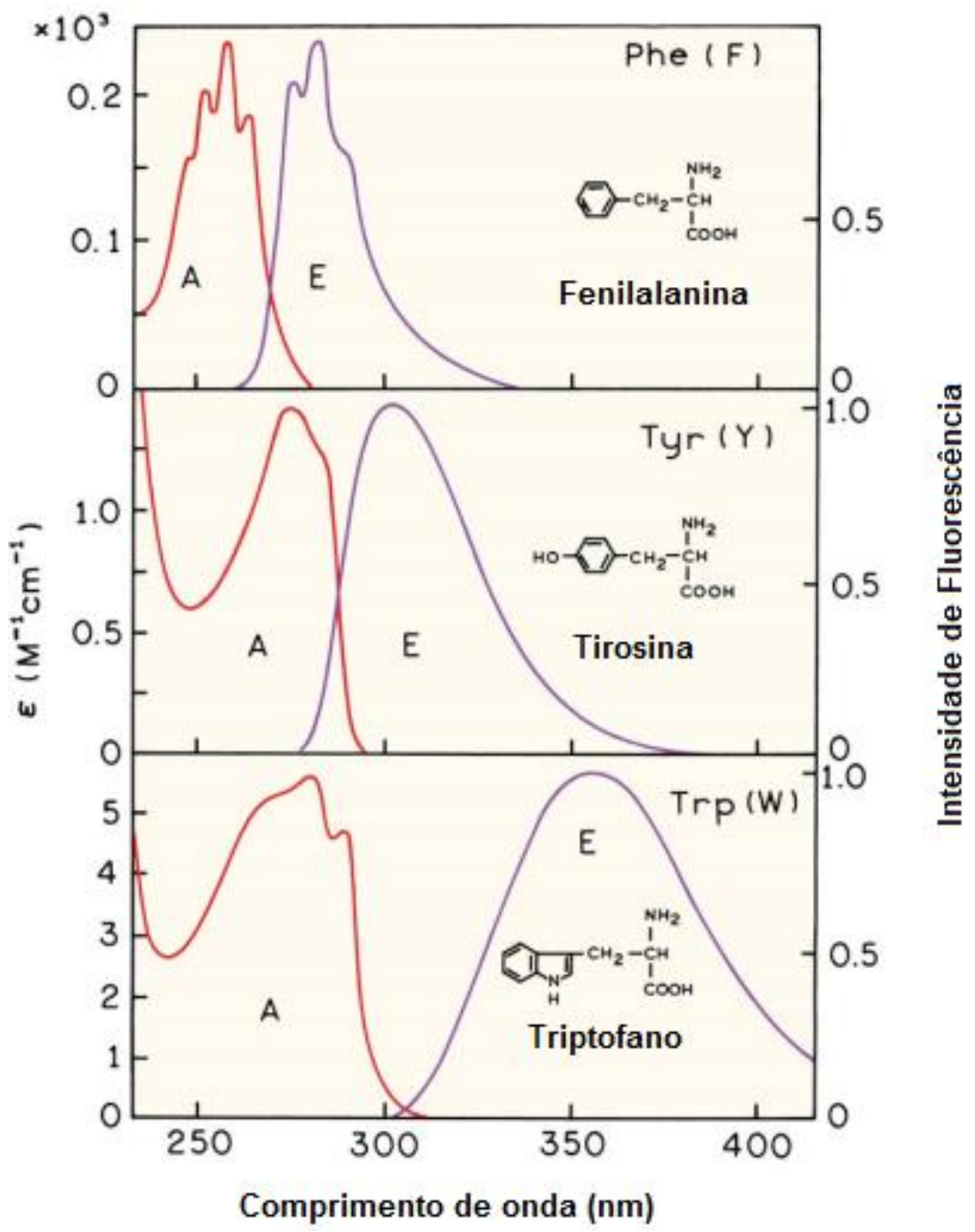

Figura 3.8: Espectros de absorbância (A) e fluorescência (F) dos aminoácidos arômáticos em solução aquasa de pH 7. Modificado de [17]

Observe que há intersecção dos espectros, tanto de absorção quanto de emissão, dos três resíduos, isto é, ao excitarmos em 250nm uma amostra que contem os três aminoácidos, os três são aptos a passar pelo processo de fluorescência nessas condições, resultando em uma sobreposição no espectro final e uma grande dificuldade na análise dos dados, uma vez que não conseguiríamos individualizar o efeito sofrido para cada aminoácido. 
O rendimento quântico nos traz informação sobre a pertinência da emissão de cada fluoróforo, é definida como a razão entre a taxa de emissão fluorescente e a taxa de decaimento total (radiativa e não radiativa). O rendimento quântico da fenilalanina, da tirosina e do triptofano são 0.03, 0.14 e 0.13, respectivamente [19] [21]. A emissão da fenilalanina é raramente observada em fluorescência de proteínas, o que pode ser explicado pelo seu baixo rendimento quântico, por sua vez o triptofano e tirosina são expressivos. [17]

Buscando a simplificação do estudo observaremos somente o comportamento do triptofano, portanto o comprimento de onda da radiação incidente será $295 \mathrm{~nm}$, onde a fenilalanina e a tirosina não absorvem. É importante resaltar algumas particularidades da fluorescência do triptofano como dois tempos de vidas quando livre em solução aquosa (0.5ns e 3.1ns) [22] ou três tempos de vida quando em proteínas [23] e sua alta sensibilidade ao microambiente próximo (Seção 3.3.3.1).

\subsubsection{Correção de Filtro Interno}

A correção de filtro de interno se faz necessária sempre que a absorbância da amostra é maior que 0.05 [17], principalmente na energia próxima a excitação do triptofano. A alta absorção do sistema pode atenuar a luz incidente antes de chegar ao ponto onde a fluorescência será observada, adicionalmente a isso também pode ocorrer a reabsorção de um fóton emitido (ver Figura 3.9). Portanto o aparente decréscimo da intensidade de fluorescência pode ser somente devido ao aumento da absorção do sistema.

A partir da definição de absorbância temos que: 


$$
\log \left(\frac{F}{F_{a p}}\right)=A(\lambda) \rightarrow 10^{A(\lambda)}=\frac{F}{F_{a p}}
$$

Onde $F$ é a intensidade de fluorescência real, $F_{a p}$ a intensidade de fluorescência aparente e $A(\lambda)$ é a absorbância por unidade de caminho óptico em um dado comprimento de onda. A correção de filtro interno é composta de dois termos, que são facilmente verificados na Figura 3.9:

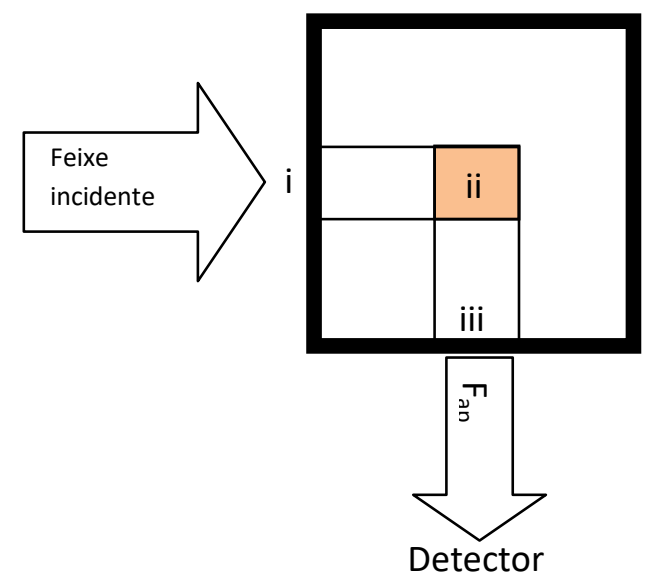

Figura 3.9: Esquema ilustrativo de uma cubeta onde há o feixe incidente no ponto i, ocorre a excitação e emissão no ponto ii e a detecção da intensidade de fluorescência no ponto iii.

Consideremos, a priori, que a fluorescência a ser observada parte da região ii (parte central da cubeta), portanto há atenuação do feixe incidente entre os pontos i e ii, antes da excitação. Além disso, há a atenuação da intensidade de fluorescência ao longo do caminho entre os pontos ii e iii. O feixe incidente provocará a excitação do fluoróforo, portanto possui uma energia bem definida e será absorvida conforme a absorbância no comprimento de onda de excitação correspondente, já o feixe emitido será atuado conforme a absorbância nos comprimentos de onda de emissão, logo, em todo o espectro de fluorescência. A equação que contém os dois fatores da correção de filtro interno é: 


$$
F=F_{a p} 10^{\left(A_{e x} x_{1}\right)} 10^{\left(A_{e m} x_{2}\right)}
$$

Onde $A_{\text {exc }}$ é a absorbância no comprimento de onda de excitação, $A_{\text {em }}$ é a absorbância nos comprimentos de onda de emissão, $x_{1}$ é o caminho óptico do feixe incidente, ou pela Figura 3.9 entre os pontos i e ii e $x_{2}$ é o caminho óptico da emissão, ou pela figura entre os pontos ii e iii. No presente trabalho tanto o caminho óptico de excitação quanto o de emissão são iguais a $0.5 \mathrm{~cm}$.

Mendonça e colaboradores [24] mostram que é possível desprezar as dimensões da região excitada e que a equação (3.7) traz resultados satisfatórios.

\subsubsection{Fluorímetro}

As medidas de fluorescência foram realizadas utilizando o fluorímetro, marca Varian modelo Cary Eclipse (Figura 3.10), presente no laboratório de Biofísica da USP, sob responsabilidade da Prof ${ }^{a}$. Dr ${ }^{a}$. Maria Teresa Lamy.

O equipamento possui uma lâmpada de xenônio como fonte da radiação UVVis, um monocromador tipo Czerny-Turner para a excitação (permitirá a passagem somente no comprimento de onda selecionado pelo software), um porta amostra, outro monocromador tipo Czerny-Turner para a emissão (localizado a $90^{\circ}$ com relação ao feixe incidente) e uma foto multiplicadora. 


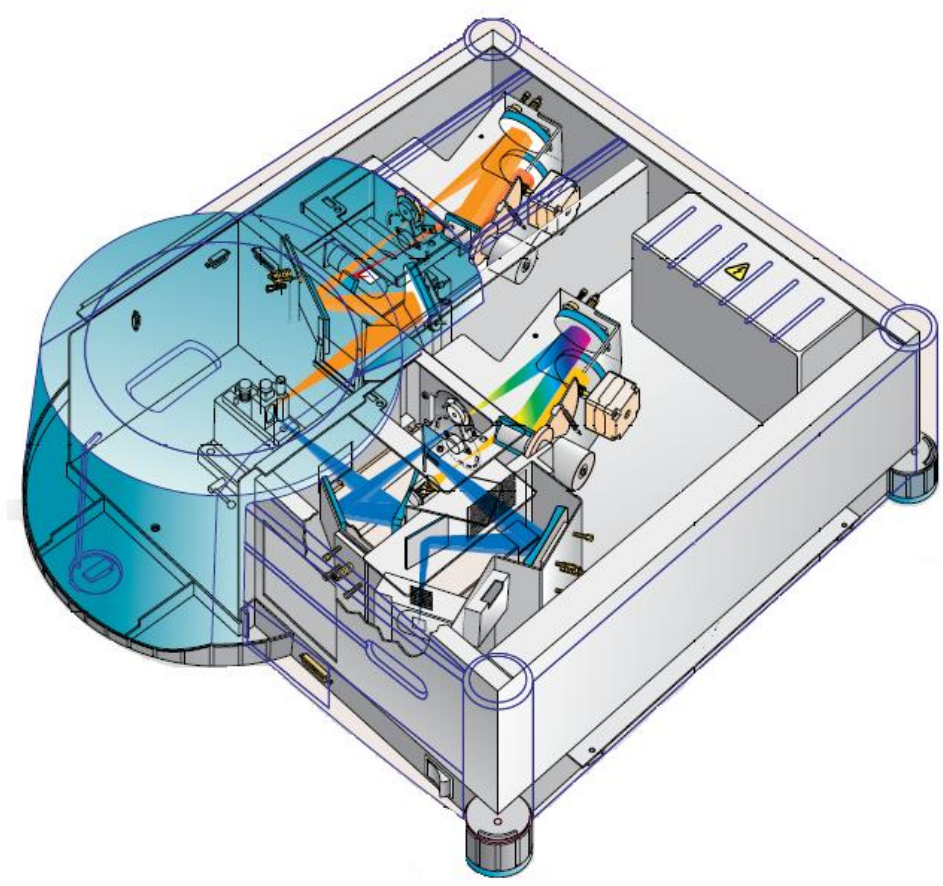

Figura 3.10: Fluorímetro Varian Cary Eclipse. Modificado de [http://www.agilant.com]

A cubeta utilizada é a mesma utilizada no espectrofotômetro citada anteriormente.

\subsubsection{Dicroísmo Circular (CD)}

A técnica de Dicroísmo Circular (CD) é uma importante ferramenta no estudo da estrutura secundária de proteínas em solução. A técnica se baseia na diferença da absorção da luz circularmente polarizada entre o sentido horário (ou à direita) e o antihorário (ou à esquerda) da cadeia polipeptídica, no caso de proteínas. Temos que o dicroísmo circular molar $\Delta \varepsilon$ é definido como a diferença entre coeficiente de extinção molar do sentido a direita e a esquerda:

$$
\Delta \varepsilon=\varepsilon_{e}-\varepsilon_{d}
$$


Considere o fato que uma onda eletromagnética linearmente polarizada (Figura 3.11 A) ao atravessar um meio circularmente dicroico (ou seja, um sistema que absorva diferentemente as componentes circulares da luz à direita e à esquerda) torna-se elipticamente polarizada (Figura 3.11 B). O dicroísmo circular pode ser caracterizado como a razão entre o semieixo menor e o semieixo maior da elipse desenhada pela polarização (tangente do ângulo de elipsidade $\theta$ ) [25]. A Figura 3.11 elucida tal definição:

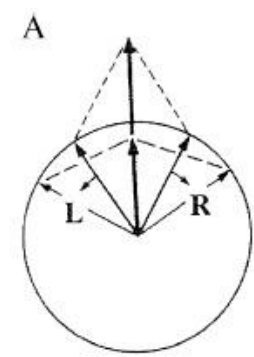

(I)

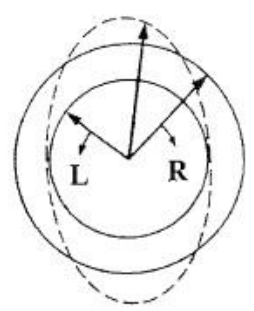

(II)

B

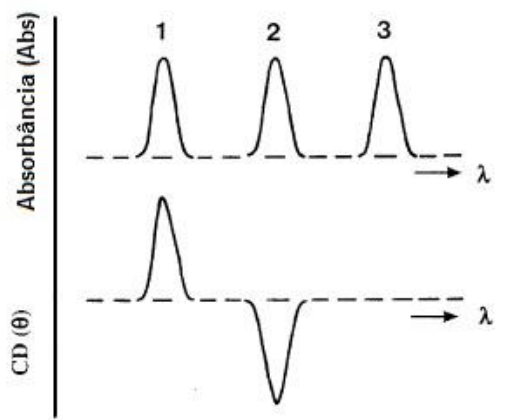

Figura 3.11: Origem do $C D(A)$ Componente a direita ( $R$ ) e a esquerda (L) de uma radiação circularmente polarizada: (I) as duas componentes possuem a mesma amplitude; (II) as duas componentes possuem amplitudes diferentes que resultam em uma polarização elíptica. (B) relação dentre a absorbância e espectro de CD. Na banda 1 ocorre maior absorção $L$ que $R$, em 2 maior absorção em $R$ que $L$, em 3 a absorção em $R$ e $L$ são iguais. [26]

De um modo geral, sistemas de interesse biológicos (proteínas, polissacarídeos, polímeros, etc) são majoritariamente compostos de Carbono, que em sua forma 
quaternária pode ser quiral, ou seja, absorve a luz circularmente polarizada à direita e à esquerda de maneira diversa. Serão essas diferenças de absorção monitoradas por CD.

A elipsidade molar [ $\theta$ ] é mais utilizada, na unidade $\frac{\text { graus.cm }}{10^{-1} \mathrm{~mol}}$ e definida como:

$$
[\theta]=100 \frac{\theta}{C l}=3298 \Delta \varepsilon
$$

Onde $C$ é a concentração do absorvedor e $l$ o caminho óptico.

Um conjunto de ligações peptídicas, com uma série de diferentes ângulos das ligações traz um espectro de CD único, assim cada tipo de estrutura secundária e sua porcentagem (número de um tipo de estrutura secundária sobre o total de estruturas secundárias presentes na proteína) podem ser identificadas. Seguem espectros característicos na Figura 3.12:

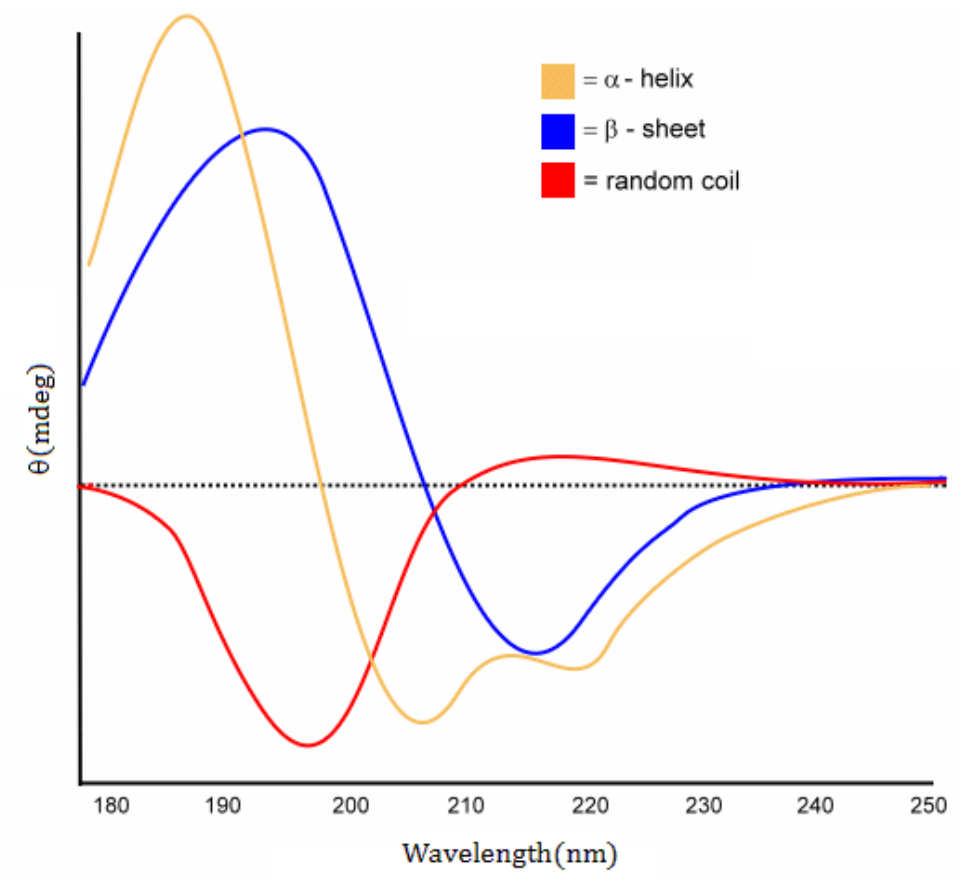


As medidas de $\mathrm{CD}$ realizadas neste trabalho foram obtidas no espectropolarímetro da marca Jasco e modelo J-810 no Centro Brasileiro de Tecnologia de Bioetanol, CTBE, Campinas-SP, com o apoio da Dra. Letícia Zanphorlin.

\subsubsection{Espalhamento de Raio-X a Baixo Ângulo (SAXS)}

A radiação eletromagnética com comprimento de onda da ordem de 0.01 a 10nm é dita raio-X, conforme a Figura 3.3, é comumente utilizada para o estudo estrutural de matéria mole e cristais. A radiação eletromagnética nesta faixa de energia interage fortemente com os elétrons mais internos dos átomos. $\mathrm{O}$ espalhamento do raio- $\mathrm{X}$ de biomoléculas depende do número destas no volume irradiado (concentração do soluto) e do contraste, isto é, a diferença de densidade eletrônica entre o soluto e o solvente. [27] [28] [29]

Podemos separar esta interação da radiação eletromagnética com o elétron (inicialmente livre) em duas principais naturezas: o espalhamento elástico ou espalhamento Thomson e o inelástico ou espalhamento Compton. No espalhamento inelástico a energia do fóton pode ser parcialmente absorvida pelo elétron, na forma de energia cinética, e emitir outro fóton com energia menor e sem correlação de fase com o fóton inicial. Tal efeito não nos traz informações sobre a estrutura da molécula, portanto normalmente é subtraído ou desprezado, assim como a criação de pares elétron-pósitron por sua baixa probabilidade. [30]

A interação considerada mais importante é o espalhamento elástico, onde o fóton põe o elétron a vibrar e irradiar, emitindo outro fóton em outra direção, porém com a mesma energia: 


$$
\varepsilon(e V)=\frac{h c}{\lambda}=\frac{12398.5}{\lambda[\AA]}
$$

Considerando uma densidade eletrônica temos agora a interferência entre os diferentes fótons, que podem ser construtiva ou destrutiva. Segundo a Lei de Bragg, para redes cristalinas há uma relação (inversa) entre o ângulo refletido e a distância entre diferentes planos que refletiram uma onda incidente, quando a interferência é construtiva e máxima.

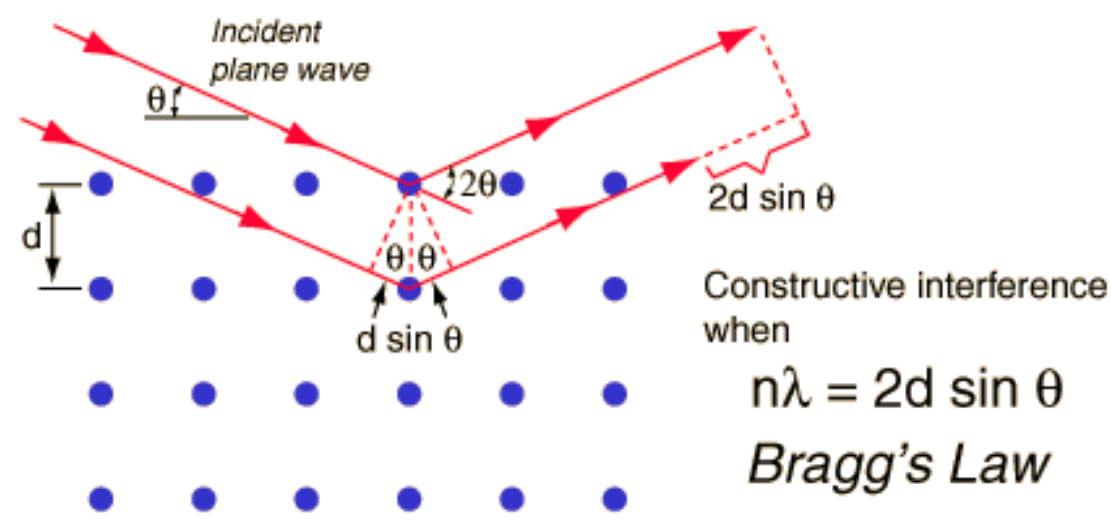

Figura 3.13: Ilustração e fórmula da Lei de Bragg. (Retirado de HTTP: hyperphysics.phy-astr.gsu.edu)

Como o sistema estudado não constitui uma rede cristalina e sim uma distribuição de moléculas dispersas com algumas distâncias que se repetem, como o tamanho médio da nuvem eletrônica da proteína ou possíveis agregados, a interpretação da intensidade de espalhamento requer maior cuidado.

Observe a Figura 3.14 (A) onde temos um feixe de raios- $x$ irradiando uma amostra, parte é espalhado pela amostra, parte atravessa sem interagir com ela. Um detector, ou um conjunto de detectores, é posicionado perpendicularmente ao feixe, assim temos um plano com pontos luminosos correspondentes aos fótons que chegaram ao detector. Normalmente para proteger o detector utiliza-se um "beam stopper" que impede que a radiação não interagente danifique o sensor devido à sua alta intensidade. 

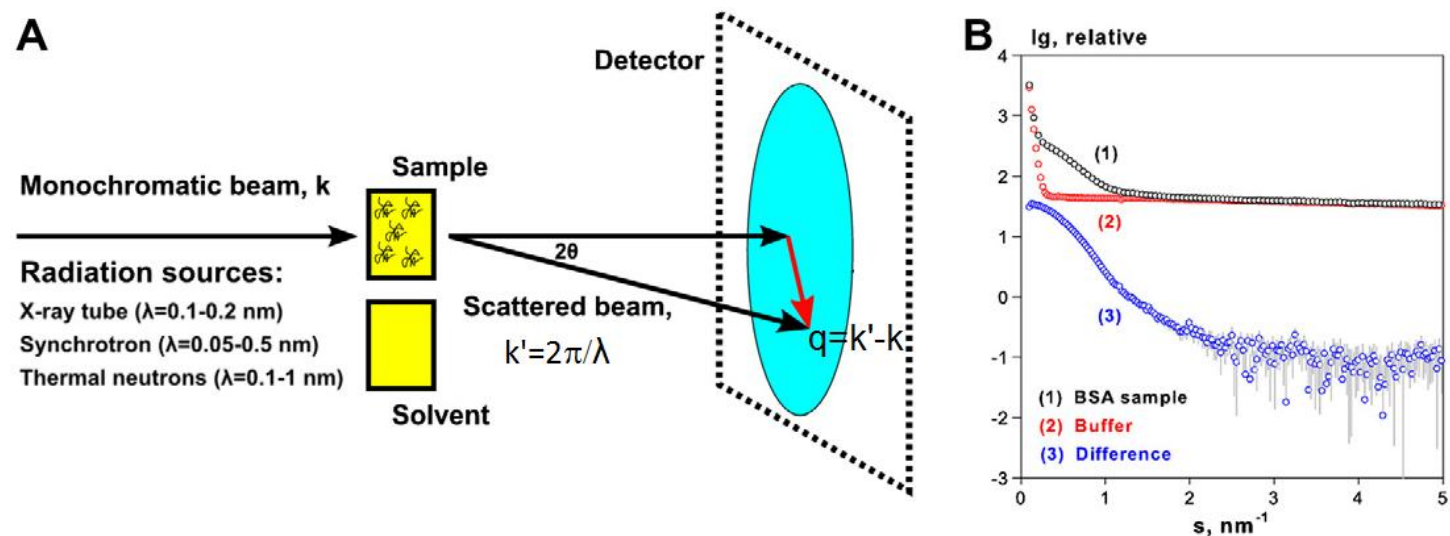

Figura 3.14: (A) Representação de um experimento de difração de raios-X. (B) Exemplo dos dados coletados para BSA. [29]

Considere $\vec{k}$ o vetor de onda da radiação incidente e $\overrightarrow{k^{\prime}}$ da radiação espalhada e $\vec{q}$ a diferença entre estes, chamado vetor de espalhamento. Desprezando o efeito Compton podemos escrever que:

$$
\vec{q}=\vec{k}-\overrightarrow{k^{\prime}}=\frac{4 \pi}{\lambda} \operatorname{sen}(\theta)
$$

A intensidade de espalhamento, como no exemplo da Figura 3.14 (B), para uma solução pode ser escrita simplificadamente como:

$$
I(q)=N\langle P(q)\rangle \cdot\langle S(q)\rangle
$$

Onde $N$ corresponde ao número de centros espalhadores, $P(q)$ é o fator de forma, contém informações sobre a forma da proteína e $S(q)$ fator de estrutura, tem relação com a interação entre as partículas vizinhas. É importante salientar que se o sistema estiver suficientemente diluído, ou seja, a distância média entre as partículas for bem maior que o tamanho característico destas, podemos escrever que $S(q) \rightarrow 1$, o que acabar por simplificando consideravelmente a análise empregada. 


\subsubsection{Representação de Kratky e Lei de Guinier}

\section{Representação de Kratky}

A representação de Kratky é largamente utilizada para uma análise preliminar do estado conformacional de proteínas em solução. A representação de Kratky consiste em analisar como a intensidade de espalhamento multiplicada pelo quadrado do vetor de espalhamento varia em função do vetor de espalhamento, ou seja, ela é feita da análise visual do gráfico de $I(q) q^{2} X q$.

Uma proteína que em sua forma nativa, enovelada e compacta, apresenta uma curva de Kratky na forma de sino e a posição é inversamente proporcional ao tamanho médio da proteína. Quando a proteína passa a uma forma completamente desenovelada a forma de sino é perdida e a curva cresce com o vetor espalhamento q. [31]

Aproximação de Guinier

A aproximação de Guinier consiste na análise à pequenos valores de vetor espalhamento. Segundo a lei de Guinier a intensidade de espalhamento para $q \rightarrow 0$ é aproximadamente igual a:

$$
I(q \rightarrow 0) \cong I(0) e^{-\frac{R_{g}^{2} q^{2}}{3}}
$$

Onde $R_{g}$ é o raio de giro, que está relacionado com tamanho médio da molécula espalhadora. Podemos linearizar a equação aplicando ln nos dois lados da equação obtendo:

$$
\ln I(q \rightarrow 0)=\ln I(0)+\ln e^{-\frac{R_{g}^{2} q^{2}}{3}}=\ln I(0)-\frac{R_{g}^{2} q^{2}}{3}
$$


Note que do gráfico $\ln I X q^{2}$ para valores pequenos de $q\left(q_{\max } R_{g} \leq 1.3\right)$ podemos obter $R_{g}$ através do coeficiente angular da reta acima. [31] 


\section{Estrutura da Dissertação}

A fim de se determinar como se dá a interação de diferentes líquidos iônicos com proteínas modelo, realizamos um estudo sistemático com três proteínas: BSA, HSA e Lisozima com 3 diferentes líquidos iônicos: $\left[\mathrm{C}_{10 \mathrm{mim}}\right][\mathrm{Cl}],\left[\mathrm{C}_{12 \mathrm{mim}}\right][\mathrm{Cl}],\left[\mathrm{C}_{14 \mathrm{mim}}\right][\mathrm{Cl}]$. Como se pode perceber, a realização de um estudo sistemático sempre gera uma grande quantidade de dados, haja vista que são 9 sistemas diferentes (3 proteínas em ausência e presença de 3 diferentes líquidos iônicos) em diferentes razões molares. Como será descrito adiante nesta dissertação, o efeito evidenciado é comum a todos os LIs, acontecendo, no entanto, em maior escala com $\left[\mathrm{C}_{14 \mathrm{mim}}\right][\mathrm{Cl}]$, e em menor escala com $\left[\mathrm{C}_{12 \mathrm{mim}}\right][\mathrm{Cl}]$ e $\left[\mathrm{C}_{10 \mathrm{mim}}\right][\mathrm{Cl}]$. Por este motivo decidimos detalhar ao longo desta dissertação os sistemas compostos por $\left[\mathrm{C}_{14 \mathrm{mim}}\right][\mathrm{Cl}]$, enquanto que os compostos por $\left[\mathrm{C}_{12 \mathrm{mim}}\right][\mathrm{Cl}]$ e $\left[\mathrm{C}_{10 \mathrm{mim}}\right][\mathrm{Cl}]$ serão discutidos porém os gráficos estarão presentes no apêndice desta dissertação, para que sua leitura não seja morosa.

Os dados a serem analisados na próxima seção estão separados de acordo com o sistema em análise, ou seja, para cada proteína sob a influência de cada líquido iônico há um conjunto de gráficos e discussões provenientes de cada técnica experimental.

Algumas informações sobre o líquido iônico puro devem ser levantadas e consideradas para a seguinte análise de sua interação com as proteínas modelos. O líquido iônico $\left[\mathrm{C}_{14 \mathrm{mim}}\right][\mathrm{Cl}]$ foi selecionado para a realização dessas medias pois além de ser o mais absorvedor é o que possui a menor CMC, portanto, seus efeitos são os mais notórios, como veremos a seguir.

É interessante mencionar que as barras de incerteza da próxima seção foram calculadas através do desvio padrão da média para um conjunto de três amostras. 


\section{Resultados e Discussões}

A Figura 5.1 mostra os espectros de absorbância do $\left[\mathrm{C}_{14 \mathrm{mim}}\right][\mathrm{Cl}]$ em diferentes concentrações (em ausência de proteínas) em tampão e à temperatura ambiente.

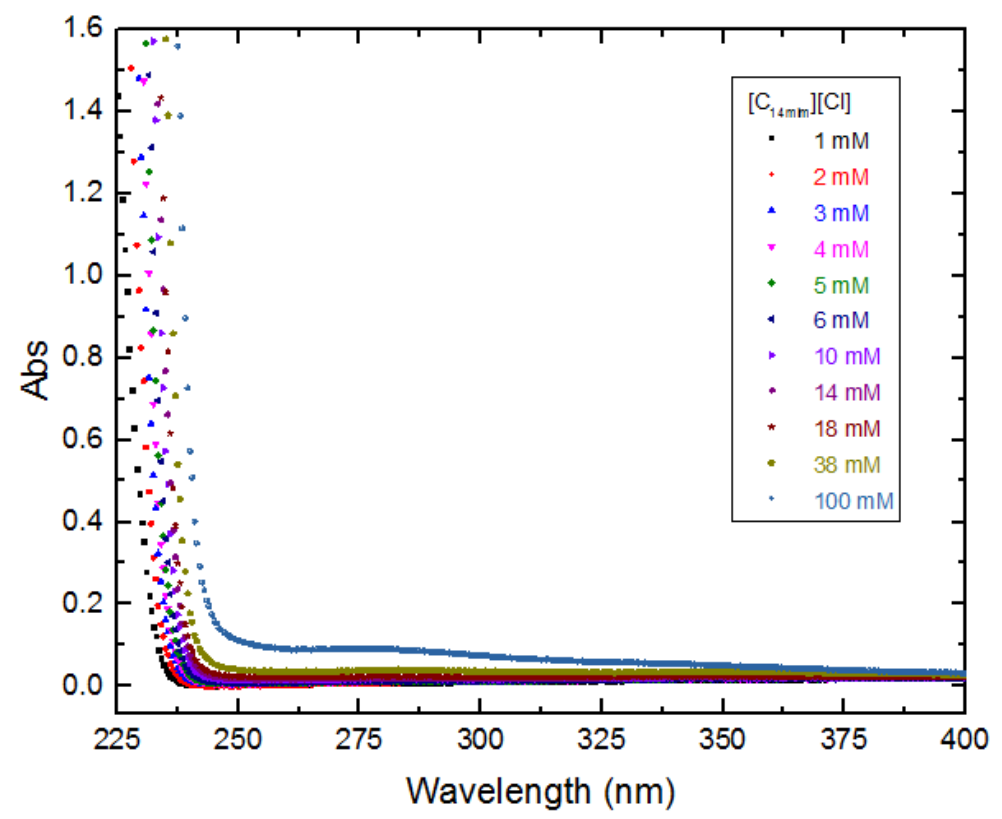

Figura 5.1: Espectro de Absorbância de variadas concentrações de $\left[C_{14 \operatorname{mim}}\right][\mathrm{Cl}]$ descritas na legenda. $A$ absorbância do tampão e da cubeta foram subtraídos das curvas.

Como podemos observar, de um modo geral, o LI não absorve significativamente $(\mathrm{A}<0.1$ para todas as concentrações, exceto $100 \mathrm{mM})$ para comprimentos de onda maiores que $250 \mathrm{~nm}$.

Buscando a melhor visualização da contribuição da absorbância do $\left[\mathrm{C}_{14 \operatorname{mim}}\right][\mathrm{Cl}]$, nos três comprimentos de onda $(280,295$ e $350 \mathrm{~nm})$ relevantes ao presente trabalho, a Figura 5.2 mostra a evolução deste parâmetro, em função da concentração do LI. O interesse nos três específicos comprimentos de onda é diferenciado, em 280nm ocorre o pico de absorbância das proteínas e onde triptofano a fenilalanina e a tirosina são excitados, já em 295nm temos a excitação majoritária do triptofano e 350nm 
corresponde ao comprimento de onda selecionado para analisar a turbidez do sistema, onde a absorção dos resíduos aromáticos pode ser desprezada.

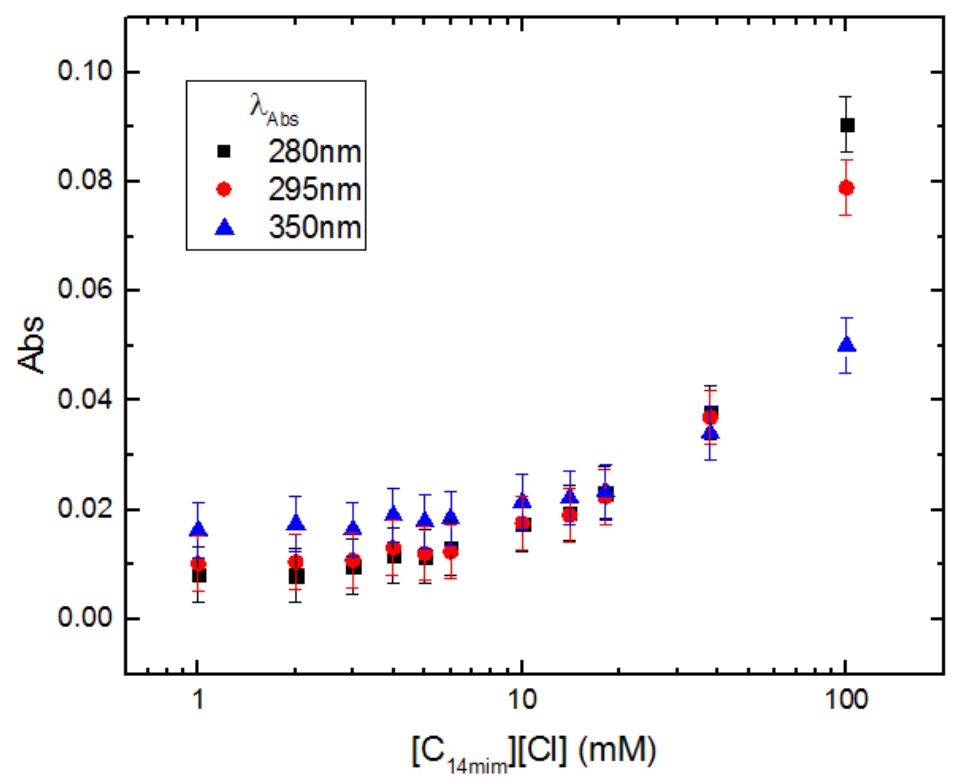

Figura 5.2: Absorbância nos comprimentos de onda $280 \mathrm{~nm}, 295 \mathrm{~nm}$ e $350 \mathrm{~nm}$ de $\left[\mathrm{C}_{14 \operatorname{mim}}\right][\mathrm{Cl}]$ em função da concentração.

Baseado na Figura 5.2 consideraremos a absorbância de LI desprezível (Abs < 0.02) até a concentração de $10 \mathrm{mM}$ para os três comprimentos de onda, assim a concentração de trabalho é sempre inferior a este valor.

A obtenção da concentração micelar crítica do $\left[\mathrm{C}_{14 \operatorname{mim}}\right][\mathrm{Cl}]$ em água e em tampão se faz importante quando houver evidências de formação de agregados nos sistemas analisados. As CMCs foram obtidas através do experimento de tensão superficial, variando a concentração de líquido iônico em água e em tampão a $24^{\circ} \mathrm{C}$, como pode ser visto na Figura 5.3. 
(A)

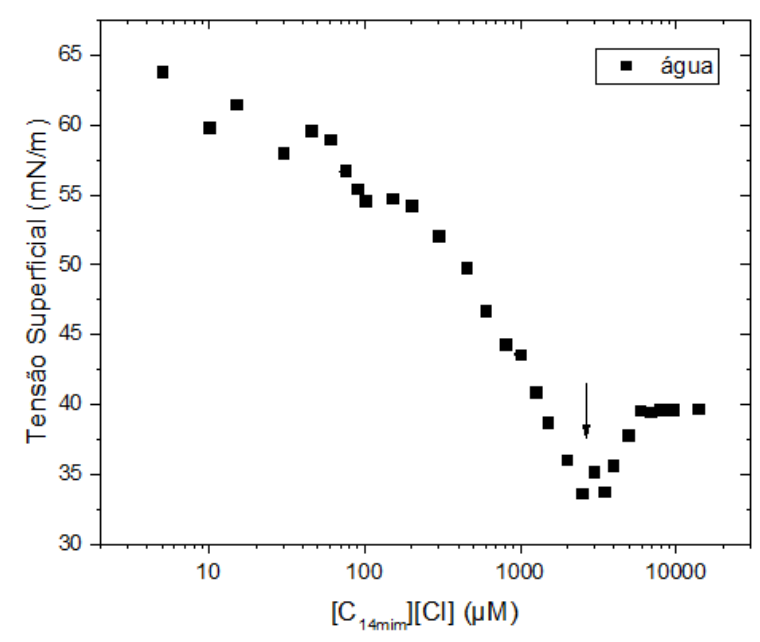

(B)

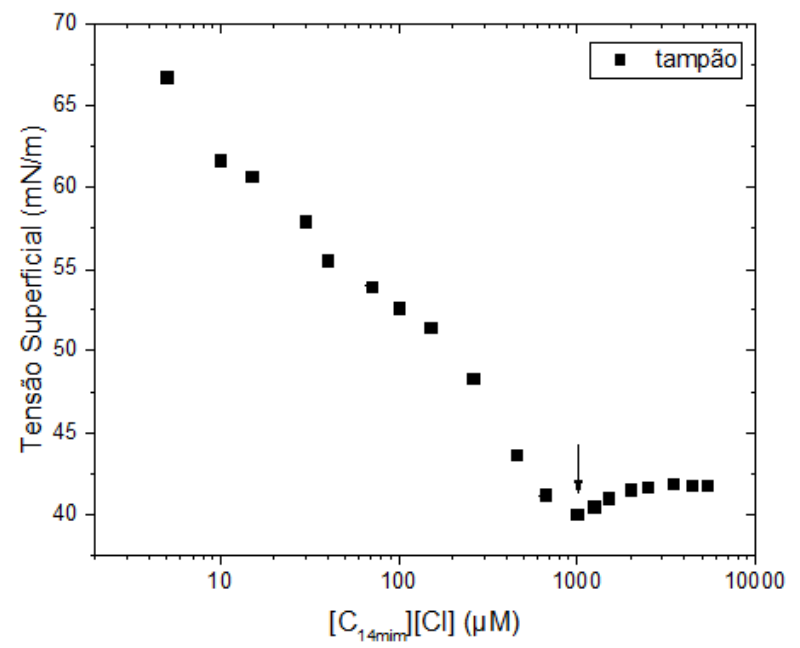

Figura 5.3: Medias de tensão superficial de $[\mathrm{C} 14 \mathrm{mim}][\mathrm{Cl}](\mathrm{A})$ em água $(\mathrm{B})$ em tampão $(\mathrm{AC}, \mathrm{FO}, \mathrm{BO} \mathrm{pH} 7.25)$.

Podemos observar claramente a diminuição da tensão superficial da solução na medida em que adicionamos o líquido iônico, como o esperado, pois se trata de uma molécula anfifílica com comportamento surfactante. Há uma mudança brusca no comportamento da curva ao atingir a CMC (setas na Figura 5.3). A CMC obtida com esses experimentos para o $\left[\mathrm{C}_{14 \mathrm{mim}}\right][\mathrm{Cl}]$, em água, é igual a 3,0 $\pm 0,1 \mathrm{mM}$ e está de acordo com o valor reportado na literatura [32] [33]. A CMC experimental de $\left[\mathrm{C}_{14 \mathrm{mim}}\right][\mathrm{Cl}]$ em tampão, por outro lado, é igual a 1,0 $\pm 0,1 \mathrm{mM}$, um valor menor do que o obtido em água, como esperado, pois com a adição de sal ao sistema temos uma "blindagem" parcial das cargas catiônicas das cabeças polares do LI, favorecendo a formação de agregados do tipo micelares.

Antes de iniciarmos o estudo da interação dos LIs com as proteínas modelo, é importante saber como estes atuam no aminoácido triptofano, uma vez que será esta interação que investigaremos com as medidas de absorbância e fluorescência. A seção a seguir mostra como se dá esta interação. 


\subsection{Triptofano e $\left[\mathrm{C}_{14 \mathrm{mim}}\right][\mathrm{Cl}]$}

Discutiremos a interação do triptofano puro em presença do LI $\left[\mathrm{C}_{14 \mathrm{mim}}\right][\mathrm{Cl}]$, tal sistema servirá de base para as discussões com as proteínas. É conveniente mencionar que o triptofano puro em solução a $\mathrm{pH}$ neutro possui carga positiva na região do grupo amina e outra negativa na região do ácido carboxílico, sendo portanto uma molécula zwiteriônica, conforme ilustrada na Figura 1.2 .

A Figura 5.4 mostra os espectros de absorbância do triptofano em ausência e presença de concentrações crescentes de LI (ver legenda na figura). Pra cada curva experimental foi subtraído a contribuição do tampão somado a cubeta.

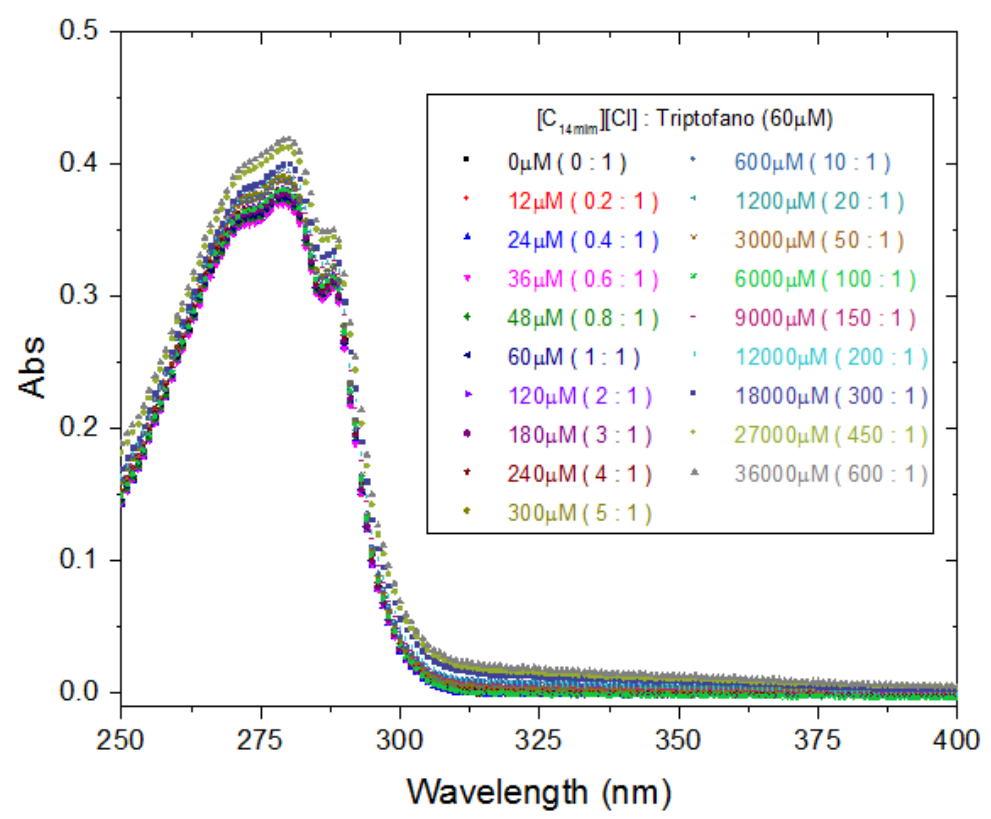

Figura 5.4: Espectro de absorbância do $\operatorname{Trp}$ a $60 \mu \mathrm{M}$ em presença de variadas concentrações de $\left[\mathrm{C}_{14 \text { mim }}\right][\mathrm{Cl}]$ descritas na legenda junto a razão molar. A absorbância do tampão e da cubeta foram subtraídas das curvas.

O espectro de absorbância do triptofano nos indica pouca, porém alguma, variação devido a presença de $\left[\mathrm{C}_{14 \mathrm{mim}}\right][\mathrm{Cl}]$. A absorbância, em 280nm, correspondente a um dos comprimentos de onda de excitação que são utilizados no experimento de 
fluorescência. A Figura 5.5(A), mostra a variação da absorção em 280nm em função da concentração de LI, enquanto que a Figura 5.5(B) mostra esta mesma variação para $\lambda=350 \mathrm{~nm}$. No primeiro caso $(\lambda=280 \mathrm{~nm})$ estamos interessados na absorção das proteínas em solução, enquanto que no segundo caso $(\lambda=350 \mathrm{~nm})$ estamos interessados na turbidez da amostra.

(A)

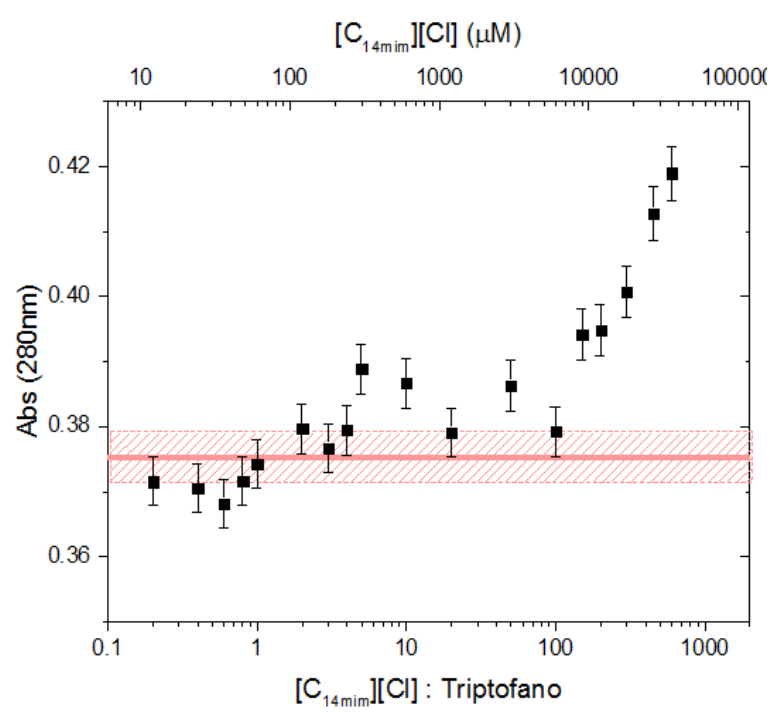

(B)

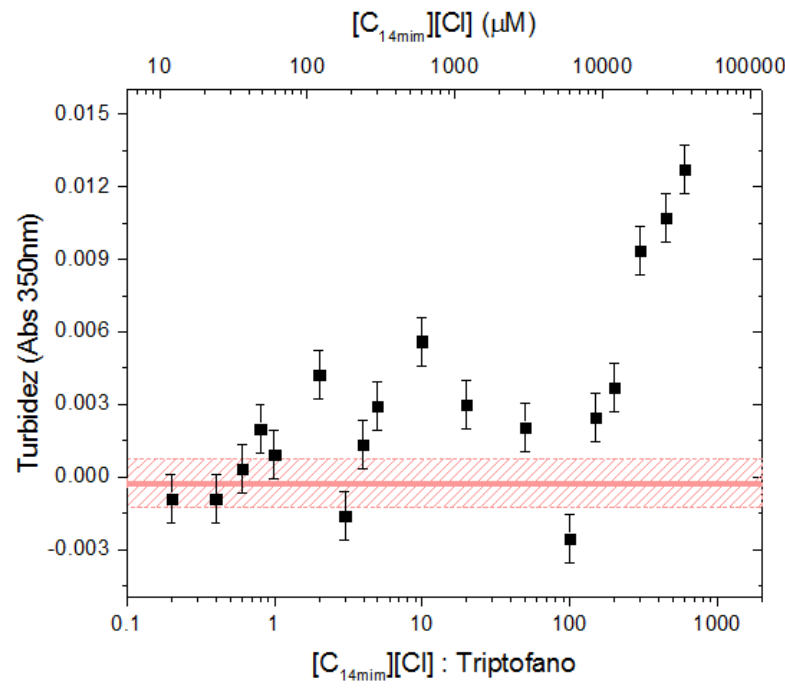

Figura 5.5: Absorbância em $280 \mathrm{~nm}$ do $\operatorname{Trp}$ a $60 \mu \mathrm{M}$ (A) e turbidez (B) em função da concentração de [ $\left.\mathrm{C}_{14 \mathrm{mim}}\right][\mathrm{Cl}]$ (escala superior) e razão molar (escala inferior), ambas logarítmicas. A faixa vermelha preenchida e listrada correspondem ao triptofano em ausência de LI e incerteza, respectivamente.

A Absorbância em 280nm corresponde ao máximo de absorção do triptofano, na abscissa optou-se pelo logaritmo da concentração de LI para facilitar a visualização (Figura 5.5A). A faixa vermelha corresponde ao valor de absorbância do triptofano em ausência de LI e a faixa listrada abrange o intervalo com a incerteza. Observe que, embora haja variações na absorbância em 280nm até a razão molar igual a 100:1 ou concentração absoluta de $\left[\mathrm{C}_{14 \mathrm{mim}}\right][\mathrm{Cl}]$ igual a $600 \mu \mathrm{M}$, os valores são compatíveis entre si e tais variações também então presentes na turbidez do sistema. A partir desta concentração há um aumento significativo tanto na absorbância em 280nm quanto na 
turbidez. Mudanças no espectro de absorbância podem significar alterações no estado eletrônico da molécula absorvedora ou mudanças no espalhamento da amostra [17], como as alterações ocorrem de forma semelhante nos dois comprimentos de onda iremos supor que são devidas somente ao espalhamento e não a alterações no estado eletrônico das moléculas de triptofano. $\mathrm{O}$ aumento excessivo na turbidez pode apontar a formação de agregados, perda de solubilidade do soluto ou desnaturação quando tratarmos das proteínas. [34] [35]

A Figura 5.6 mostra a absorbância normalizada, tal artifício matemático facilita a visualização de possíveis mudanças na forma da curva com o aumento da concentração de LI.

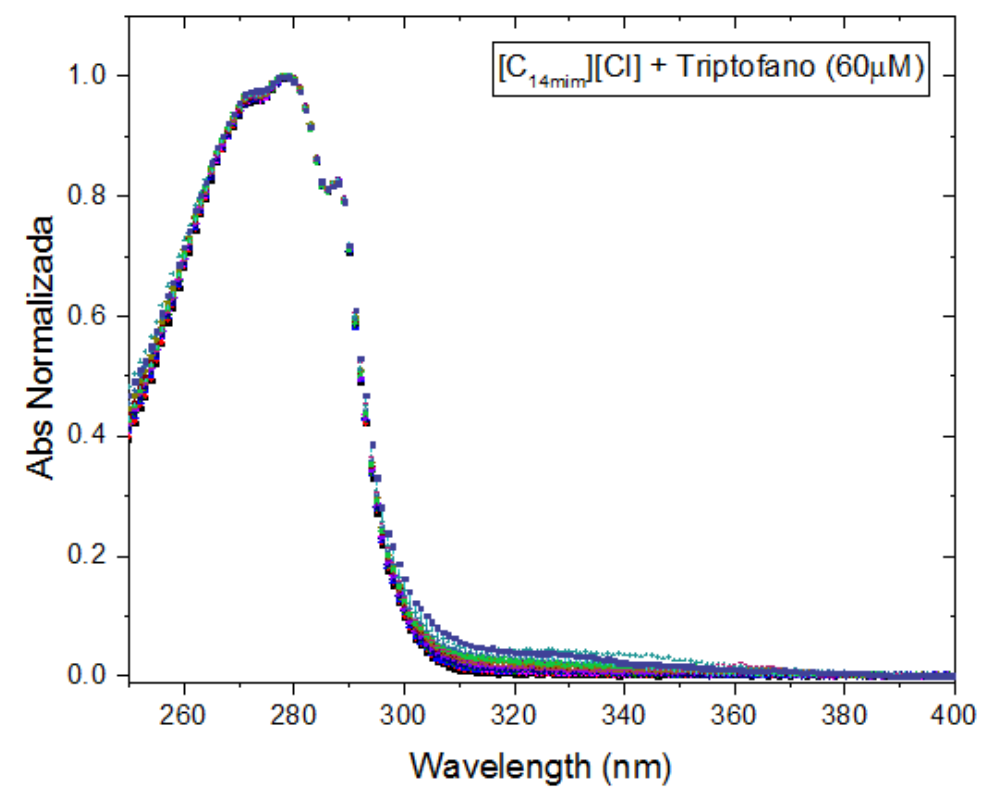

Figura 5.6: Absorbância normalizada pelo pico para o sistema triptofano a $60 \mu \mathrm{M}$ e $\left[\mathrm{C}_{14 \mathrm{mim}}\right][\mathrm{Cl}]$.

De um modo geral, não há mudanças na forma da curva de absorbância do sistema com o aumento da concentração de LI, sustentando que a interação entre o 
triptofano e $\left[\mathrm{C}_{14 \mathrm{mim}}\right][\mathrm{Cl}]$ não é capaz de alterar, significativamente, a estrutura eletrônica do aminoácido. [16]

Os espectros de fluorescência do triptofano podem ser apreciados na Figura 5.7. O comprimento de onda de excitação é igual a $280 \mathrm{~nm}$ correspondente ao pico de absorbância do triptofano. As curvas foram corrigidas pela contribuição de filtro interno, conforme descrito na Seção 3.3.3.4.

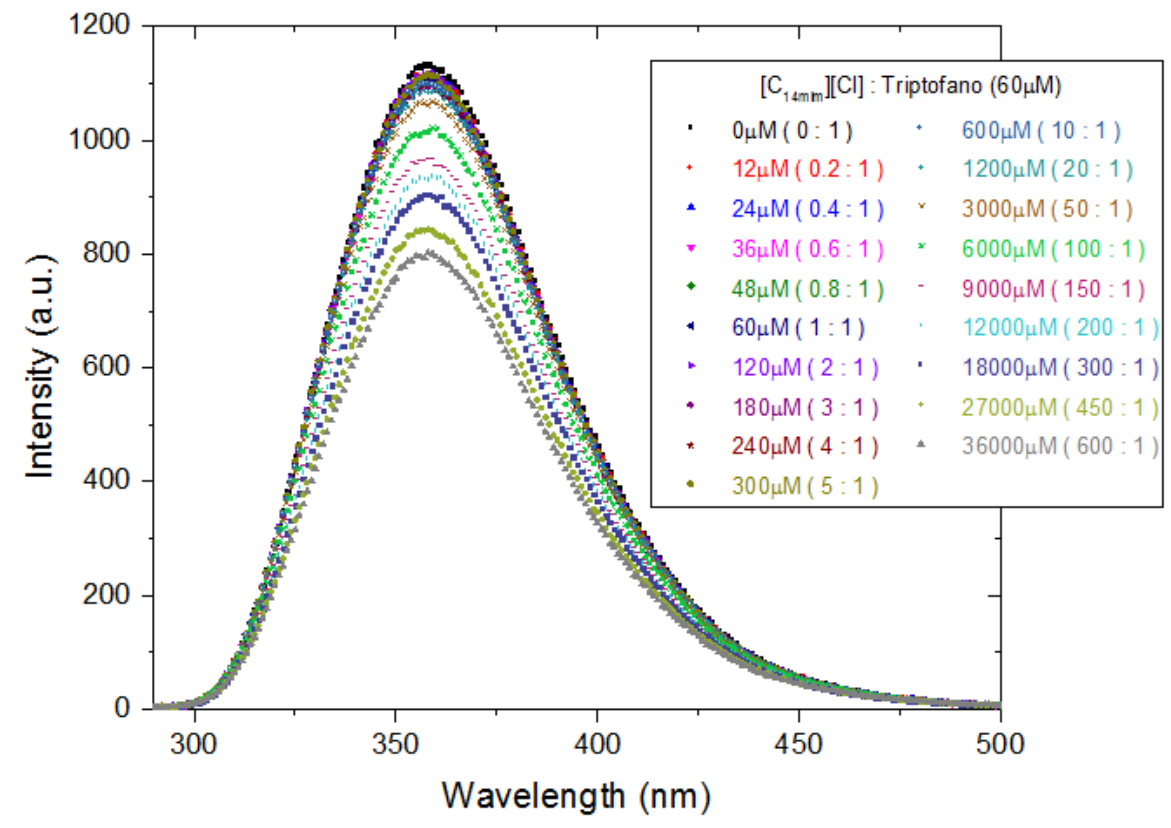

Figura 5.7: Espectro de fluorescência do Trp a $60 \mu \mathrm{M}$ em presença de variadas concentrações de $\left[\mathrm{C}_{14 \text { mim }}\right][\mathrm{Cl}]$ descritas na legenda junto a razão molar. Espectros com correção de filtro interno.

A diminuição da intensidade de fluorescência com o aumento da concentração de LI nos espectros nos evidencia a supressão da fluorescência do Trp pelo LI. Podemos verificar o grau de supressão através da variação do máximo da intensidade de fluorescência, que no caso ocorre em $\lambda=357 \mathrm{~nm}$, na Figura 5.8 . 


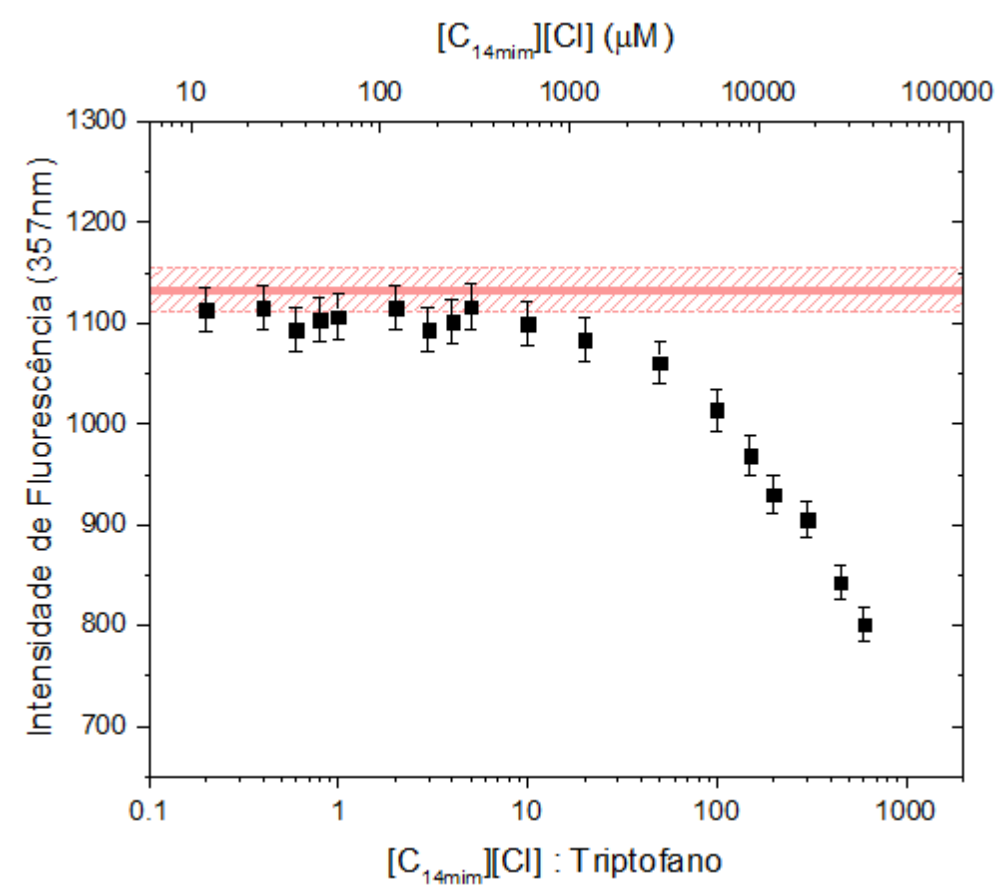

Figura 5.8: Intensidade do pico de fluorescência $(357 \mathrm{~nm})$ do $\operatorname{Trp}$ a $60 \mu \mathrm{M}$ em função da concentração de $\left[\mathrm{C}_{14 \mathrm{mim}}\right][\mathrm{Cl}]$ (escala superior) e razão molar (escala inferior), ambas logarítmicas. A faixa vermelha preenchida e listrada correspondem ao triptofano em ausência de LI e incerteza, respectivamente.

A intensidade de fluorescência inicialmente permanece constante e passa a diminuir a partir de $600 \mu \mathrm{M}(10: 1)$ de $\left[\mathrm{C}_{14 \mathrm{mim}}\right][\mathrm{Cl}]$ (Figura 5.8). Portanto podemos concluir que o LI é um supressor do triptofano, como esperado, pois o grupo imidazólio, presente na cabeça polar do LI, é um supressor natural deste aminoácido [17]. A fim de analisar a capacidade de supressão do $\left[\mathrm{C}_{14 \mathrm{mim}}\right][\mathrm{Cl}]$ sobre o triptofano calcularemos a constante de Stern-Volmer. A razão entre a intensidade de fluorescência em ausência e em presença do supressor obedece a seguinte relação: [17]

$$
\frac{F_{0}}{F}=1+K_{S V}[Q]
$$

Onde $F_{0}$ é a intensidade de fluorescência na ausência do supressor, $F$ é a intensidade de fluorescência na presença de supressor, [Q] é a concentração de supressor em Molar e $K_{S V}$ é a constante de Stern-Volmer. Portanto a partir do gráfico 
$F_{0} / F$ versus [Q] é possível obter a constante de Stern-Volmer através do coeficiente angular, conforme mostrado na Figura 5.9.

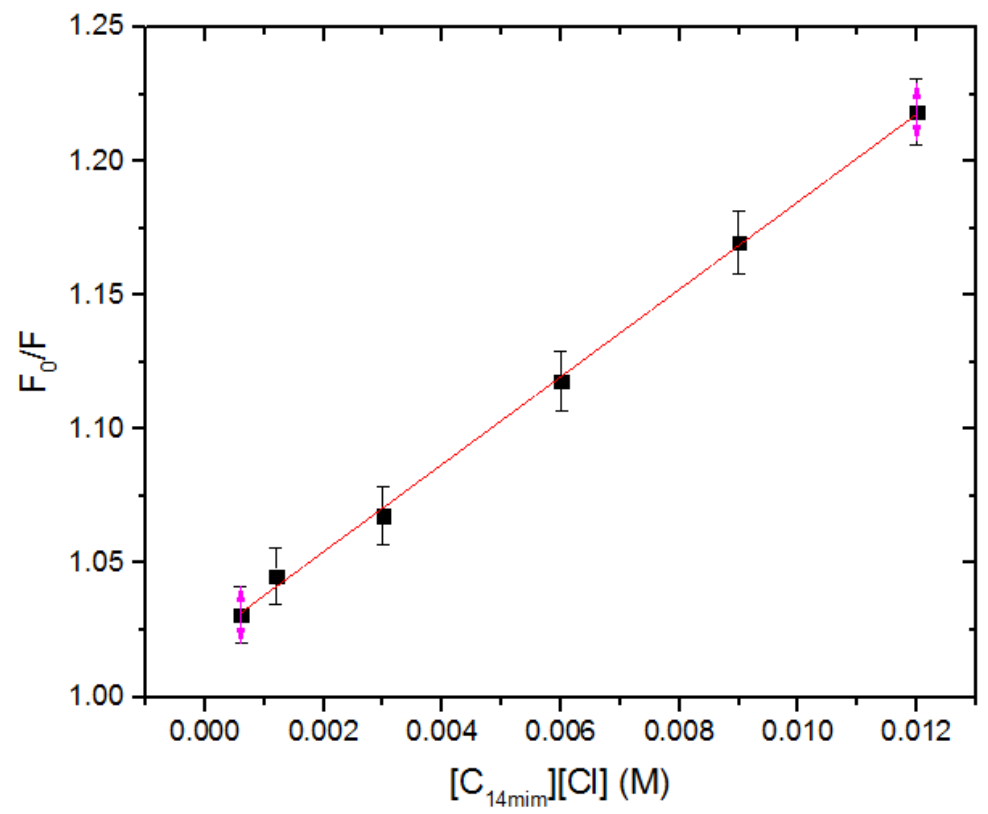

Figura 5.9: Supressão do triptofano a $60 \mu \mathrm{M}$ para $\left[\mathrm{C}_{14 \mathrm{mim}}\right][\mathrm{Cl}]$.

A equação encontrada para a reta ajustada é:

$$
\frac{F_{0}}{F}=(1.022 \pm 0.001)+(16.3 \pm 0.3)\left[\left[C_{14 m i m}\right][C l]\right]
$$

Portanto a supressão do triptofano por $\left[\mathrm{C}_{14 \mathrm{mim}}\right][\mathrm{Cl}]$ possui $\mathrm{K}_{\mathrm{SV}}=(16.3 \pm 0.3) \mathrm{M}^{-1}$. Bushueva e colaboradores [36] estudaram a supressão do triptofano e de algumas proteínas para os supressores iodeto de potássio e acrilamida. Os valores de $\mathrm{K}_{\mathrm{SV}}$ encontrados para o triptofano são $(12.8 \pm 0.2) \mathrm{M}^{-1}$ para iodeto de potássio e $(18.0 \pm 1.8) \mathrm{M}^{-1}$ para acrilamida. Observe que quanto maior o valor da constante de Stern-Volmer maior é a capacidade de supressão, portanto podemos concluir que $\left[\mathrm{C}_{14 \mathrm{mim}}\right][\mathrm{Cl}]$ é um supressor mais eficiente que iodeto de potássio e menos eficiente que a acrilamida. 
A Figura 5.10 traz a intensidade de fluorescência normalizada a fim de verificar eventuais deslocamentos das curvas.

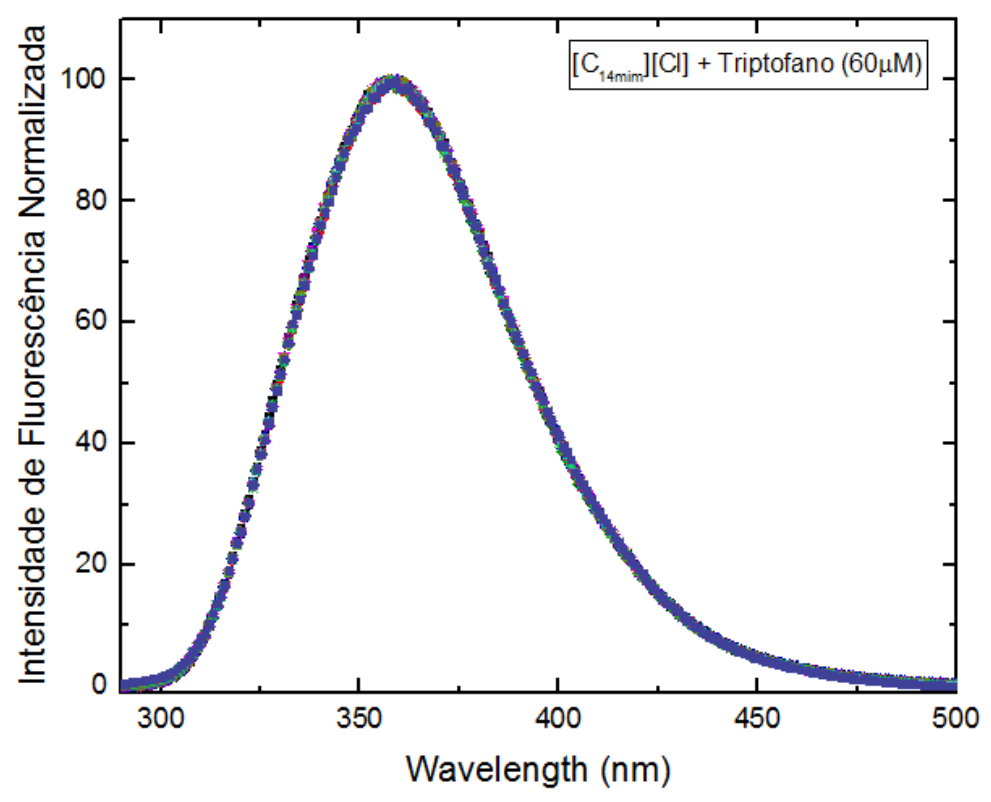

Figura 5.10: Intensidades de fluorescência normalizadas pelo pico do sistema $\operatorname{Trp}+\left[\mathrm{C}_{14 \mathrm{mim}}\right][\mathrm{Cl}]$.

É possível afirmar, baseado na Figura 5.10, que a forma da curva não se altera e que também não há deslocamentos, ou mudança na polaridade do meio, em presença de LI nas das concentrações estudadas.

De posse dessas informações, passaremos agora ao estudo da influencia do $\left[\mathrm{C}_{14 \mathrm{mim}}\right][\mathrm{Cl}]$ na Albumina de Soro Bovina. 


\subsection{Albumina de Soro Bovina e $\left[\mathrm{C}_{14 \mathrm{mim}}\right][\mathrm{Cl}]$}

A Figura 5.11 mostra os espectros de absorbância da BSA $(30 \mu \mathrm{M})$ em ausência e presença de concentrações crescentes de $\left.\left[\mathrm{C}_{14 \mathrm{mim}}\right][\mathrm{Cl}]\right]$ (de 0 a $\left.90 \mathrm{mM}\right)$.

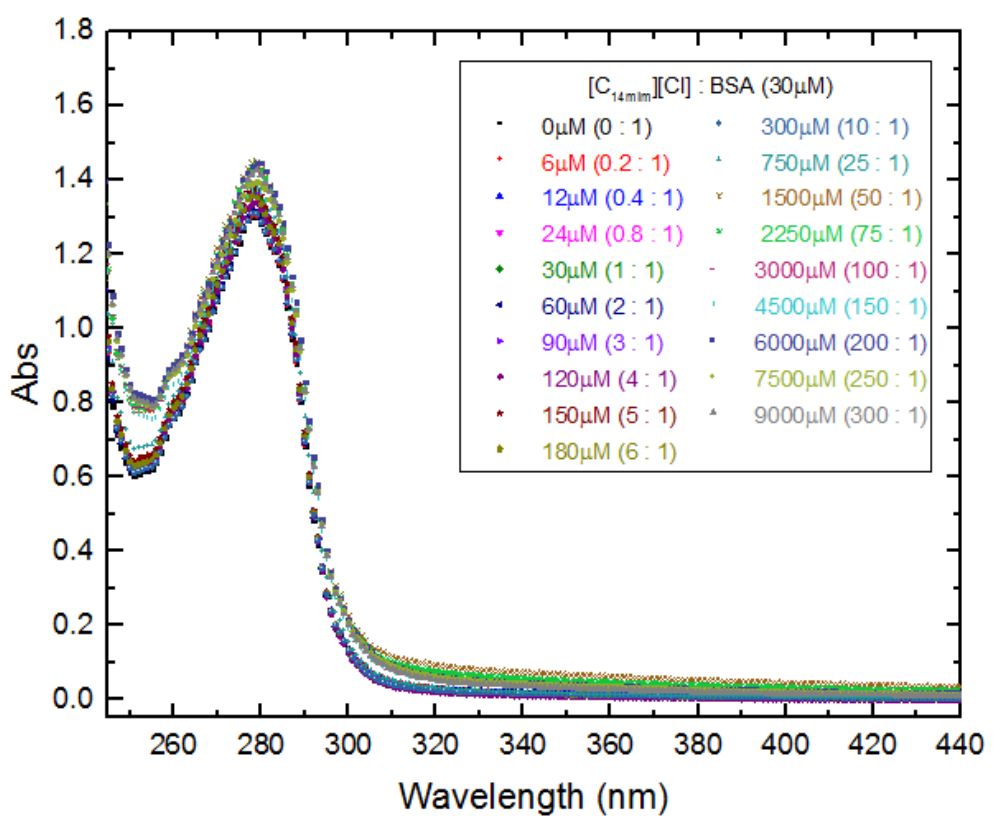

Figura 5.11: Espectro de absorbância da BSA a $30 \mu \mathrm{M}$ em presença de variadas concentrações de $\left[\mathrm{C}_{14 \text { mim }}\right][\mathrm{Cl}]$ descritas na legenda junto a razão molar. A absorbância do tampão e da cubeta foram subtraídas das curvas.

Note que os espectros de absorbância pouco se alteram com a presença de LI, porém a análise dos principais comprimentos de onda trará um maior detalhamento deste efeito. A Figura 5.12 (A) apresenta a absorbância em 295nm, que corresponde ao comprimento de onda de excitação da fluorescência e a Figura 5.12 (B) apresenta a absorbância em 350nm ou turbidez, onde é possível verificar o espalhamento da luz do sistema com o aumento da concentração de $\left[\mathrm{C}_{14 \mathrm{mim}}\right][\mathrm{Cl}]$. 
(A)

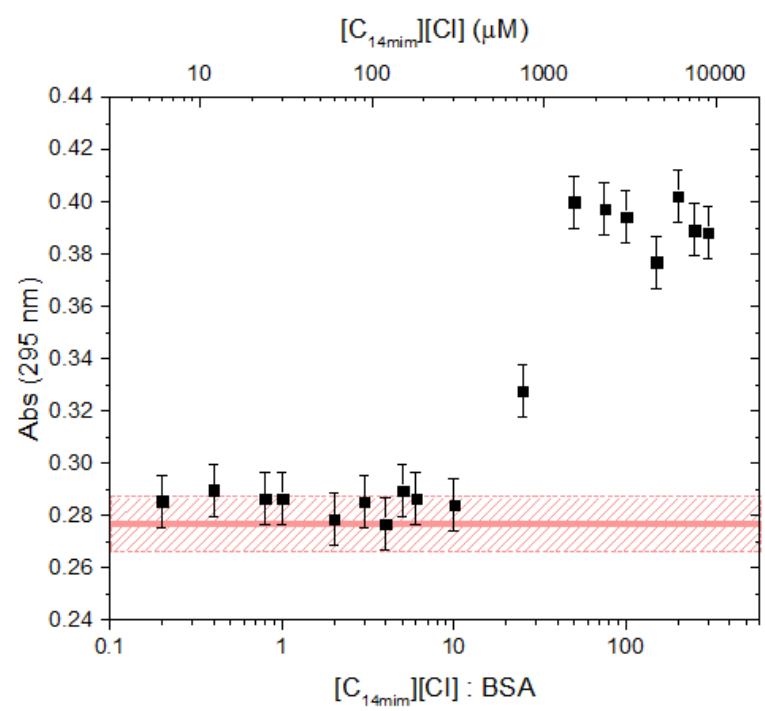

(B)

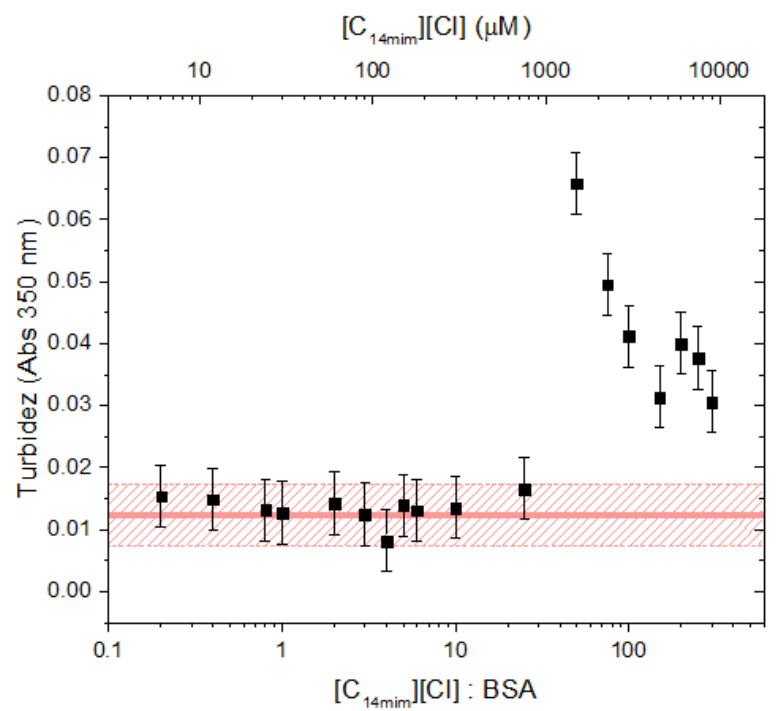

Figura 5.12: Absorbância em $295 \mathrm{~nm}$ (A) e turbidez (B) da BSA a $30 \mu \mathrm{M}$ em função da concentração de [ $\left.\mathrm{C}_{14 \mathrm{mim}}\right][\mathrm{Cl}]$ (escala superior) e razão molar (escala inferior), ambas logarítmicas. A faixa vermelha preenchida e listrada correspondem a BSA em ausência de LI e incerteza, respectivamente.

A absorbância em 295nm não varia até $300 \mu \mathrm{M}$ de [ $\left.\mathrm{C}_{14 \mathrm{mim}}\right][\mathrm{Cl}]$ (razão 10:1), mas após este valor aumenta consideravelmente e permanece constante a partir de $1.6 \mathrm{mM}$ ou razão molar igual a 40:1 (Figura $5.12 \mathrm{~A}$ ). O primeiro patamar $\left(\mathrm{de}\left[\mathrm{C}_{14 \mathrm{mim}}\right][\mathrm{Cl}]<\right.$ $300 \mu \mathrm{M})$ sugere uma concentração mínima de $\left[\mathrm{C}_{14 \mathrm{mim}}\right][\mathrm{Cl}]$ para que ocorra uma interação significativa, ou seja, capaz de alterar o valor da absorbância. A turbidez não varia e é compatível com zero até $750 \mu \mathrm{M}$ de $\left[\mathrm{C}_{14 \mathrm{mim}}\right][\mathrm{Cl}]$ ou 25:1 de razão molar (Figura 5.12 B), em torno de 1.2mM (40:1) torna-se significante e máxima, voltando a diminuir na medida em que aumentamos a concentração de LI. Um aumento significativo da turbidez em um sistema pode significar formação de agregados, ou ainda em sistemas proteicos, desenovelamento da proteína ou auto-agregação. O aumento na absorbância em $295 \mathrm{~nm}$ pode significar, além do aumento do espalhamento, a formação de complexos que alteram o estado fundamental do fluoróforo. [37] [34] 
A Figura 5.13 mostra os espectros de fluorescência da BSA $(30 \mu \mathrm{M})$ em ausência e presença de concentrações crescentes do $\left[\mathrm{C}_{14 \mathrm{mim}}\right][\mathrm{Cl}]$ após a correção de filtro interno. Para este experimento utilizou-se o comprimento de onda de excitação $\lambda_{\text {exc }}=295 \mathrm{~nm}$ a fim de se evitar a excitação dos aminoácidos aromáticos fenilalanina e tirosina, como já discutido anteriormente.

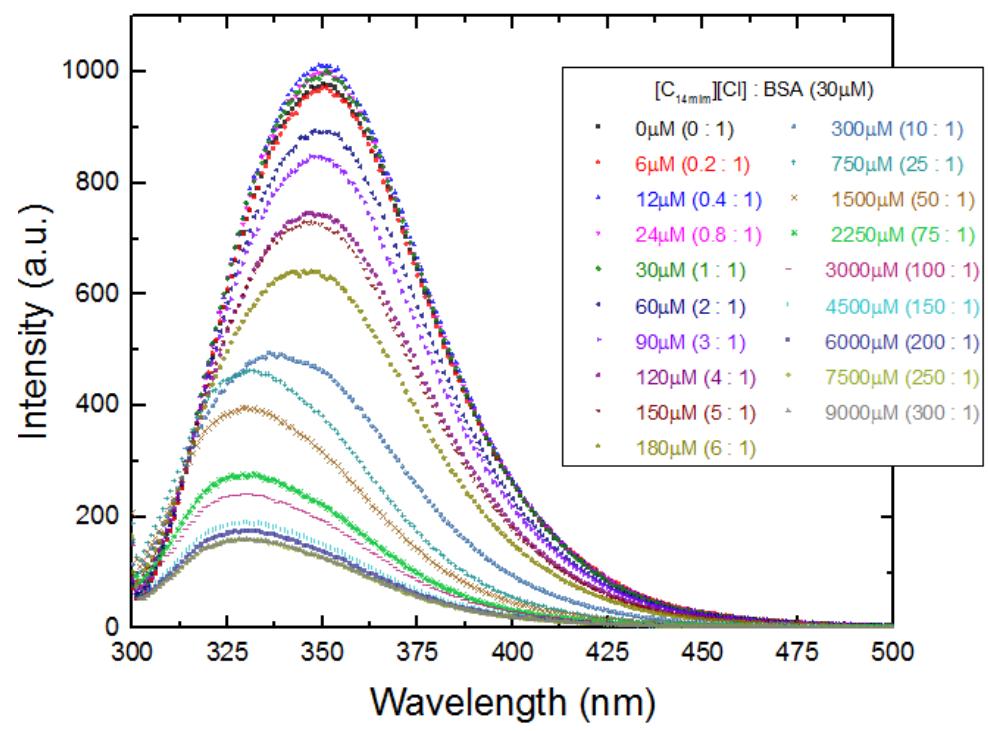

Figura 5.13: Espectro de fluorescência da BSA a $30 \mu \mathrm{M}$ em presença de variadas concentrações de $\left[\mathrm{C}_{14 \text { mim }}\right][\mathrm{Cl}]$ descritas na legenda junto a razão molar. Espectros com correção de filtro interno.

Os espectros de fluorescência nos mostram a supressão da fluorescência com a adição de LI, e deslocamento do comprimento de onda de máxima emissão para o azul (menores comprimentos de onda), ambos os efeitos serão analisados separadamente para auxiliar sua compreensão.

A Figura 5.14 traz a intensidade de fluorescência integrada (de $300 \mathrm{~nm}$ a 500nm) em função da concentração do líquido iônico. 


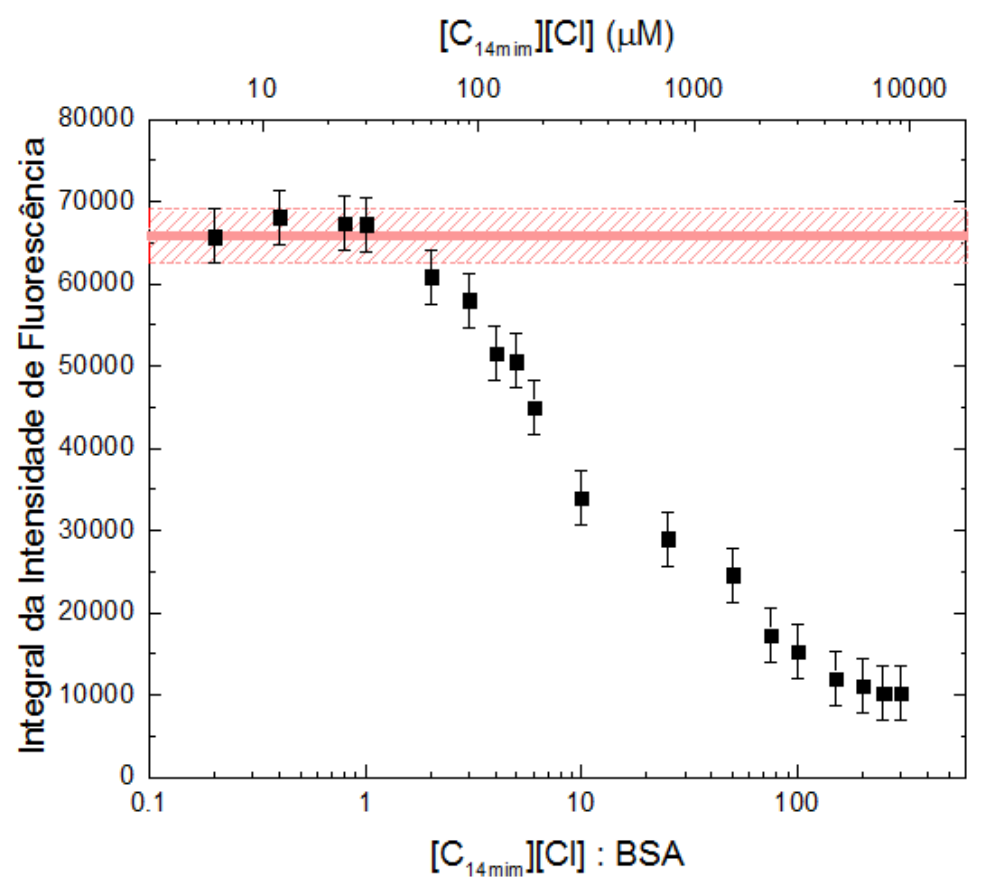

Figura 5.14: Integral da intensidade de fluorescência (de $300 \mathrm{~nm}$ a $500 \mathrm{~nm}$ ) da BSA a $30 \mu \mathrm{M}$ em função da concentração de $\left[C_{14 m i m}\right][C l]$ (escala superior) e razão molar (escala inferior), ambas logarítmicas. A faixa vermelha preenchida e listrada correspondem a BSA em ausência de LI e incerteza, respectivamente.

A diminuição da intensidade de fluorescência com o aumento da concentração de $\left[\mathrm{C}_{14 \mathrm{mim}}\right][\mathrm{Cl}]$ aponta que o LI é um supressor do triptofano, que está de acordo com o experimento de fluorescência realizado na seção anterior. Como discutida anteriormente, (na Seção 3.3.3.2), a supressão de fluorescência requer proximidade entre o fluoróforo e o seu supressor, portanto, podemos concluir que há interação entre a proteína e $\left[\mathrm{C}_{14 \operatorname{mim}}\right][\mathrm{Cl}]$, ao menos com um dos triptofanos presentes na BSA. A interação é máxima no intervalo de $60 \mu \mathrm{M}$ a $3 \mathrm{mM}$ de $\left[\mathrm{C}_{14 \mathrm{mim}}\right][\mathrm{Cl}]$ ou razão molar de 2:1 a 100:1. O patamar nas menores concentrações de LI (razão molar menor que 1) sinaliza um número mínimo de moléculas em solução para que a interação seja significativa e o patamar para maiores concentrações (razão molar maior que 100) uma limitação desta interação. É interessante perceber que necessitamos de ao menos uma molécula de LI, para cada molécula de BSA, interagindo para iniciarmos a visualização dos efeitos. 
Gelamo e colaboradores [38] estudaram a interação da BSA e HSA com um surfactante aniônico (dodecil sulfato de sódio ou SDS), um zwiteriônico (N-hexadecilN,N-dimetil-3-amônio-1-propanosulfonato ou HPS) e um catiônico (cloreto de Nhexadecil-N,N,N-trimetil amônio ou CTAC) através de espectroscopia e modelagem molecular. O estudo mostra a supressão da fluorescência da BSA pelos três surfactantes. A fluorescência da BSA é diminuída para entre 55-60\%, da fluorescência inicial, para 0.1mM de SDS ou razão molar 10:1, 65\% para $0.8 \mathrm{mM}$ de HPS ou razão molar 80:1 e $55 \%$ para $0.5 \mathrm{mM}$ de CTAC ou razão molar 50:1. Enquanto que encontramos uma diminuição da fluorescência para $60 \%$ da fluorescência inicial de BSA em $0.33 \mathrm{mM}$ de $\left[\mathrm{C}_{14 \mathrm{mim}}\right][\mathrm{Cl}]$ ou razão molar 11:1. Observe que a supressão da BSA pelo $\left[\mathrm{C}_{14 \mathrm{mim}}\right][\mathrm{Cl}]$ é mais próxima a encontrada pelo SDS do que das encontradas para os outros surfactantes. É interessante mencionar que Gelamo observou para BSA em presença de CTAC um comportamento atípico, após a diminuição de 55\% da fluorescência inicial houve um aumento para $85 \%$, o que não foi observado no presente trabalho, indicando que o comportamento do $\left[\mathrm{C}_{14 \mathrm{mim}}\right][\mathrm{Cl}]$ não é igual ao CTAC mesmo ambos sendo catiônicos.

Fei Geng e colaboradores [39] estudaram a influência do líquido iônico $\left[\mathrm{C}_{14 \mathrm{mim}}\right][\mathrm{Br}]$ na fluorescência da BSA, assim como no presente trabalho foram constatados blue-shift e supressão de fluorescência. A diminuição para $26 \%$ da fluorescência inicial ocorre para $3 \mathrm{mM}$ de $\left[\mathrm{C}_{14 \mathrm{mim}}\right][\mathrm{Br}]$, no presente trabalho encontramos a mesma diminuição de $26 \%$ da fluorescência inicial para $(2.7 \pm 0.2) \mathrm{mM}$ de $\left[\mathrm{C}_{14 \mathrm{mim}}\right][\mathrm{Cl}]$, os valores são compatíveis entre si, como esperado pois as estruturas do $\left[\mathrm{C}_{14 \mathrm{mim}}\right][\mathrm{Br}]$ e $\left[\mathrm{C}_{14 \mathrm{mim}}\right][\mathrm{Cl}]$ são análogas, a menos dos contraíons cloreto e brometo.

A intensidade de fluorescência normalizada, Figura 5.15, nos mostra eventuais deformações e deslocamentos. 


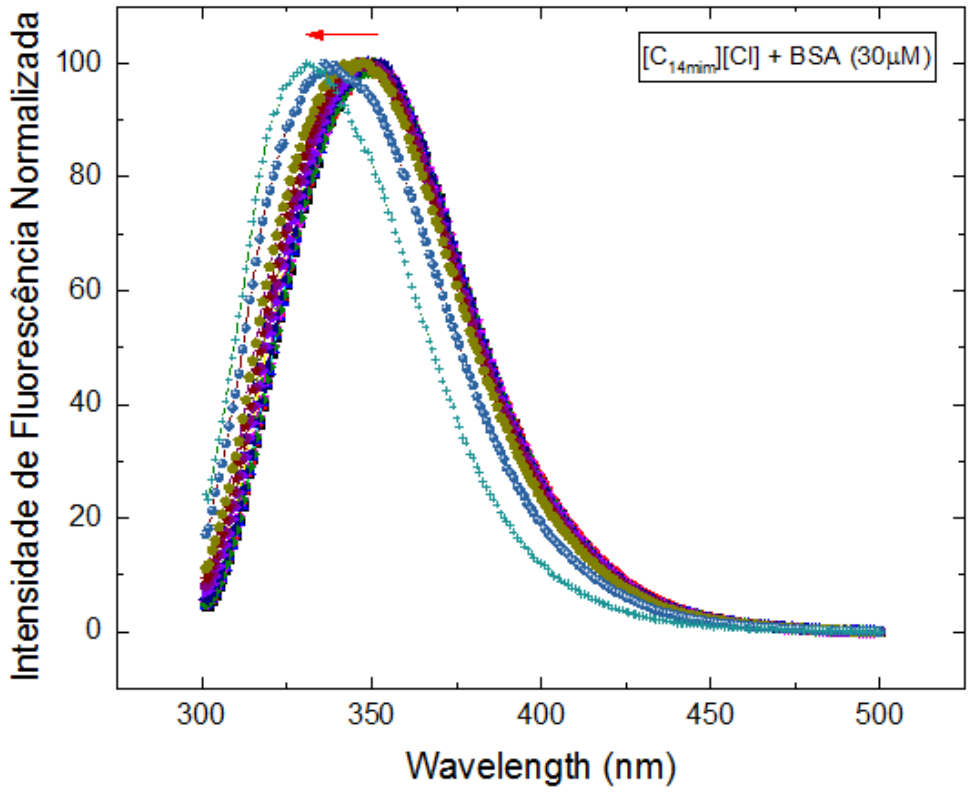

Figura 5.15: Espectro de fluorescência normalizado pelo pico do sistema $B S A+\left[C_{14 m i m}\right][C l]$. A seta indica o deslocamento com o aumento da concentração de $\left[\mathrm{C}_{14 \mathrm{mim}}\right][\mathrm{Cl}]$.

A forma da curva de fluorescência não altera significativamente com o aumento da concentração de $\left[\mathrm{C}_{14 \mathrm{mim}}\right][\mathrm{Cl}]$, porém há um deslocamento do pico para menores comprimentos de onda ou blue-shift, que pode ser observado na Figura 5.16. 


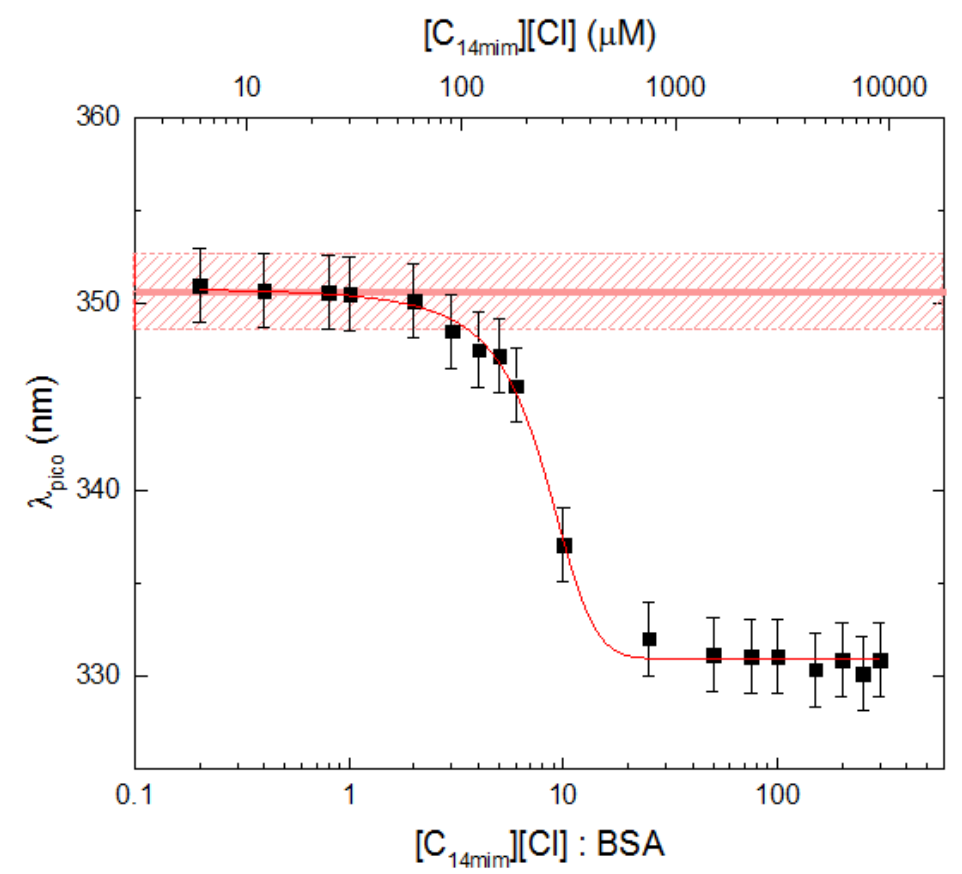

Figura 5.16: Comprimento de onda correspondente ao máximo de fluorescência da BSA a $30 \mu \mathrm{M}$ em função da concentração de $\left[\mathrm{C}_{14 \mathrm{mim}}\right][\mathrm{Cl}]$ (escala superior) e razão molar (escala inferior), ambas logarítmicas. A faixa vermelha preenchida e listrada correspondem a BSA em ausência de LI e incerteza, respectivamente. A linha vermelha é o ajuste utilizando a função de Boltzmann.

O deslocamento do pico de fluorescência está intimamente ligado ao microambiente próximo ao fluoróforo, como visto na Seção 3.3.3.1, neste caso o blueshift pode ser explicado por um ambiente mais hidrofóbico. O deslocamento é máximo no intervalo $60 \mu \mathrm{M}$ a $1.5 \mathrm{mM}$ de $\left[\mathrm{C}_{14 \mathrm{mim}}\right][\mathrm{Cl}]$ (de $2: 1$ a $50: 1$ ), nos extremos temos dois patamares, e uma região intermediária sugerindo a presença de um sistema de dois estados, ou três regiões, portanto foi ajustado a função de Boltzmann. O ponto de inflexão do ajuste se dá na razão $(7.99 \pm 0.21): 1$ ou $(239.7 \pm 6.3) \mu \mathrm{M}$ de $\left[\mathrm{C}_{14 \operatorname{mim}}\right][\mathrm{Cl}]$.

Gelamo e colaboradores [38] também identificaram o deslocamento para o azul no espectro de fluorescência da BSA para os surfactantes SDS, CTAC e HPS e caracterizaram as curvas através de três regiões. A primeira região refere-se ao primeiro patamar e está associada a BSA na forma nativa, a segunda região é onde ocorre o maior deslocamento e está associada a formação do complexo BSA-surfactante e a 
terceira região está associada ao esgotamento da interação e desnaturação parcial da BSA.

Dasmandal e colaboradores [40] discutem a interação entre BSA e um aminoácido surfactante, com cadeia hidrofóbica de 10 carbonos e cabeça polar carregada negativamente (o AAS), através de várias técnicas biofísicas, inclusive fluorescência, onde também há supressão e blue-shift. Tais efeitos são explicados, através de modelos teóricos, como causa da aproximação da cadeia carbônica do surfactante e formação de ligações de hidrogênio com outros aminoácidos da proteína próximos ao triptofano.

Anurag e colaboradores [41] estudaram diferenças conformacionais da BSA em presença do surfactante catiônico $\mathrm{CTAB}$, onde também foi possível observar a supressão da fluorescência e o deslocamento do pico de fluorescência para o azul. No trabalho é feito uma comparação do máximo deslocamento do pico de emissão da fluorescência $(\Delta \lambda)$ da BSA causado por três surfactantes: $(15 \pm 1) n m$ para DTAB

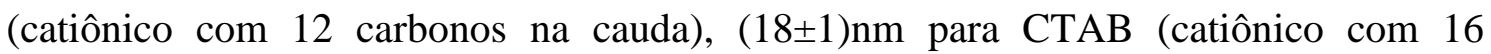
carbonos na cauda), e $(27 \pm 1) n m$ para SDS (aniônico com 12 carbonos na cauda). Enquanto que encontramos o máximo deslocamento igual a $(21 \pm 1) \mathrm{nm}$ para $\left[\mathrm{C}_{14 \mathrm{mim}}\right][\mathrm{Cl}]$ (catiônico com 14 carbonos na cauda).

Portanto podemos observar que os efeitos contemplados pelo experimento de fluorescência são comuns quando tratamos da interação da proteína BSA e surfactantes catiônicos, zwiteriônicos e aniônicos, porém o grau das alterações irá depender de características particulares do sistema. Tais efeitos são explicados por sítios de interação da proteína com o surfactante que causa uma proximidade da cadeia carbônica e da formação de ligações de hidrogênio próximos ao triptofano. 
Fei Geng e colaboradores [39], trabalho já citado anteriormente, obteve o deslocamento máximo do pico de fluorescência da BSA igual a $20 \mathrm{~nm}$ para $3 \mathrm{mM}$ de $\left[\mathrm{C}_{14 \mathrm{mim}}\right][\mathrm{Br}]$, lembrando que encontramos valor compatível de deslocamento igual a $(21 \pm 1)$ nm para $\left[\mathrm{C}_{14 \mathrm{mim}}\right][\mathrm{Cl}]$. Ainda de acordo com o esperado devido à semelhança entre $\left[\mathrm{C}_{14 \mathrm{mim}}\right][\mathrm{Br}]$ e $\left[\mathrm{C}_{14 \mathrm{mim}}\right][\mathrm{Cl}]$.

A fim de se obter maiores informações acerca desses sistemas, realizamos medidas de SAXS nessas mesmas amostras. As curvas de SAXS podem trazer informações sobre o envelope da proteína, desnaturação ou formação de agregados, a Figura 5.17 traz as curvas deslocadas para facilitar a visualização.

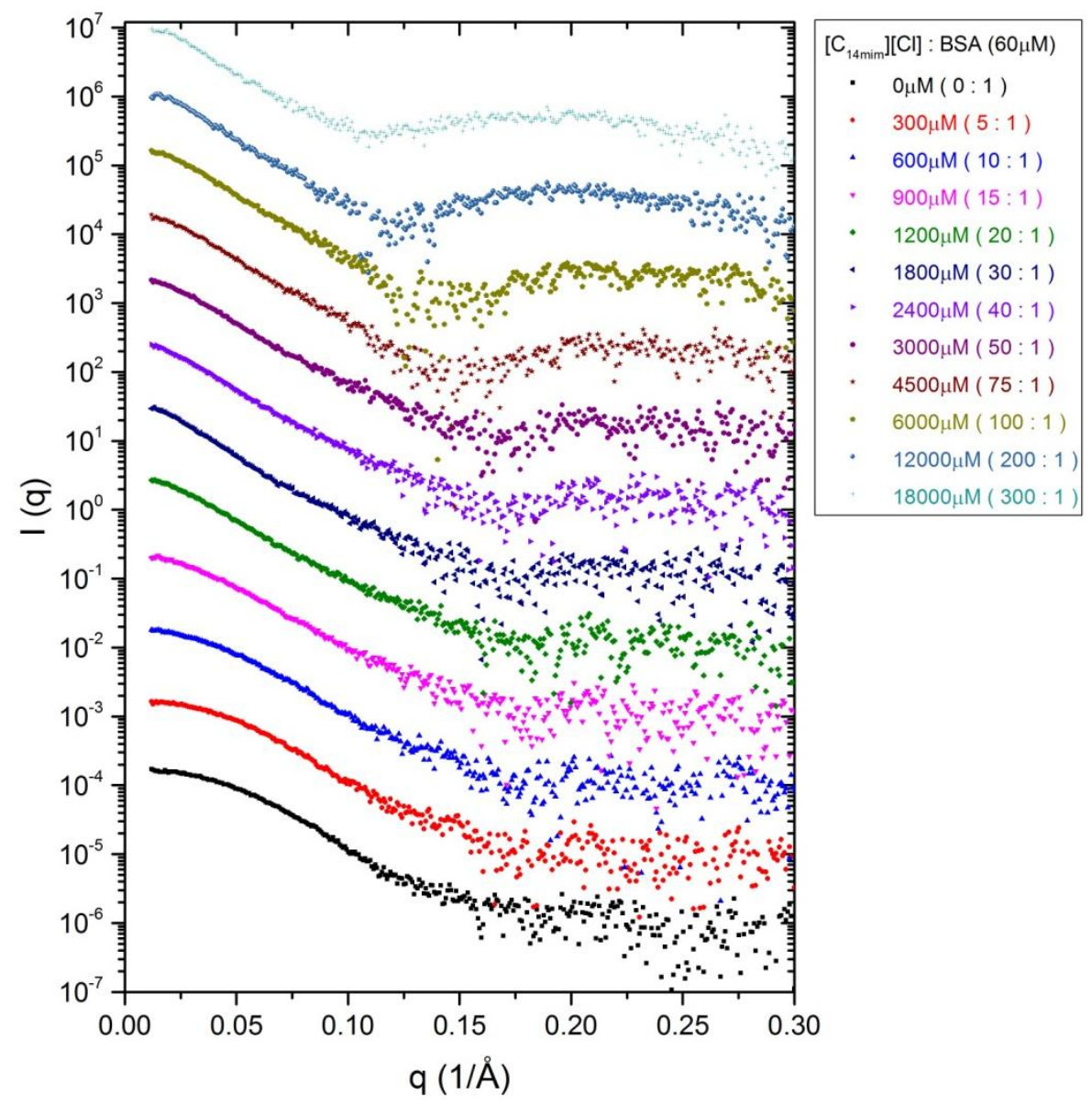

Figura 5.17: Curvas de SAXS obtidas para o sistema BSA a $60 \mu \mathrm{M}$ e variadas concentrações de $\left[\mathrm{C}_{14 \operatorname{mim}}\right][\mathrm{Cl}]$ descritas na legenda junto a razão molar. As curvas estão deslocadas na vertical para melhor visualização. 
Observe que as curvas de SAXS pouco se alteram até $900 \mu \mathrm{M}$ de $\left[\mathrm{C}_{14 \mathrm{mim}}\right][\mathrm{Cl}]$ ou razão molar $15: 1$, a partir de $1200 \mu \mathrm{M}$ de $\left[\mathrm{C}_{14 \text { mim }}\right][\mathrm{Cl}]$ ou razão molar 20:1 de há a formação de um segundo pico próximo a $q=0.23 \AA^{-1}$ que torna-se mais evidente para concentrações maiores de LI, tal pico é uma conhecida marca para formação de micelas [42], portanto atribuiremos a esse fato a formação de estruturas em forma de micelas em solução, o que é razoável haja visto que a $\mathrm{CMC}$ do $\left[\mathrm{C}_{14 \mathrm{mim}}\right][\mathrm{Cl}]$ é em torno de $1 \mathrm{mM}$ em tampão.

A aproximação de Guinier foi utilizada para o cálculo do raio de giro a partir das curvas de SAXS gerando a Figura 5.18.

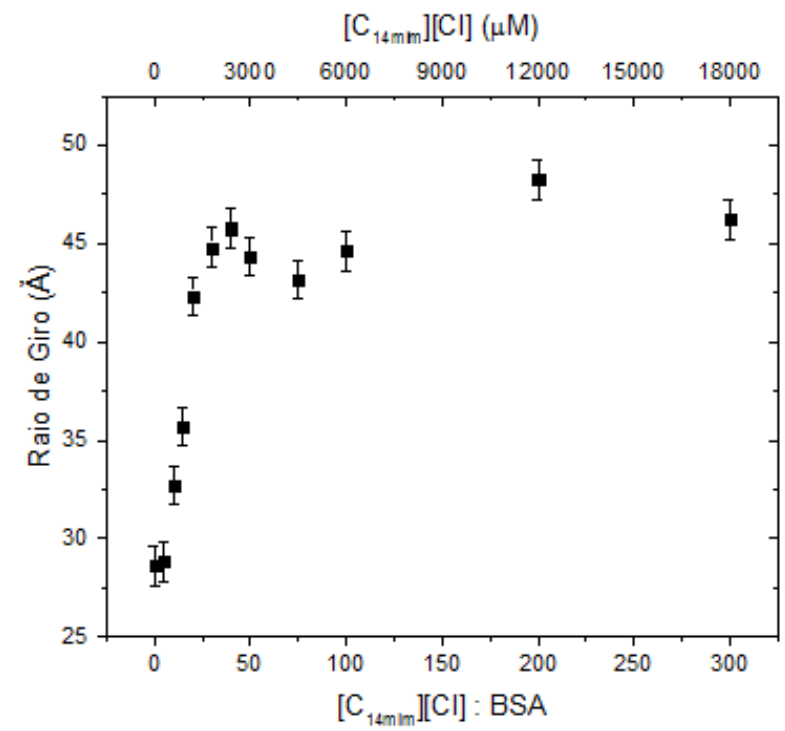

Figura 5.18: Raio de giro da BSA a $60 \mu \mathrm{M}$ em função da concentração de [ $\left.\mathrm{C}_{14 \mathrm{mim}}\right][\mathrm{Cl}]$ (escala superior) e razão molar (escala inferior), ambas logarítmicas.

O raio de giro da BSA em ausência de LI é igual a $(29 \pm 1) \AA$, valor compatível com $30 \AA$ da literatura [42]. Em presença de $\left[\mathrm{C}_{14 \mathrm{mim}}\right][\mathrm{Cl}]$ o raio de giro aumenta até $(45.8 \pm 1.0) \AA$ em presença de $2400 \mu \mathrm{M}(40: 1)$ de LI e torna-se aproximadamente constante. Itri e colaboradores [43] investigaram o efeito da ureia na BSA, um conhecido atuante no desenovelamento da proteína [31], através de várias técnicas 
biofísicas, inclusive SAXS. Os raios de giro encontrados são iguais a $45 \AA$ e $72 \AA$ em presença de $3 \mathrm{M}$ e $5 \mathrm{M}$ de ureia. Note que o desenovelamento causado por $3 \mathrm{M}$ de ureia é próximo ao causado por $2.4 \mathrm{mM}$ de $\left[\mathrm{C}_{14 \mathrm{mim}}\right][\mathrm{Cl}]$.

Santos e colaboradores [42] investigam a interação da BSA com SDS através de SAXS e constataram o aumento do raio de giro da BSA para $39 \AA ̊$ em presença de $5 \mathrm{mM}$ de SDS. Portanto podemos supor que o $\left[\mathrm{C}_{14 \mathrm{mim}}\right][\mathrm{Cl}]$ é um eficiente desnaturante da proteína BSA., ao menos no que tange os parâmetros estruturais, em particular o raio de giro.

O gráfico de Kratky possibilita uma análise qualitativa da forma da macromolécula em estudo e pode ser apreciada na Figura 5.19.

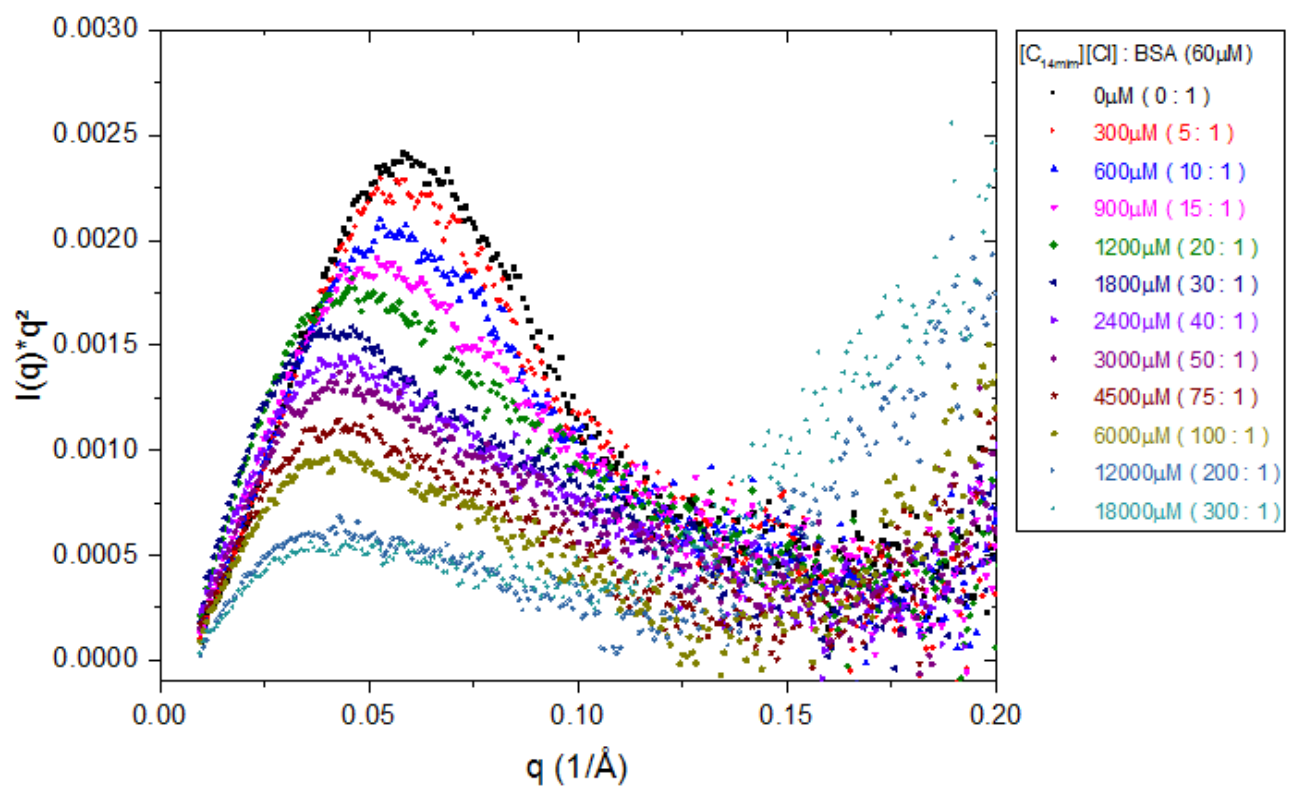

Figura 5.19: Curvas de Kratky obtidas para o sistema BSA a $60 \mu \mathrm{M}$ e variadas concentrações de [ $\left.\mathrm{C}_{14 \operatorname{mim}}\right][\mathrm{Cl}]$ descritas na legenda junto a razão molar.

A proteína nativa possui a curva de Kratky na forma de um sino cuja posição do pico está relacionada com o raio de giro da mesma. Quando a proteína passa a uma conformação mais estendida a forma de curva deixa de ser um sino gradativamente e se 
houver aumento do tamanho médio o pico desloca-se para menores valores de $q$ [31]. A forma de sino da curva da BSA em ausência de $\left[\mathrm{C}_{14 \mathrm{mim}}\right][\mathrm{Cl}]$ é condizente com sua estrutura globular em solução, já a perda da forma de sino com a audição de LI é mais um indício do desenovelamento da proteína, corroborando a análise de Guinnier

A análise de SAXS realizada por Santos e colaboradores [42] sugere a formação de agregados micelares a partir de 10mM de SDS e para tanto propõem o modelo colar de perolas. Neste modelo a proteína perde sua estrutura terciária e quaternária, permanecendo, majoritariamente desenovelada, além disso, existe também a presença de micelas distribuídas ao longo da cadeia polipeptídica. [42] [44]

A fim de verificar se tal modelo será compatível com nossos dados, realizamos medidas de dicroísmo circular (CD) desses mesmos sistemas, ou seja, BSA em ausência e presença de concentrações crescentes de LI. Os espectros de CD da BSA podem ser apreciados na Figura 5.20.

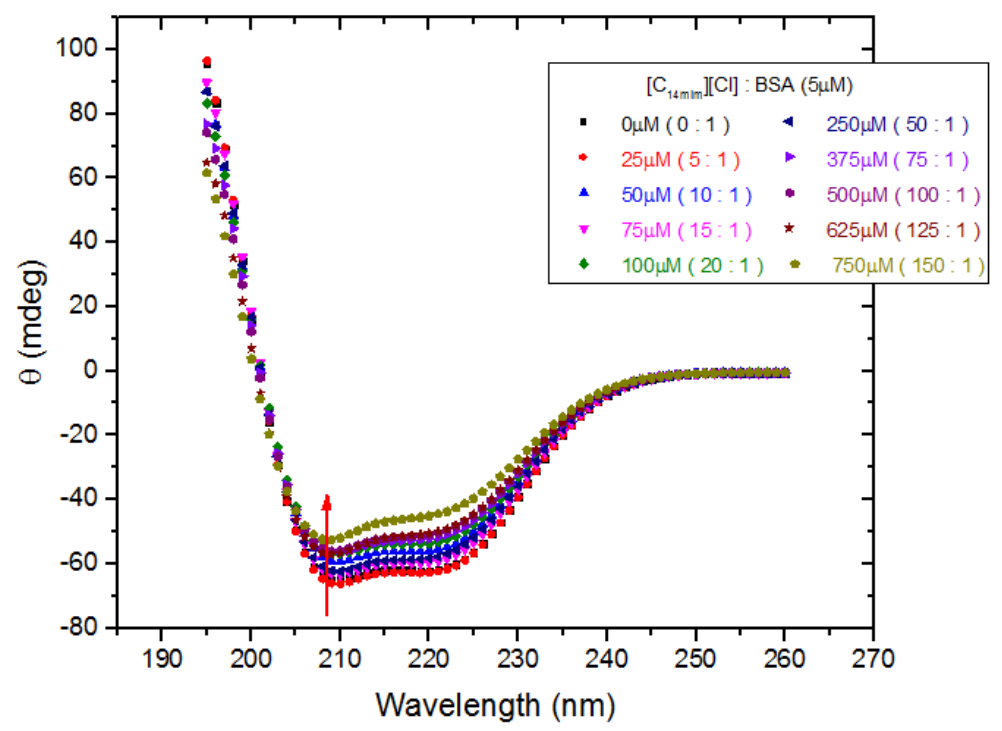

Figura 5.20: Espectro de CD para BSA $(5 \mu \mathrm{M})$ em ausência e em presença de variadas concentrações de $\left[\mathrm{C}_{14 \mathrm{mim}}\right][\mathrm{Cl}]$ descritas na legenda junto a razão molar. A seta vermelha indica a direção do deslocamento das curvas com o aumento da concentração de LI. 
Podemos observar que com o aumento da concentração de $\left[\mathrm{C}_{14 \operatorname{mim}}\right][\mathrm{Cl}]$ a amplitude do espectro diminui, isto é, o módulo de $\theta$ diminuí, principalmente para os valores de 208 e 222nm, que são específicos para a estrutura do tipo alfa-hélice. Constatamos que há uma diminuição em média de $23 \%$ do módulo de $\theta$ em 208nm e 222nm para $750 \mu \mathrm{M}$ de $\left[\mathrm{C}_{14 \mathrm{mim}}\right][\mathrm{Cl}](150: 1)$, portanto assumiremos que há uma perda parcial da estrutura secundária da proteína BSA em presença de $\left[\mathrm{C}_{14 \mathrm{mim}}\right][\mathrm{Cl}]$. Uma análise mais minuciosa, como a porcentagem de cada tipo de estrutura secundária, não foi possível devido a grande absorção do LI em menores comprimentos de onda.

\subsection{Albumina de Soro Bovina e $\left[\mathrm{C}_{1 \mathrm{xmim}}\right][\mathrm{Cl}]$}

As alterações que os líquidos iônicos provocam em cada proteína têm semelhanças, variando somente em intensidade e amplitude de acordo com o tamanho da cadeia carbônica do LI em estudo. Prevenindo a excessiva repetição desta dissertação o detalhamento referente aos sistemas $\mathrm{BSA}+\left[\mathrm{C}_{12 \mathrm{mim}}\right][\mathrm{Cl}]$ e $\mathrm{BSA}+\left[\mathrm{C}_{10 \mathrm{mim}}\right][\mathrm{Cl}]$ será menor e em forma essencialmente comparativa. Embora as discussões ainda possam ser apreciadas ao longo da seção, os gráficos estarão disponíveis somente no apêndice.

Os espectros de absorbância da BSA em presença de $\left[\mathrm{C}_{12 \mathrm{mim}}\right][\mathrm{Cl}]$ e $\left[\mathrm{C}_{10 \mathrm{mim}}\right][\mathrm{Cl}]$ (Figura A. 1 Figura A. 2, Figura A. 10 e Figura A. 11), assim como em presença de $\left[\mathrm{C}_{14 \mathrm{mim}}\right][\mathrm{Cl}]$, não apresentam alterações na forma, porém há um aumento significativo da absorbância em $295 \mathrm{~nm}$ e na turbidez observada a partir de $3 \mathrm{mM}$ de $\left[\mathrm{C}_{12 \mathrm{mim}}\right][\mathrm{Cl}]$ ou razão 100:1 e a partir de $6 \mathrm{mM}$ de $\left[\mathrm{C}_{10 \mathrm{mim}}\right][\mathrm{Cl}]$ ou razão 200:1, lembrando que observamos tal aumento na seção anterior a partir de $750 \mu \mathrm{M}$ de $\left[\mathrm{C}_{14 \operatorname{mim}}\right][\mathrm{Cl}]$ ou razão $25: 1$. 
Nos espectros de fluorescência da BSA em presença de $\left[\mathrm{C}_{12 \mathrm{mim}}\right][\mathrm{Cl}] \mathrm{e}$ $\left[\mathrm{C}_{10 \mathrm{mim}}\right][\mathrm{Cl}]$ (Figura A. 3 a Figura A. 6 e Figura A. 12 a Figura A. 15), assim como em presença de $\left[\mathrm{C}_{14 \mathrm{mim}}\right][\mathrm{Cl}]$, constatamos a diminuição da intensidade de fluorescência (supressão) e deslocamento do pico de fluorescência para menores comprimentos de onda (blue-shift) com o aumento da concentração de LI. A análise da posição do pico de fluorescência e da integral da intensidade de fluorescência também foram realizadas.

A posição do pico permanece aproximadamente inalterada para baixas concentrações de LI: até $300 \mu \mathrm{M}$ de $\left[\mathrm{C}_{12 \mathrm{mim}}\right][\mathrm{Cl}]$ ou razão molar $(10: 1)$ e $1.5 \mathrm{mM}$ de $\left[\mathrm{C}_{12 \text { mim }}\right][\mathrm{Cl}]$ ou razão molar $(50: 1)$, lembrando que para $\left[\mathrm{C}_{14 \operatorname{mim}}\right][\mathrm{Cl}]$ a posição do pico permanecia constante até aproximadamente $90 \mu \mathrm{M}$ de $\left[\mathrm{C}_{14 \mathrm{mim}}\right][\mathrm{Cl}]$ ou razão molar $(3: 1)$. Após tais concentrações há uma brusca diminuição do comprimento de onda correspondente ao máximo de fluorescência, portanto para os três LIs foi possível ajustar a função de Bolztman e obter os pontos de inflexão $\left(x_{0}\right)$ nos concentração $(1.16 \pm 0.01) \mathrm{mM}$ de $\left[\mathrm{C}_{12 \mathrm{mim}}\right][\mathrm{Cl}]$ ou razão molar igual a $(38.6 \pm 0.2): 1$ e $(5.5 \pm 0.2) \mathrm{mM}$ de $\left[\mathrm{C}_{10 \mathrm{mim}}\right][\mathrm{Cl}]$ ou razão molar igual a $(184 \pm 3): 1$, lembrando que a concentração do ponto de inflexão no sistema contendo $\left[\mathrm{C}_{14 \mathrm{mim}}\right][\mathrm{Cl}]$ é $(240 \pm 6) \mu \mathrm{M}$ de $\left[\mathrm{C}_{14 \mathrm{mim}}\right][\mathrm{Cl}]$ ou (8.0 0.2$): 1$. Visto que a única diferença entre os LIs é o tamanho da cadeia carbônica, podemos observar que a concentração do ponto de inflexão aumenta conforme número de carbonos da cauda diminui, portanto podemos supor que o efeito hidrofóbico é um importante fator da interação entre LI e a BSA.

O efeito da supressão da BSA pelos os três líquidos iônicos será analisada pela diminuição porcentual da integral da intensidade de fluorescência perdida, chamaremos de supressão relativa, entre dois pontos que temos em comum nos três sistemas, isto é:

$$
S_{0-0.6 m M}=\frac{I_{0 m M}-I_{0.6 m M}}{I_{0 m M}}
$$


Onde $I_{0 m M}$ é a integral da intensidade do espectro de fluorescência da BSA em ausência de LI e $I_{0.6 m M}$ é a integral da intensidade do espectro de fluorescência da BSA em presença de $0.6 \mathrm{mM}$ de LI. Os valores de tal fator para $\left[\mathrm{C}_{14 \mathrm{mim}}\right][\mathrm{Cl}],\left[\mathrm{C}_{12 \mathrm{mim}}\right][\mathrm{Cl}] \mathrm{e}$ $\left[\mathrm{C}_{10 \mathrm{mim}}\right][\mathrm{Cl}]$ são respectivamente iguais a $55 \pm 3,38 \pm 2$ e $11.0 \pm 0.5$, portanto a intensidade da supressão também depende e é favorecida pelo tamanho da cadeia carbônica.

Objetivando resumir e elucidar os dados mencionados anteriormente a Tabela 5.1 traz a comparações entre estes.

\begin{tabular}{|c|c|c|}
\hline $\begin{array}{l}\text { BSA à } \\
30 \mu \mathrm{M}\end{array}$ & $\begin{array}{c}S_{0-0.6 m M} \\
{[\%]}\end{array}$ & $\begin{array}{c}x_{0} \\
\text { (razão molar) }\end{array}$ \\
\hline$\left[\mathrm{C}_{14 \mathrm{mim}}\right][\mathrm{Cl}]$ & $55 \pm 3$ & $(8.0 \pm 0.2): 1$ \\
\hline$\left[\mathrm{C}_{12 \operatorname{mim}}\right][\mathrm{Cl}]$ & $38 \pm 2$ & $(38.6 \pm 0.2): 1$ \\
\hline$\left[\mathrm{C}_{10 \operatorname{mim}}\right][\mathrm{Cl}]$ & $11.0 \pm 0.5$ & $(184 \pm 3): 1$ \\
\hline
\end{tabular}

Note que quanto menor é o tamanho da cadeia carbônica menor é a supressão relativa, observe também que quanto maior a cadeia carbônica menor é $x_{0}$, isto é, menor é concentração de LI necessária para alcançar o ponto intermediário de estados. Portanto podemos afirmar que o efeito hidrofóbico é um importante fator na interação entre a BSA e os líquidos iônicos estudados, já que todos os fatores estudados têm maior intensidade quanto maior a cadeia carbônica.

O experimento de SAXS foi realizada para BSA em presença e ausência de $\left[\mathrm{C}_{12 \mathrm{mim}}\right][\mathrm{Cl}]$ (Figura A. 7) e as conclusões serão discutidas, porém para $\left[\mathrm{C}_{10 \mathrm{mim}}\right][\mathrm{Cl}]$ os dados foram insuficientes para uma discussão apurada, portanto não serão mencionados. 
Através das curvas de SAXS da BSA a $60 \mu \mathrm{M}$ em presença de $\left[\mathrm{C}_{12 \mathrm{mim}}\right][\mathrm{Cl}]$ foi possível observar a formação de estruturas micelares a partir de $4.5 \mathrm{mM}$ de $\left[\mathrm{C}_{12 \mathrm{mim}}\right][\mathrm{Cl}]$ ou razão molar igual a 75:1 . Recordando que tais estruturas apareceram a partir de $1.2 \mathrm{mM}$ de $\left[\mathrm{C}_{14 \mathrm{mim}}\right]$ ou razão molar igual a 20:1 [Cl].

Utilizando a aproximação de Guinier observamos os valores de raio de giro da BSA em ausência de $\left[\mathrm{C}_{12 \mathrm{mim}}\right][\mathrm{Cl}]$ partem de $(29 \pm 1) \AA$ para $(45 \pm 1) \AA$ em presença de $4.5 \mathrm{mM}$ de $\left[\mathrm{C}_{12 \mathrm{mim}}\right][\mathrm{Cl}]$, ou razão molar igual a 75:1 e tendem a uma estabilidade, valorem semelhantes aos encontrados para $\left[\mathrm{C}_{14 \mathrm{mim}}\right][\mathrm{Cl}]$, porém a estabilidade foi alcançada em menor concentração de LI $\left(2.4 \mathrm{mM}\right.$ de $\left.\left[\mathrm{C}_{14 \mathrm{mim}}\right][\mathrm{Cl}]\right)$, fato este concordante com a discussão anterior.

Os espectros de CD da BSA apresentaram o mesmo comportamento para todos os LIs. A diminuição do módulo de $\theta$ em $208 \mathrm{~nm}$ e em $222 \mathrm{~nm}$ é em média $13 \%$ em presença de $1.5 \mathrm{mM}$ de $\left[\mathrm{C}_{12 \mathrm{mim}}\right][\mathrm{Cl}](300: 1)$ e em média $5 \%$ em presença da mesma concentração de $\left[\mathrm{C}_{10 \mathrm{mim}}\right][\mathrm{Cl}]$, enquanto que para $0.75 \mathrm{mM}$ de $\left[\mathrm{C}_{14 \mathrm{mim}}\right][\mathrm{Cl}](150: 1)$ é em média $23 \%$. Portanto a diminuição da estrutura secundária é maior quanto maior a cadeia carbônica, em concordância com os dados de fluorescência.

Propomos que a interação da BSA com os líquidos iônicos está potencialmente dividida em três estágios, que podem ser vistos na Figura 5.21, onde cada estágio está marcado em cor diferente. O primeiro estágio está caracterizado pela proteína ainda em sua forma nativa, a interação, ainda fraca, se inicia predominantemente devido às forças eletrostáticas proporcionado pelas cargas opostas na superfície da BSA e da cabeça polar dos LIs. Os parâmetros estudados não variam significativamente nesta região, como pode ser visto na região verde da Figura 5.21. Com a aproximação dos LI à superfície da proteína há o desenovelamento da mesma aumentando a possibilidade da 
interação entre sítios hidrofóbicos da proteína, inicialmente escondidos do solvente, com as cadeias carbônicas dos LIs, assim como ligações de hidrogênio com os resíduos da proteína. O efeito hidrofóbico é a maior contribuinte da interação, potencializando as ligações e formação do complexo BSA-LI, interação essa evidenciada pela grande variação dos parâmetros estudados, como pode ser observado na região amarela da Figura 5.21. Quanto maior for a cadeia carbônica do LI, menor a concentração em que se pode ver tal região e maior serão os efeitos da interação. Com o aumento da concentração de LI em solução há a possibilidade de formação de agregados em forma micelas, podendo estes estar em solução e ao longo da proteína, modelo deste chamado de colar-de-pérolas. Nesta última etapa a interação entre a BSA e LI foi esgotada, pois além do número finito de sítios de ligação, há a formação de micelas em solução, como pode ser constatado na região azul da Figura 5.21 onde os parâmetros analisados se estabilizam.

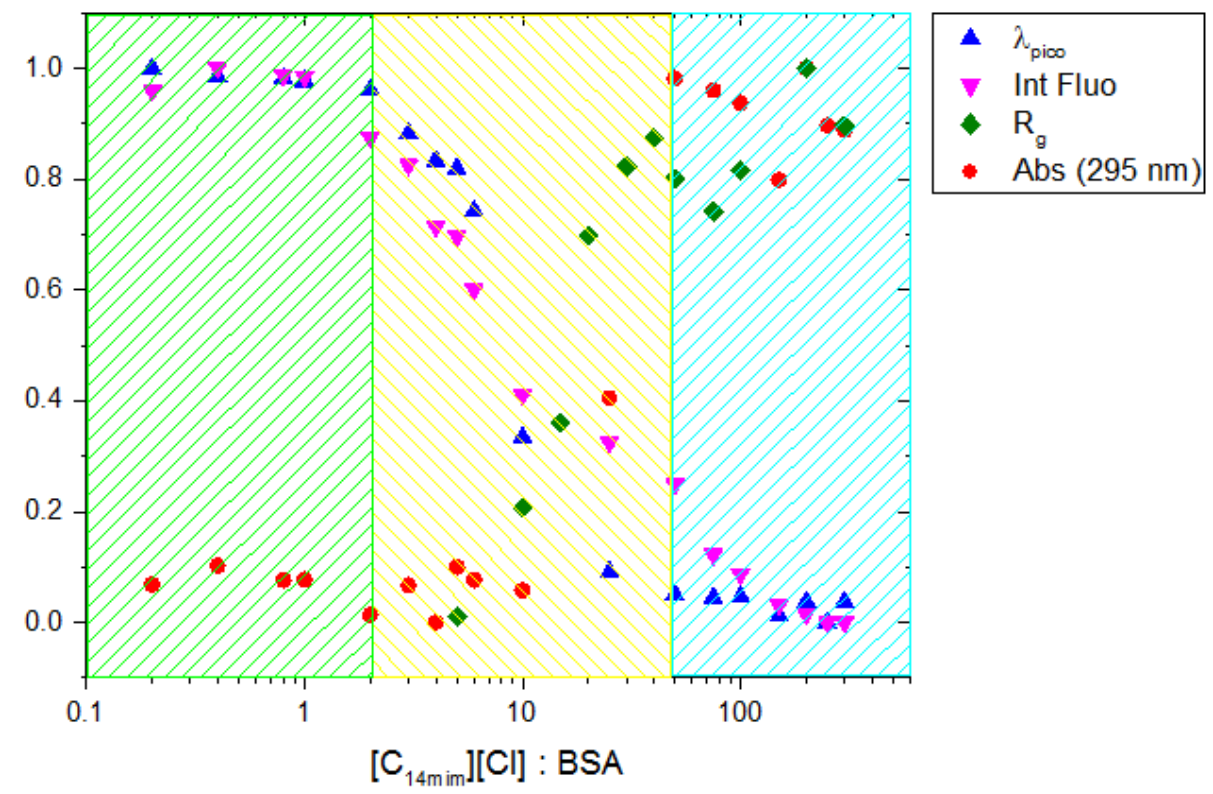

Figura 5.21: Variação dos parâmetros estudados separados por estágios de interação. 


\subsection{Albumina de Soro Humana e $\left[\mathrm{C}_{14 \mathrm{mim}}\right][\mathrm{Cl}]$}

A concentração de trabalho escolhida para a análise da HSA é de $60 \mu \mathrm{M}$, o dobro da escolhida para a BSA, pois a HSA possui somente um triptofano enquanto a BSA possui dois. Optou-se por manter constante o número de triptofanos em solução ao invés do número de moléculas de proteínas, priorizando as medidas de fluorescência. Entretanto tal escolha pode trazer um complicador para uma análise comparativa, buscando evitar possíveis contradições, as comparações serão feitas tanto para a concentração absoluta de LI quanto para a razão molar dos sistemas.

Os espectros de absorbância, presentes na Figura 5.22, foram obtido a partir de amostras a $60 \mu \mathrm{M}$ de HSA em presença de concentrações crescentes de $\left[\mathrm{C}_{14 \mathrm{mim}}\right][\mathrm{Cl}]$.

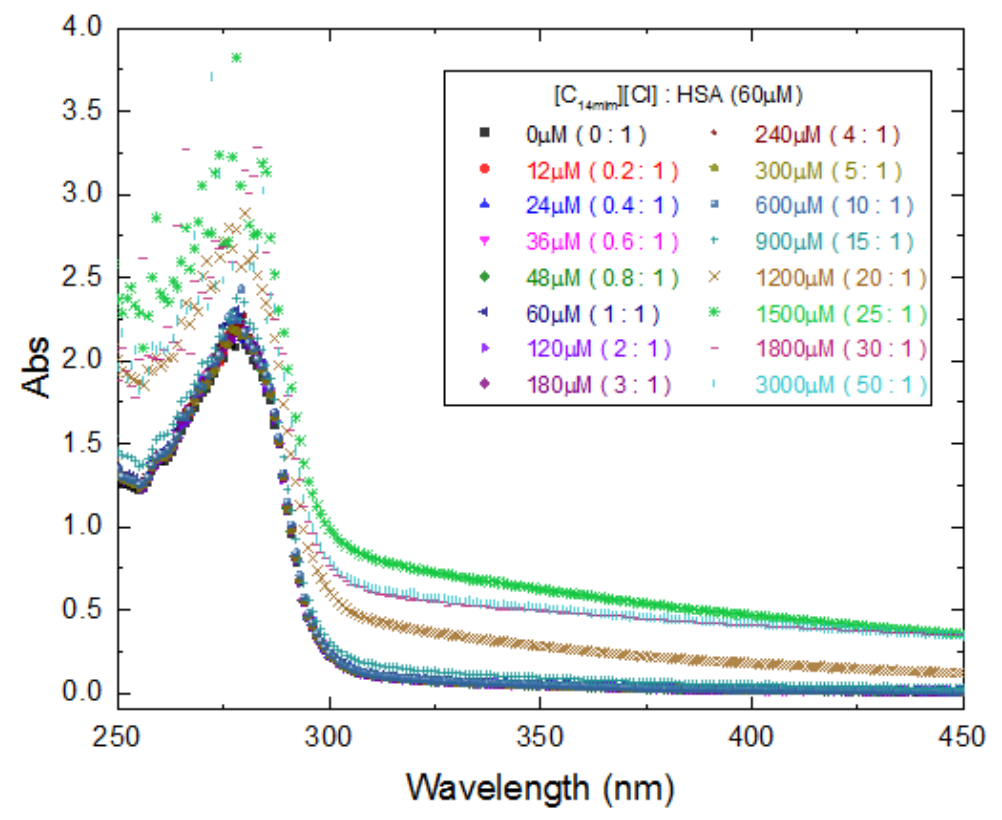

Figura 5.22: Espectro de absorbância da HSA a $60 \mu \mathrm{M}$ em presença de variadas concentrações de $\left[\mathrm{C}_{14 \mathrm{mim}}\right][\mathrm{Cl}]$ descritas na legenda junto a razão molar. A absorbância do tampão e da cubeta foram subtraídas das curvas.

Podemos observar que o espectro de absorbância pouco se altera até $900 \mu \mathrm{M}$, a partir de $1200 \mu \mathrm{M}$, no entanto, há um aumento significativo. A absorbância nos principais comprimentos de onda pode ser apreciada na Figura 5.23. 
(A)

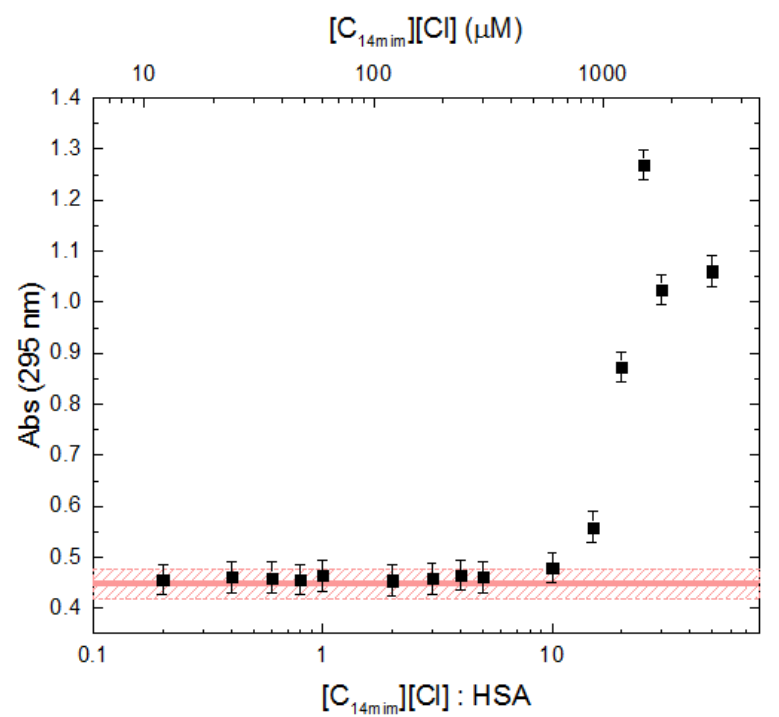

(B)

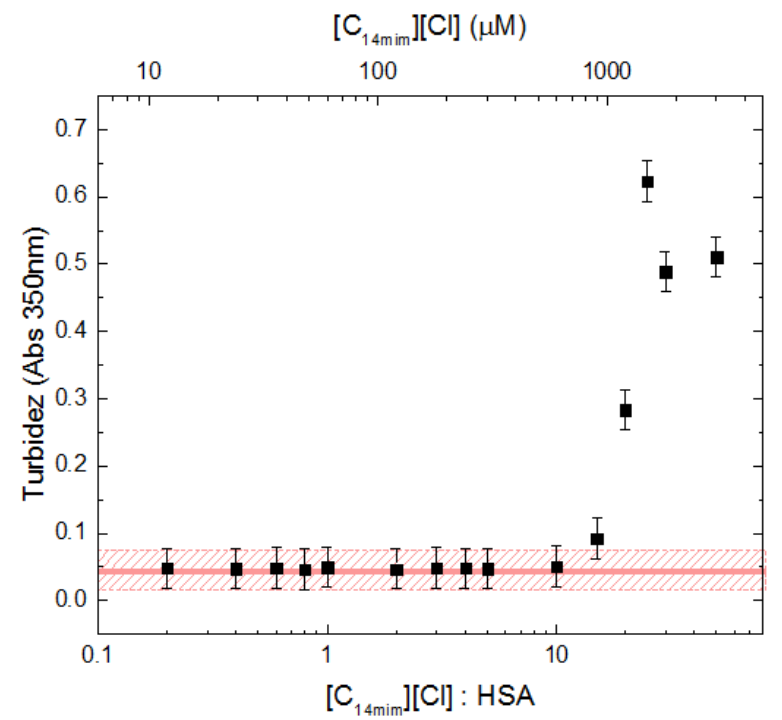

Figura 5.23: Absorbância em $295 \mathrm{~nm}$ (A) e turbidez (B) da HSA a $60 \mu \mathrm{M}$ em função da concentração de [ $\left.\mathrm{C}_{14 \text { mim }}\right][\mathrm{Cl}]$ (escala superior) e razão molar (escala inferior), ambas logarítmicas. A faixa vermelha preenchida e listrada correspondem a HSA em ausência de LI e incerteza, respectivamente.

Podemos observar que tanto a absorbância em 295nm quanto a turbidez permanecem constantes até $600 \mu \mathrm{M}$ de $\left[\mathrm{C}_{14 \mathrm{mim}}\right][\mathrm{Cl}]$ ou razão molar $10: 1$, onde passa a aumentar até $1500 \mu \mathrm{M}(25: 1)$ e torna e diminuir, semelhantemente ao comportamento encontrado nos sistemas com BSA, porém com aumento mais expressivo, tal efeito indica a formação de grandes agregados em solução e conseguinte sedimentação destes. O aumento da absorbância em 295nm também pode indicar a formação de um complexo que altera o estado fundamental do fluoróforo. [34]

O excessivo aumento na turbidez torna o espectro de fluorescência impreciso, portanto somente as amostras de menor turbidez sustentam a análise de fluorescência. $O$ aumento da turbidez das amostras em presença de HSA, em comparação a BSA é um forte indicio de diferenças na interação dos LIs com as duas proteínas. Além disso, este grande aumento de turbidez indica a formação de agregados proteína-LI. 
Os espectros de fluorescência da HSA foram monitorados em ausência e em presença de concentrações de crescentes $\left[\mathrm{C}_{14 \mathrm{mim}}\right][\mathrm{Cl}]$, estabelecendo a razão molar entre ambos, gerando a Figura 5.24. Os espectros foram corrigidos pela absorção de filtro interno.

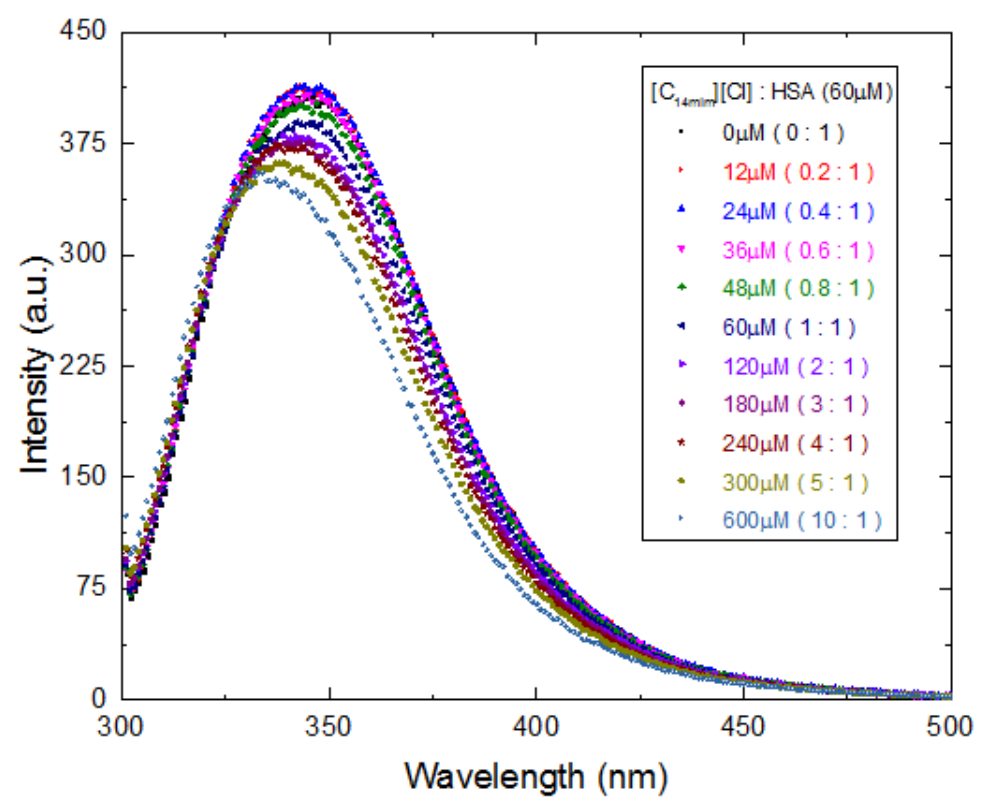

Figura 5.24: Espectro de fluorescência da HSA a $60 \mu \mathrm{M}$ em presença de variadas concentrações de $\left[\mathrm{C}_{14 \text { mim }}\right][\mathrm{Cl}]$ descritas na legenda junto a razão molar. Espectros com correção de filtro interno.

A intensidade de fluorescência da HSA diminui com o aumento da concentração de $\left[\mathrm{C}_{14 \mathrm{mim}}\right][\mathrm{Cl}]$ e promove um blue-shift, semelhante a todos os casos anteriores. Consequentemente concluiremos que o triptofano da HSA, embora mais interno e protegido, sofre influência do LI, de modo análogo a BSA. A magnitude de tal interação será melhor constatada com a reunião de todas as variáveis e a comparação com a proteína BSA.

A Figura 5.25 apresenta a integral da intensidade de fluorescência no intervalo de 300nm a 500nm, quantificando a supressão. 


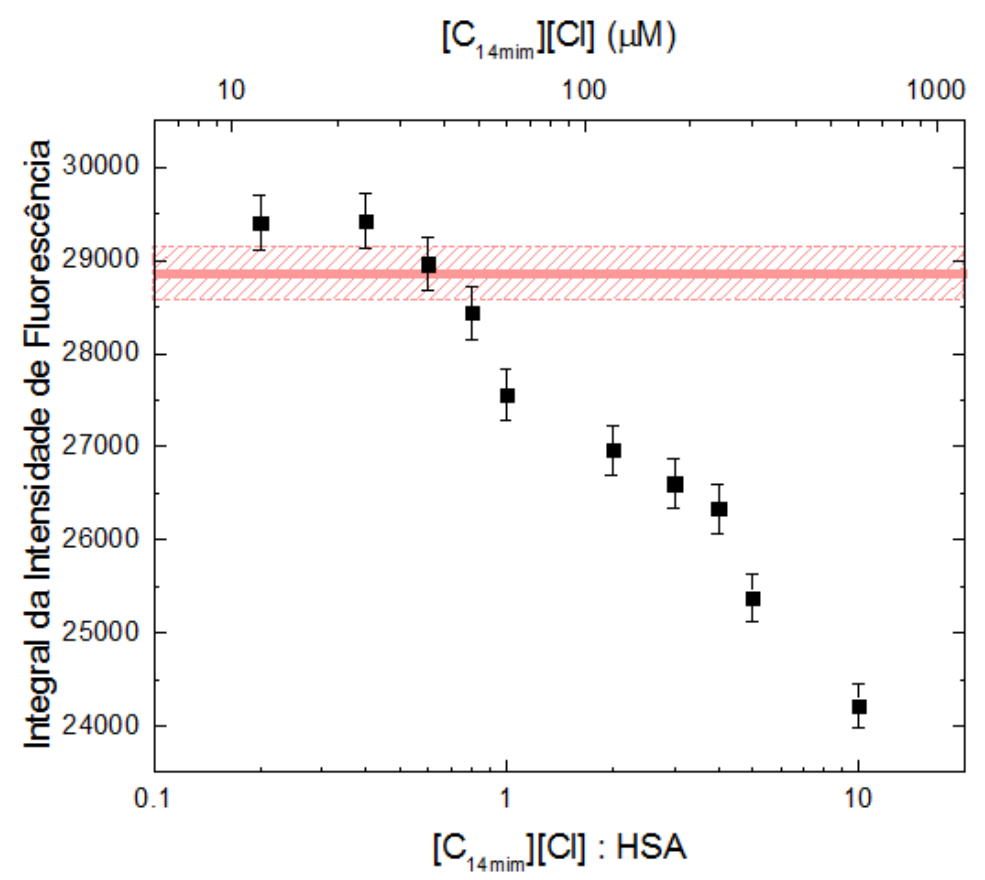

Figura 5.25: Integral da intensidade de fluorescência (de $300 \mathrm{~nm}$ a $500 \mathrm{~nm}$ ) da HSA a $60 \mu \mathrm{M}$ em função da concentração de $\left[\mathrm{C}_{14 \mathrm{mim}}\right][\mathrm{Cl}]$ (escala superior) e razão molar (escala inferior), ambas logarítmicas. A faixa vermelha preenchida e listrada correspondem a HSA em ausência de LI e incerteza, respectivamente.

Verifique que a integral da intensidade de fluorescência da HSA pouco se altera até $24 \mu \mathrm{M}$ de $\left[\mathrm{C}_{14 \mathrm{mim}}\right][\mathrm{Cl}](0.4: 1)$ e passa a diminuir. Infelizmente a alta turbidez do sistema impossibilita averiguar se há a formação de outro patamar a altas concentração de LI. Vale ressaltar que a presença de uma molécula de LI por HSA já é capaz de promover alterações significativas na proteína.

A supressão relativa entre $0 \mu \mathrm{M}(0: 1)$ e $600 \mu \mathrm{M}(10: 1)$ de $\left[\mathrm{C}_{14 \mathrm{mim}}\right][\mathrm{Cl}]$ para a HSA vale $(16 \pm 1) \%$ enquanto para BSA entre as razão 0:1 e 10:1 vale $(28 \pm 2) \%$ e entre as concentrações $0 \mu \mathrm{M}$ e $600 \mu \mathrm{M}$ de $\left[\mathrm{C}_{14 \mathrm{mim}}\right][\mathrm{Cl}]$ vale $(55 \pm 3) \%$. Desta maneira tanto a supressão em função da razão molar quanto da concentração absoluta de LI é menor no sistema com HSA do que com a BSA, concordante com o fato da HSA só possuir o triptofano mais interno, onde o LI tem menor acesso, porém não nulo. 
A intensidade de fluorescência normalizada, Figura 5.26, é gerada a partir da normalização pelo pico do espectro de fluorescência, trará informações sobre possíveis distorções e deslocamentos do mesmo.

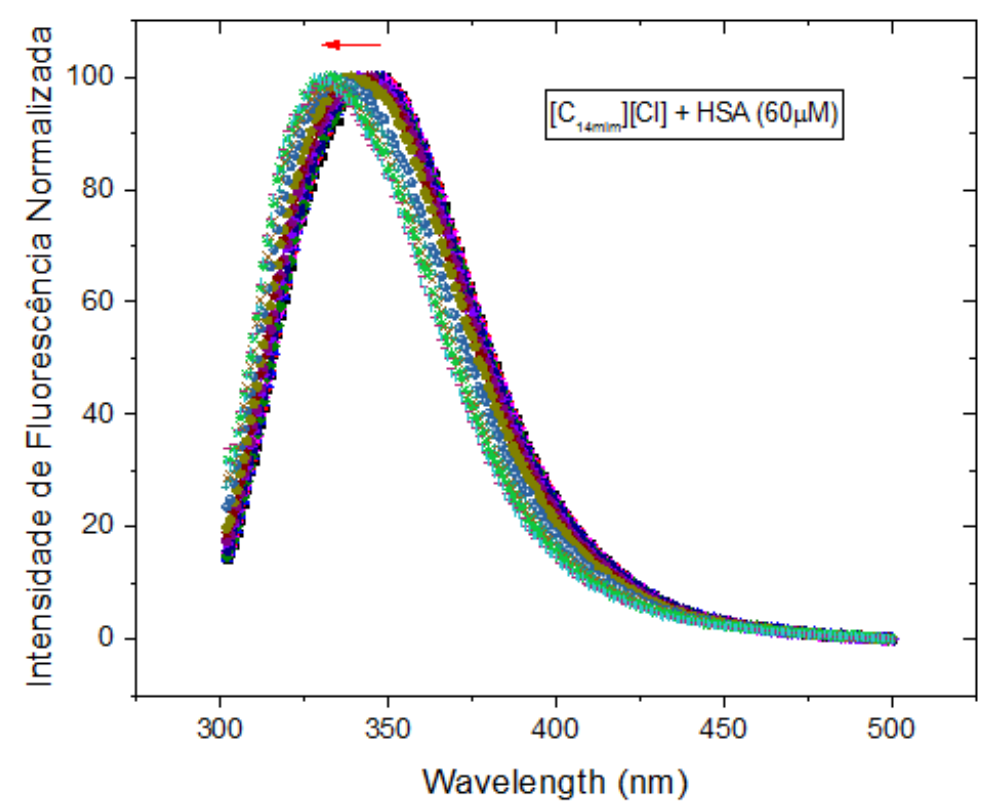

Figura 5.26: Intensidades de fluorescência normalizadas pelo pico do sistema $\mathrm{HSA}+\left[\mathrm{C}_{14 \mathrm{mim}}\right][\mathrm{Cl}]$.

A forma da curva de fluorescência não sofre distorções, porém sofre um deslocamento para menores comprimentos de onda, o blue-shift, que será quantificado pelo comprimento de onda referente ao pico de emissão presente na Figura 5.27. 


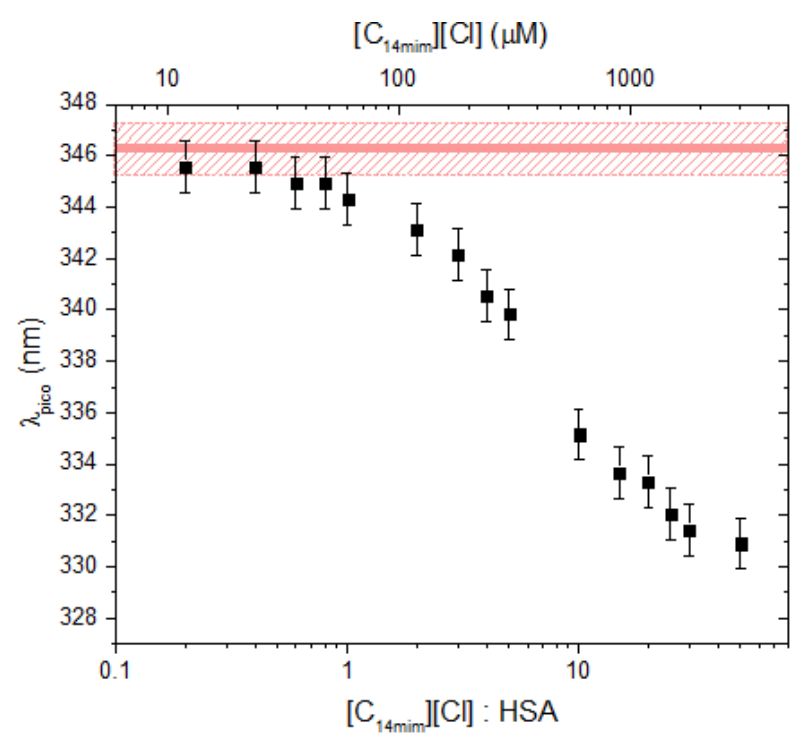

Figura 5.27: Comprimento de onda correspondente ao máximo de fluorescência da HSA a $60 \mu \mathrm{M}$ em função da concentração de $\left[\mathrm{C}_{14 \mathrm{mim}}\right][\mathrm{Cl}]$ (escala superior) e razão molar (escala inferior), ambas logarítmicas. A faixa vermelha preenchida e listrada correspondem a HSA em ausência de LI e incerteza, respectivamente.

As posições do pico de emissão da HSA na ausência e em presença de até aproximadamente $48 \mu \mathrm{M}(0.8: 1)$ de $\left[\mathrm{C}_{14 \mathrm{mim}}\right][\mathrm{Cl}]$ permanecem constantes e em seguida passam a diminuir. Atente-se que o mesmo intervalo de concentrações de $\left[\mathrm{C}_{14 \mathrm{mim}}\right][\mathrm{Cl}]$ promove um maior deslocamento no pico de fluorescência da BSA que na HSA. O máximo deslocamento alcançado pela HSA é de $(16 \pm 1) \mathrm{nm}$ para $3000 \mu \mathrm{M}(50: 1)$ de $\left[\mathrm{C}_{14 \mathrm{mim}}\right][\mathrm{Cl}]$ enquanto que tanto $3000 \mu \mathrm{M}(100: 1)$ quanto $1500 \mu \mathrm{M}(50: 1)$ de $\left[\mathrm{C}_{14 \mathrm{mim}}\right][\mathrm{Cl}]$ promovem deslocamento em torno de $(20 \pm 1) \mathrm{nm}$ no espectro de fluorescência da BSA.

Abdol-Khalegh e colaboradores [45] investigaram a interação da HSA com o cloreto de cetilpiridina (CPC), um surfactante catiônico com 16 carbonos em sua cauda. Assim como no presente trabalho, eles observaram a supressão da fluorescência e o deslocamento do pico de fluorescência para menores comprimentos de onda. O máximo deslocamento observado é de $20 \mathrm{~nm}$ em presença de CPC, enquanto que observamos $(16 \pm 1) \mathrm{nm}$, porém é interessante observar que o patamar inferior que constitui o esgotamento da interação não foi alcançado. 
Meena Kumari e colaboradores [46] estudaram a interação de HSA e o líquido iônico BMOP, catiônico com somente quatro carbonos na cadeia carbônica, e observaram supressão da fluorescência e blue-shift, como em todos os sistemas que exploramos até agora. Foi constado o máximo deslocamento de $16 \mathrm{~nm}$ em presença de $0.1 \mathrm{M}$ de BMOP, valor compatível com $(16 \pm 1) \mathrm{nm}$ em presença de $\left[\mathrm{C}_{14 \mathrm{mim}}\right][\mathrm{Cl}]$. Menna Kumari descreve a interação entre HSA e BMOP como ligação movida predominantemente por forças hidrofóbicas e ligações de hidrogênio nos sítios hidrofóbicos da HSA.

A

Figura 5.28 traz as curvas de SAXS do sistema HSA a $60 \mu \mathrm{M}$ em presença de crescentes concentrações de $\left[\mathrm{C}_{14 \mathrm{mim}}\right][\mathrm{Cl}]$, onde as curvas foram deslocadas para possibilitar a visualização.

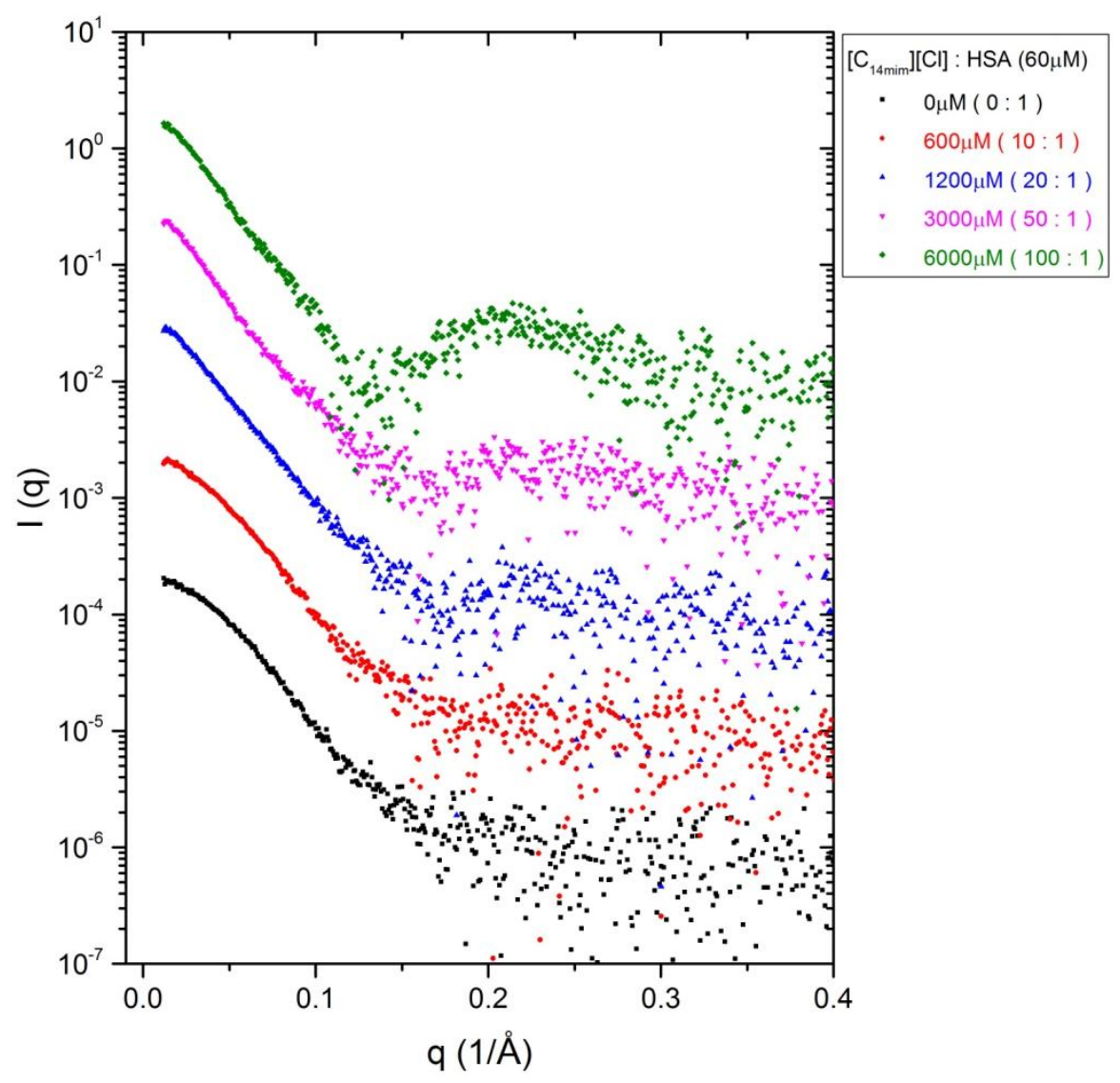


Figura 5.28: Curvas de SAXS obtidas para o sistema HSA a $60 \mu \mathrm{M}$ e variadas concentrações de $\left[\mathrm{C}_{14 \text { mim }}\right][\mathrm{Cl}]$ descritas na legenda junto a razão molar. As curvas estão deslocadas na vertical para melhor visualização.

A formação do segundo pico, a partir de $1.2 \mathrm{mM}$ (20:1), porém mais evidente a partir de $3 \mathrm{mM}$ de $\left[\mathrm{C}_{14 \mathrm{mim}}\right][\mathrm{Cl}]$ (50:1), caracteriza a formação de micelas de LI, o que é razoável pois tais concentrações são superiores a CMC do LI em tampão. [42]

A partir das curvas de SAXS, utilizando a aproximação de Guinier, é possível obter o raio de giro de cada sistema explicitados na Figura 5.29.

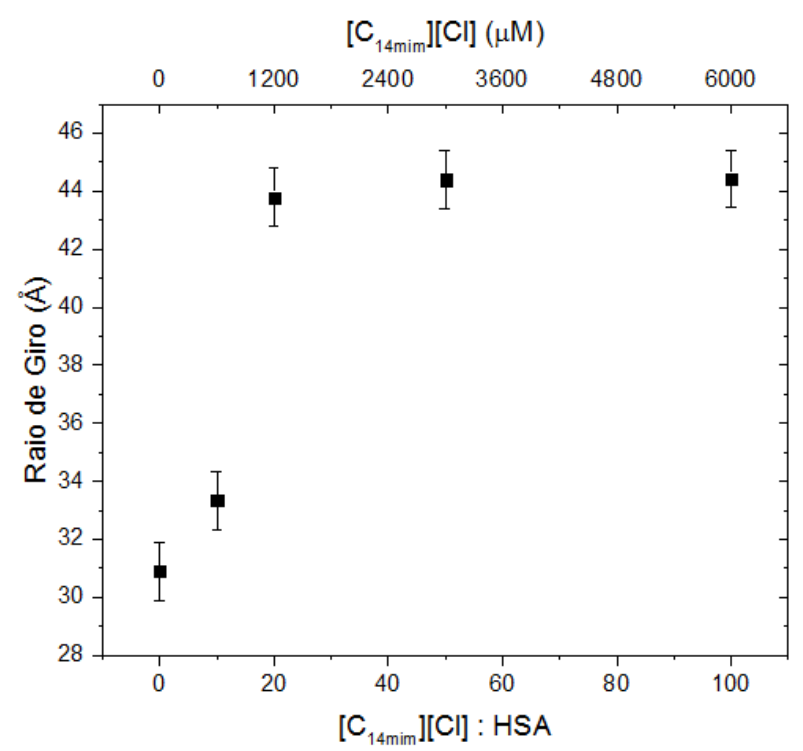

Figura 5.29: Raio de giro da HSA a $60 \mu \mathrm{M}$ em função da concentração de [ $\left.\mathrm{C}_{14 \mathrm{mim}}\right][\mathrm{Cl}]$ (escala superior) e razão molar (escala inferior), ambas logarítmicas.

$\mathrm{O}$ valor do raio de giro encontrado para a proteína em ausência de $\left[\mathrm{C}_{14 \operatorname{mim}}\right][\mathrm{Cl}]$ é igual a $(30 \pm 1) \AA$ valor compatível com $31.5 \AA$ da literatura [31]. O raio de giro da HSA passa a aumentar em presença de LI e estabiliza-se em torno de $(44 \pm 1) \AA ̊$ em presença de $1.2 \mathrm{mM}$ de $\left[\mathrm{C}_{14 \mathrm{mim}}\right][\mathrm{Cl}]$ ou razão molar 20:1. Tais comportamentos são semelhantes aos encontrados para a BSA em presença de $\left[\mathrm{C}_{14 \mathrm{mim}}\right][\mathrm{Cl}]$, onde a partir do raio de giro em ausência de LI igual a $(28.5 \pm 1.0) \AA$ passa a $(45.8 \pm 1.0) \AA$ em presença de $2.4 \mathrm{mM}$ (40:1) de $\left[\mathrm{C}_{14 \mathrm{mim}}\right][\mathrm{Cl}]$. 
Também a partir das curvas de SAXS é possível utilizar a representação de Kratky, onde poderemos verificar se há desenovelamento da proteína. A proteína em sua conformação natural, enovelada, gera uma curva em forma de sino na representação de Kratky, quando sofre desenovelamento tal forma se perde [31]. A Figura 5.30 mostra as curvas de SAXS na representação de Kratky.

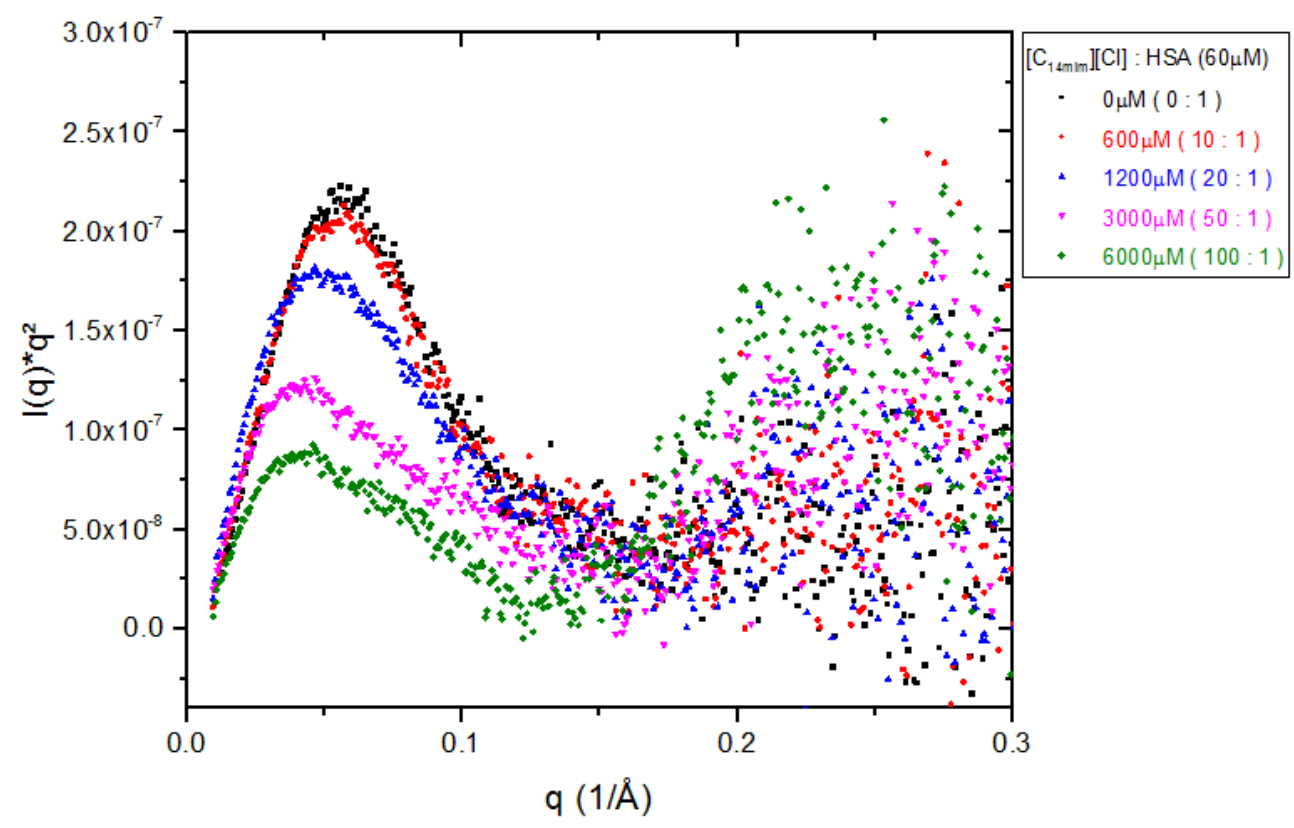

Figura 5.30: Curvas de Kratky obtidas para o sistema HSA a $60 \mu \mathrm{M}$ e variadas concentrações de $\left[\mathrm{C}_{14 \operatorname{mim}}\right][\mathrm{Cl}]$ descritas na legenda junto a razão molar.

Observe que conforme a concentração de $\left[\mathrm{C}_{14 \mathrm{mim}}\right][\mathrm{Cl}]$ a forma de sino é perdida e o pico é deslocado para a esquerda, portanto a proteína perde sua estrutura terciária e sua dimensão aumenta indicando o desenovelamento.

Os espectros de CD da HSA podem ser apreciados na Figura 5.31. 


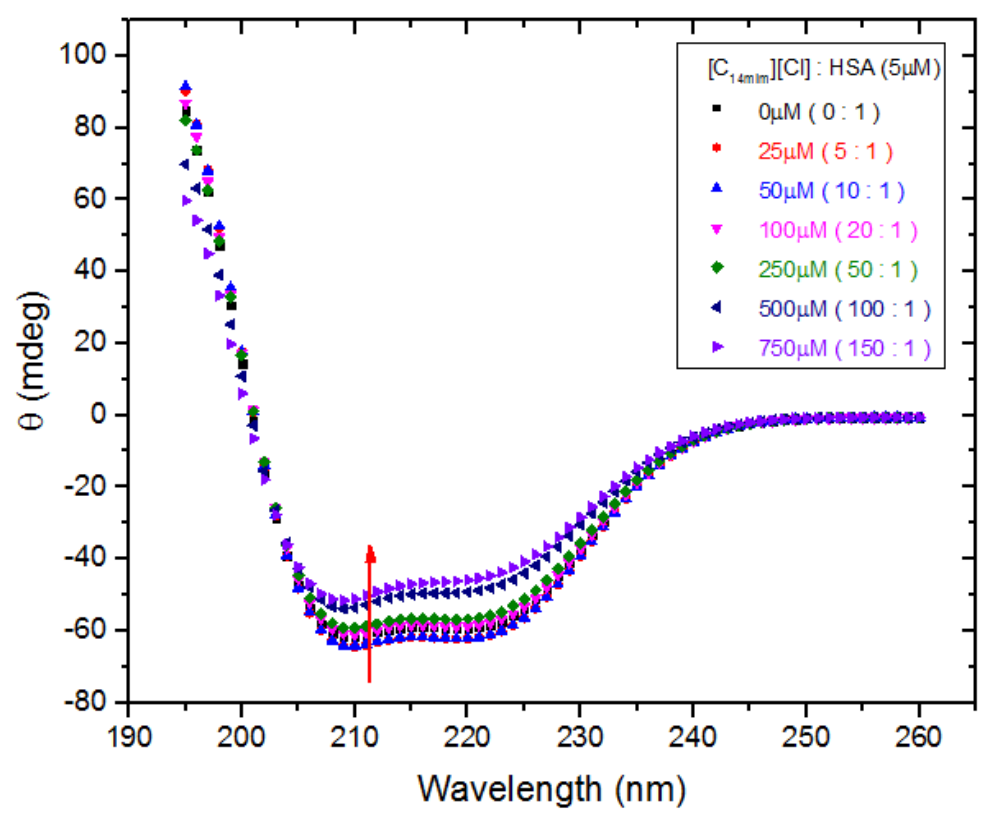

Figura 5.31: Espectro de CD para HSA $(5 \mu \mathrm{M})$ em ausência e em presença de variadas concentrações de $\left[\mathrm{C}_{14 \mathrm{mim}}\right][\mathrm{Cl}]$ descritas na legenda junto a razão molar. A seta vermelha indica a direção do deslocamento das curvas com o aumento da concentração de LI.

Podemos observar no espectro de CD da HSA que com o aumento da concentração de $\left[\mathrm{C}_{14 \mathrm{mim}}\right][\mathrm{Cl}]$ a o módulo de $\theta$ diminuí, análogo ao comportamento presente no sistema com BSA. Os vales característicos da estrutura secundária alfahélice posicionados a $208 \mathrm{~nm}$ e $222 \mathrm{~nm}$ tornam-se menos pronunciados. Há uma diminuição em média de $20 \%$ do módulo de $\theta$ em $208 \mathrm{~nm}$ e $222 \mathrm{~nm}$ para $750 \mu \mathrm{M}$ de $\left[\mathrm{C}_{14 \operatorname{mim}}\right][\mathrm{Cl}](150: 1)$, portanto assumiremos que há uma perda parcial da estrutura secundária da proteína HSA em presença de $\left[\mathrm{C}_{14 \mathrm{mim}}\right][\mathrm{Cl}]$.

A interação entre HSA e o surfactante catiônico CPC (cloreto de cetilpiridina) foi explicada por Abdol-Khalegh [45] através de uma ligação inicial, a baixas concentrações de CPC, por atração eletrostática em sítios de carga oposta na superfície da HSA induzindo o desenovelamento da proteína expondo sítios hidrofóbicos para ligações com o surfactante a maiores concentrações. Explicação cabível ao sistema do presente trabalho pela semelhança dos efeitos observados e entre $\mathrm{CPC}$ e $\left[\mathrm{C}_{14 \mathrm{mim}}\right][\mathrm{Cl}]$. 


\subsection{Albumina de Soro Humana e $\left[\mathrm{C}_{1 \mathrm{xmim}}\right][\mathrm{Cl}]$}

Como descrito anteriormente, as alterações que os líquidos iônicos provocam em cada proteína têm semelhanças, variando somente em intensidade e amplitude de acordo com o tamanho da cadeia carbônica do LI. Portanto embora as discussões referentes a interação da $\mathrm{HSA}$ com $\left[\mathrm{C}_{12 \mathrm{mim}}\right][\mathrm{Cl}]$ e $\left[\mathrm{C}_{10 \mathrm{mim}}\right][\mathrm{Cl}]$ ainda possam ser apreciadas ao longo da dissertação, essencialmente de forma comparativa, os gráficos estarão disponíveis somente no apêndice.

O espectro de absorbância da HSA a $60 \mu \mathrm{M}$ foi monitorado na ausência e presença de crescentes concentrações de LI, até $1200 \mu \mathrm{M}(20: 1)$ de $\left[\mathrm{C}_{12 \mathrm{mim}}\right][\mathrm{Cl}]$ (Figura A. 19) e até $1800 \mu \mathrm{M}(30: 1)$ de $\left[\mathrm{C}_{10 \mathrm{mim}}\right][\mathrm{Cl}]$ (Figura A. 25), concentrações maiores não foram possíveis pois a aparência das amostras mudavam bruscamente, passando a um aspecto leitoso, evidenciando uma alta agregação do sistema.

Não é possível notar qualquer alteração no espectro de absorbância da HSA em presença de qualquer um dos dois LIs. Os valores da absorbância em 295nm não variam conforme o aumento da concentração de $\left[\mathrm{C}_{12 \mathrm{mim}}\right][\mathrm{Cl}]$ ou de $\left[\mathrm{C}_{10 \operatorname{mim}}\right][\mathrm{Cl}]$, todos são compatíveis, o mesmo ocorre com a turbidez destes sistemas (Figura A. 20 e Figura A. 26).

Os espectros de fluorescência da HSA mostram que a intensidade de fluorescência diminui e as curvas são deslocadas para menores comprimentos de onda com o aumento da concentração de $\mathrm{LI}$, tanto para $\left[\mathrm{C}_{12 \mathrm{mim}}\right][\mathrm{Cl}]$ quanto para $\left[\mathrm{C}_{10 \mathrm{mim}}\right][\mathrm{Cl}]$ Figura A. 21 e Figura A. 27). A impossibilidade de realizar as medidas espectroscópicas da HSA para maiores concentração de LI, devido a sua grande turbidez, impediu a identificação dos dois patamares, tanto para a integral da intensidade de fluorescência quanto para o deslocamento do pico de fluorescência, portanto a função de Boltzman 
não pôde ser ajustada. Objetivando não perder um fator de comparação, ao invés de listar o ponto de inflexão da função ajustada relacionaremos o deslocamento causado por uma concentração de LI presente nos três sistemas, no caso de $0 \mu \mathrm{M}$ a $600 \mu \mathrm{M}$ de LI. Tal deslocamento e a supressão relativa definida anteriormente podem ser apreciados na Tabela 5.2. Tabela 5.2: Supressão relativa e deslocamento do pico de fluorescência da HSA para $\left[\mathrm{C}_{14 \text { mim }}\right][\mathrm{Cl}],\left[\mathrm{C}_{12 \mathrm{mim}}\right][\mathrm{Cl}]$ e
$\left[\mathrm{C}_{10 \mathrm{mim}}\right][\mathrm{Cl}]$.

\begin{tabular}{|l|c|c|}
\hline $\begin{array}{l}\mathrm{HSA} \\
60 \mu \mathrm{M}\end{array}$ & $\begin{array}{c}S_{0-0.6 \mathrm{mM}}[\%] \\
{\left[\mathrm{C}_{14 \mathrm{mim}}\right][\mathrm{Cl}]}\end{array}$ & $\begin{array}{c}\Delta \lambda \text { entre } 0 \mu \mathrm{M}(0: 1) \text { e } 600 \mu \mathrm{M}(10: 1) \mathrm{de} \text { LI } \\
{[\mathrm{nm}]}\end{array}$ \\
\hline$\left[\mathrm{C}_{12 \mathrm{mim}}\right][\mathrm{Cl}]$ & $16.1 \pm 0.8$ & $11 \pm 1$ \\
\hline$\left[\mathrm{C}_{10 \mathrm{mim}}\right][\mathrm{Cl}]$ & $13.2 \pm 0.7$ & $8 \pm 1$ \\
\hline
\end{tabular}

Note que, como nos casos anteriores, quanto maior o tamanho da cadeia carbônica maior é a interação entre a HSA e o LI, evidenciando a importância do efeito hidrofóbico nestes sistemas. É interessante observar também que tanto a supressão quanto o blue-shift foram em menor escala se comparados aos observados para a BSA, tal fato é esperado, pois a HSA possui somente um triptofano e este está menos acessível às moléculas de LI.

Os espectros de CD da proteína HSA em presença e em ausência dos líquidos iônicos $\left[\mathrm{C}_{12 \mathrm{mim}}\right][\mathrm{Cl}]$ e $\left[\mathrm{C}_{10 \mathrm{mim}}\right][\mathrm{Cl}]$ não apresentaram mudanças significativos, portanto iremos supor que para tais LIs não há perda significativa da estrutura secundária da proteína.

A estrutura da BSA e da HSA são semelhantes, assim como os efeitos observados, portanto, manteremos o modelo de interação da HSA com os líquidos iônicos composto por três estágios. Onde o primeiro estágio é predominantemente composto pela proteína 
em sua forma nativa e a interação desta com os LI se dá, inicialmente, devido às forças eletrostáticas entre a carga superficial da proteína e a cabeça polar dos LIs. Após a aproximação dos LIs, no segundo estágio, a proteína sofre um desenovelamento e possibilita a formação de ligações de hidrogênio e maior interação entre sítios hidrofóbicos da HSA e as cadeias carbônicas LI. Neste estágio há a formação de estruturas tipo micelas, possivelmente compatível com o modelo colar-de-pérola. $\mathrm{O}$ terceiro estágio, onde ocorre a estabilização dos parâmetros e esgotamento da interação, não pode ser bem observado para a HSA.

\subsection{Lisozima e $\left[\mathrm{C}_{14 \mathrm{mim}}\right][\mathrm{Cl}]$}

Embora a lisozima possua seis triptofanos sua intensidade de fluorescência é baixa, assim a concentração de trabalho escolhida é $60 \mu \mathrm{M}$. O monitoramento foi realizado à concentração constante de proteína e aumentando, a partir de zero, a concentração de $\left[\mathrm{C}_{14 \operatorname{mim}}\right][\mathrm{Cl}]$, como pode ser contemplado na Figura 5.32.

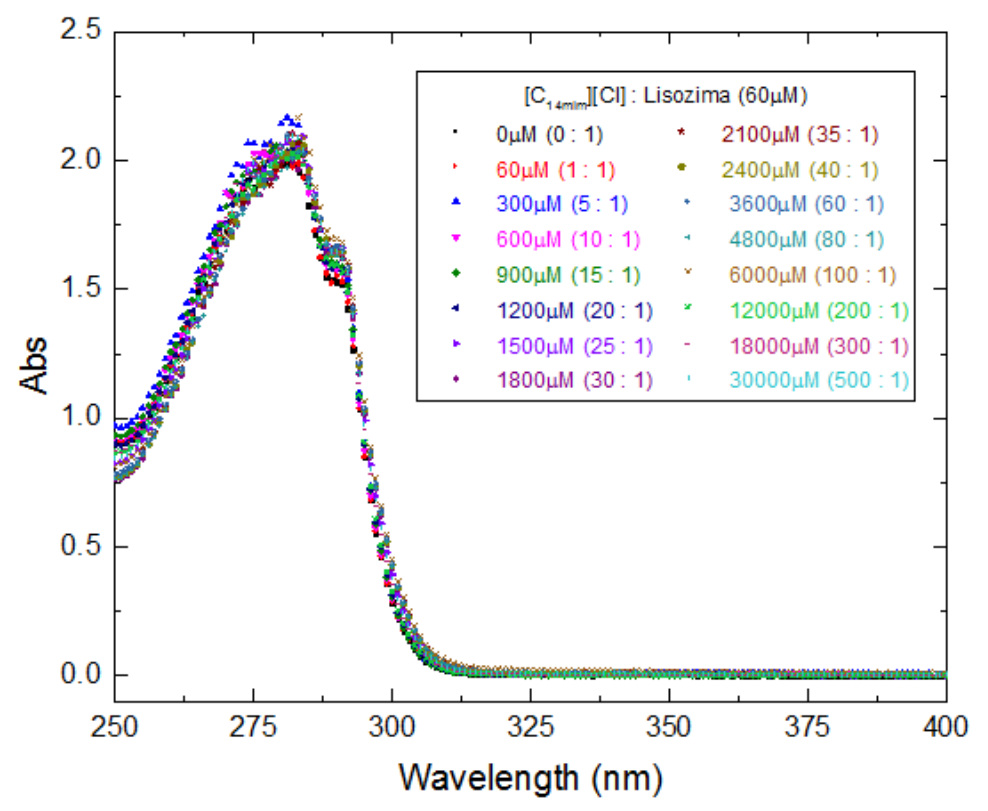

Figura 5.32: Espectro de absorbância da lisozima a $60 \mu \mathrm{M}$ em presença de variadas concentrações de $\left[\mathrm{C}_{14 \text { mim }}\right][\mathrm{Cl}]$ descritas na legenda junto a razão molar. A absorbância do tampão e da cubeta foram subtraídas das curvas. 
O espectro de absorbância da lisozima pouco se altera com a presença de $\left[\mathrm{C}_{14 \mathrm{mim}}\right][\mathrm{Cl}]$. As mudanças nos valores de absorbância em 295nm, comprimento de onda selecionado para a excitação da lisozima, podem ser observadas na Figura 5.33A assim como a turbidez do sistema na Figura 5.33B.

(A)

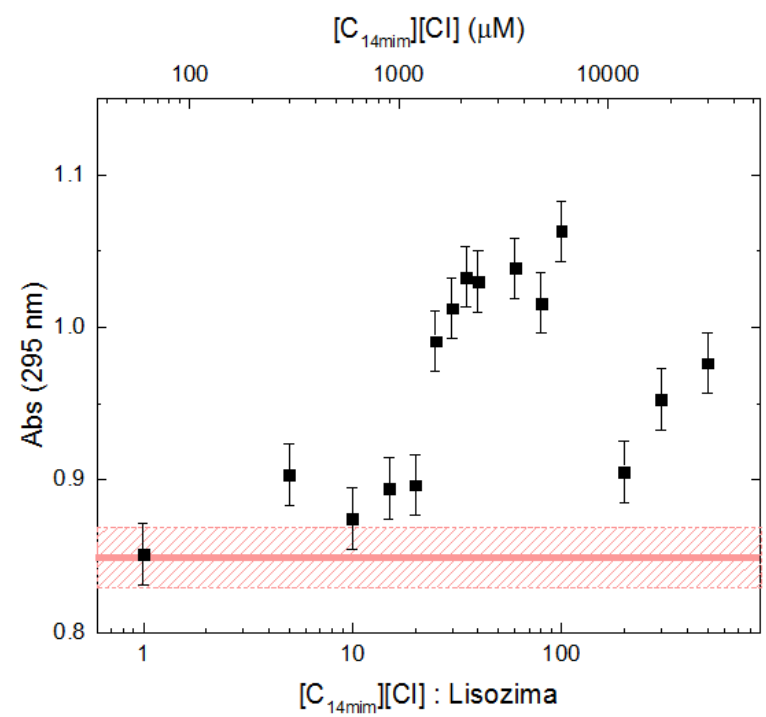

(B)

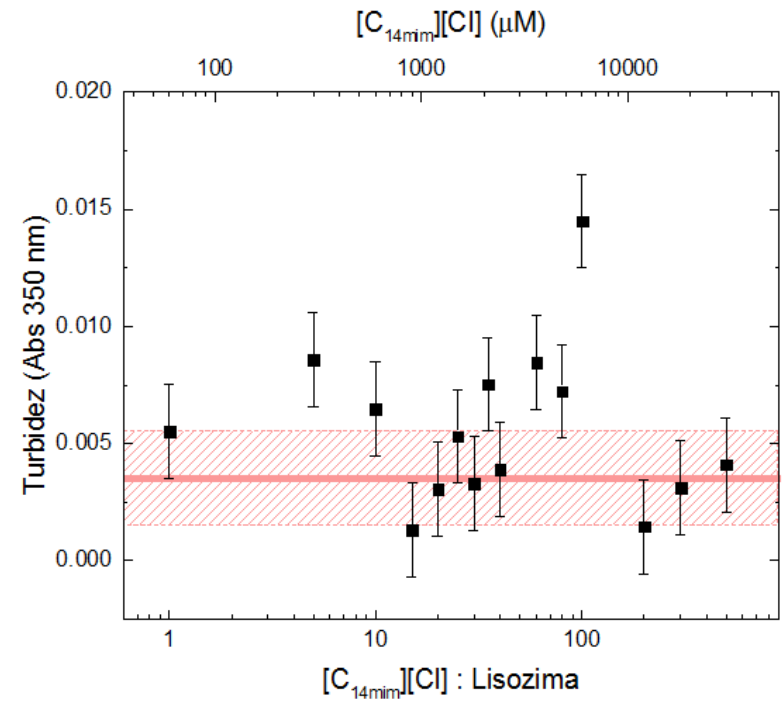

Figura 5.33: Absorbância em 295nm (A) e turbidez (B) da lisozima a 60 $\mu \mathrm{M}$ em função da concentração de $\left[\mathrm{C}_{14 \mathrm{mim}}\right][\mathrm{Cl}]$ (escala superior) e razão molar (escala inferior), ambas logarítmicas. A faixa vermelha preenchida e listrada correspondem a HSA em ausência de LI e incerteza, respectivamente.

É possível observar que a absorbância da lisozima em 295nm é aproximadamente constante até $1200 \mu \mathrm{M}(20: 1)$ de $\left[\mathrm{C}_{14 \mathrm{mim}}\right][\mathrm{Cl}]$, passa a crescer até $6000 \mu \mathrm{M}(100: 1)$ onde diminui. Já na turbidez, embora variem, os valores são compatíveis dentro do intervalo de três incertezas, indicando uma solução límpida sem a formação de grandes agregados. A alteração da absorbância em $295 \mathrm{~nm}$ sem uma respectiva mudança na turbidez sugere a formação de complexo que modifica o estado fundamental do fluoróforo. [9] 
Os espectros de fluorescência da lisozima a $60 \mu \mathrm{M}$ em presença de crescentes concentrações de $\left[\mathrm{C}_{14 \mathrm{mim}}\right][\mathrm{Cl}]$, utilizando as mesmas amostras do experimento de absorbância podem ser apreciados na Figura 5.34.

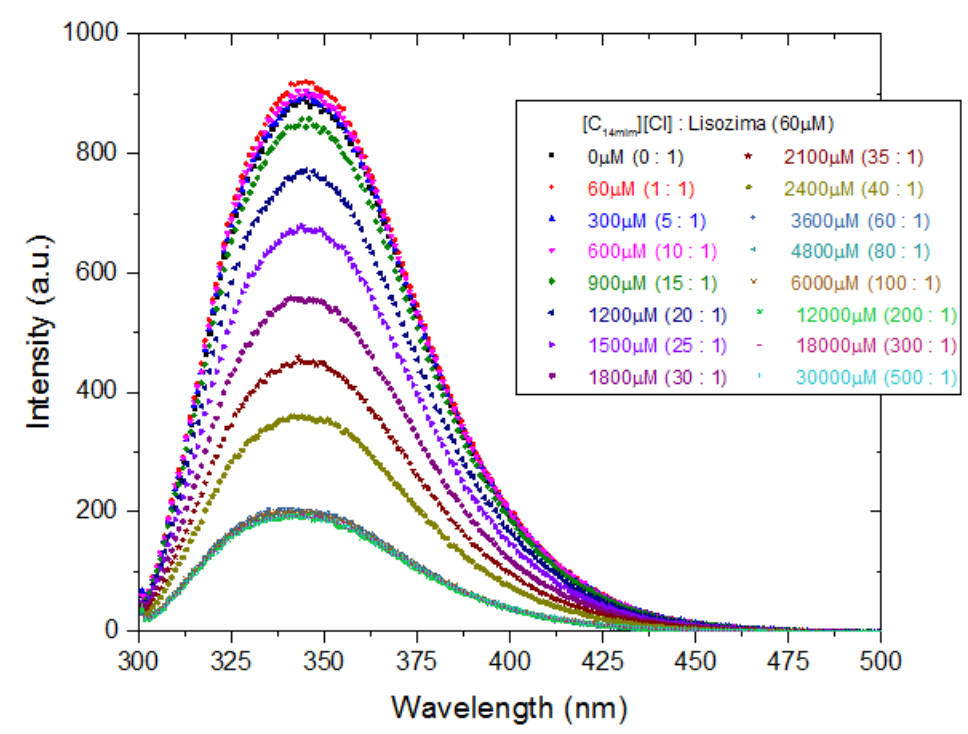

Figura 5.34: Espectro de fluorescência da lisozima a $60 \mu \mathrm{M}$ em presença de variadas concentrações de $\left[\mathrm{C}_{14 \mathrm{mim}}\right][\mathrm{Cl}]$ descritas na legenda junto a razão molar. Espectros com correção de filtro interno.

O espectro de fluorescência da lisozima nos traz uma novidade, claramente a intensidade continua a diminuir conforme o aumento da concentração de $\left[\mathrm{C}_{14 \mathrm{mim}}\right][\mathrm{Cl}]$, porém não há deslocamento do pico de fluorescência como visto nos casos anteriores. Na Figura 5.35, a intensidade de fluorescência normalizada sustenta que, além da forma da curva não mudar, o deslocamento não é significativo como nos casos anteriores. 


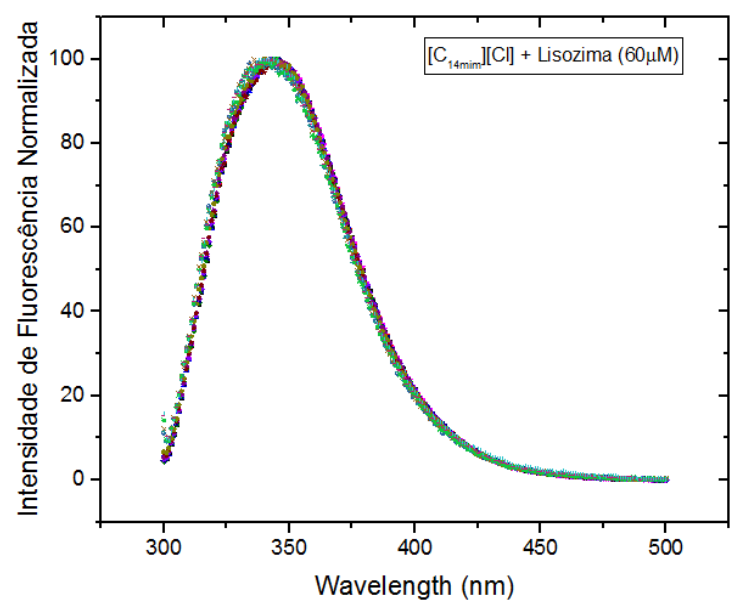

Figura 5.35: Espectro de fluorescência normalizado pelo pico do sistema lisozima $+\left[\mathrm{C}_{14 \mathrm{mim}}\right][\mathrm{Cl}]$.

Maurya e colaboradores [9] investigaram a interação da lisozima com o líquido iônico catiônico de cadeia dupla $\left[\mathrm{C}_{12}-4-\mathrm{C}_{12 \mathrm{im}}\right]\left[\mathrm{Br}_{2}\right]$, onde observara, o mesmo comportamento, supressão da fluorescência sem o deslocamento do pico de fluorescência.

A quantificação da supressão será possibilitada pela integral da intensidade de fluorescência, disponível na Figura 5.36

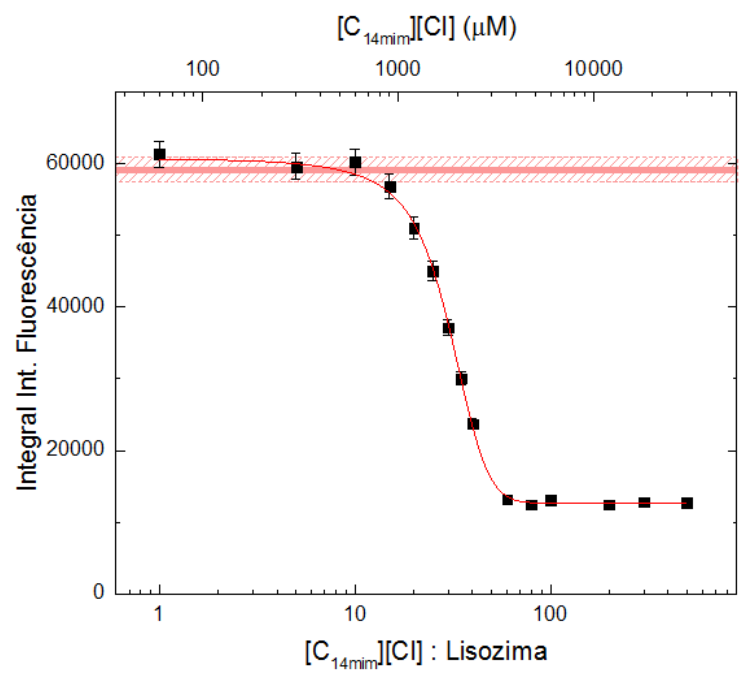

Figura 5.36: Integral da intensidade de fluorescência (de $300 \mathrm{~nm}$ a $500 \mathrm{~nm}$ ) da lisozima a $60 \mu \mathrm{M}$ em função da concentração de $\left[\mathrm{C}_{14 \mathrm{mim}}\right][\mathrm{Cl}]$ (escala superior) e razão molar (escala inferior), ambas logarítmicas. A faixa vermelha preenchida e listrada correspondem ao triptofano em ausência de LI e incerteza, respectivamente. A linha vermelha é o ajuste utilizando a função de Boltzmann. 
Observe que a integral da intensidade de fluorescência permanece constante até $600 \mu \mathrm{M}(10: 1)$ de $\left[\mathrm{C}_{14 \mathrm{mim}}\right][\mathrm{Cl}]$, diminui bruscamente até $3600 \mu \mathrm{M}(60: 1)$ de $\left[\mathrm{C}_{14 \mathrm{mim}}\right][\mathrm{Cl}]$ onde volta a ser constante. Suporemos que há uma concentração mínima de LI para que haja a supressão, ou uma interação de contato, e esta é saturada após um segundo limite. Tal perfil sugere um sistema de dois estados, no qual é possível ajustar a função de Boltamann. O ponto de inflexão encontrado é igual $(1.80 \pm 0.02) \mathrm{mM}$ de $\left[\mathrm{C}_{14 \mathrm{mim}}\right][\mathrm{Cl}]$ ou razão molar (30.3 \pm 0.4$)$.

A Figura 5.37 mostra as curvas de SAXS, do atual sistema, deslocadas para possibilitar melhor visualização. A concentração de lisozima utilizada neste experimento é igual a $280 \mu \mathrm{M}$, muito superior às utilizadas anteriormente, pois houve a necessidade de melhorar a relação sinal/ruído dos dados.

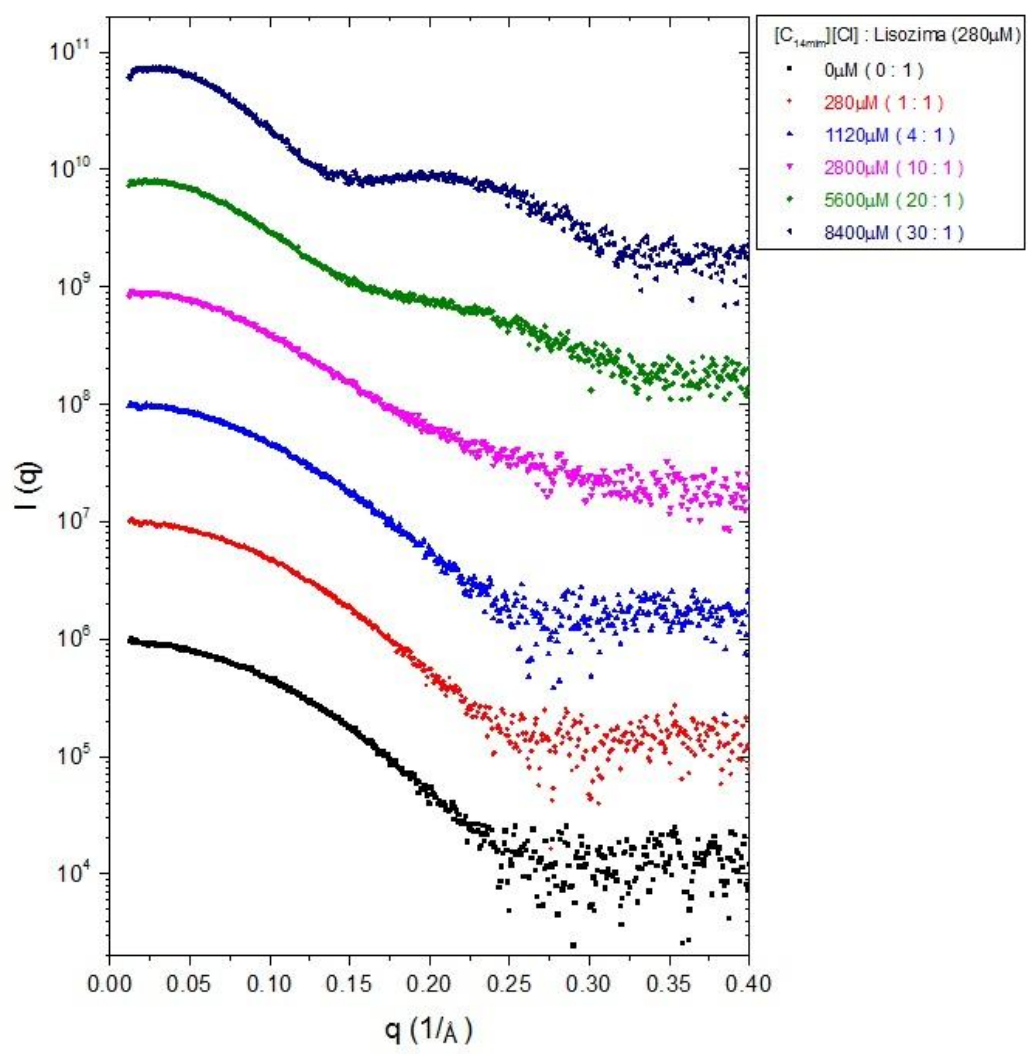

Figura 5.37: Curvas de SAXS obtidas para o sistema lisozima a $60 \mu \mathrm{M}$ e variadas concentrações de $\left[\mathrm{C}_{14 \operatorname{mim}}\right][\mathrm{Cl}]$ descritas na legenda junto a razão molar. As curvas estão deslocadas na vertical para melhor visualização. 
Note que há a formação de um segundo pico entre $q=0.2 \AA^{-1}$ e $q=0.25 \AA^{-1} \mathrm{a}$ partir de 5.6mM (20:1) de $\left[\mathrm{C}_{14 \mathrm{mim}}\right][\mathrm{Cl}]$, concentração a cima da $\mathrm{CMC}$, indicando a formação de micelas de LI. A Figura 5.38 traz os valores do raio de giro obtidos através da aproximação de Guinier utilizando as curvas de SAXS anterior.

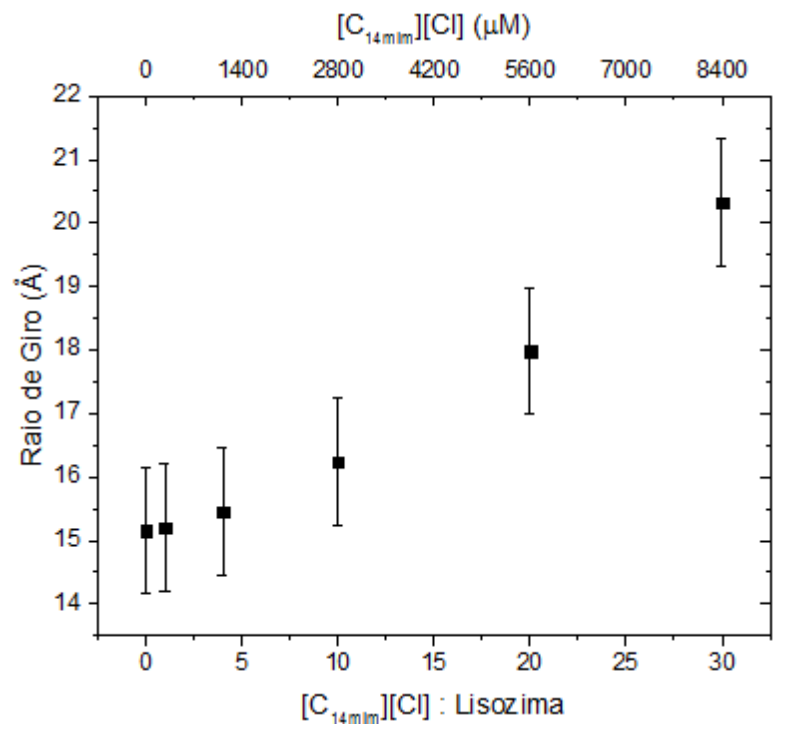

Figura 5.38: Raio de giro da lisozima a $60 \mu \mathrm{M}$ em função da concentração de $\left[\mathrm{C}_{14 \mathrm{mim}}\right][\mathrm{Cl}]$ (escala superior) e razão molar (escala inferior), ambas logarítmicas.

Embora os valores sejam compatíveis entre si, há um indício do aumento do raio de giro conforme o aumento da concentração de $\left[\mathrm{C}_{14 \operatorname{mim}}\right][\mathrm{Cl}]$. Em ausência de LI a lisozima possui $R_{g}=(15 \pm 1) \AA$, compatível com $17.3 \AA$ da literatura [47] e em presença $8.4 \mathrm{mM}(30: 1)$ de $\left[\mathrm{C}_{14 \mathrm{mim}}\right][\mathrm{Cl}] R_{g}=(20 \pm 1) \AA$.

Huang e colaboradores [47] caracterizaram o efeito da temperatura no desenovelamento da lisozima através da técnica de SAXS, obtiveram para a proteína em seu estado nativo, a $303 \mathrm{~K}$, raio de giro igual a $17.3 \AA$ e em seu estado desenovelado 27.6 $\AA$. Observe que o LI $\left[\mathrm{C}_{14 \mathrm{mim}}\right][\mathrm{Cl}]$ não possui um alto poder de desnaturante da lisozima, diferente do discutido para a BSA e HSA. 
O gráfico proveniente da análise de Kratky das curvas de SAXS está disponível na Figura 5.39.

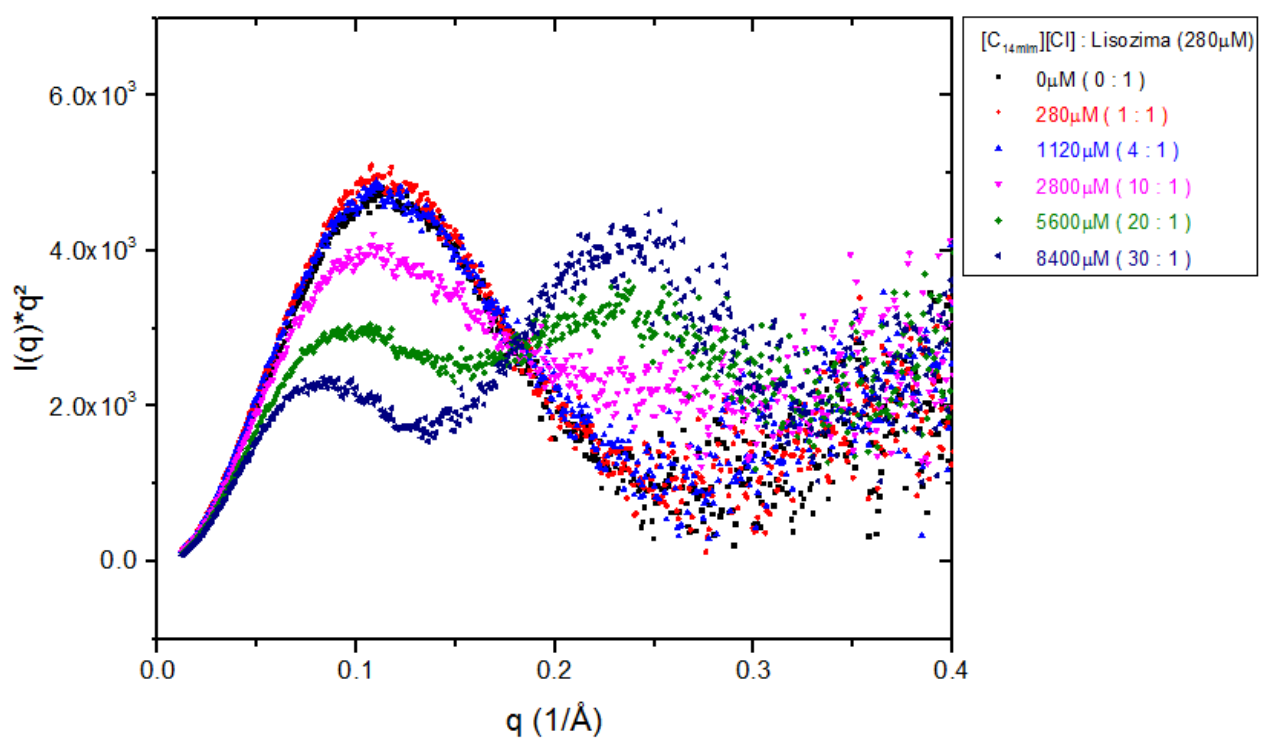

Figura 5.39: Curvas de Kratky obtidas para o sistema lisozima a $60 \mu \mathrm{M}$ e variadas concentrações de $\left[\mathrm{C}_{14 \mathrm{mim}}\right][\mathrm{Cl}]$ descritas na legenda junto a razão molar.

Por meio do gráfico de Kratky fica evidente o aumento do raio de giro da lisozima, através do deslocamento do primeiro pico para valores menores de $q$ com o aumento da concentração de $\left[\mathrm{C}_{14 \mathrm{mim}}\right][\mathrm{Cl}]$. O aparecimento de um segundo pico em q em torno de $0.23 \AA^{-1}$ caracteriza a formação de uma segunda estrutura, potencialmente micelar.

\subsection{Lisozima e $\left[\mathrm{C}_{1 \times \mathrm{xmim}}\right][\mathrm{Cl}]$}

As alterações que os líquidos iônicos provocam em cada proteína têm semelhanças, inclusive com a lisozima, variando somente em intensidade e amplitude de acordo com o tamanho da cadeia carbônica do LI. Portanto embora as discussões referentes à interação da lisozima com $\left[\mathrm{C}_{12 \mathrm{mim}}\right][\mathrm{Cl}]$ e $\left[\mathrm{C}_{10 \mathrm{mim}}\right][\mathrm{Cl}]$ ainda possam ser 
apreciadas ao longo da dissertação, essencialmente de forma comparativa, os gráficos estarão disponíveis somente no apêndice.

A forma do espectro de absorbância da lisozima a $60 \mu \mathrm{M}$ tanto para $\left[\mathrm{C}_{12 \mathrm{mim}}\right][\mathrm{Cl}]$ quanto $\left[\mathrm{C}_{10 \mathrm{mim}}\right][\mathrm{Cl}]$ não se altera com o aumento da concentração de LI. Os valores de turbidez para $\left[\mathrm{C}_{12 \mathrm{mim}}\right][\mathrm{Cl}]$ embora variem são compatíveis entre si. A absorbância em 295nm apresenta pouca variação até a razão molar 100:1 seguida de aumento até 600:1 de $\left[\mathrm{C}_{12 \mathrm{mim}}\right][\mathrm{Cl}]$. Já a turbidez da lisozima em presença de $\left[\mathrm{C}_{10 \mathrm{mim}}\right][\mathrm{Cl}]$ apresenta um aumento significativo a partir da razão molar 40:1 e a absorbância em 295nm possui aumento aproximadamente linear tornando-se significativo a partir de 100:1.

Os espectros de fluorescência da lisozima mostram que a intensidade de fluorescência diminui tanto para $\left[\mathrm{C}_{12 \mathrm{mim}}\right][\mathrm{Cl}]$ quanto para $\left[\mathrm{C}_{10 \mathrm{mim}}\right][\mathrm{Cl}]$, sem $\mathrm{o}$ deslocamento do pico. Foi possível ajustar a função de Boltzman para as intensidades integradas de fluorescência, valores de razão molar correspondente ao ponto inflexão $\left(x_{0}^{\prime}\right)$ e a supressão relativa podem ser apreciados na Tabela 5.3: Tabela 5.3: Supressão relativa e deslocamento do pico de fluorescência da HSA para $\left[\mathrm{C}_{14 \mathrm{mim}}\right][\mathrm{Cl}],\left[\mathrm{C}_{12 \mathrm{mim}}\right][\mathrm{Cl}]$ e
$\left[\mathrm{C}_{10 \mathrm{mim}}\right][\mathrm{Cl}]$.

\begin{tabular}{|l|c|c|c|}
\hline $\begin{array}{l}\text { Lisozima } \\
60 \mu \mathrm{M}\end{array}$ & $S_{0-0.6 \mathrm{mM}}[\%]$ & $S_{0-6 \mathrm{mM}}[\%]$ & $\begin{array}{c}x^{\prime}{ }_{0} \\
\text { (razão molar) }\end{array}$ \\
\hline$\left[\mathrm{C}_{14 \mathrm{mim}}\right][\mathrm{Cl}]$ & $4.1 \pm 0.2$ & $78 \pm 4$ & $(30.3 \pm 0.4): 1$ \\
\hline$\left[\mathrm{C}_{12 \mathrm{mim}}\right][\mathrm{Cl}]$ & $0.6 \pm 0.1$ & $14.4 \pm 0.7$ & $(135 \pm 1): 1$ \\
\hline$\left[\mathrm{C}_{10 \mathrm{mim}}\right][\mathrm{Cl}]$ & $0.0 \pm 0.1$ & $6.2 \pm 0.3$ & $(335 \pm 29): 1$ \\
\hline
\end{tabular}

Optamos pela supressão relativa entre 0 e $0.6 \mathrm{mM}$ de LI para comparação com outros sistemas proteicos e entre 0 e $6 \mathrm{mM}$ de LI para comparação do efeito de cada LI com a lisozima. Note que quanto menor é o tamanho da cadeia carbônica menor é a supressão relativa, observe também que quanto menor a cadeia carbônica menor é $x$ ', 
isto é, menor é a concentração de LI necessária para alcançar o ponto intermediário de estados. Portanto podemos afirmar que a lisozima sofre mudanças conformacionais sob influência dos LI, baseada na existência da supressão e aumento do raio de giro, e que o efeito hidrofóbico é um importante fator na interação entre a lisozima e os líquidos iônicos estudados, já que todos os fatores estudados têm maior intensidade quanto maior a cadeia carbônica.

Propomos, assim como para a BSA, que é possível identificar três momentos da interação entre a lisozima e os LIs. Em um primeiro momento a proteína está na sua forma nativa, a interação inicial ocorrerá por ação da força eletrostática, onde o LI se aproximará de sítios de ligação da proteína, como a lisozima em pH 7.3 possui a mesma carga que os LIs tal interação será mais fraca do que as observadas anteriormente. A aproximação do LI iniciará o desenovelamento da lisozima, expondo sítios hidrofóbicos e possibilitando ligações de hidrogênio e maior interação com as cadeias carbônicas dos LIs. Em um terceiro momento há a exaustão das ligações e formação de micelas de LIs. Modelo este também proposto por Jitendra Kumar Maurya [9] para lisozima e $\left[\mathrm{C}_{12}-4\right.$ $\left.\mathrm{C}_{12 \mathrm{im}}\right]\left[\mathrm{Br}_{2}\right]$. 


\section{Conclusões}

Durante esses últimos dois anos estudamos de maneira sistemática a influencia de três diferentes líquidos iônicos $\left(\left[\mathrm{C}_{14 \mathrm{mim}}\right][\mathrm{Cl}],\left[\mathrm{C}_{12 \mathrm{mim}}\right][\mathrm{Cl}]\right.$ e $\left.\left[\mathrm{C}_{10 \mathrm{mim}}\right][\mathrm{Cl}]\right)$ na estrutura e na conformação das proteínas modelo BSA, HSA e Lisozima. Ao longo deste texto, descrevemos de modo mais sucinto as interações do $\left(\left[\mathrm{C}_{14 \mathrm{mim}}\right][\mathrm{Cl}]\right.$ com as proteínas BSA e HSA, no entanto, o efeito causado pelos LIs foi observado na três proteínas estudadas, em diferentes proporções. O LI que resultou em maiores alterações conformacionais, nos três casos estudados, foi o $\left(\left[\mathrm{C}_{14 \mathrm{mim}}\right][\mathrm{Cl}]\right.$, indicando que a interação LI:proteína deve ser guiada por interações hidrofóbicas, ao menos majoritariamente. No entanto não podemos, ao menos com as medidas realizadas no presente estudo, descartar as contribuições de cunho eletrostático, uma vez que a carga catiônica dos LIs pode interagir com as regiões aniônicas presentes na superfície da proteína influenciando de modo significativo na interação total proteína-LI.

Com base nas medidas de fluorescência, acreditamos que as moléculas de LI se encontram nas proximidades dos resíduos de Trp para a BSA e a HSA, juntamente a este fato, temos uma pequena alteração na estrutura secundaria dessas (segundo as medidas de $\mathrm{CD}$ ), acompanhado por um aumento no raio de giro das proteínas. Esses fatos sugerem que a interação dos LI com as proteínas modelo é significativa, sendo capaz de alterar a estrutura das mesmas em diferentes níveis.

Além disso, propomos que a interação do LI com as proteínas, se dá em três diferentes regiões, sendo que no início, ocorre pouca alteração nos parâmetros conformacionais da proteína, já na região intermediária, a proteína começa a perder sua estrutura terciaria (evidenciada pelo aumento no valor do raio de giro) e parte da sua estrutura secundaria, ainda há uma provável formação de complexo entre a proteína e o 
cátion $\left[\mathrm{C}_{14} \mathrm{mim}\right]^{+}$. Na terceira e última etapa a interação é esgotada e há a formação de estruturas micelares de LI. Acreditamos que este trabalho fornece maiores informações sobre a interação proteína-LI e que considerar os LI como moléculas ativas na química verde deve ser tomada com cuidado, uma vez que ela é capaz de interagir e alterar a estrutura de sistemas de relevância biológica como mostrado ao longo deste trabalho, seu entendimento deve ser melhor explorado antes ainda da eventual utilização destas moléculas em larga escala. 


\section{Referências Bibliográficas}

[1] Sheldon, R.A., "Green solvents for sustainable organic synthesis: State of the arte.," Creen Chemistry, n. 7, pp. 267-278, 2005.

[2] Wei Sun, Ruifang Gao, and Kui Jiao, "Electrochemistry and Electrocatalysis of Hemoglobin in Nafion/nano-CaCO3 Film on a New lonic Liquid BPPF6 Modified Carbon Paste Electrode," J. Phys. Chem. B., vol. 111, n. 17, pp. 4560-4567, 2007.

[3] Tae Young Kim, Hyun Wook Lee et al., "High-Performance Supercapacitors Based on Poly(ionic liquid)-Modified Graphene Electrodes," ACS Nano, vol. 5, n. 1, pp. 436-442, 2011.

[4] Ventuea, S.P.M., Santos, L.D.F., Saraiva, J.A., and Coutinho, J.A.P., "Ionic liquids microemulsions: the key to Candida antarctica lipase B superactivity.," Green Chemistry, vol. 14, pp. 1620-1625, 2012.

[5] Kazlauskas, Seongsoon Park and Romas J, "Biocatalysis in ionic liquids - advantages beyond green," Current Opinion in Biotechnology, vol. 14, n. 4, pp. 432-437, 2003.

[6] Drummond, Tamar L. Greaves and Calum J., "Protic lonic Liquids: Properties and Application," Chem. Rev., vol. 108, n. 1, pp. 206-237, 2008.

[7] Soujiang Zhang, Ning Sun, Xuezhong He, Xingmei Lu, and Xianggping Zhang, "Physical Properties of Ionic Liquids: Database and Evaluation," J. Phys. Chem. Ref Data, vol. 35, n. 4, pp. 1475-1517, 2006.

[8] Westphal, G., Kristen, G., Wegener, W., Ambatiello, P., Geyer, H., Epron, B., Bonal, C., Steinhauser, G. and Götzfried, Ullmann's Encyclopedia of Industrial Chemistry, Wiley-VCH, 2010.

[9] Jitendra Kumar Maurya, Muzaffar UI Hassan Mir, Upendra Kumar Singh, Neha Maurya, "Molecular Investigation of the Interaction between Ionic Liquid Type Gemini Surfactant and Lysozyme: A Spectroscopic and Computational Approach," Biopolymers., vol. 103, n. 7, pp. 406-415, 2015.

[10] Daibin Kuang, Torsten Brezesinski, and Bernd Smarsly, "Hierarchical Porous Silica Materials with a Trimodal Pore System Using Surfactant Templates," J. Am. Chem. Soc., vol. 126, n. 34, p. 10534-10535, 2004.

[11] Devlin, Thomas M., Manual de Bioquímica com correlações clínicas, São Paulo: Blucher, 2011. 
[12] Donald Voet, Judith G. Voet, Charlotte W. Pratt, Fundamentos de Bioquímica, Porto Alegre: Artes Médicas Sul Ltda., 2000.

[13] Jr., Theodore Peters, All about Albumin. Biochemistry, Genetics, and Medical Applications, San Diego: Academic Press, Inc., 1996.

[14] Daltin, Decio, Tensoativos: Química, propriedades e aplicações., São Paulo: Blucher, 2011.

[15] Hans-Jürgen Butt, Karlheinz Graf, Michael Kappl, Physics and Chemistry of Interfaces, Willey, 2006.

[16] Igor N. Serdyuk, Nathan R. Zaccai and Joseph Zaccai, Methods in Molecular Biophysics, New York: Cambridge University Press, 2007.

[17] Lakowicz, Joseph R., Principles of Fluorescence Spectroscopy, New York: Kluwer Academic, 1999.

[18] M. Sauer, J. Hofkens and J. Enderlein, Handbook of Fluorescence Spectroscopy and Imaging, Weinheim: WILEY-VCH Verlag GmbH \& Co. KGaA, 2011.

[19] Permyakov, E. A., Luminescent Spectroscopy of Proteins, Boca Raton: CRC Press, 1993.

[20] Chung, Amar B. T. Ghisaidoobe and Sang J., "Intrinsic Tryptophan Fluorescence in the Detection and Analysis of Protein: A Focus on Förster Resonance Enerfy Tranfer Techniques," Int. J. Mol Sct., n. 15, pp. 22518-22538, 2014.

[21] Chen, Raymond F., "Florescence quantum yields of tryptophan and tyrosine," Analytical Letters, vol. 1, n. 1, pp. 35-42, 1967.

[22] Albani, J., "Origin of tryptophan fluorescence lifetimes part 1. Fluorescence lifetimes origin of tryptophan free in solution.," J. Fluoresc., vol. 24, pp. 93-104, 2014.

[23] Albani, J., "Origin of tryptophan fluorescence lifetimes part 2. Fluorescence lifetimes origin of tryptophan free in proteins.," J. Fluoresc., vol. 24, pp. 105-117, 2014.

[24] Ana Mendonça, Ana C. Rocha, Armando C. Duarte, Eduarda B. H. Santos, "The inner filter and their correction in fluorescence spectra of salt marsh humic matter," Analytica Chimica Acta, n. 788, pp. 99-107, 2013.

[25] Fasman, Gerald D., Circular Dichroism and the Conformational Analysis of Biomolecules, New York: Plenum Press, 1996.

[26] Sharon M. Kelly, Thomas J. Jess, Nicholas C. Price, "How to study proteins by circular dichroism," Biochimica et Biophysian Acta, vol. 1751, pp. 119-139, 2005.

[27] Dmitri I. Svergun, Michel H. J. Koch, Peter A. Timmins, Peter A. Timmins, Roland P. May, Small Angle X-Ray and Neutron Scattering from Solutions of Biological Macromolecules, 
Oxford: Oxford University Press, 2013.

[28] Stribeck, N., X-Ray Scattering of Soft Matter, Berlin: Springer-Verlag Berlin Heidelberg, 2007.

[29] Haydyn D.T. Mertens, Dmitri I. Svergun, "Structural characterization of proteins and complexes using small-angle X-ray solution scattering," Journal of Structural Biology, vol. 172, pp. 128-141, 2010.

[30] Morelhão, Sérgio L., Fundamentos da Física de Raios-X, São Paulo: Edgar Blücher Ltda., 2014.

[31] Piñeiro, Juan M. Ruso and Ángel, Protein in Solution and at Interfaces: Methods and Applications in Biotechnology and Materials Science., Wiley-Blackwell, 2013.

[32] Zsombor Miskolczy, Krisztina Sebök-Nagy, "Aggregation and micelle formation of ionic liquids in aqueous solution," Chemical Physics Letters, vol. 400, 2004.

[33] Justyna Luczak, Jan Hupka, Jorg Thöming, Christian Jungnickel, "Self-organization of imidazolium ionic liquids in aqueous solution," Colloids and Surfaces A: Physicochem. Eng. Aspects, vol. 329, pp. 125-133, 2008.

[34] Hanns-Christian Mahler, Wolfgang Friess, Ulla Grauschopf, Sylvia Hiese, "Protein Aggregation: Pathways, Induction Factors and Analysis," J Pharm Sci, vol. 9, n. 98, pp. 29009-34, 2009.

[35] Cross, John, Anionic Surfactants, New York: Marcel Dekker, Inc., 1998.

[36] T. L. Bushueva, E. P. Busel, and E. A. Burstein, "Some Regularities of Dynamic Accessibility of Buried Fluorescent Risidues to External Quenchers in Protein.," Archives of Biochemistry and Biophysics, vol. 204, n. 1, pp. 161-166, 1980.

[37] Hanns-Christian Mahler, Robert Müller, Wolfgang Frie, Aurelie Delille, Susanne Matheus, "Induction and analysis og aggregates in a liquid IgG1-antibody formulation," European Journal and Biopharmaceutics, n. 59, pp. 407-417, 2005.

[38] E.L. Gelamo, C.H.T.P. Silva, H. Imasato, M. Tabak, "Interaction of bovine (BSA) and human (HSA) serum albumins with ionic surfactants: spectroscopy and modelling.," Biochimica et Biophysica Acta, vol. 1594, pp. 84-99, 2002.

[39] Fei Geng, Liqiang Zheng, Li Yu, Ganzuo Li, Chenho Tung, "Interaction of bovine serum albumin and long-chain imidazalium ionic liquid measured by fluorescence spectra ans surface tension.," Process Biochemistry, n. 45, pp. 306-311, 2010.

[40] Somanth Dasmandal, Arjama Kundu, SUparna Rudra and Ambikesh Mahapatra, "Binding interaction of an anionic amino acid surfactant with bovine serum albumin: physicochemical and spectroscopic investigations combined with docking study.," RSC 
Adv., vol. 5, pp. 79107-79118, 2015.

[41] Anurag Sharma, Pratibha K., Shashank Deep, "Characterization of different conformations of bovine serum albumin and their propensity to aggregate in the presence of $\mathrm{N}$-cetyl$\mathrm{N}, \mathrm{N}, \mathrm{N}$-trimethyl ammonium bromide," Journal of Colloid and Interface Science, vol. 343, pp. 454-462, 2010.

[42] Sonia F. Santos, Dino Zanette, Hannes Fischer and Rosangela Itri, "A systematic study of bovine serum albumin (BSA) and sodium dodecyl sulfate (SDS) interactions by surface tension and small angle X-ray scattering," Journal of Colloid and Interface Science, vol. 262, pp. 400-408, 2003.

[43] Rosangela Itri, Wilker Caetano, Leandro R. S. Barbosa, and Mauricio S. Baptista, "Effect of Urea on Bovine Serum Albumin in Aqueous and Reverse Micelle Environments Investigated by Small Angle X-Ray Scattering, Fluorescence and Circular Dichroism," Brazilian Journal of Physics, vol. 34, pp. 58-63, 2004.

[44] Pozzo, Mónica Ospinal-Jiménez and Danilo C., "Structural Analysis of Protein Complexes with Sodium Alkyl Sulfates by Small-Angle Scattering and Polyacrylamide Gel Electrophoresis," Langmui, vol. 27, n. 3, pp. 928-935, 2011.

[45] Abdol-Khalegh Bordbar, Asghar Taheri-Kafrani, "Binding and fluorescence study on interaction of human serum albumin (HSA) with cetylpyridinium chloride (CPC)," Colloids and Surfaces B: Biointerfaces, vol. 55, pp. 84-89, 2007.

[46] Meena Kumari a, Jitendra Kumar Maurya, Munazzah Tasleem, Prashant Singh, Rajan Patel, "Probing HSA-ionic liquid interactions by spectroscopic and molecular docking methods," Journal of Photochemistry and Photobiology B: Biology, vol. 138, pp. 27-34, 2014.

[47] Yu-Shan Huang, U-Ser Jeng, Ying-Jen Shiu,Ying-Huang Lai and Ya-Sen Suna, "Charge interaction and temperature effects on the solution structure of lysozyme as revealed by small-angle X-ray scattering," Journal of Applied Crystallography, vol. 40, pp. 165-169, 2007.

[48] W. F. U. G. S. K. Hanns-Christian Mahler, "Protein Aggregation: Pathways, Induction Factors and Analysis," Journal of Pharmaceutical Sciences, vol. 98, no. 9, pp. 2909-2934, 2009.

[49] Belatik A, Hotchandani S, Carpentier R, Tajmir-Riahi HA, "Locating the binding sites of $\mathrm{Pb}(\mathrm{II})$ ion with human and bovine serum albumins.," PLoS One, $\mathrm{p}$. doi:10.1371/journal.pone.0036723, 2012.

[50] Swati De, Agnishwar Girigoswami, Susmita Das, "Fluorescence probing of albuminsurfactant interaction," Journal of Colloid and Interface Science, n. 562-573, p. 285, 2005. 


\section{Apêndices}

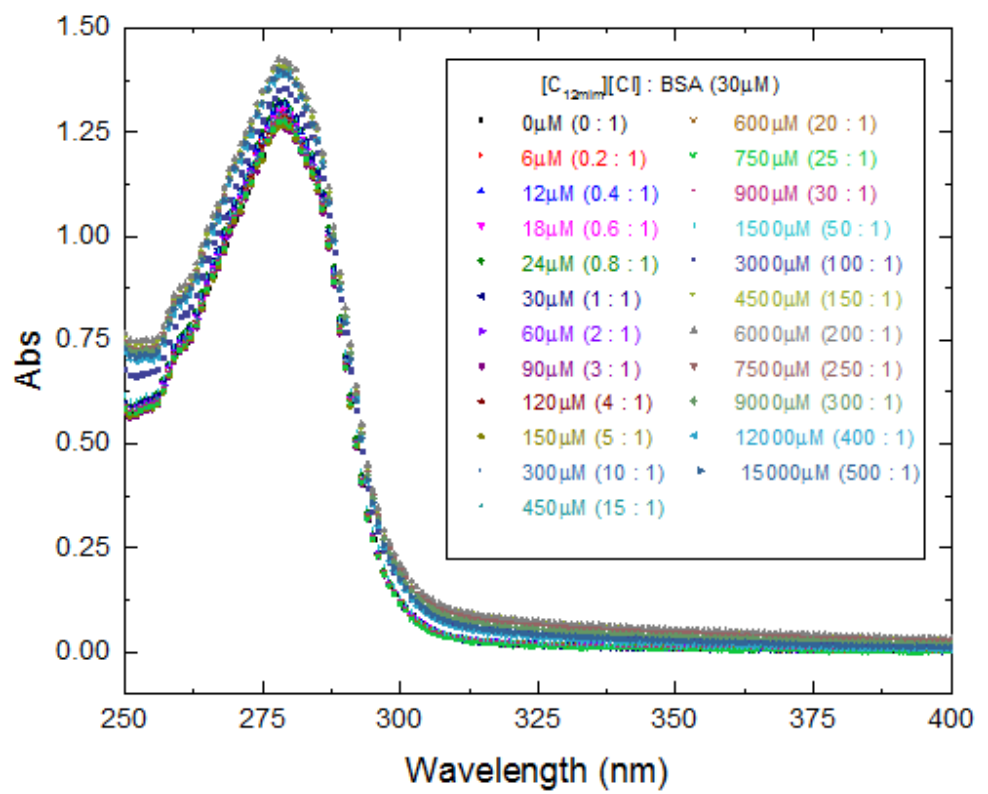

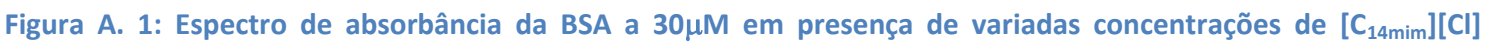
descritas na legenda junto a razão molar. A absorbância do tampão e da cubeta foram subtraídas das curvas.

(A)

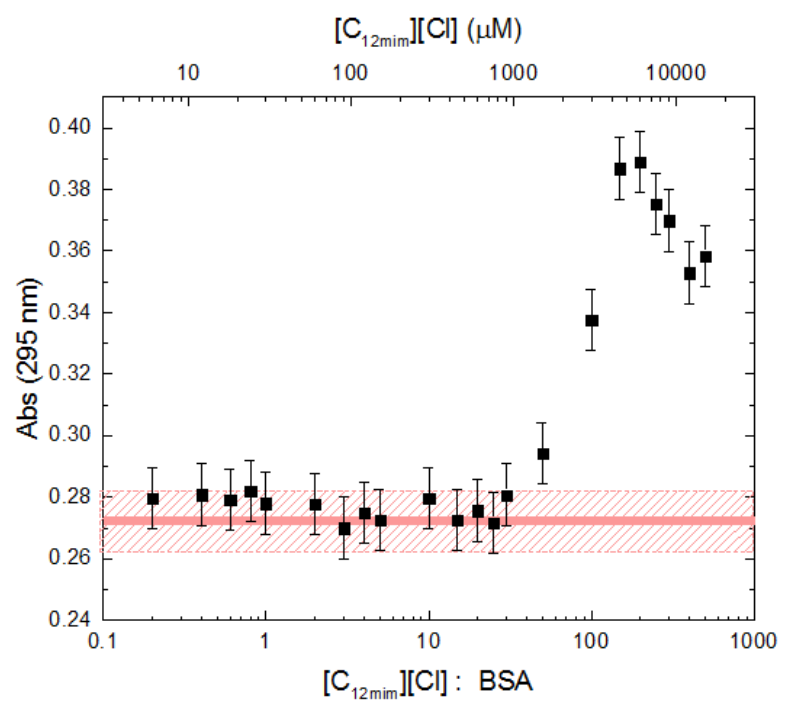

(B)

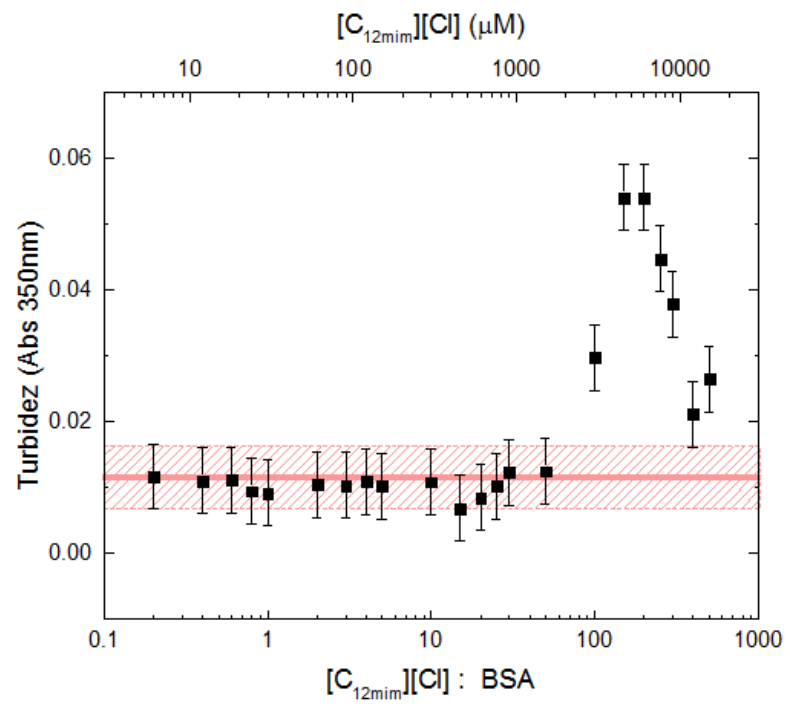

Figura A. 2: Absorbância em $295 \mathrm{~nm}$ (A) e turbidez (B) da BSA a $30 \mu \mathrm{M}$ em função da concentração de [ $\left.\mathrm{C}_{12 \mathrm{mim}}\right][\mathrm{Cl}]$ (escala superior) e razão molar (escala inferior), ambas logarítmicas. A faixa vermelha preenchida e listrada correspondem a BSA em ausência de LI e incerteza, respectivamente. 


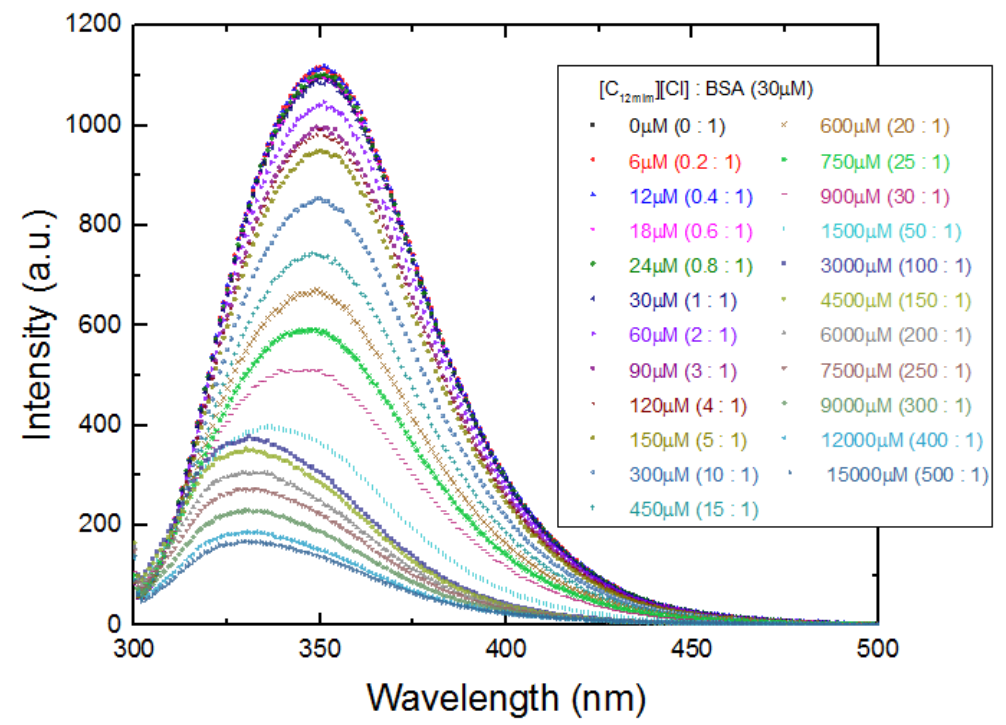

Figura A. 3:Espectro de fluorescência da BSA a $30 \mu \mathrm{M}$ em presença de variadas concentrações de $\left[\mathrm{C}_{12 \mathrm{mim}}\right][\mathrm{Cl}]$ descritas na legenda junto a razão molar. Espectros com correção de filtro interno.

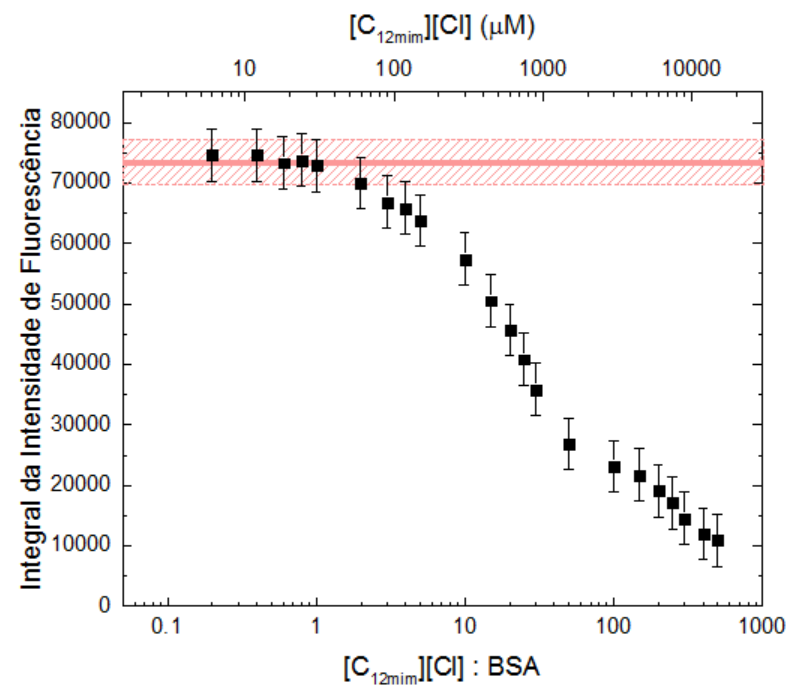

Figura A. 4:Integral da intensidade de fluorescência (de $300 \mathrm{~nm}$ a $500 \mathrm{~nm}$ ) da BSA a $30 \mu \mathrm{M}$ em função da concentração de $\left[\mathrm{C}_{12 \mathrm{mim}}\right][\mathrm{Cl}]$ (escala superior) e razão molar (escala inferior), ambas logarítmicas. A faixa vermelha preenchida e listrada correspondem a BSA em ausência de LI e incerteza, respectivamente. 


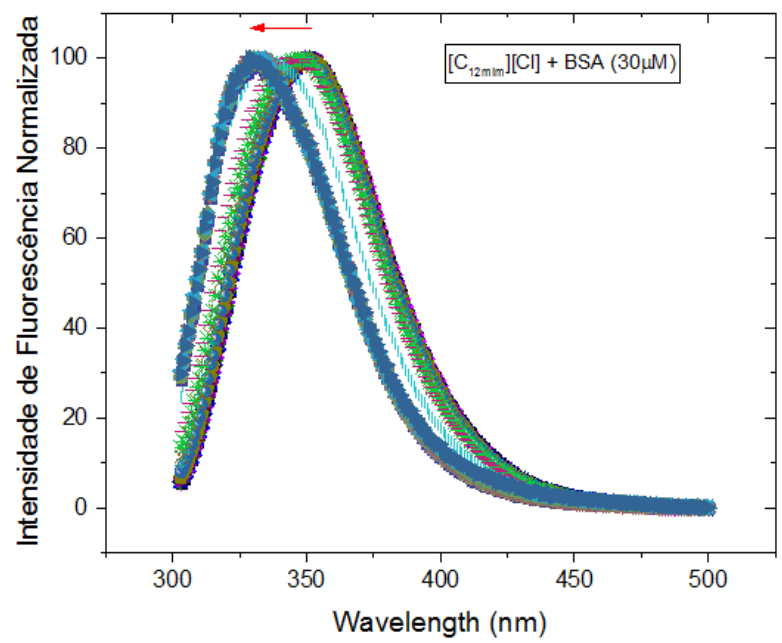

Figura A. 5: Espectro de fluorescência normalizado pelo pico do sistema $B S A+\left[C_{12 m i m}\right][C l]$. A seta indica o deslocamento com o aumento da concentração de $\left[\mathrm{C}_{12 \mathrm{mim}}\right][\mathrm{Cl}]$.

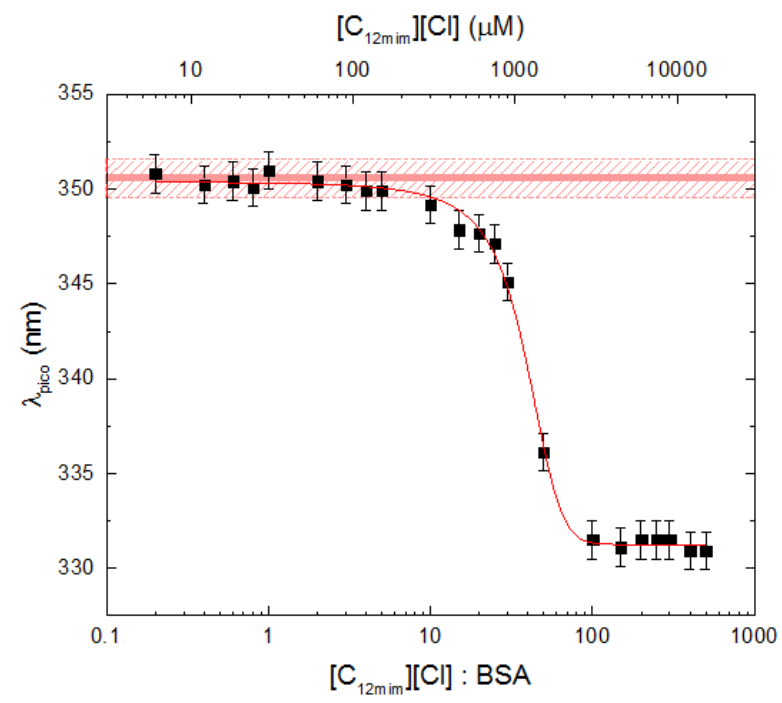

Figura A. 6: Comprimento de onda correspondente ao máximo de fluorescência da BSA a $30 \mu \mathrm{M}$ em função da concentração de $\left[\mathrm{C}_{12 \mathrm{mim}}\right][\mathrm{Cl}]$ (escala superior) e razão molar (escala inferior), ambas logarítmicas. A faixa vermelha preenchida e listrada correspondem a BSA em ausência de LI e incerteza, respectivamente. A linha vermelha é o ajuste utilizando a função de Boltzmann. 


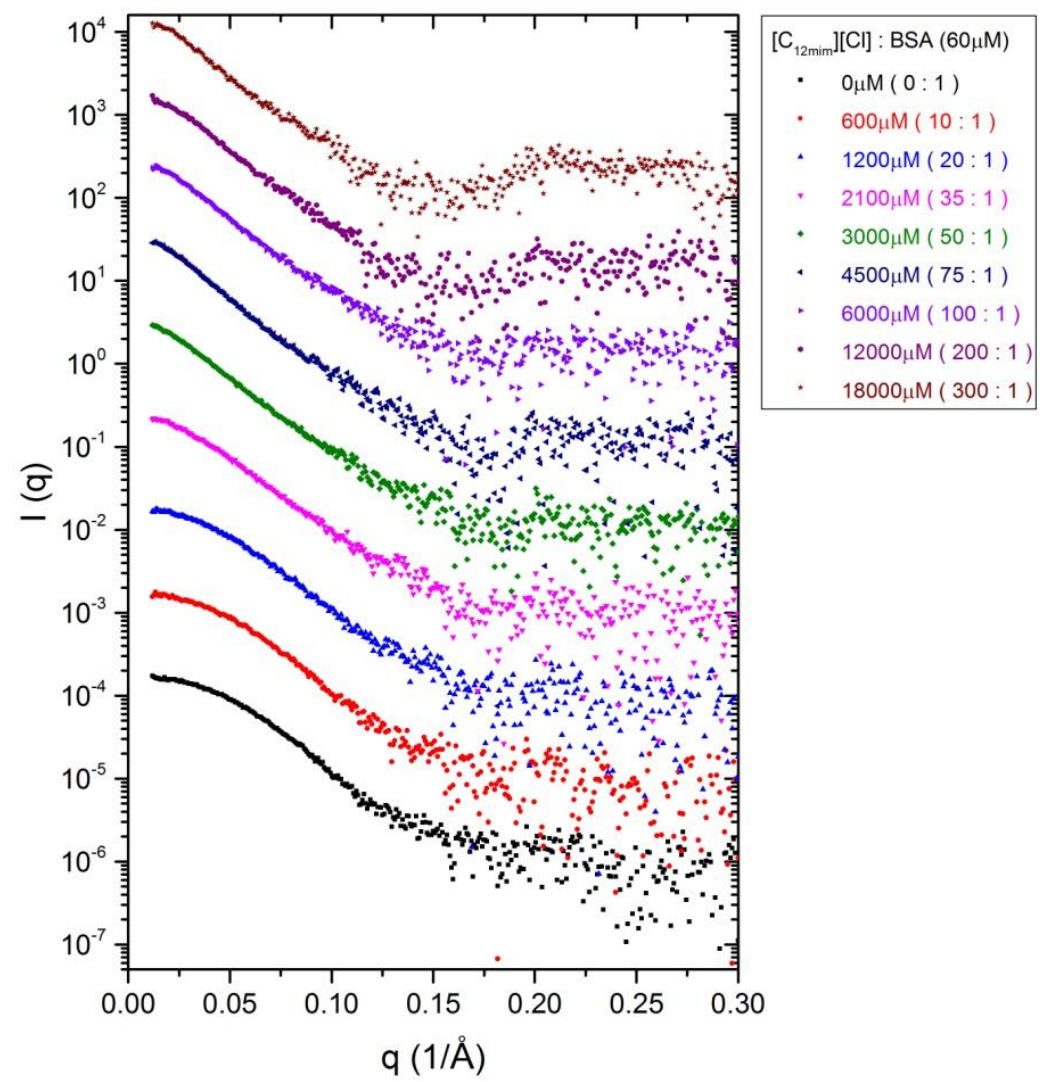

Figura A. 7: Curvas de SAXS obtidas para o sistema BSA a $60 \mu \mathrm{M}$ e variadas concentrações de $\left[\mathrm{C}_{12 \mathrm{mim}}\right][\mathrm{Cl}]$ descritas na legenda junto a razão molar. As curvas estão deslocadas na vertical para melhor visualização.

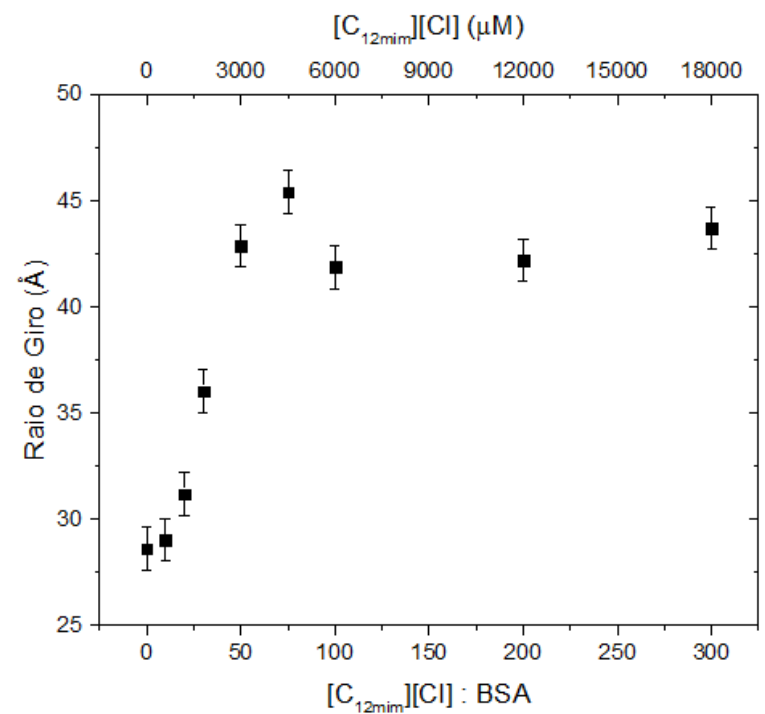

Figura A. 8: Curvas de Kratky obtidas para o sistema BSA a $60 \mu \mathrm{M}$ e variadas concentrações de $\left[\mathrm{C}_{12 \mathrm{mim}}\right][\mathrm{Cl}]$ descritas na legenda junto a razão molar. 


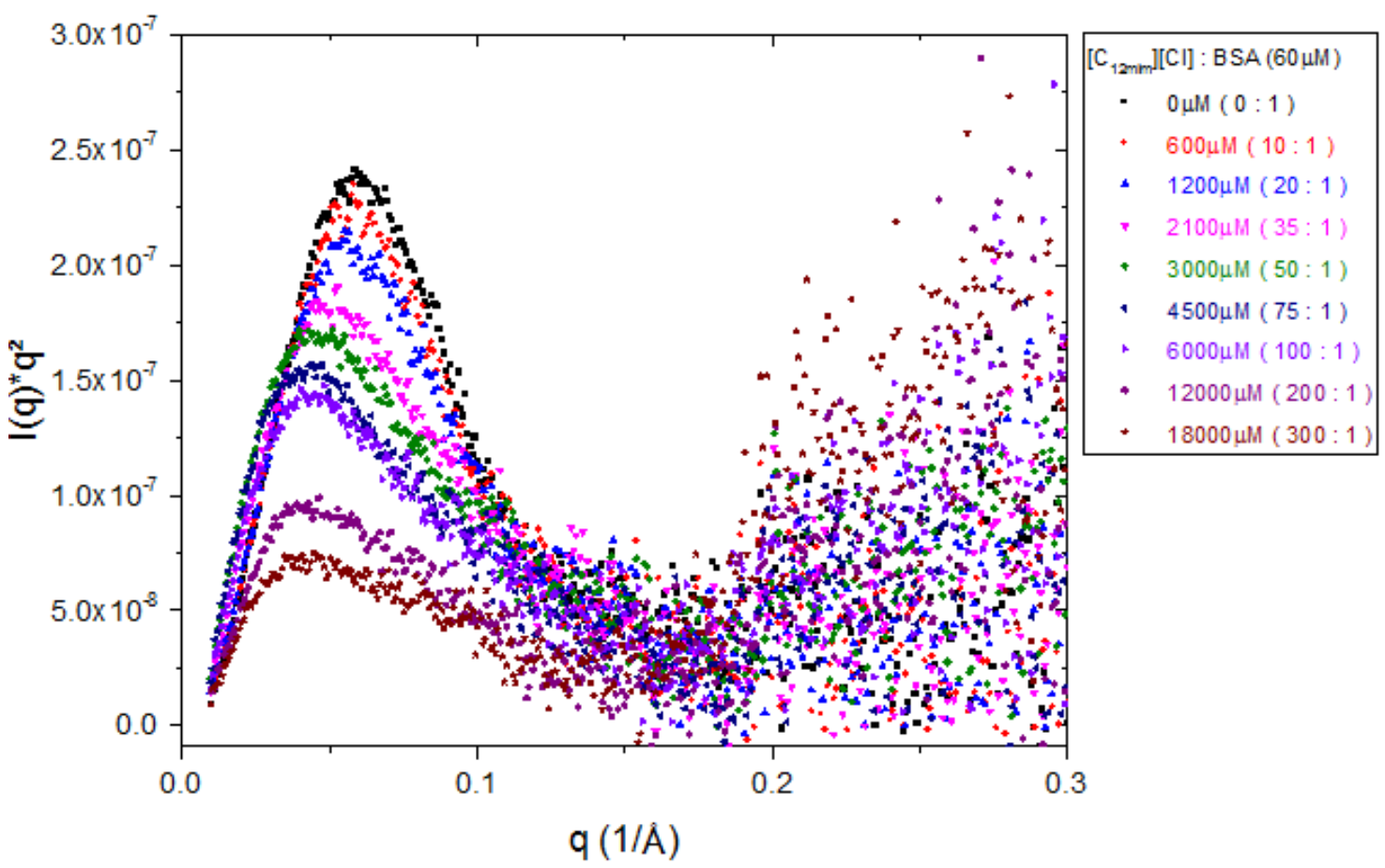

Figura A. 9: Curvas de Kratky obtidas para o sistema BSA a $60 \mu \mathrm{M}$ e variadas concentrações de $\left[\mathrm{C}_{12 \mathrm{mim}}\right][\mathrm{Cl}]$ descritas na legenda junto a razão molar.

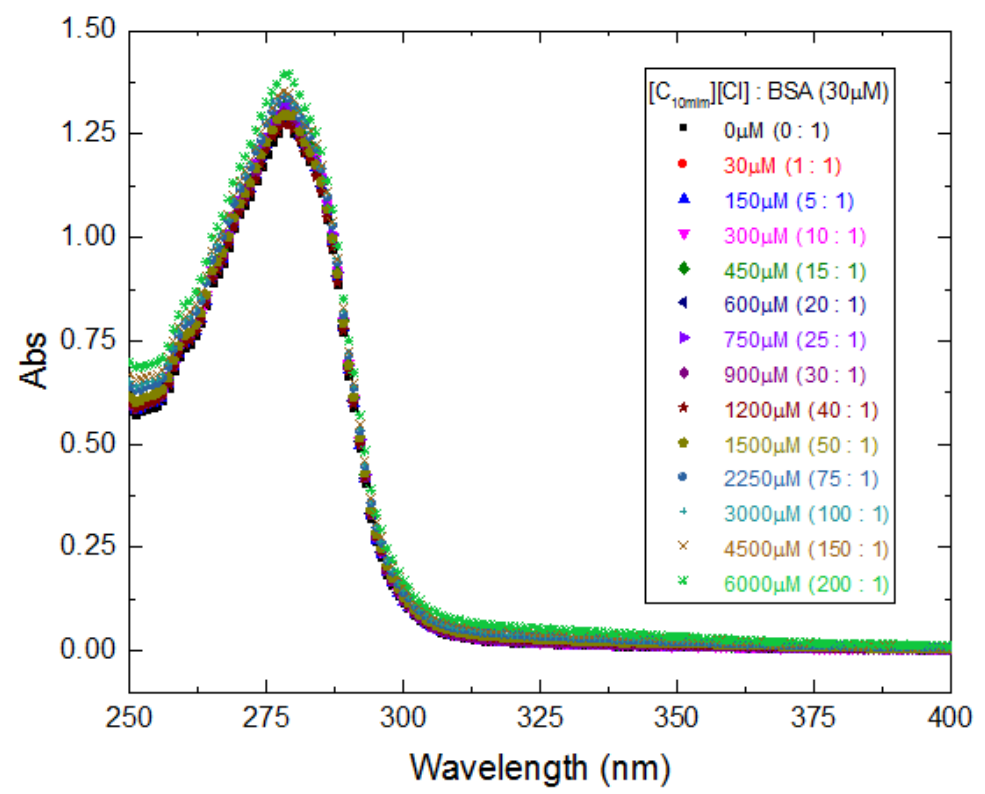

Figura A. 10: Espectro de absorbância da BSA a $30 \mu \mathrm{M}$ em presença de variadas concentrações de $\left[\mathrm{C}_{10 \mathrm{mim}}\right][\mathrm{Cl}]$ descritas na legenda junto a razão molar. A absorbância do tampão e da cubeta foram subtraídas das curvas. 
(A)

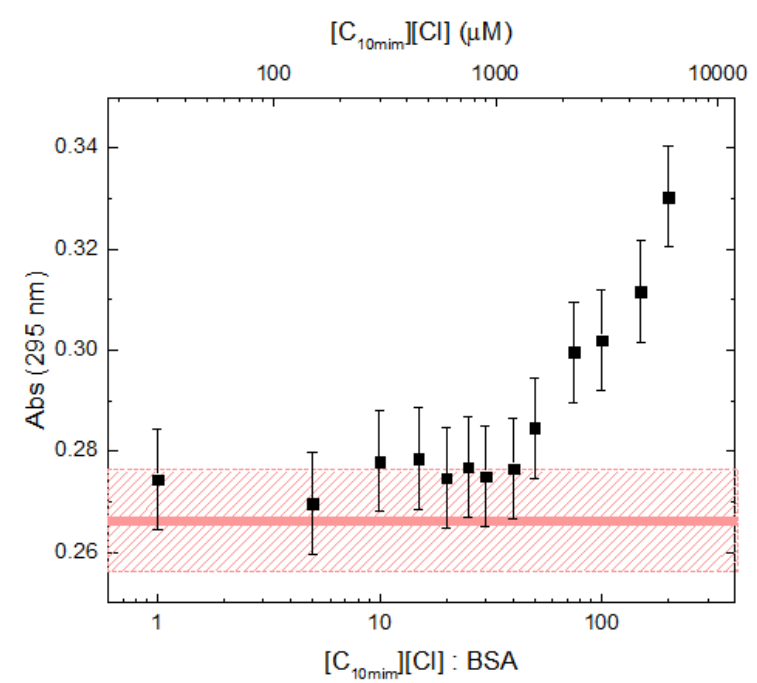

(B)

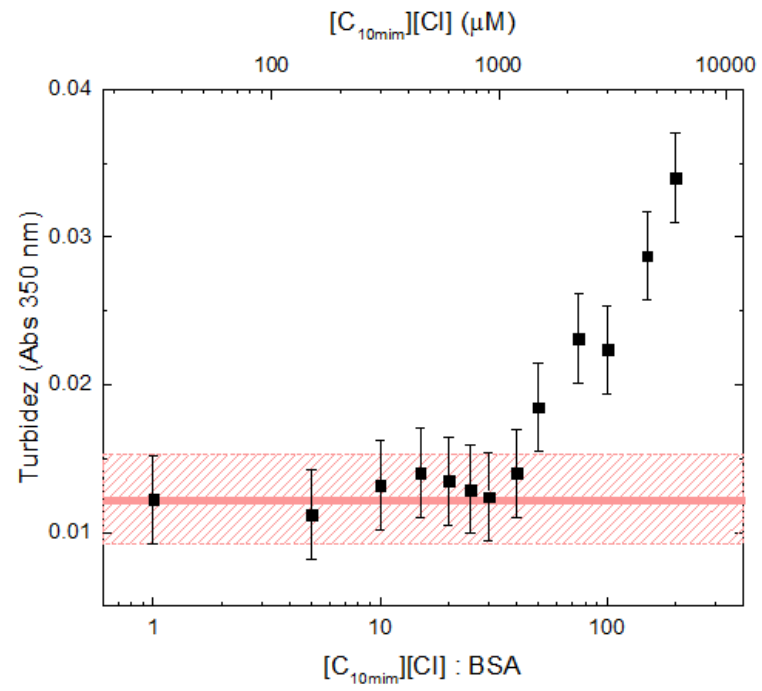

Figura A. 11: Absorbância em 295nm (A) e turbidez (B) da BSA a 30 $\mu \mathrm{M}$ em função da concentração de [C $\left.{ }_{10 \text { mim }}\right][\mathrm{Cl}]$ (escala superior) e razão molar (escala inferior), ambas logarítmicas. A faixa vermelha preenchida e listrada correspondem a BSA em ausência de LI e incerteza, respectivamente.

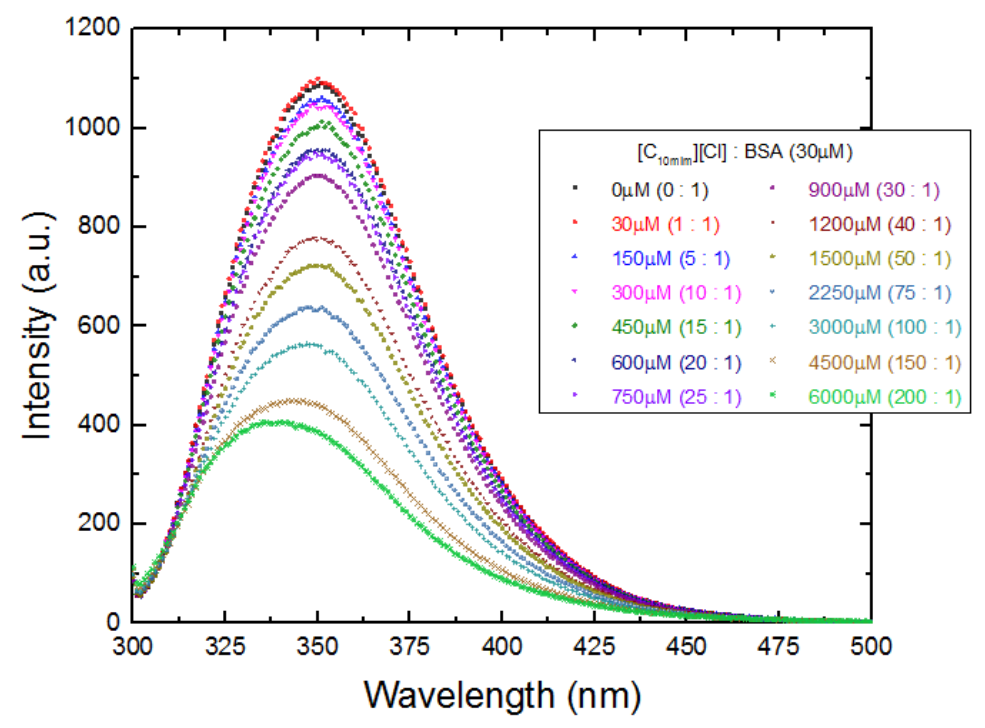

Figura A. 12: Espectro de fluorescência da BSA a $30 \mu \mathrm{M}$ em presença de variadas concentrações de $\left[\mathrm{C}_{10 \mathrm{mim}}\right][\mathrm{Cl}]$ descritas na legenda junto a razão molar. Espectros com correção de filtro interno. 


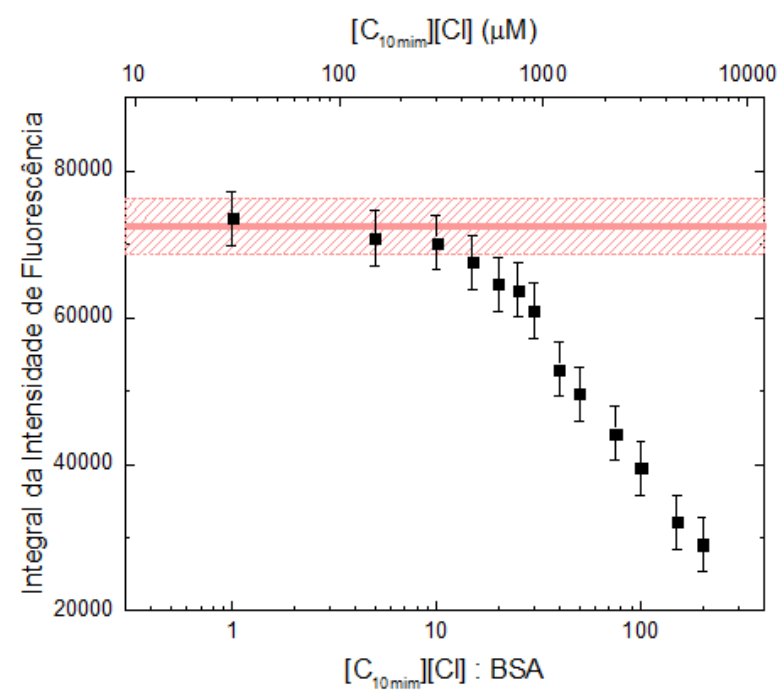

Figura A. 13: Integral da intensidade de fluorescência (de $300 \mathrm{~nm}$ a $500 \mathrm{~nm}$ ) da BSA a $30 \mu \mathrm{M}$ em função da concentração de $\left[C_{10 \text { mim }}\right][C l]$ (escala superior) e razão molar (escala inferior), ambas logarítmicas. A faixa vermelha preenchida e listrada correspondem a BSA em ausência de LI e incerteza, respectivamente.

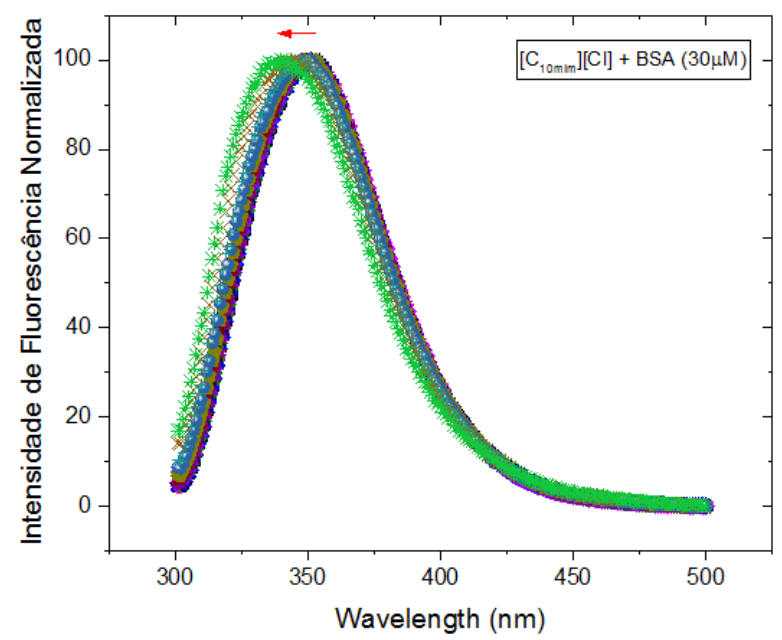

Figura A. 14: Espectro de fluorescência normalizado pelo pico do sistema $B S A+\left[C_{10 m i m}\right][C l]$. A seta indica o deslocamento com o aumento da concentração de $\left[\mathrm{C}_{10 \mathrm{mim}}\right][\mathrm{Cl}]$. 


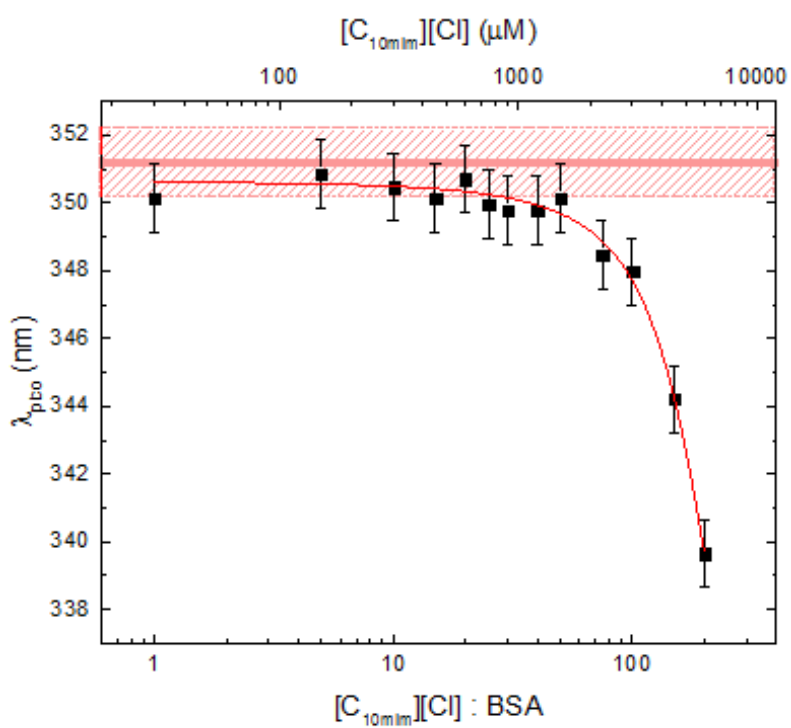

Figura A. 15: Comprimento de onda correspondente ao máximo de fluorescência da BSA a $30 \mu \mathrm{M}$ em função da concentração de $\left[\mathrm{C}_{10 \mathrm{mim}}\right][\mathrm{Cl}]$ (escala superior) e razão molar (escala inferior), ambas logarítmicas. $A$ faixa vermelha preenchida e listrada correspondem a BSA em ausência de LI e incerteza, respectivamente. A linha vermelha é o ajuste utilizando a função de Boltzmann.

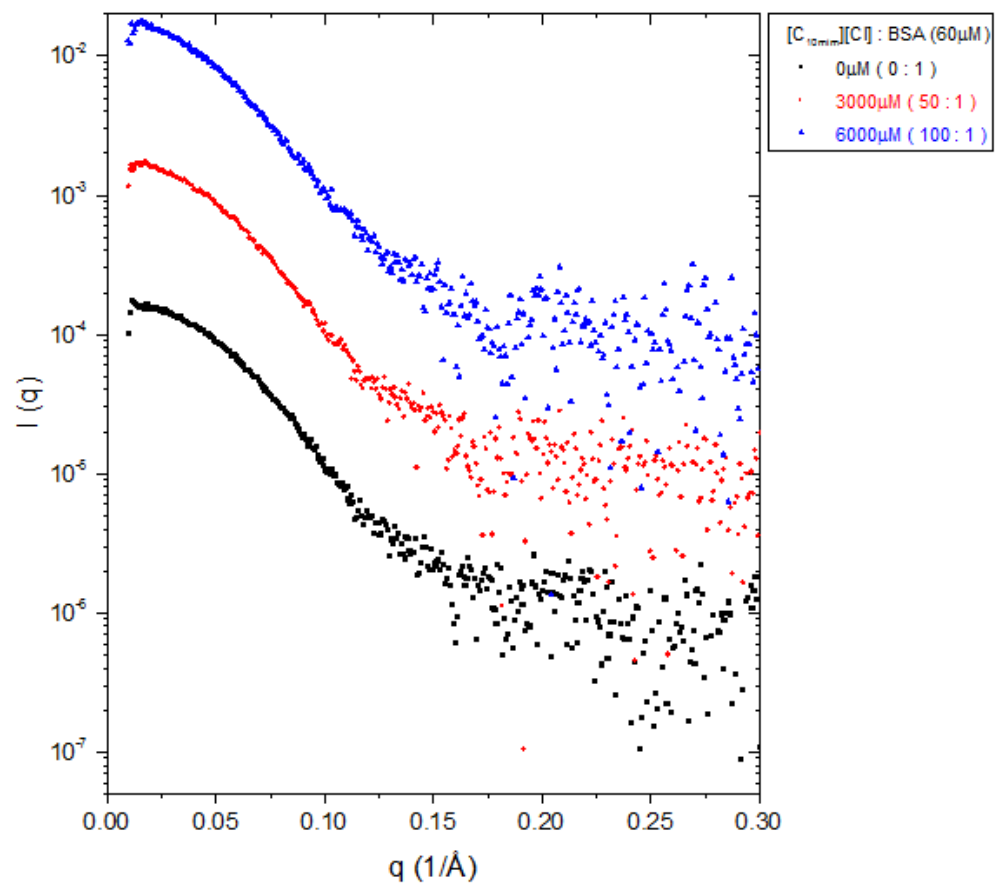

Figura A. 16: Curvas de SAXS obtidas para o sistema BSA a $60 \mu \mathrm{M}$ e variadas concentrações de $\left[\mathrm{C}_{10 \text { mim }}\right][\mathrm{Cl}]$ descritas na legenda junto a razão molar. As curvas estão deslocadas na vertical para melhor visualização. 


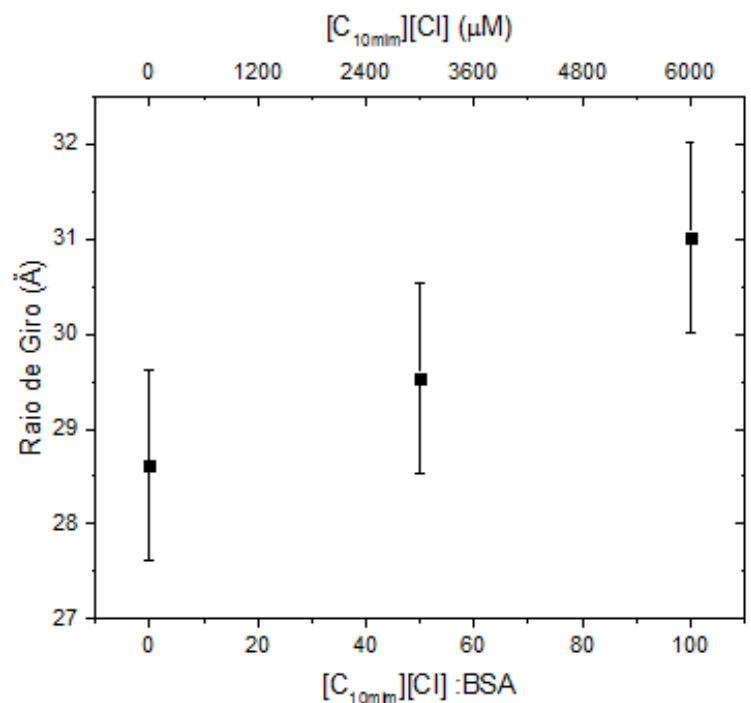

Figura A. 17: Raio de giro da BSA a $60 \mu \mathrm{M}$ em função da concentração de [ $\left.\mathrm{C}_{10 \mathrm{mim}}\right][\mathrm{Cl}]$ (escala superior) e razão molar (escala inferior), ambas logarítmicas.

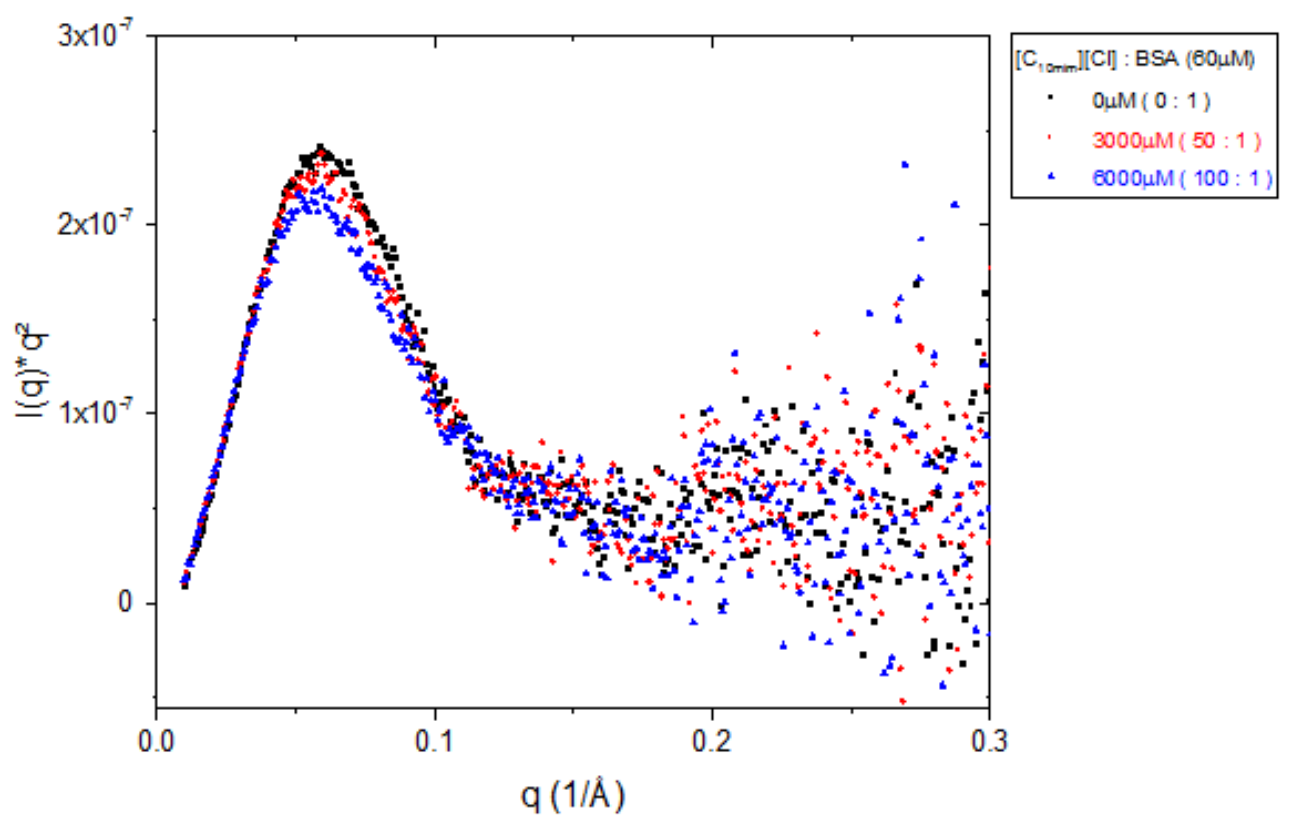

Figura A. 18: Curvas de Kratky obtidas para o sistema BSA a $60 \mu \mathrm{M}$ e variadas concentrações de $\left[\mathrm{C}_{10 \mathrm{mim}}\right][\mathrm{Cl}]$ descritas na legenda junto a razão molar. 


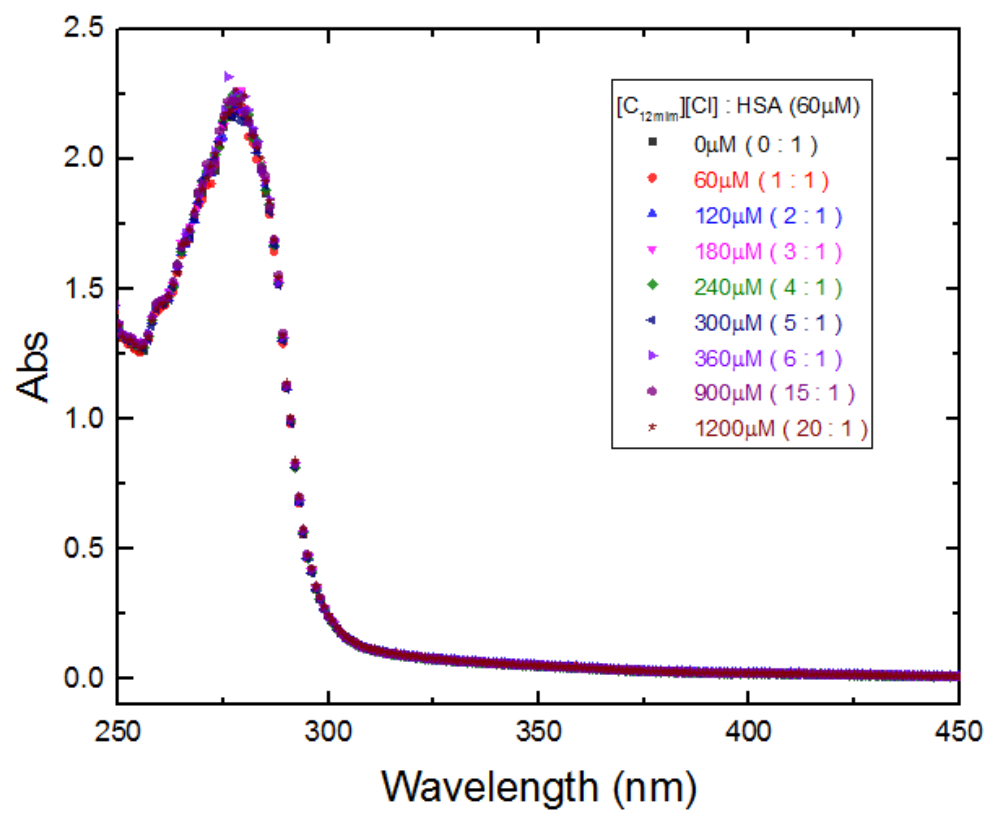

Figura A. 19: Espectro de absorbância da HSA a $60 \mu \mathrm{M}$ em presença de variadas concentrações de $\left[\mathrm{C}_{12 \mathrm{mim}}\right][\mathrm{Cl}]$ descritas na legenda junto a razão molar. A absorbância do tampão e da cubeta foram subtraídas das curvas.

(A)

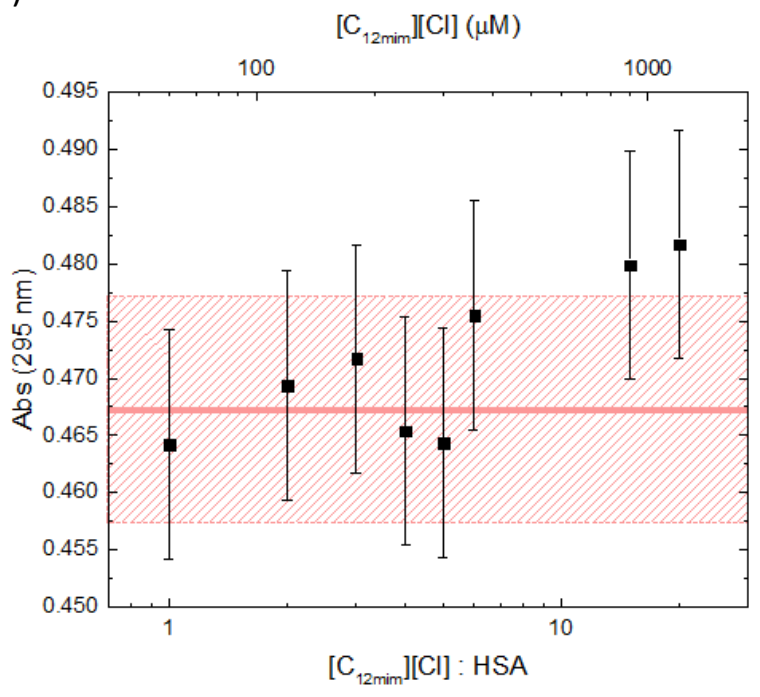

(B)

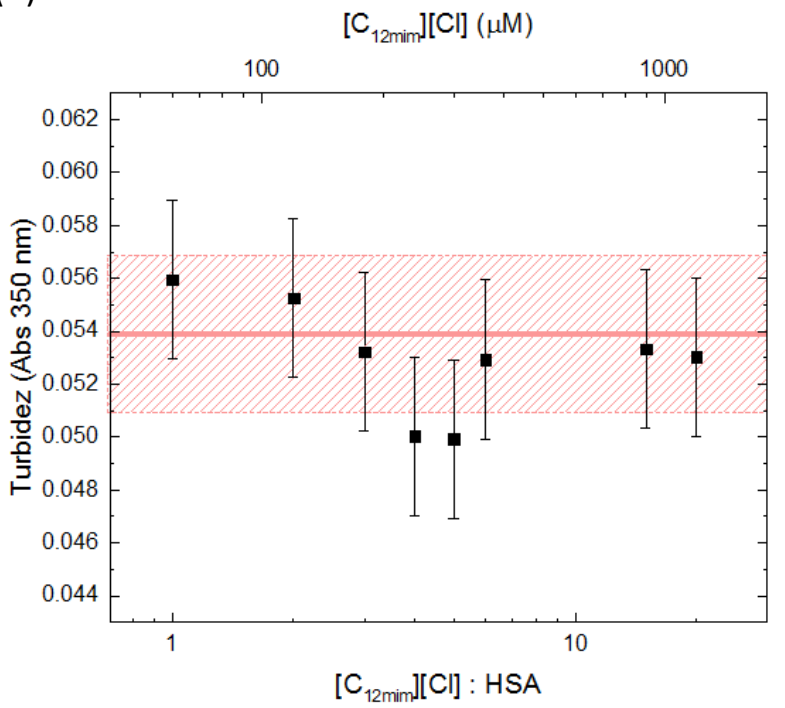

Figura A. 20: Absorbância em 295nm (A) e turbidez (B) da HSA a $60 \mu \mathrm{M}$ em função da concentração de [ $\left.\mathrm{C}_{12 \mathrm{mim}}\right][\mathrm{Cl}]$ (escala superior) e razão molar (escala inferior), ambas logarítmicas. A faixa vermelha preenchida e listrada correspondem a HSA em ausência de LI e incerteza, respectivamente. 


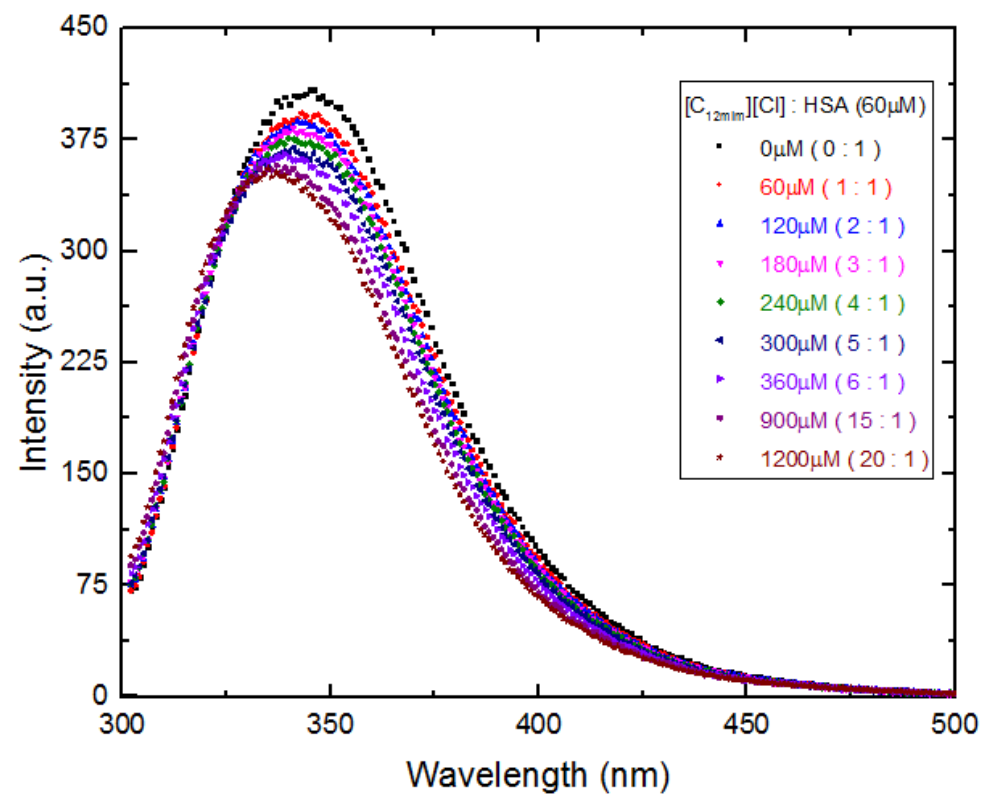

Figura A. 21: Espectro de fluorescência da HSA a $60 \mu \mathrm{M}$ em presença de variadas concentrações de $\left[\mathrm{C}_{12 \mathrm{mim}}\right][\mathrm{Cl}]$ descritas na legenda junto a razão molar. Espectros com correção de filtro interno.

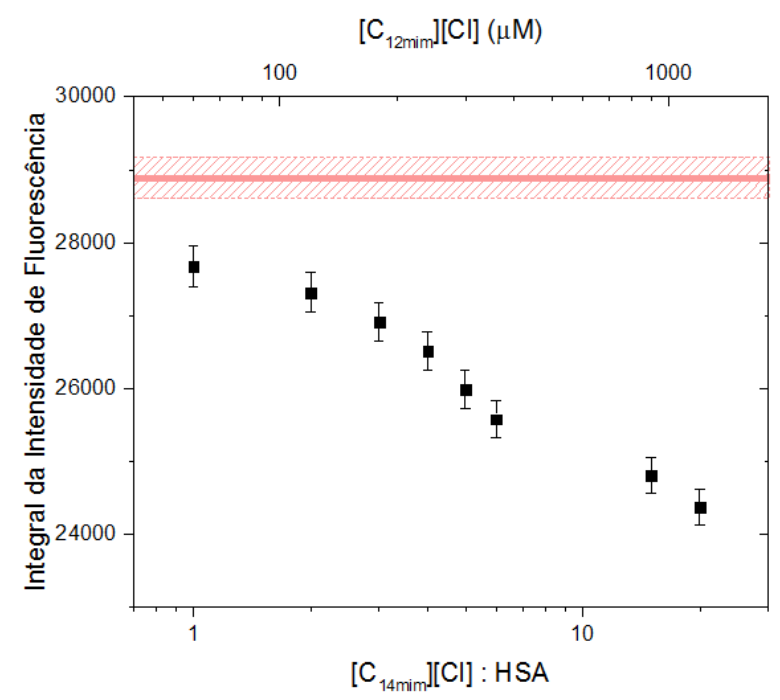

Figura A. 22: Integral da intensidade de fluorescência (de $300 \mathrm{~nm}$ a $500 \mathrm{~nm}$ ) da HSA a $60 \mu \mathrm{M}$ em função da concentração de $\left[\mathrm{C}_{12 \mathrm{mim}}\right][\mathrm{Cl}]$ (escala superior) e razão molar (escala inferior), ambas logarítmicas. $A$ faixa vermelha preenchida e listrada correspondem a HSA em ausência de LI e incerteza, respectivamente. 


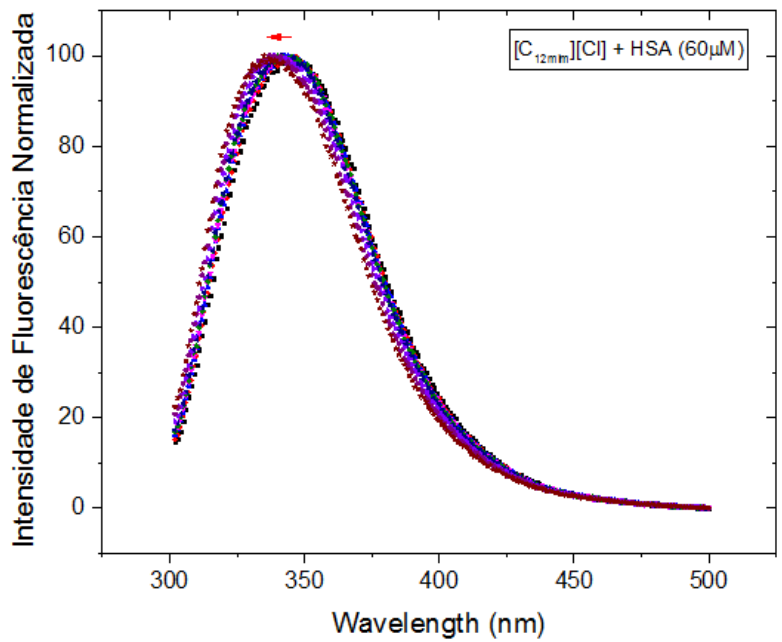

Figura A. 23: Intensidades de fluorescência normalizadas pelo pico do sistema $\mathrm{HSA}+\left[\mathrm{C}_{12 \mathrm{mim}}\right][\mathrm{Cl}]$.

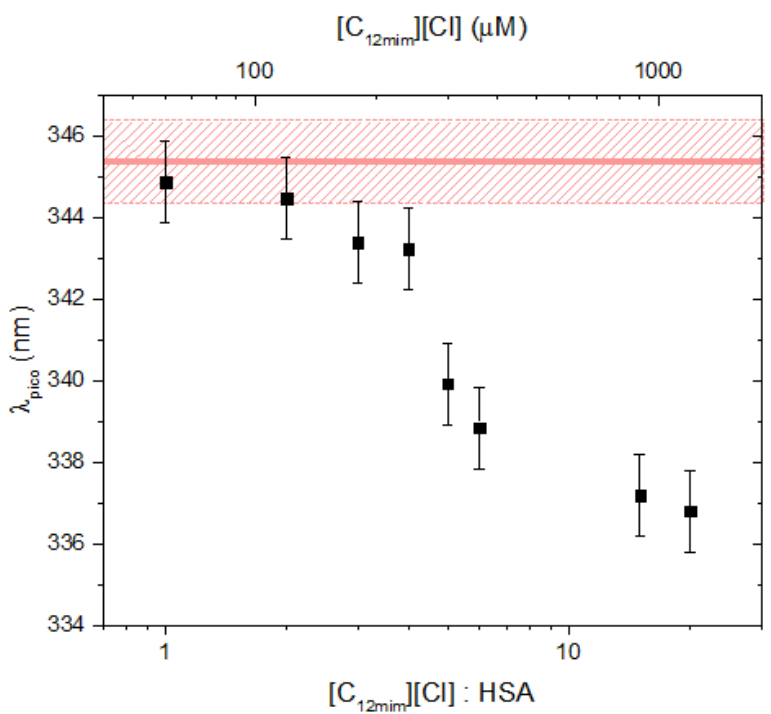

Figura A. 24: Comprimento de onda correspondente ao máximo de fluorescência da HSA a $60 \mu \mathrm{M}$ em função da concentração de $\left[\mathrm{C}_{12 \mathrm{mim}}\right][\mathrm{Cl}]$ (escala superior) e razão molar (escala inferior), ambas logarítmicas. A faixa vermelha preenchida e listrada correspondem a HSA em ausência de LI e incerteza, respectivamente. 


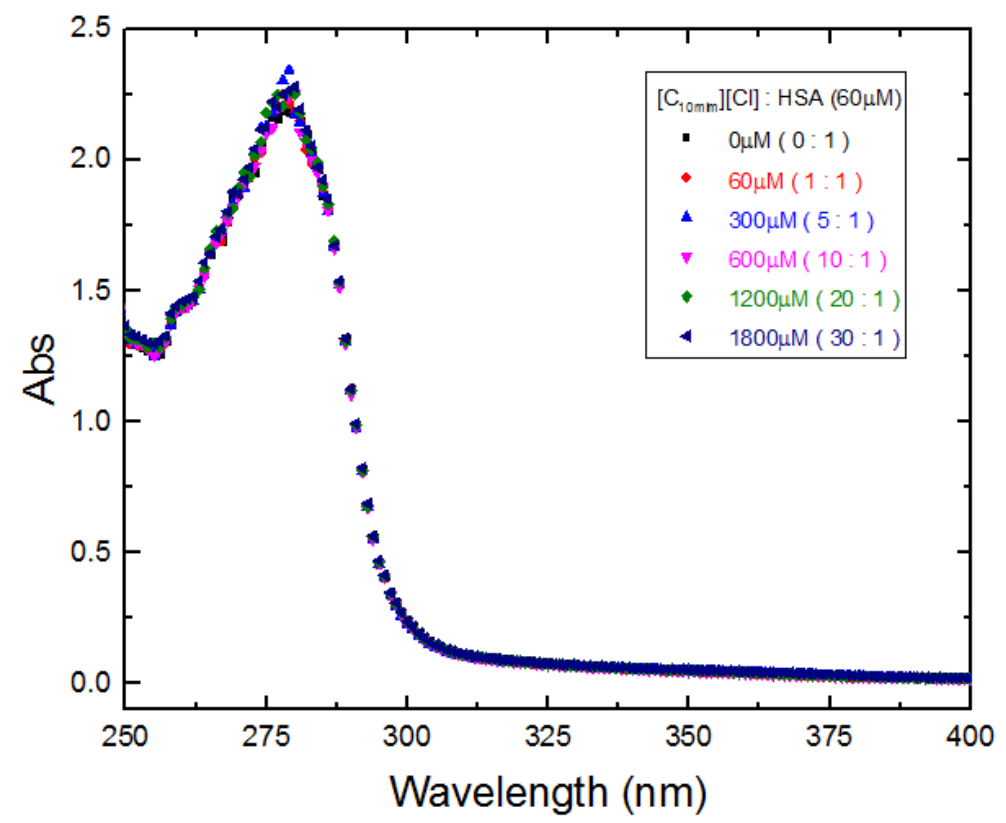

Figura A. 25: Espectro de absorbância da HSA a $60 \mu \mathrm{M}$ em presença de variadas concentrações de $\left[\mathrm{C}_{10 \text { mim }}\right][\mathrm{Cl}]$ descritas na legenda junto a razão molar. A absorbância do tampão e da cubeta foram subtraídas das curvas.

(A)

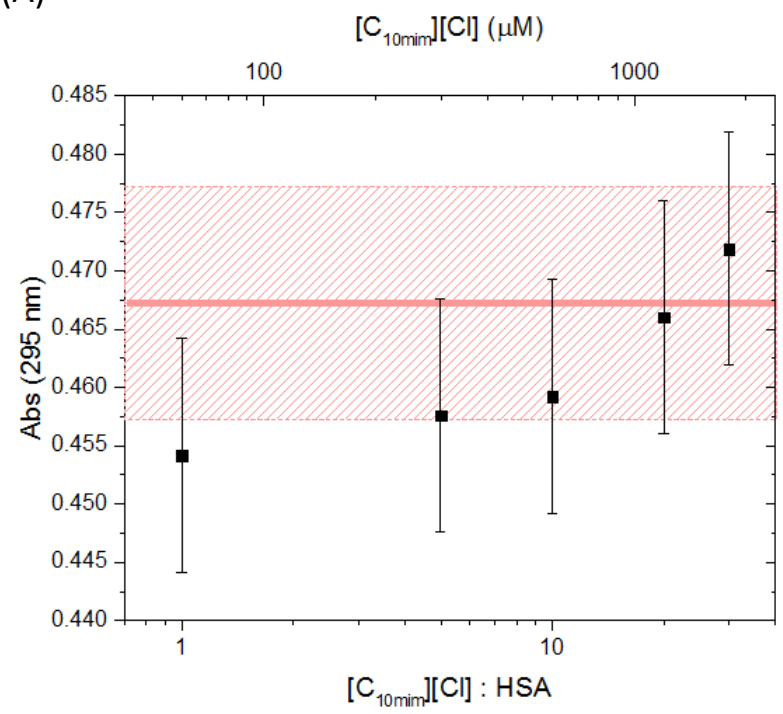

(B)

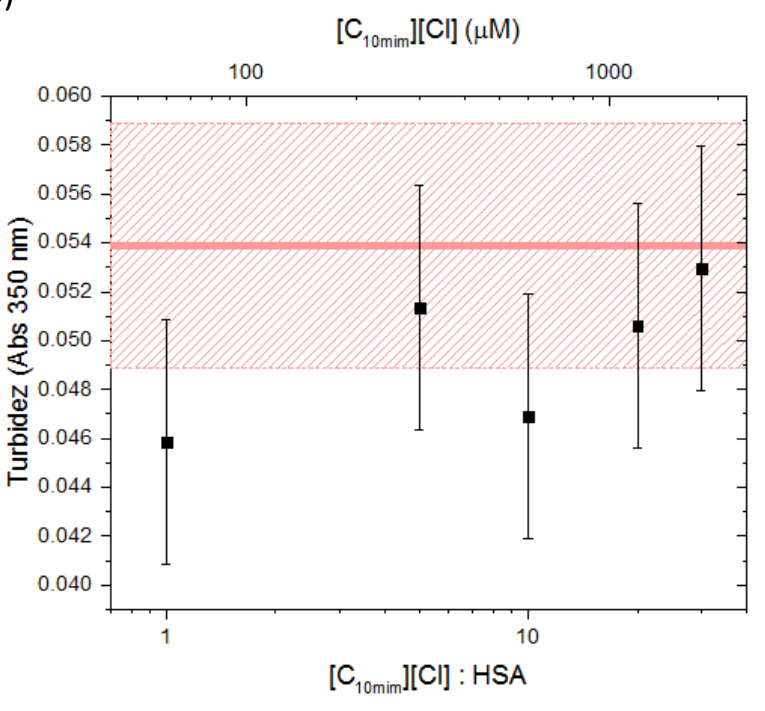

Figura A. 26: Absorbância em 295nm (A) e turbidez (B) da HSA a $60 \mu \mathrm{M}$ em função da concentração de [ $\left.\mathrm{C}_{14 \mathrm{mim}}\right][\mathrm{Cl}]$ (escala superior) e razão molar (escala inferior), ambas logarítmicas. A faixa vermelha preenchida e listrada correspondem a HSA em ausência de LI e incerteza, respectivamente. 


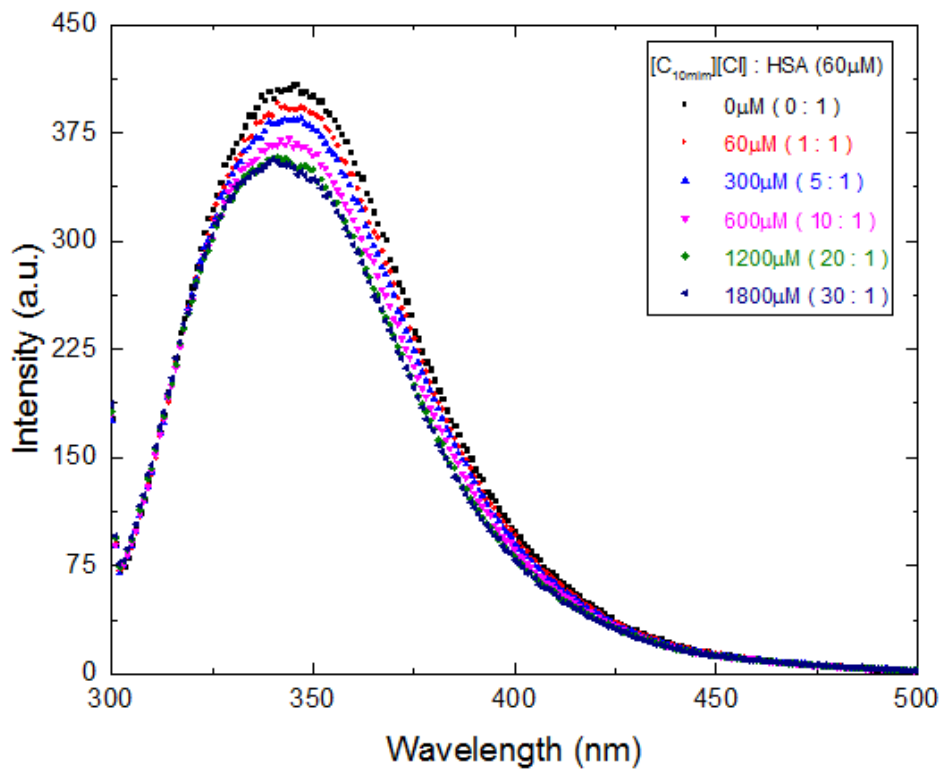

Figura A. 27: Espectro de fluorescência da HSA a $60 \mu \mathrm{M}$ em presença de variadas concentrações de $\left[\mathrm{C}_{10 \mathrm{mim}}\right][\mathrm{Cl}]$ descritas na legenda junto a razão molar. Espectros com correção de filtro interno.

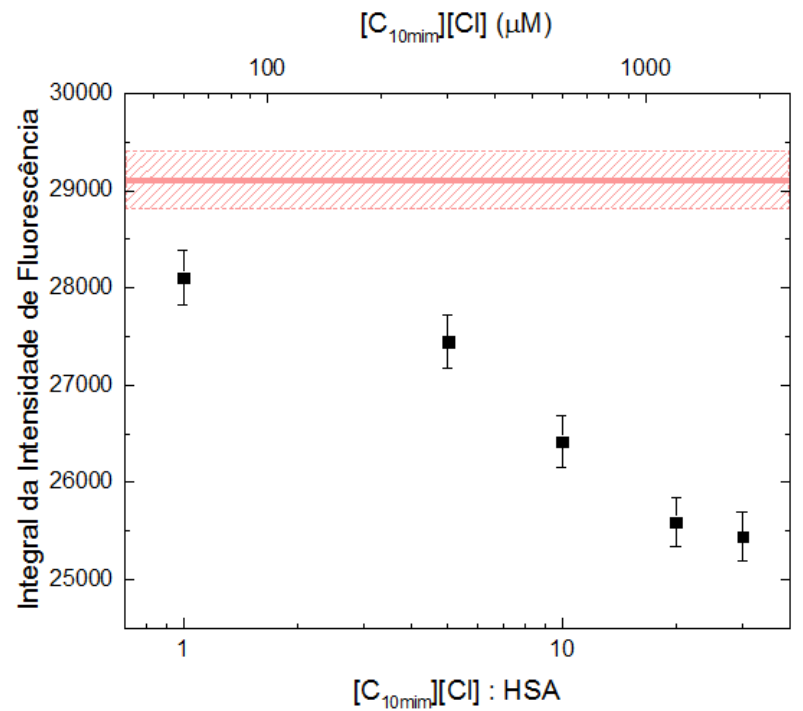

Figura A. 28: Integral da intensidade de fluorescência (de $300 \mathrm{~nm}$ a $500 \mathrm{~nm}$ ) da HSA a $60 \mu \mathrm{M}$ em função da concentração de $\left[C_{10 m i m}\right][C l]$ (escala superior) e razão molar (escala inferior), ambas logarítmicas. A faixa vermelha preenchida e listrada correspondem a HSA em ausência de LI e incerteza, respectivamente. 


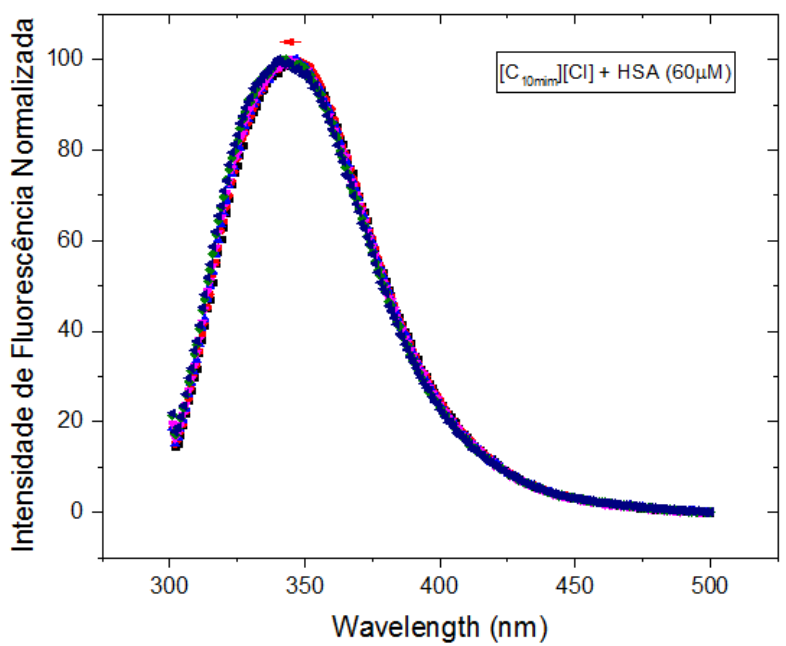

Figura A. 29: Intensidades de fluorescência normalizadas pelo pico do sistema $\mathrm{HSA}+\left[\mathrm{C}_{10 \mathrm{mim}}\right][\mathrm{Cl}]$.

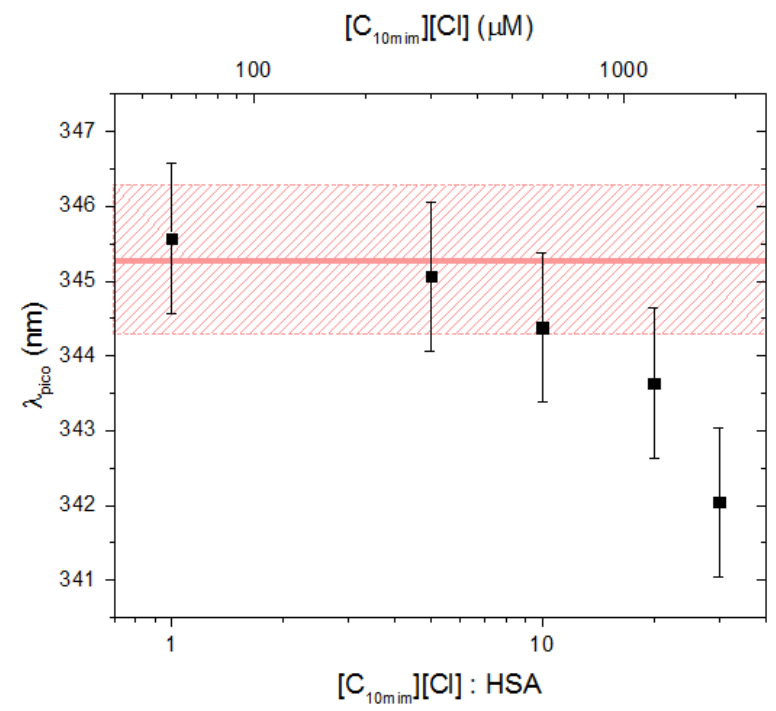

Figura A. 30: Comprimento de onda correspondente ao máximo de fluorescência da HSA a $60 \mu \mathrm{M}$ em função da concentração de $\left[\mathrm{C}_{10 \mathrm{mim}}\right][\mathrm{Cl}]$ (escala superior) e razão molar (escala inferior), ambas logarítmicas. A faixa vermelha preenchida e listrada correspondem a HSA em ausência de LI e incerteza, respectivamente. 


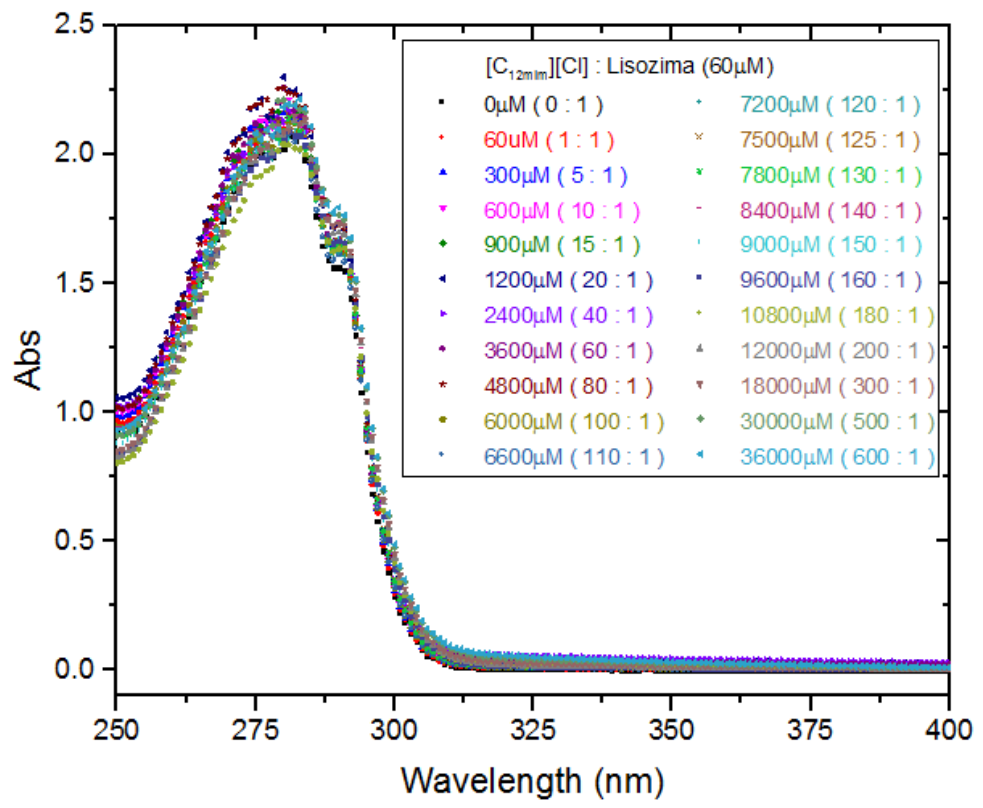

Figura A. 31: Espectro de absorbância da lisozima a $60 \mu \mathrm{M}$ em presença de variadas concentrações de $\left[\mathrm{C}_{12 \mathrm{mim}}\right][\mathrm{Cl}]$ descritas na legenda junto a razão molar. A absorbância do tampão e da cubeta foram subtraídas das curvas.

(A)

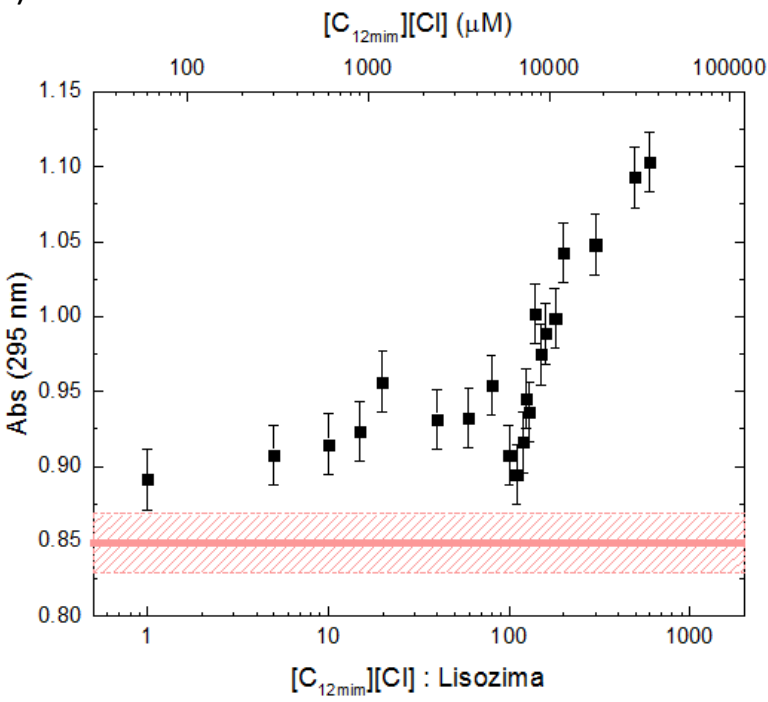

(B)

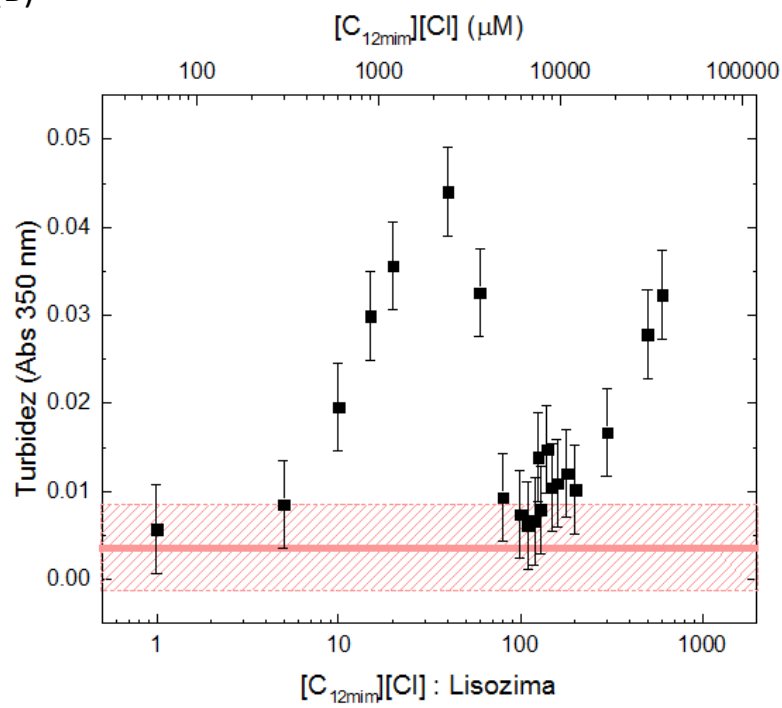

Figura A. 32: Absorbância em $295 \mathrm{~nm}$ (A) e turbidez (B) da lisozima a $60 \mu \mathrm{M}$ em função da concentração de $\left[C_{12 \text { mim }}\right][\mathrm{Cl}]$ (escala superior) e razão molar (escala inferior), ambas logarítmicas. A faixa vermelha preenchida e listrada correspondem a HSA em ausência de LI e incerteza, respectivamente. 


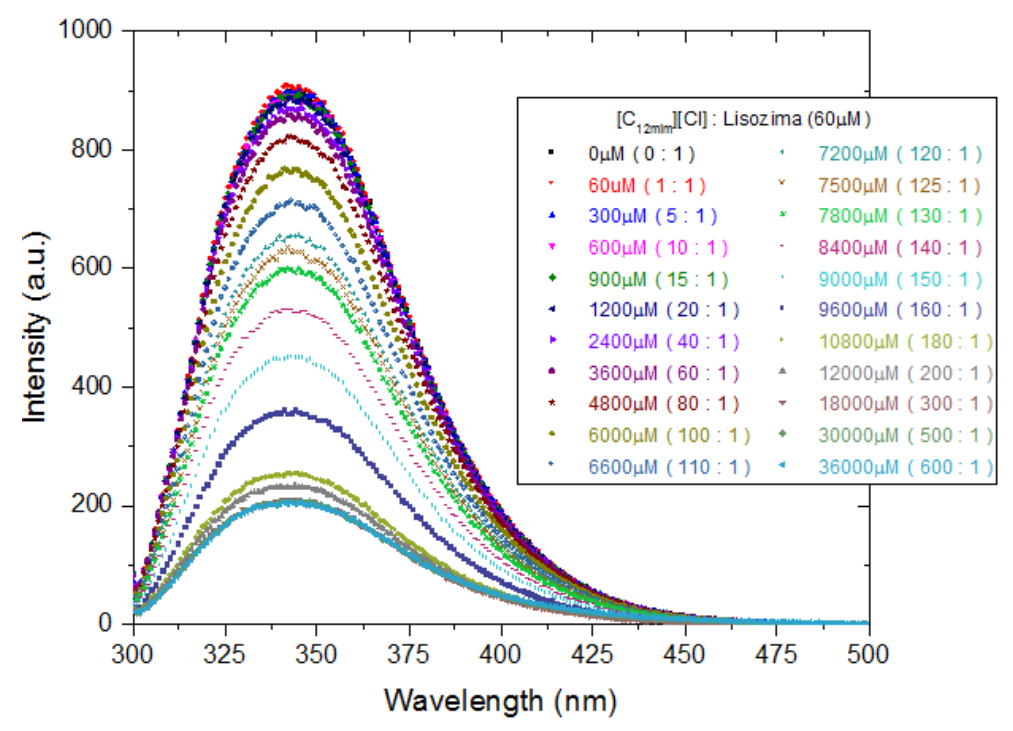

Figura A. 33: Espectro de fluorescência da lisozima a $60 \mu \mathrm{M}$ em presença de variadas concentrações de $\left[\mathrm{C}_{12 \mathrm{mim}}\right][\mathrm{Cl}]$ descritas na legenda junto a razão molar. Espectros com correção de filtro interno.

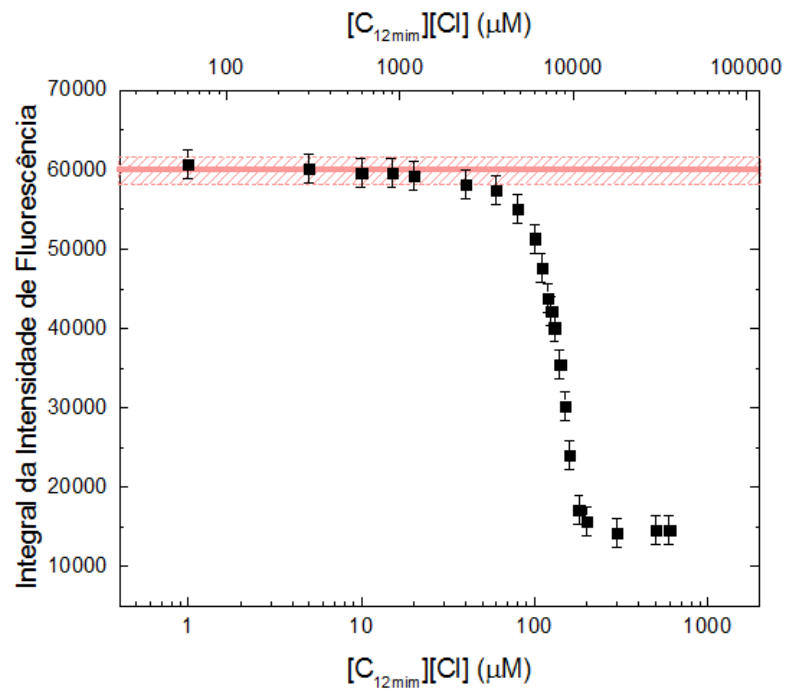

Figura A. 34: Integral da intensidade de fluorescência (de $300 \mathrm{~nm}$ a $500 \mathrm{~nm}$ ) da lisozima a $60 \mu \mathrm{M}$ em função da concentração de $\left[C_{12 m i m}\right][\mathrm{Cl}]$ (escala superior) e razão molar (escala inferior), ambas logarítmicas. A faixa vermelha preenchida e listrada correspondem a lisozima em ausência de LI e incerteza, respectivamente. 


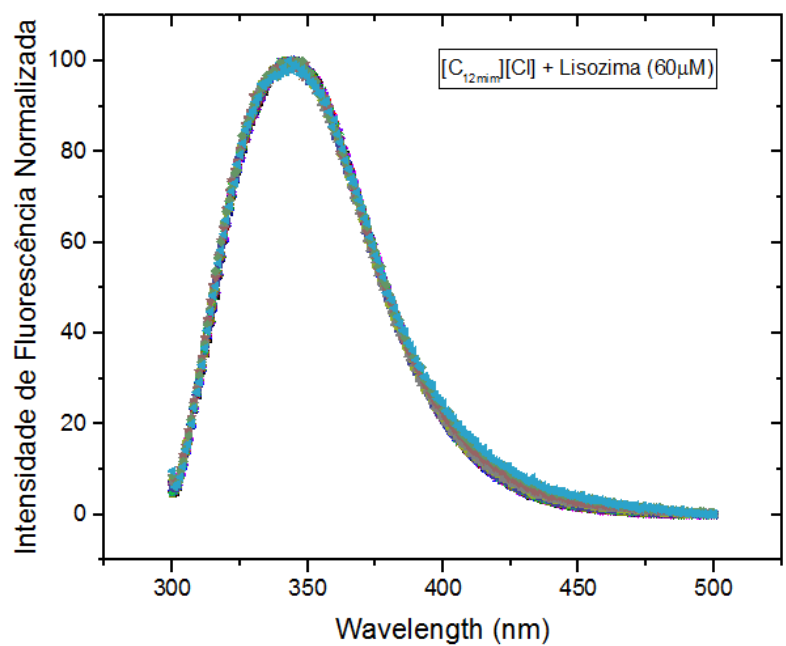

Figura A. 35: Intensidades de fluorescência normalizadas pelo pico do sistema lisozima $+\left[\mathrm{C}_{12 \mathrm{mim}}\right][\mathrm{Cl}]$.

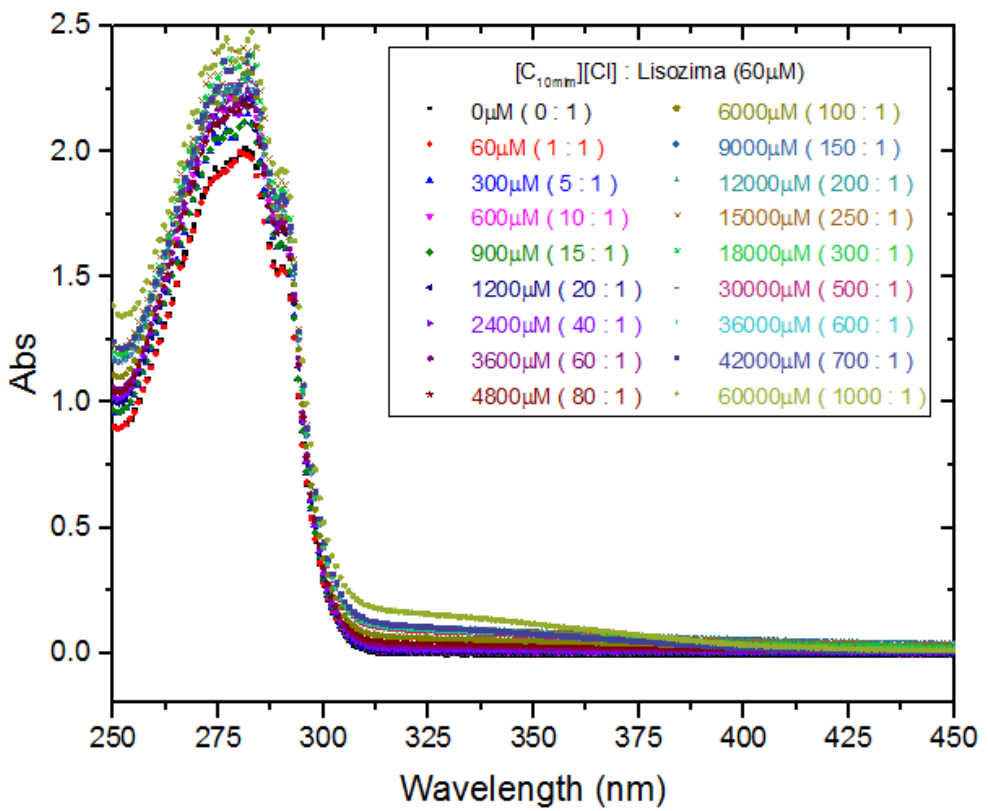

Figura A. 36: Espectro de absorbância da lisozima a $60 \mu \mathrm{M}$ em presença de variadas concentrações de $\left[\mathrm{C}_{10 \mathrm{mim}}\right][\mathrm{Cl}]$ descritas na legenda junto a razão molar. A absorbância do tampão e da cubeta foram subtraídas das curvas. 
(A)

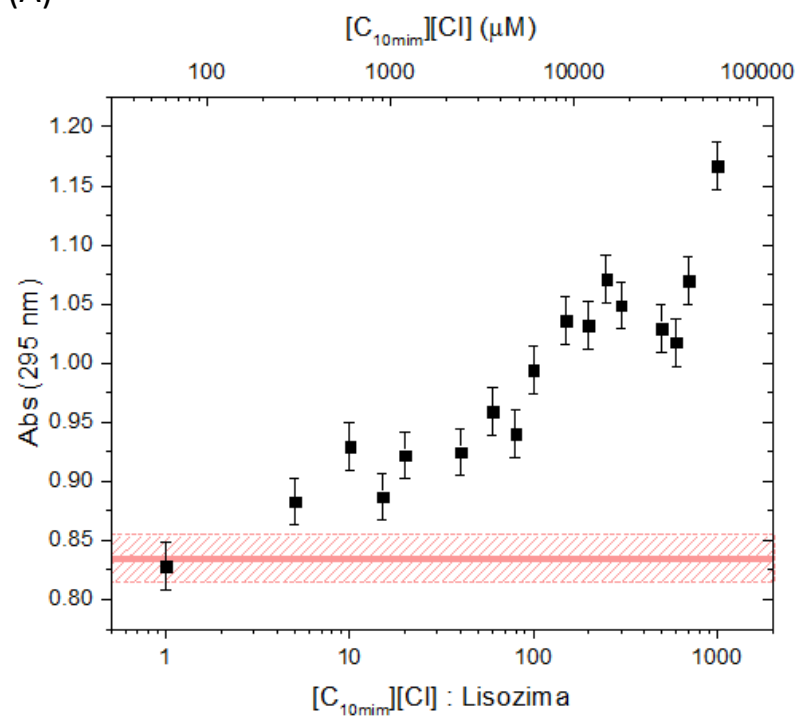

(B)

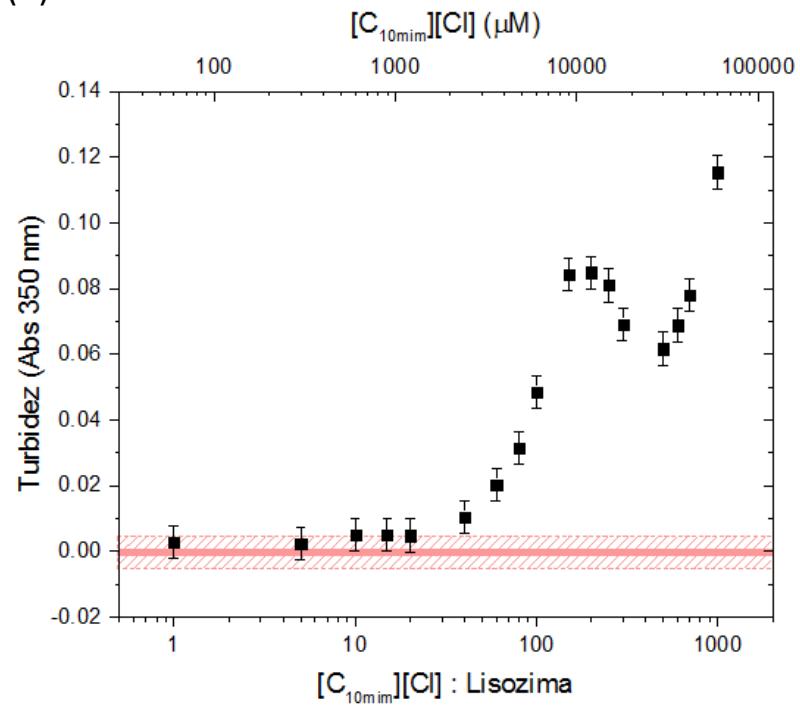

Figura A. 37: Absorbância em $295 \mathrm{~nm}$ (A) e turbidez (B) da lisozima a $60 \mu \mathrm{M}$ em função da concentração de $\left[\mathrm{C}_{10 \mathrm{mim}}\right][\mathrm{Cl}]$ (escala superior) e razão molar (escala inferior), ambas logarítmicas. A faixa vermelha preenchida e listrada correspondem a lisozima em ausência de Ll e incerteza, respectivamente.

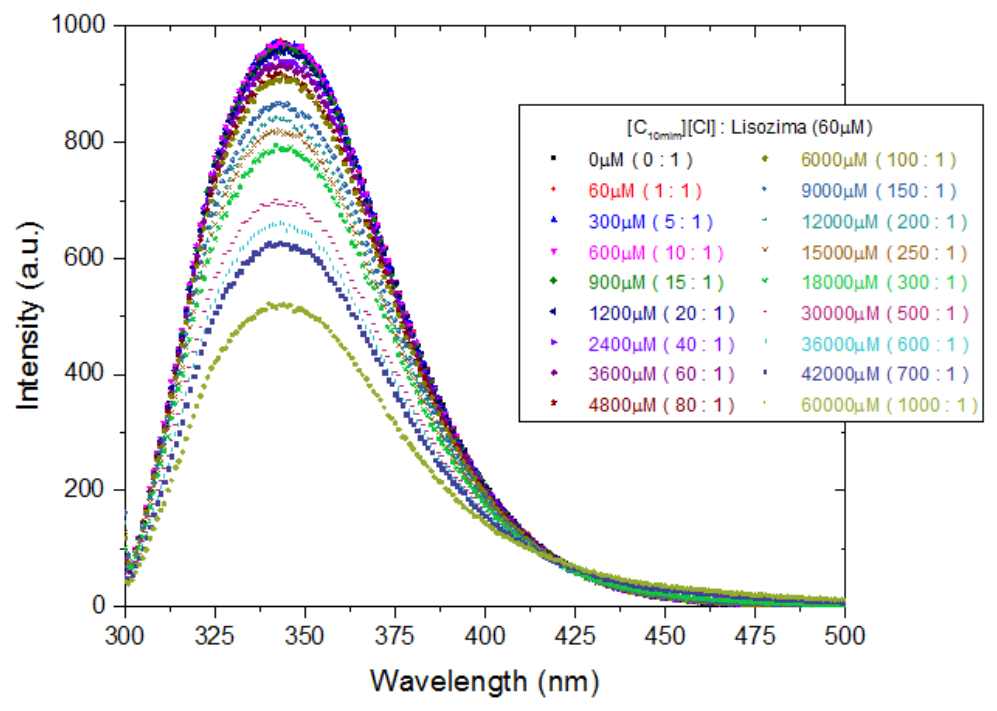

Figura A. 38: Espectro de fluorescência da lisozima a $60 \mu \mathrm{M}$ em presença de variadas concentrações de $\left[\mathrm{C}_{10 \mathrm{mim}}\right][\mathrm{Cl}]$ descritas na legenda junto a razão molar. Espectros com correção de filtro interno. 


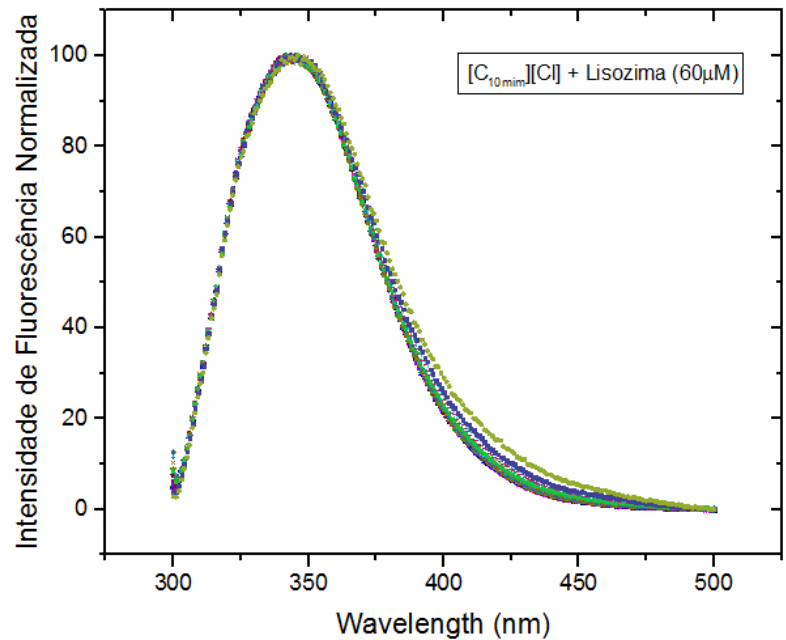

Figura A. 39: Intensidades de fluorescência normalizadas pelo pico do sistema lisozima $+\left[\mathrm{C}_{10 \mathrm{mim}}\right][\mathrm{Cl}]$. 